\author{
UNIVERSITY OF SÃO PAULO \\ SCHOOL OF ECONOMICS, BUSINESS AND ACCOUNTING \\ BUSINESS DEPARTMENT \\ BUSINESS GRADUATE PROGRAM
}

DISTANCE EDUCATION ON THE STAKEHOLDERS' PERSPECTIVES:
STUDENT'S, INSTRUCTOR'S AND ADMINISTRATOR'S PERCEPTIONS

Daielly Melina Nassif Mantovani

Advisor: Profa. Dra. Maria Aparecida Gouvêa

SÃO PAULO

2012 
Prof. Dr. João Grandino Rodas

Rector of the University of São Paulo

Prof. Dr. Reinaldo Guerreiro

Dean of the School of Economics, Business and Accounting

Prof. Dr. Adalberto Américo Fischmann

Business Department Chairman

Prof. Dr. Lindolfo Galvão Albuquerque

Graduate Coordinator 
DAIELLY MELINA NASSIF MANTOVANI

\section{DISTANCE EDUCATION ON THE STAKEHOLDERS' PERSPECTIVES: STUDENT'S, INSTRUCTOR'S AND ADMINISTRATOR'S PERCEPTIONS}

Doctoral Dissertation presented to the Business Department, School of Economics, Business and Accounting, University of São Paulo, as a requisite to the acquisition of a $\mathrm{PhD}$ Degree in Sciences.

Advisor: Profa. Dra. Maria Aparecida Gouvêa

Original Version

SÃO PAULO

2012 


\section{FICHA CATALOGRÁFICA}

\section{Elaborada pela Seção de Processamento Técnico do SBD/FEA/USP}

Mantovani, Daielly Melina Nassif

Distance education on the stakeholders' perspectives : student's, instructor's and administrator's perceptions / Daielly Melina Nassif

Mantovani. - São Paulo, 2012. $273 \mathrm{p}$.

Tese (Doutorado) - Universidade de São Paulo, 2012.

Orientador: Maria Aparecida Gouvêa.

1. Educação a distância 2. Percepção 3. Qualidade da educação 4. Satisfação do consumidor 5. Lealdade I. Universidade de São Paulo. Faculdade de Economia, Administração e Contabilidade. II. Título.

CDD - 371.334 
I dedicate this study to my parents, Ede Mare and Paulo and to André, my husband, my friend and my true love 


\section{ACKNOWLEDGEMENTS}

Initially I thank Lord for bringing me until here, even with all the difficulties I found on my way. I also thank:

My parents who made all the efforts they could to make my dreams come true.

My husband, André, who was there for me and supported me on every step of the way. My advisor, professor Maria Aparecida Gouvêa, a great teacher and a great advisor, with whom I had the pleasure of working with.

My advisor at the University of Illinois, Dr. Korte, an amazing researcher, and a great person.

Professor Edgard Cornachione, who made the difference in my career and brought me to think "out of the box".

All the professors from the program, specially Prof. Adolpho Canton, Prof. César Sousa, Prof. Nicolau Reinhard, Prof. Antonio Geraldo Vidal, Prof. Gilberto Martins, Prof. Edgard Cornachione, Prof. Silvia Casa Nova, Prof. Alessandra Montini and Prof. Maria Aparecida Gouvêa, who inspired me during the disciplines.

All the students, professors and tutors from the Open University of Brazil (UAB) who participated in my research and made this study possible.

All the coordinators from the UAB Public Management course who supported my study and to whom I will be always thankful.

FEA staff, especially, Maria Aparecida Salles, Eloísa Alessio, Fabiana Caseiro e Daniella Martins.

My friend Carla Mori, who even being geographically far, was always by my side.

Luana Guedes, a brilliant English reviewer.

My colleagues, for all the moments of talk and laughter provided during these four years.

FEA/USP, the institution where I had the honor to study and that made me a better professional and a better person.

CAPES for the financial support in Brazil and in the United States (BEX 4186/ 11-7). Everyone, who; somehow, helped this study come out. 


\begin{abstract}
Distance education (DE) in Brazilian higher education level has been growing since the early 2000. This educational method has been becoming more popular, due to its geographic and space flexibility as well as for its potential to take education to remote areas; that is, to people who would not be able to access a traditional face-to-face institution. Additionally, this growth leads to an increase in competition, which enhances the need to assess results. For this purpose there are models in the educational field that help the evaluation of programs, as well as models in the business field which use a marketing perspective and are rarely applied in educational services. Thus, this dissertation aims to evaluate DE considering students', instructors' and institutional (coordinators' points of view) perceptions under a services marketing perspective. A case study was conducted considering Open University of Brazil Public Management undergraduate course. Study followed three phases. In the first phase a survey was conducted in order to acquire students' perceptions of course quality, image, satisfaction and loyalty. In the second phase, a survey was conducted considering professors and tutors in order to acquire their attitudes toward technology and DE. Finally, in the third phase coordinators were interviewed in order to understand course's characteristics and their view of problems and potential strengths. Ten universities member of the Open University participated of the study, which totalizes 593 students, 120 instructors and nine coordinators. Students' sample presented favorable perceptions of course quality, satisfaction, image, loyalty and institutional support. There is significant relationship between perceived quality and student satisfaction, as well as satisfaction and quality, directly and indirectly, influence student loyalty. Finally, image regarding the Open University influences course perceived quality. In addition, in this case there are similar proportion of men and women and male students showed slightly higher satisfaction and loyalty to the course. Instructors' sample did not show relationship among attitudes and participation in DE nor among perceptions of technology and DE use. However, in general, instructors' attitudes are favorable on considered dimensions. Coordinators reported within the main reasons for DE adoption the opportunity to disseminate education to unprivileged areas. In addition; some difficulties found relate to infrastructure. Gap analysis showed coordinators have higher perception scores on quality dimensions than students. In general, results for the three stakeholders were positive; considered constructs showed satisfactory results, reinforcing importance of the study of DE under business perspective in order to identify weaknesses and strengths and to conduct modifications on course strategies and policies.
\end{abstract}




\section{RESUMO}

A educação a distância (EAD) no nível superior no Brasil tem observado grande expansão desde o início dos anos 2000. Esse método de ensino tem se popularizado, por sua flexibilidade geográfica e espacial e pela possibilidade de levar a educação a áreas remotas e, por conseguinte, a indivíduos que não teriam acesso a uma instituição tradicional. Adicionalmente, esse fenômeno de alto crescimento, implica aumento da competição no mercado educacional e, traz consigo, a necessidade de se avaliarem os resultados dessas iniciativas. Para tanto, há modelos na área de educação que subsidiam as avaliações de programa, bem como modelos da área de negócio, que aplicam uma perspectiva de marketing a essas avaliações, esses últimos pouco explorados na área educacional. Assim, esta tese tem como objetivo avaliar a educação a distância sob as perspectivas dos alunos, dos instrutores e da instituição (por meio de sua coordenação) sob uma abordagem de marketing de serviços. Realizou-se um estudo de caso no curso de bacharelado em Administração Pública da Universidade Aberta do Brasil (UAB), incluindo três fases. A primeira fase consistiu de um survey realizado com alunos do curso de Administração Pública da UAB, a fim de aferir sua percepção de qualidade, imagem da instituição, satisfação com o curso e lealdade ao mesmo. A segunda fase consistiu de um survey com os instrutores, professores e tutores do curso, a fim de avaliar suas atitudes em relação à tecnologia e à EAD. Finalmente, a terceira fase consistiu da realização de entrevistas com os coordenadores de curso com vistas a compreender as características do curso e sua visão a respeito dos problemas e potenciais do curso a distância. Participaram do estudo dez universidades membros do sistema UAB, totalizando uma amostra de 593 alunos, 120 instrutores e nove coordenadores. A amostra de alunos apresentou percepções favoráveis acerca da qualidade do curso, satisfação, imagem, lealdade e apoio institucional. Observou-se relação significante entre a qualidade percebida e a satisfação do aluno, assim como influência da satisfação e da qualidade, de forma direta e indireta, sobre a lealdade do estudante. Finalmente, a imagem sobre o sistema UAB influencia a percepção de qualidade sobre o curso. Adicionalmente, no caso estudado há proporções parecidas de homens e mulheres e os homens mostraram satisfação e lealdade ligeiramente maiores que suas colegas do gênero feminino. Na amostra de instrutores não se identificou relação entre attitudes e participação na EAD nem entre a percepção sobre o uso da tecnologia e da EAD. Entretanto, observou-se que, em geral, as atitudes dos instrutores é favorável nas dimensões avaliadas. Os coordenadores reportaram que dentre as principais razões para a adoção da EAD nas instituições está a oportunidade de disseminar a educação em áreas desprivilegiadas. Ademais, algumas dificuldades encontradas são relacionadas à infraestrutura. A análise de gaps de qualidade revelou que os coordenadores possuem percepção mais favorável sobre a qualidade do curso do que os alunos. De forma geral, os resultados obtidos para os três stakeholders considerados foram positivos; os construtos avaliados mostraram resultados satisfatórios, o que reforça a possibilidade de se estudar a EAD sob a perspectiva de negócios, para que se identifiquem forças e fraquezas e que possam ser realizadas alterações nas estratégias e políticas do curso. 


\section{SUMMARY}

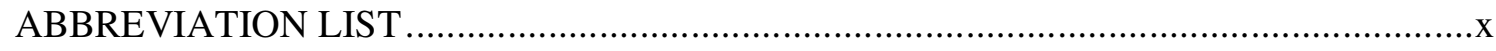

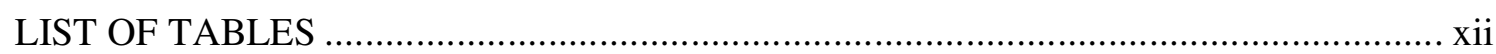

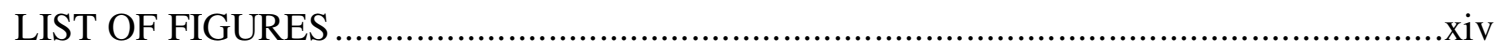

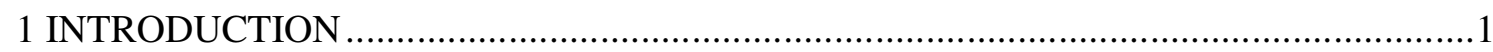

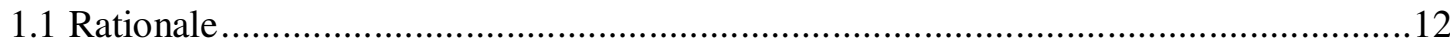

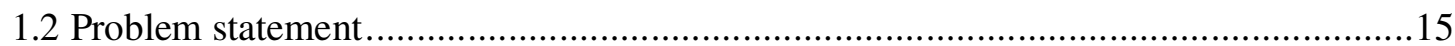

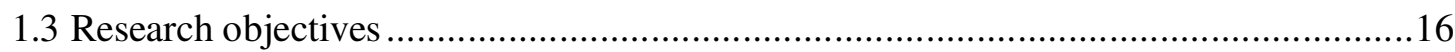

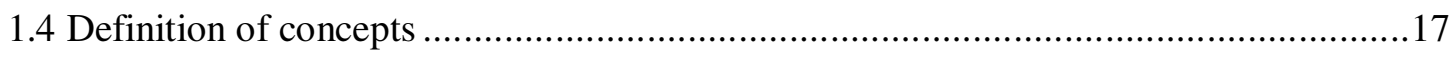

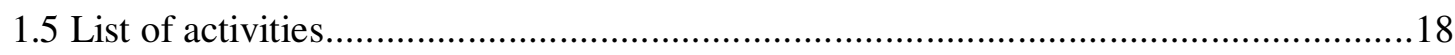

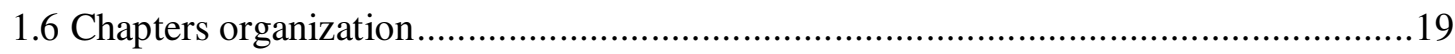

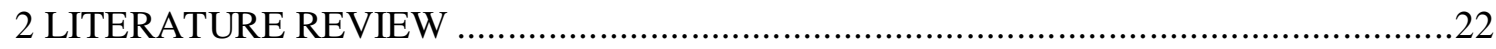

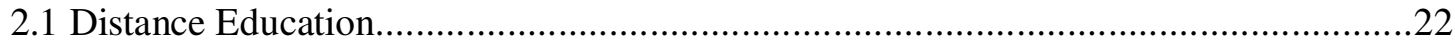

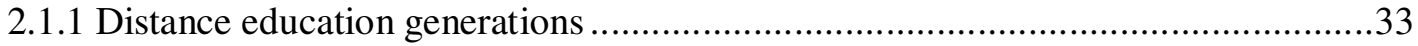

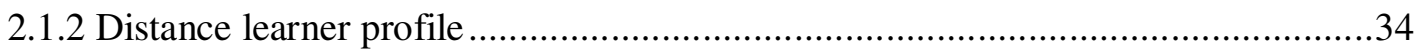

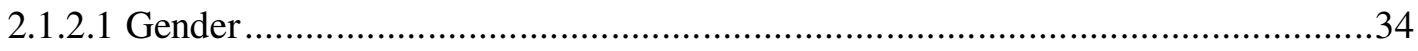

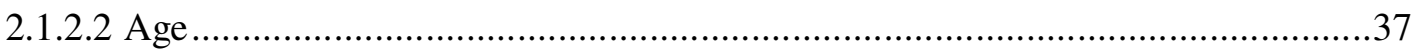

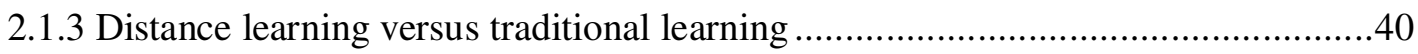

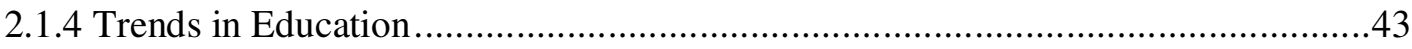

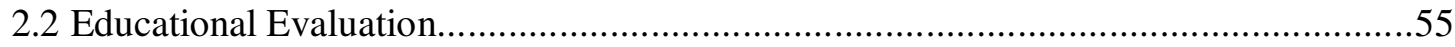

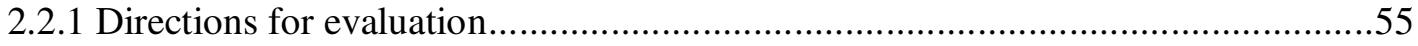

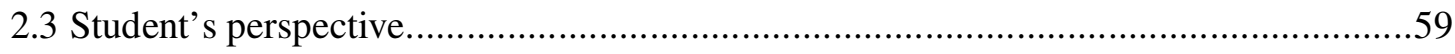

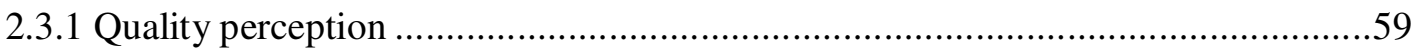

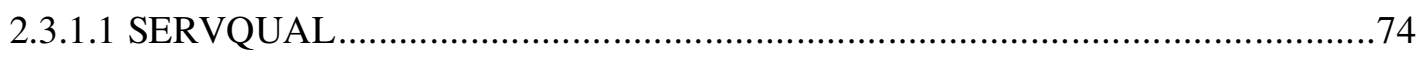

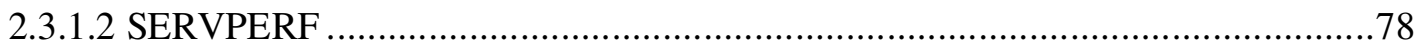

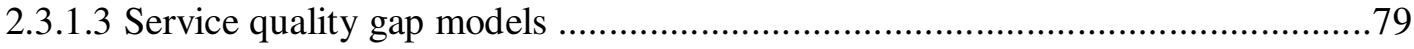

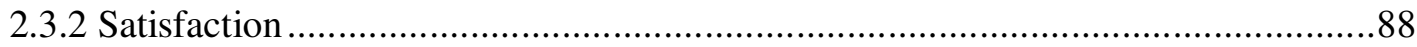

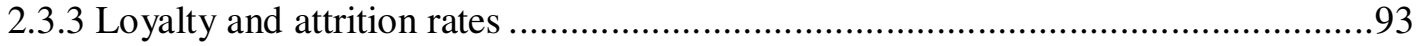

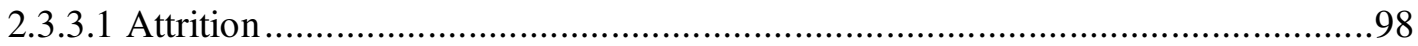

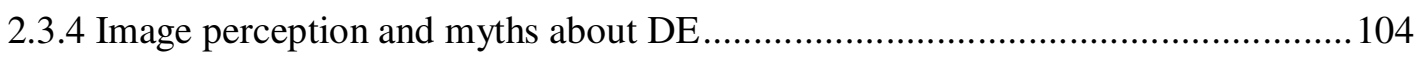

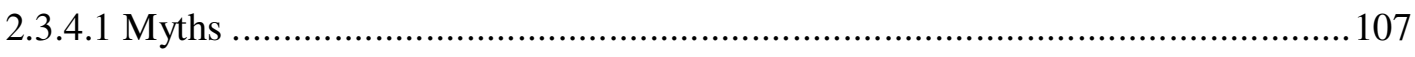

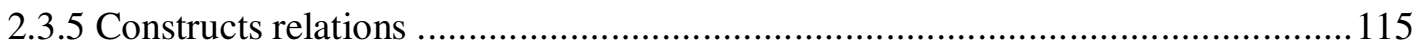

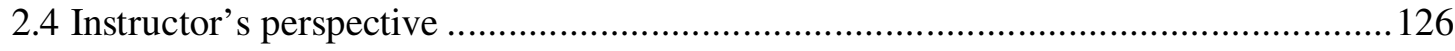




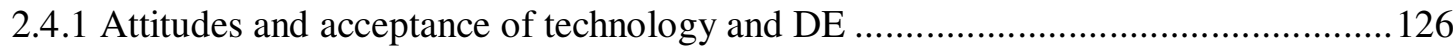

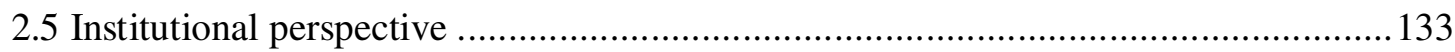

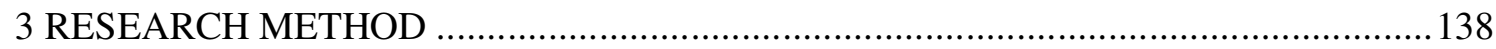

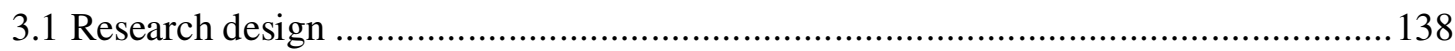

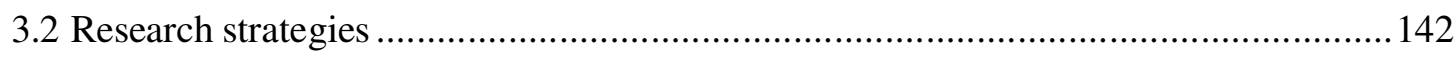

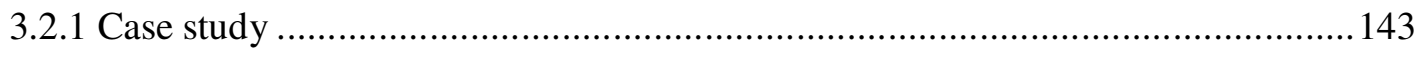

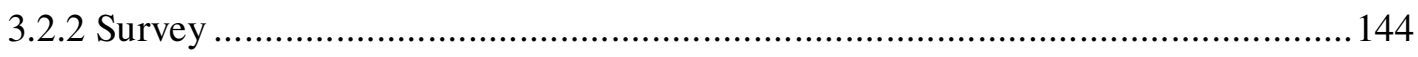

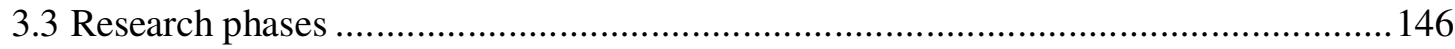

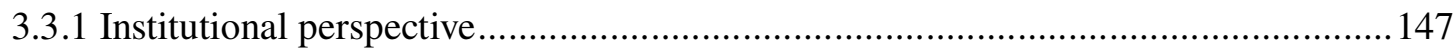

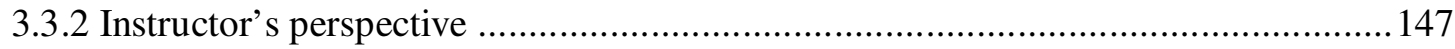

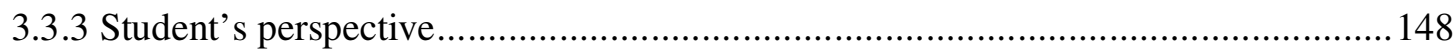

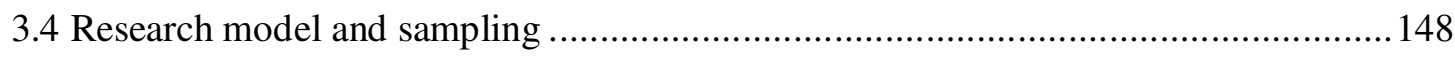

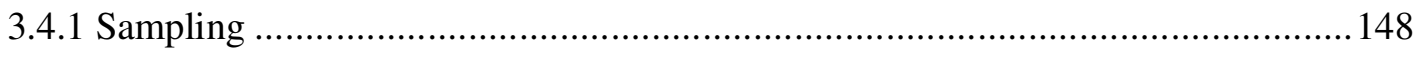

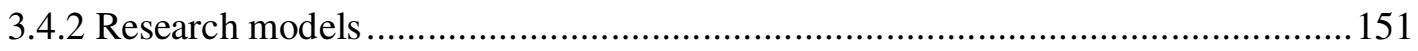

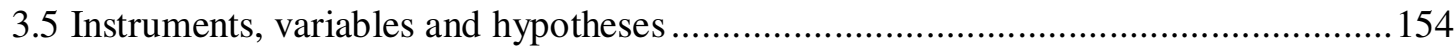

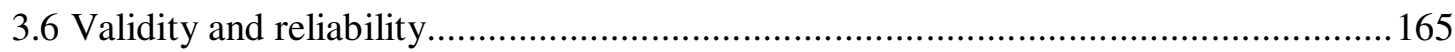

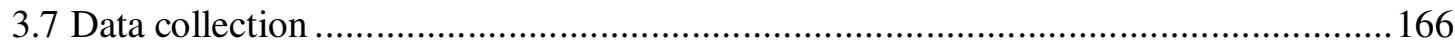

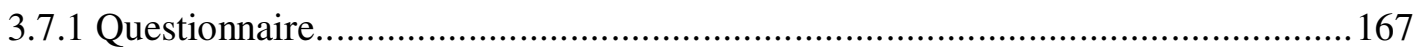

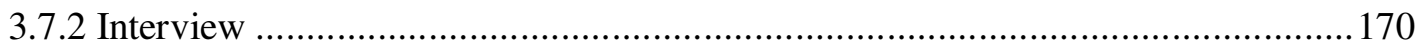

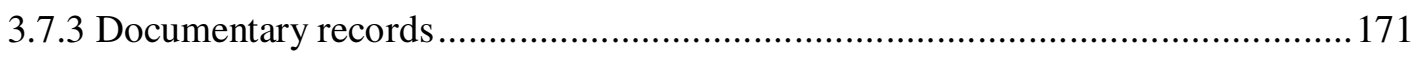

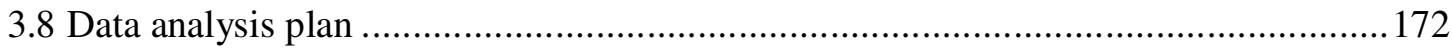

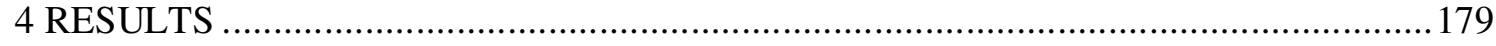

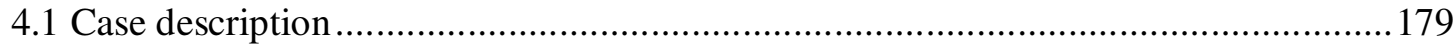

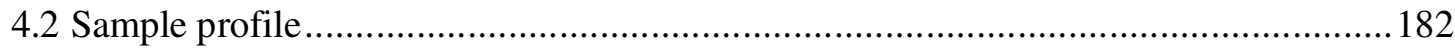

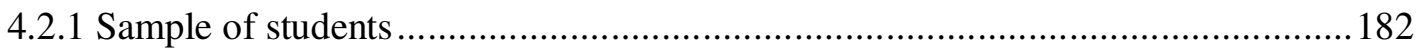

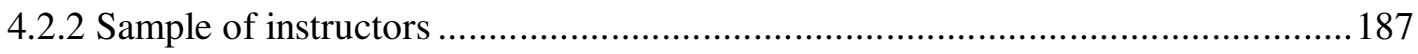

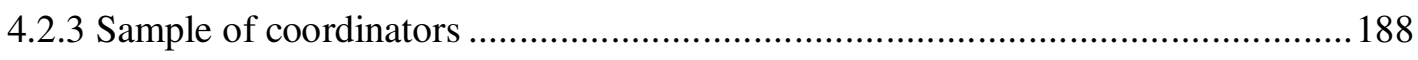

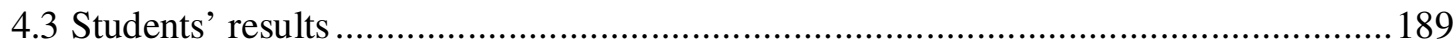

4.3.1 Structural equation modeling - Partial least square ................................................189

4.3.2 Descriptive statistics, correlation analysis, regression analysis and significance tests

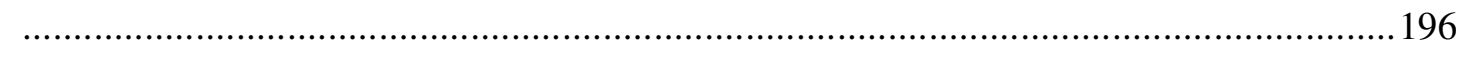

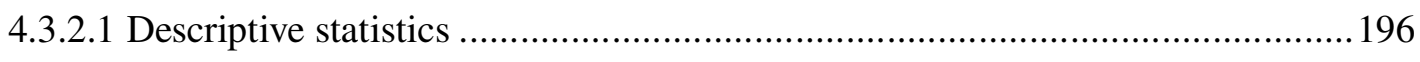

4.3.2.2 Correlation analysis and regression analysis........................................... 197

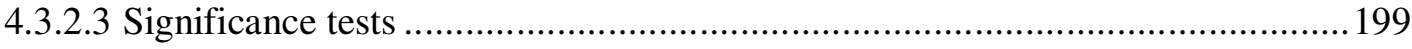




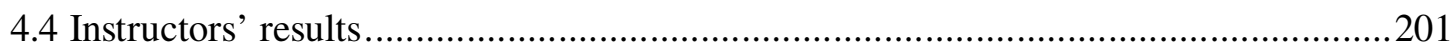

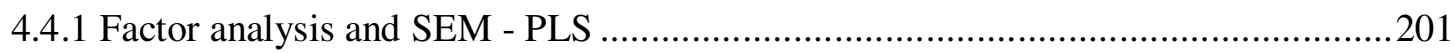

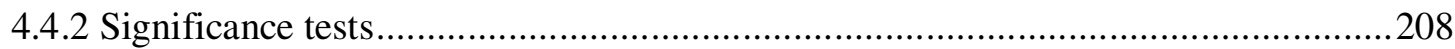

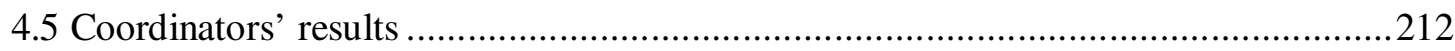

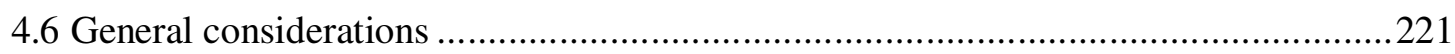

4.6.1 Student's perception versus coordinator's perception........................................221

4.6.2 Instructors' perception versus coordinators' perception .....................................226

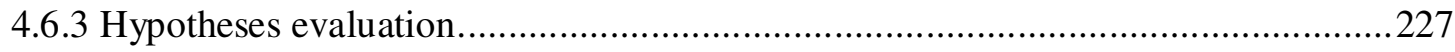

5 CONCLUSIONS, LIMITATIONS AND FUTURE RESEARCH ...............................231

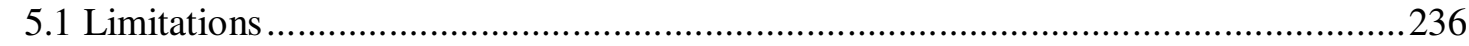

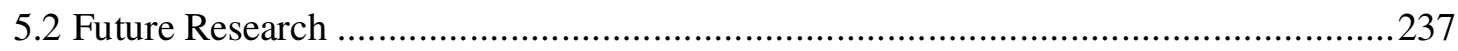

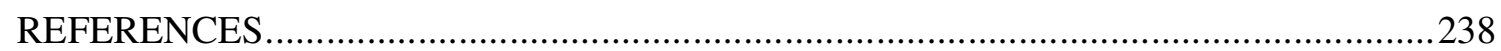

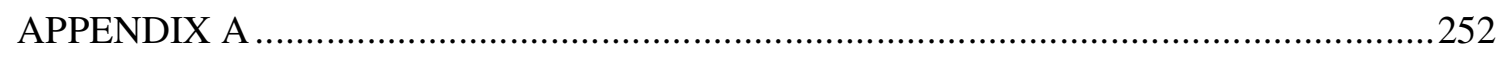

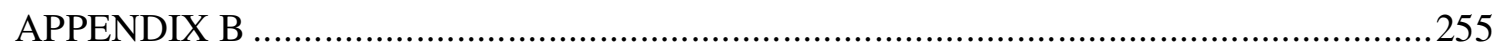

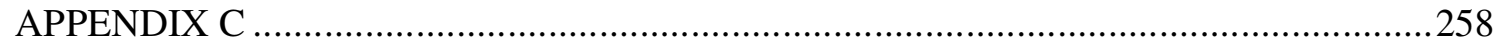

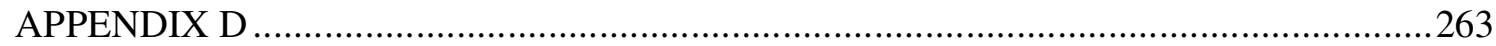

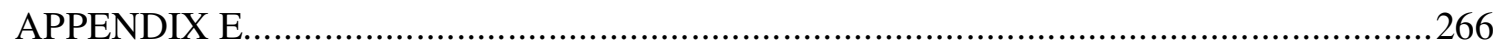

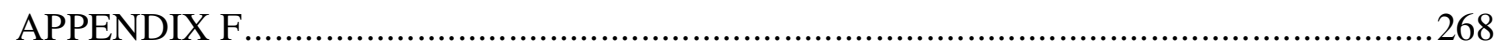




\section{ABBREVIATION LIST}

AVE: Average variance extracted

CAPES: Coordenação de Aperfeiçoamento de Pessoal de Nível Superior/ Coordination for the Development of Higher Education Professionals

CFA: Confirmatory factor analysis

CV: Coefficient of Variation

DE: Distance Education

ENADE: Exame Nacional de Desempenho de Estudantes/ National Exam of Students' Performance

FNDE: Fundo Nacional de Desenvolvimento da Educação/ National Fund for Education Development

HE: Higher education

HEI: Higher Education Institution

ICT: Information and communication technology

INEP: Instituto Nacional de Pesquisas e Estudos Educacionais Anísio Teixeira/ National Institute of Educational Research and Studies Anísio Teixeira

IT: Information technology

KMO: Kaiser-Meyer-Olkin Measure

K-S: Kolmogorov-Smirnov test 
LMS: Learning management system

MEC: Ministério da Educação/ Ministry of Education

MSA: Measure of Sampling Adequacy

PLS: Partial least square

PNAP: Programa Nacional de Formação em Administração Pública/ National Program of Development in Public Management

QUAL: Qualitative

QUAN: Quantitative

R-Square: Coefficient of determination

STD: Standard Deviation

SEM: Structural Equation Modeling

SINAES: Sistema Nacional de Avaliação da Educação Superior/ National System for Evaluation of Higher Education

TAM: Technology Acceptance Model

TCC: Trabalho de conclusão de curso/ Course conclusion work

UAB: Universidade Aberta do Brasil/ Open University of Brazil

UTAUT: Unified Theory of Acceptance and Use of Technology 


\section{LIST OF TABLES}

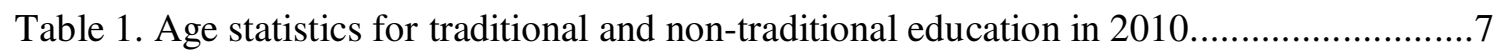

Table 2. Critical success factors found in the literature .....................................................

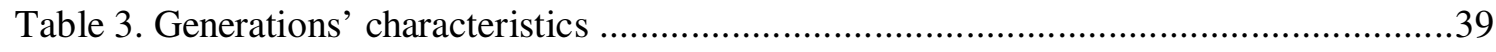

Table 4. Quality perception in education studies - Summary table .......................................72

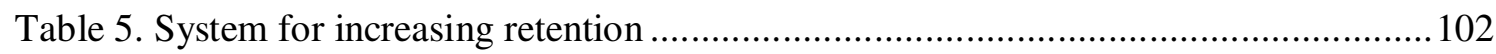

Table 6. Myths about distance education courses ......................................................... 109

Table 7. Sample profile and models goodness of fit of the educational studies considered in

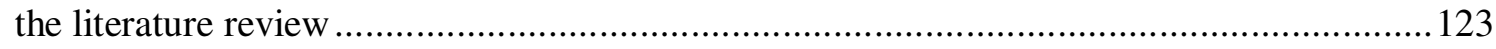

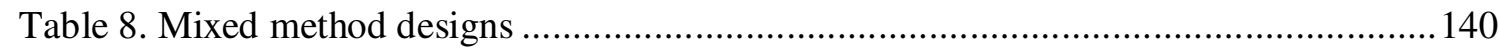

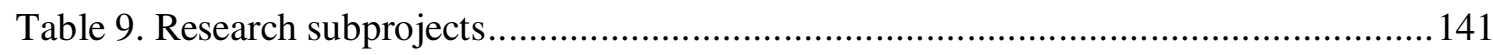

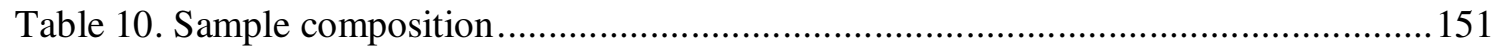

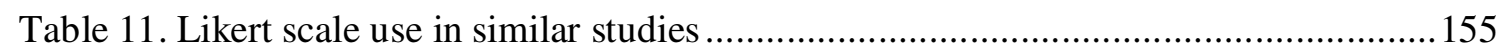

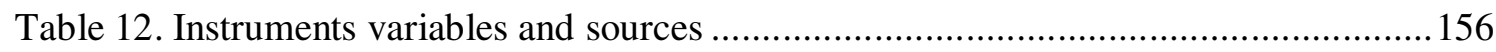

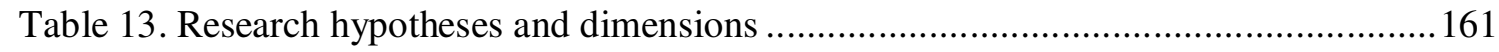

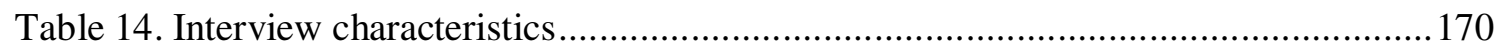

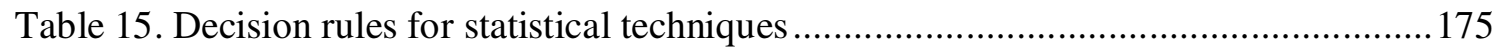

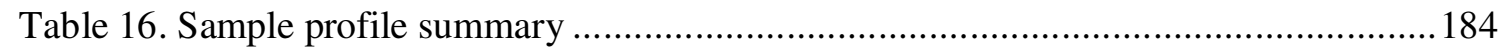

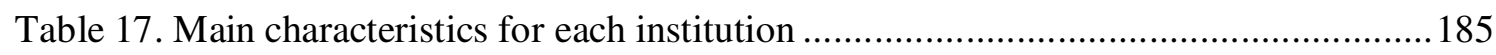

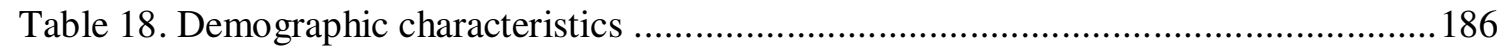

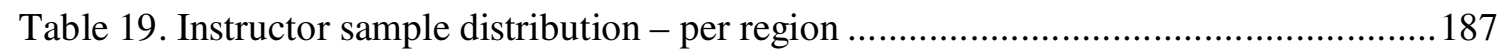

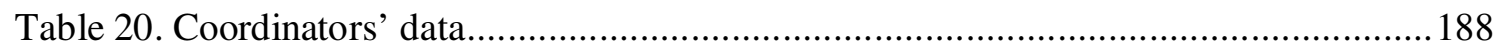

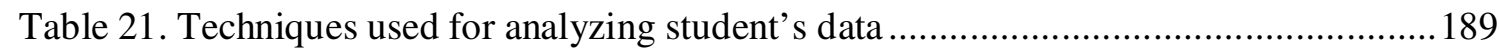

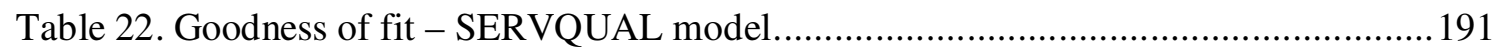

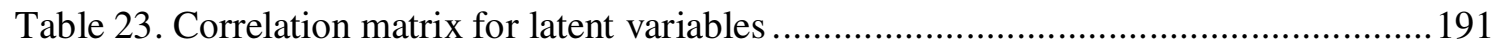

Table 24. Research model statistics ............................................................................. 193

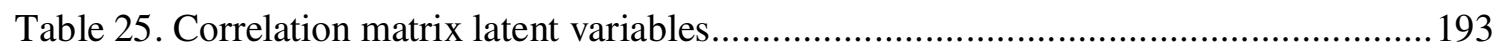

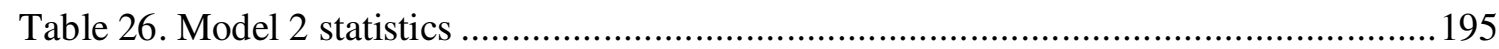

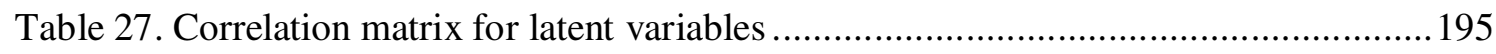

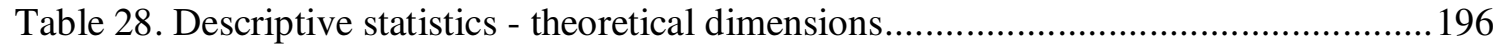

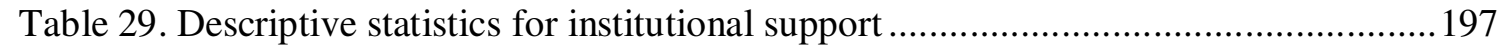

Table 30. Correlation coefficients between performance expectation and some other construct

198

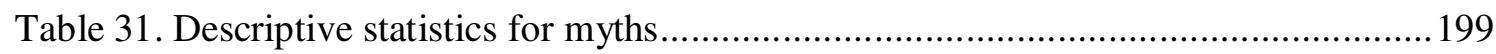

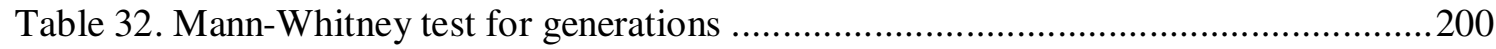

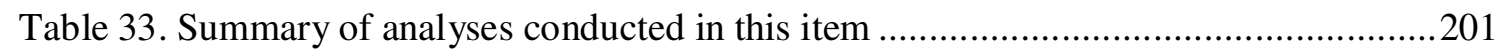

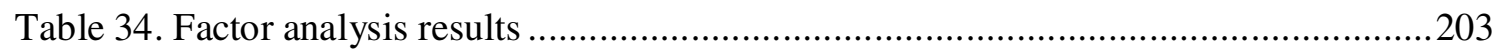

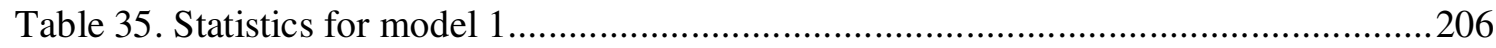

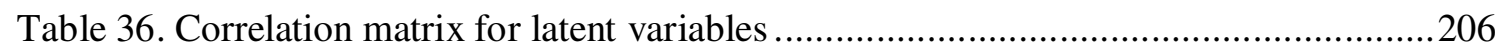

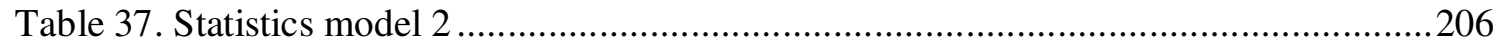

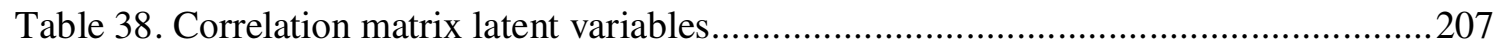

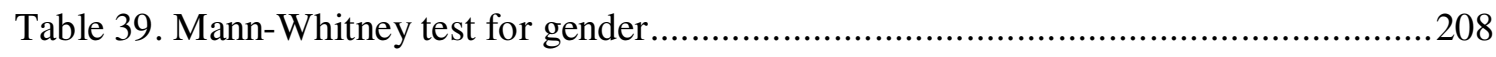

Table 40. Kruskal- Wallis test for generations ..............................................................209 
Table 41. Mann-Whitney test for level of participation in DE ......................................210

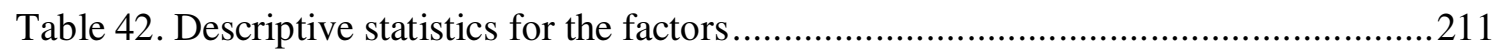

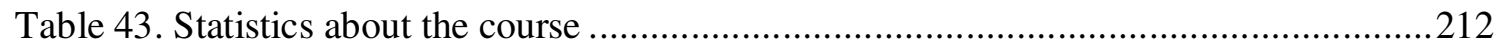

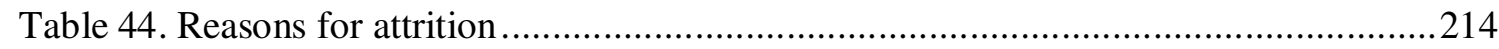

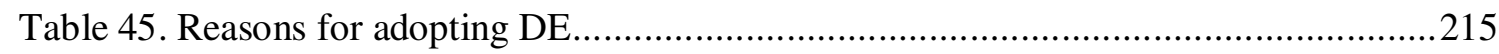

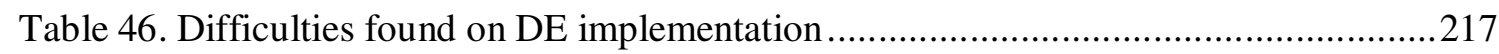

Table 47. Support services provided for instructors and students ......................................218

Table 48. Positive and negative reactions from students..................................................219

Table 49. Scores for SERVQUAL dimensions - coordinators' perceptions..........................222

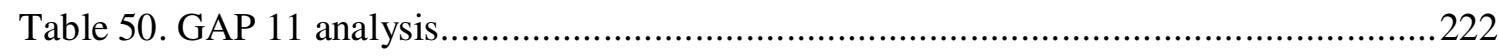

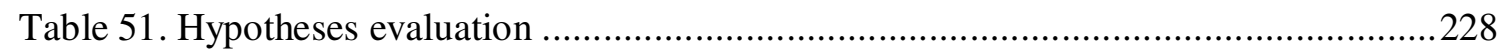




\section{LIST OF FIGURES}

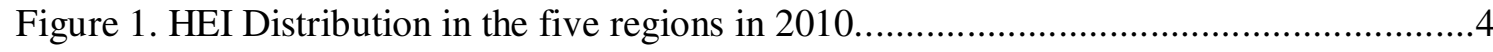

Figure 2. Number of students in traditional and distance education courses from 2001 to 2010

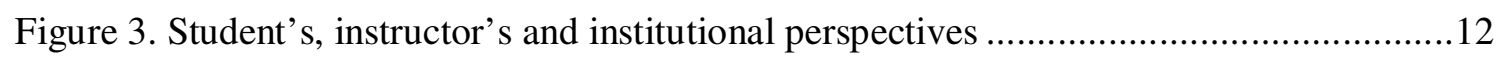

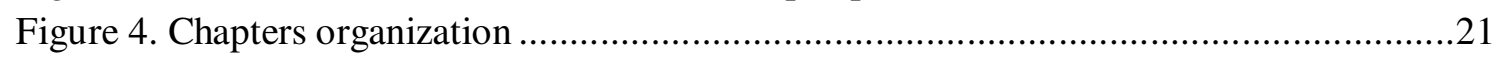

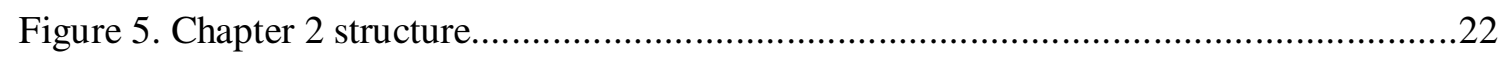

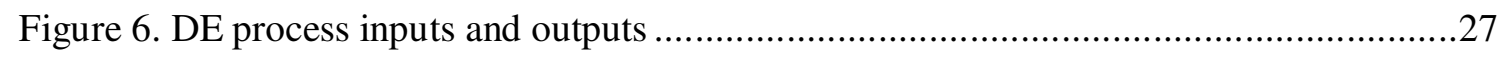

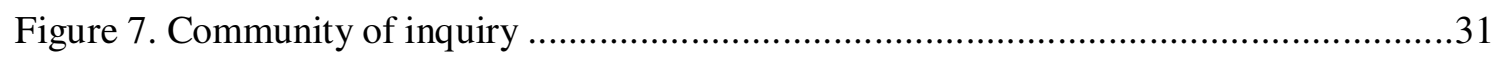

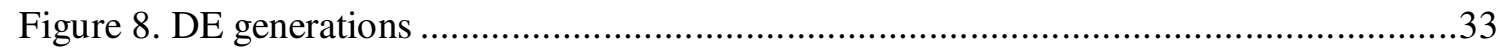

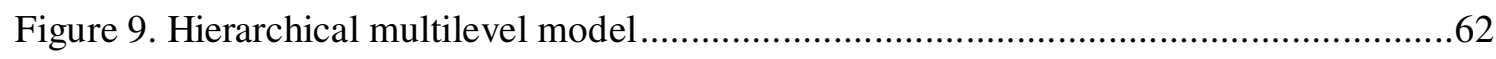

Figure 10. Behavioral and financial consequences of service quality................................63

Figure 11. Chaney et al. (2007) model for quality assessment in DE for health education .....66

Figure 12. Quality perception model - Peltier et al. (2007) .............................................68

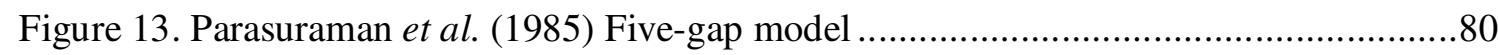

Figure 14. Extended model for service quality (ZEITHAML et al., 1988).............................84

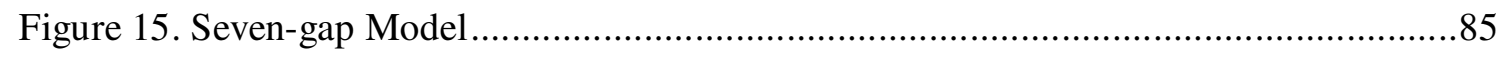

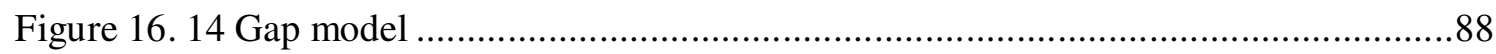

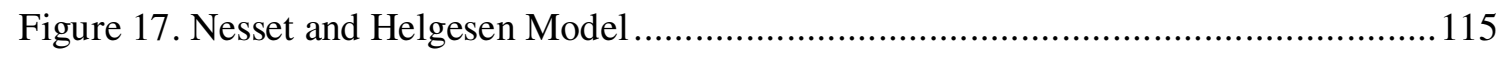

Figure 18. Rojas-Méndez et al. (2009) model for determinants of loyalty ..........................116

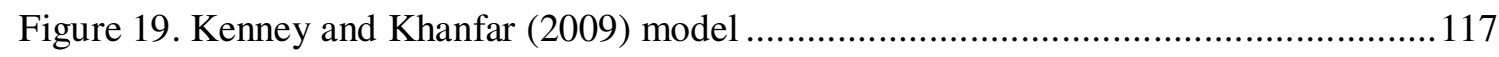

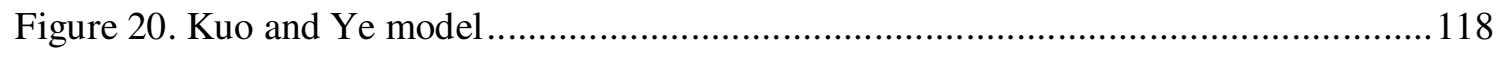

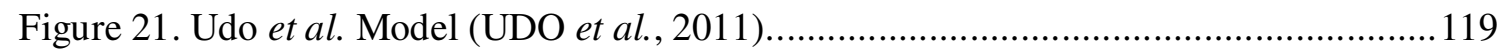

Figure 22. Brown and Mazzarol (2009) model ............................................................... 120

Figure 23. Bloemer et al. (1998) model for banking services ......................................... 122

Figure 24. Bloemer and Ruyter (1998) model for retail store ......................................... 123

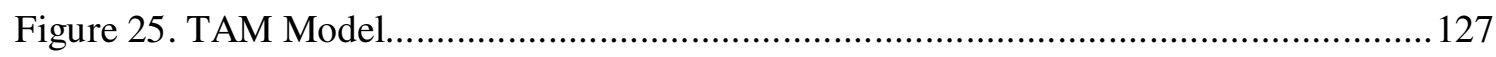

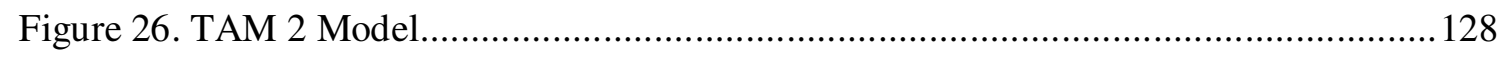

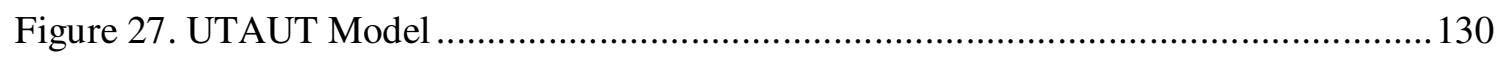

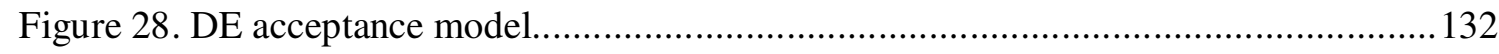

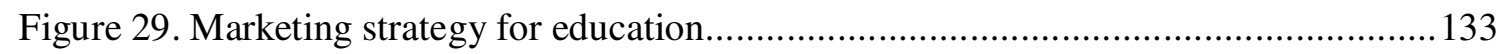

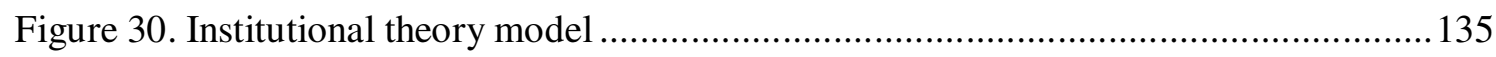

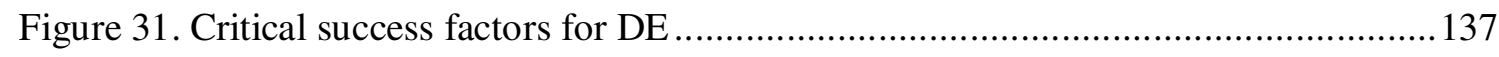

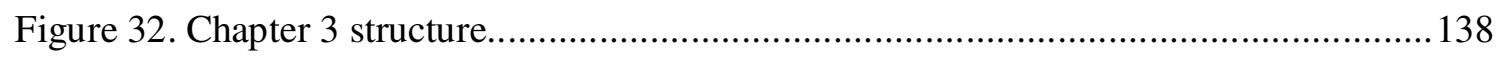

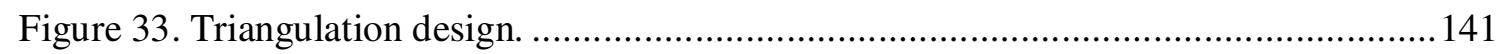

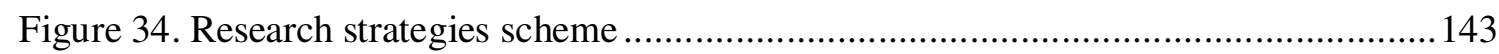

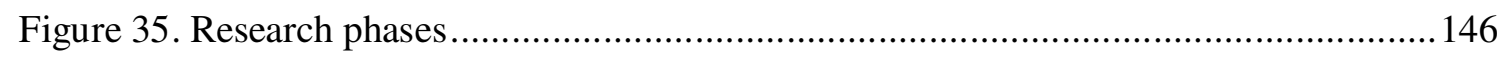

Figure 36. Stratified cluster sample scheme .................................................................. 150

Figure 37. Research model for student's perspective..................................................... 152

Figure 38. Research model for instructors' perspective ................................................ 153

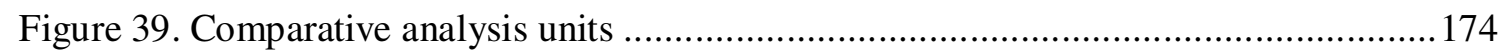

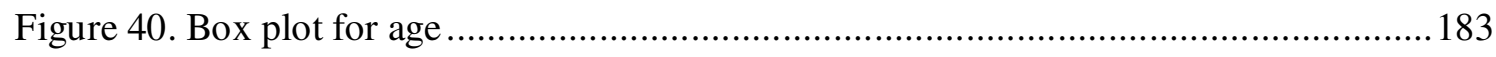

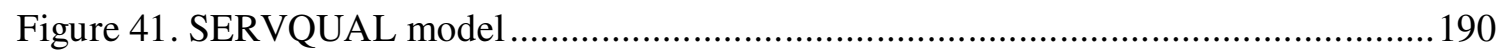


Figure 42. T-student test results for SERVQUAL model................................................ 192

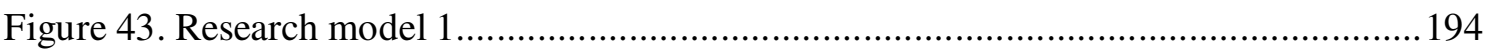

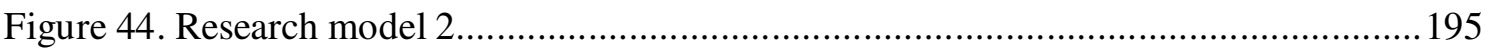

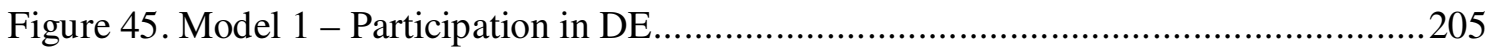

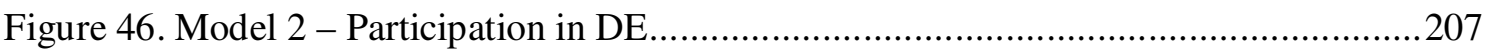

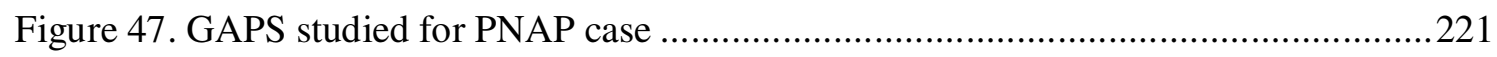




\section{INTRODUCTION}

Higher education institutions (HEI) have been facing local and global competition and big challenges, such as high attrition rates and difficulties in comprehending the needs and expectations of their students and of the market. In addition, the fact that distance education has been growing largely in the higher education level helps to increase, even more, the competition among the educational institutions. Then, those institutions which are effective on the use of education technologies will remain competitive on the long-term (CELSI; WOLFINBARGER, 2002).

The market has been changing radically along the last decades especially due to the technological advances, the globalization and the change on the consumer's preferences. It affects the market dynamics and makes a multitask workforce needed. As consequence, these changes force the educational institutions to change as well, focusing on developing competent students, which means, students who have the ability and competence to deal with challenges they will face on their jobs. Colleges must stimulate the development of the hard skills (technical and analytical skills) as well as the soft skills (communication, leadership and problem solving skills), which are essential to increase the student's probability of success in the new business context (KAPLAN et al., 2010); it means education should assume a market-oriented perspective.

It is important to remark education is not like other kinds of services, since it plays a key role in society and has a noncommercial core mission, which is developing people and stimulating democratic values. For those reasons, there is resistance from researchers from educational field to use marketing theory to study educational problems or to consider students as customers (KENNEY; KHANFAR, 2009; BOWDEN, 2011). For Bowden (2011) a possible reason for this resistance is the idea of privileging marketing on the expense of pedagogical objectives; but the author also points both pedagogical and marketing goals may be achieved conjointly without prejudice to any of them. In reality marketing approach implies creating a two-way interaction and dialogue between the institution and the students (BOWDEN, 2011). Thus, both students and institution work together in the educational services production, in order to create value; for this reason, the author suggests the adoption of a marketing perspective within higher education (BOWDEN, 2011). 
Kuo and Ye (2009) argument that education market has turned customer-oriented, instead of being teaching-oriented as it used to be in the past. Then, an educational organization can be considered a products/services provider, which makes the study of services quality relevant as well as the adequate promotion of institution's image (KUO; YE, 2009). Despite of this controversy this research will make use of marketing concepts and constructs to evaluate distance education, believing that this approach may add value to educational evaluation models and may help generating insights for improving educational experiences and business performance.

Distance education due to its dynamic and interaction has a strong potential to assist the education institutions in this challenge. It brings structural and cultural changes to the institutions and allows them to reach people located all over the world; that is how the global competition happens to the education market. Therefore, each institution should recognize its expertise areas, in which they have competitive advantage, and elaborate and offer courses in these areas, becoming specialized in a set of disciplines. Thus, it is fundamental that the colleges reexamine their marketing strategies (MOORE; KEARSLEY, 2008).

According to Moore and Kearsley (2008), distance education has been fomented to meet some needs, such as:

- Provide access to education.

- Offer development opportunity.

- Reduce existent education structure costs.

- Support existent education structure quality.

- Reduce inequality among age groups.

- Create education opportunities for specific targets.

- Offer immediate training to relevant groups.

- Expand operations in different knowledge areas.

- Mix education to professional and personal lives.

- Internationalize education.

The dissemination of distance education allows people, who originally did not have access to education, for instance, people in the rural areas, to attend schools that were previously accessible to a few privileged groups (MOORE; KEARSLEY, 2008). 
Kramarae (2001) points out some factors that explain distance education growth, considering US experience: reduction on the amount of public subsidies for public higher education institutions; increase of the cost of higher education in general; increase in the number of employed women; decrease in the long-term jobs; increasing number of companies requiring credentials from their employees; fast technology changes; growth of online businesses; increasing in higher education enrollment; requirement of lifelong learning (continuous pursuit of educational development for personal or professional reasons); stronger competition among educational institutions; growth of globalization, including in educational market; increase of the use of technology and the web to deliver education and training in the workplace (KRAMARAE, 2001).

Despite of these reasons for expansion, DE, as an educational method, still faces, in many cases, a stereotyped view by its stakeholders (students, instructors, institution managers, society etc.). This view is based on a set of myths that surrounds DE, such as less effectiveness compared to face-to-face education (CLARK, 2002); belief that it is a demotivating method (CLARK, 2002); faculty team resists to DE (COX, 2005); quality in DE is inferior to face-to-face education (GAYTAN, 2009); students have trouble on managing time and organizing their routine for distance studying (GAYTAN, 2009); isolation (LI; AKINS, 2004); it aims to provide education to excluded people (POWELL; KEEN, 2006). Many other myths about DE exist and will be discussed in chapter 2; however, it is worth to say all these myths may be reality or not depending on the educational context. This discussion reinforces the challenging condition of $\mathrm{DE}$ and the relevance of investigating variables related to the myths in order to deeply comprehend DE actual status in Brazilian reality. Then, quality, satisfaction, retention, image and attitudes toward technology will be studied to provide information about Brazilian DE scenario.

Regarding Brazilian context, it is important to verify the direction of DE trend, which reinforces the relevance of studying this theme. Distance education is becoming an increasingly important part of higher education. In Brazil, higher education both face-to-face and at a distance has been increasing since the last decade (years 2000), as a response to market's demand for a better qualified workforce and to the federal efforts to develop economy, reduce social inequality and expand job opportunities for unprivileged population. Data from the National Census show a rising trend on the number of higher education 
institutions (HEI) in the country; in the year 2001 there were 1,391 HEI and this number reached 2,378 in 2010, a $71 \%$ increase in the last decade (INEP - National Institute of Educational Research and Studies Anísio Teixeira, 2012). Figure 1 shows the number of educational institutions for each of the five regions of the country. Southeast region (states: São Paulo, Rio de Janeiro, Minas Gerais and Espírito Santo) owns most of the institutions, both traditional and non-traditional, followed by Northeast and South. It reveals education is concentrated in the South and Southeast states. The graph also exposes the dominant position of traditional (face-to-face) institutions, which represents an expansion opportunity to DE, especially where there is a lower offer (e.g. North and Midwest).

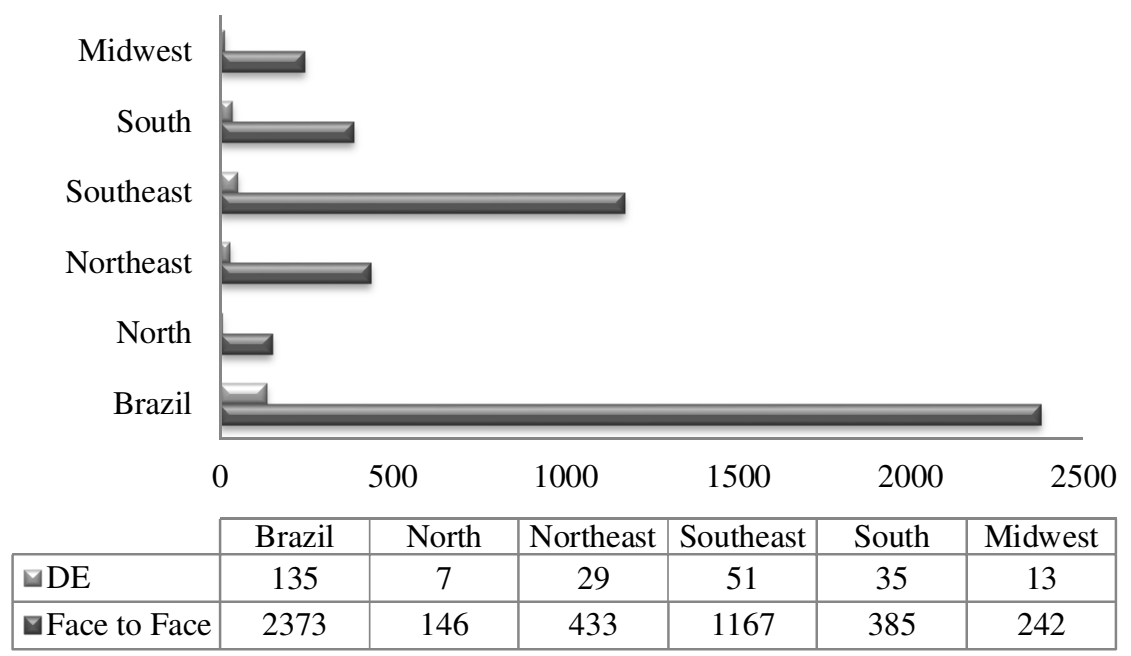

Figure 1. HEI Distribution in the five regions in 2010.

Source: By the author, based on National Census data (INEP, 2012) ${ }^{1}$.

Considering the number of undergraduate courses credentialed, there was a $13 \%$ increase in 2009 in relation to 2008 and considering the modality of education, DE had a $30.4 \%$ increase while face-to-face courses increased $12.5 \%$ (INEP, 2010).

The number of students enrolled in a higher education course also raised during the first decade of the $21^{\text {st }}$ century. In the year 2001 there were 3,036,113 undergraduate students in Brazil; in 2010 this number reached 6,379,299 undergraduate students, which means a 110\% increase. This statistic is even more impressive, when the education models (traditional or non-traditional) are analyzed separately: in 2001 face-to-face students represented $99.8 \%$ of

\footnotetext{
${ }^{1}$ Some institutions may be credentialed for offering both distance and traditional courses.
} 
total undergraduate students in the country; in 2010 face-to-face students were $85.4 \%$ of the whole student population; in other words, distance students moved from $0.2 \%$ in 2001 to 14.6\% in 2010 (INEP, 2012). Figure 2 presents the evolution of enrolled students in higher education from 2001 to 2010 . These data reveals that in 2001 there were just a few students in distance education courses (5,359 students); however this number started increasing in 2006 and acquired an ascendant trend (930,179 students in 2010).

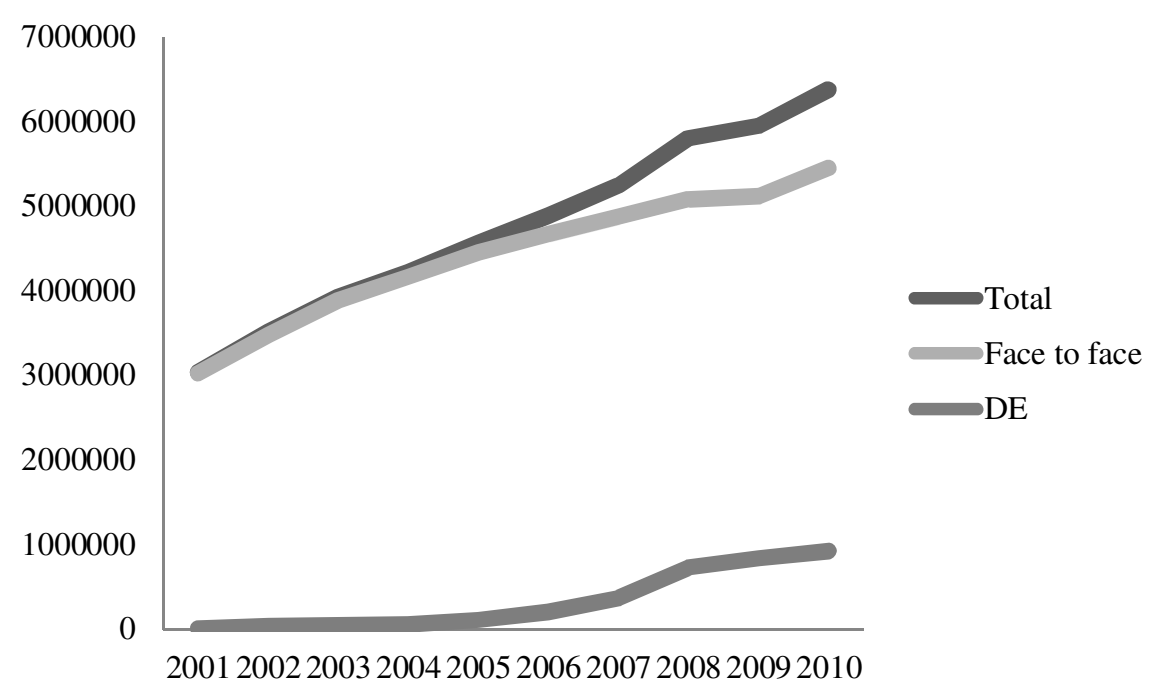

Figure 2. Number of students in traditional and distance education courses from 2001 to 2010 Source: By the author, based on National Census data (INEP, 2012).

This growth of distance education in Brazil may be explained by the expansion on higher education in general (traditional and DE) and by the public policies created by national government to stimulate distance education adoption as a way to provide education to people living in distant areas or who had limited access to higher education. In this sense, it is remarkable to mention that Brazilian government created the Open University of Brazil (UAB - Universidade Aberta do Brasil), research object of this dissertation, in 2006 in order to provide public, free and high quality courses on the online model. UAB creation in 2006 matches the beginning of the growth of distance education in Brazil, as seen in Figure 2. This fact reinforces its importance for national scenario. UAB characteristics will be discussed later in this chapter.

Traditional and distance education have some differences in the Brazilian case. While in $2010,73 \%$ of face-to-face courses consisted on bachelor's degree, only $29 \%$ of DE courses 
were baccalaureate; similarly, $17 \%$ of face-to-face courses consisted on full degree courses (teacher degree) while they were $46 \%$ of DE courses. Technician degree represented $10 \%$ of traditional courses and $25 \%$ of DE courses. It means, face-to-face courses are predominantly bachelor's degree, while for DE the dominance is represented by full degree courses (INEP, 2012). The full degree predominance is due to the fact that distance education main objective in Brazil was to provide qualification to teachers/instructors on the basic education levels, who, in many cases, did not own a Pedagogy/Education degree.

It becomes clear when the major higher education courses are pointed. Considering general data, Business Management is the major higher education course in Brazil (18.5\% of total students); followed by Law (10.9\% of the students), Pedagogy (9.6\% of the students), Engineering (7.1\%), Nursing (4.0\%) and Accounting (4.0\%). Segregating data by education modality, the distribution of students is different for distance and face-to-face. For face-toface education, Business is the main course, with $17.1 \%$ of the students, followed by Law (12.7\%), Engineering (8.2\%), Pedagogy (5.6\%), Nursing (4.6\%) and Social Communication (4.0\%). For distance education, the main course is Pedagogy which owns $34.2 \%$ of the enrolled students, followed by Business (27.3\%); Social Services (8.1\%), Languages (5.9\%), Accounting (3.6\%) and Mathematics (2.8\%) (INEP, 2010).

The data discussed above explains why distance education in Brazil offers mostly full degree courses; as courses in the education field are usually full degree type and dominant for DE (e.g. Pedagogy, Languages and Mathematics are usually full degree). Notice that distance courses on health sciences or hard sciences are not frequent. On the other hand, face-to-face focuses on baccalaureate courses such as applied social sciences, hard sciences and health sciences fields.

Analyzing the Brazilian student profile, it seems that, in general, students are mostly women (57\% of the students in 2010). Age varies for both types of education, as presented on Table 1; distance students are older than face-to-face ones when they start or finish undergraduate level. These numbers indicate age and gender are important variables for studying education (INEP, 2012). 
Table 1. Age statistics for traditional and non-traditional education in 2010

\begin{tabular}{lllll}
\hline Type of Education & Mean (years) & Median & $\begin{array}{l}\text { Frequency } \\
\text { (number of } \\
\text { students) }\end{array}$ \\
\hline \multirow{2}{*}{ Starting age } & DE & 32 & 31 & 380,328 \\
\cline { 2 - 5 } & Face-to-face & 25 & 22 & $1,801,901$ \\
\hline Graduation age & DE & 36 & 35 & 144,553 \\
\cline { 2 - 5 } & Face-to-face & 28 & 25 & 829,286 \\
\hline
\end{tabular}

Source: Adapted from INEP (2012, p. 45)

In view of the exposed data, education expansion in Brazil, specifically distance education explosion, raises the need of evaluating these programs in order to ensure their sustainability in the long-term. Additionally, considering the relevance of distance education for higher education, it is important to comprehend what makes a distance course more successful or effective than its competitors. Educational research field offers some models for program evaluation, such as Kirkpatrick four levels model and Scriven summative and formative evaluation approaches, which will be briefly discussed in chapter 2 .

Evaluation models aim to analyze programs outcomes taking into account different variables, such as student's and instructor's satisfaction and student's performance, frequently focusing on the aspects related to student's perspective of process. However, in the distance education field, success can be interpreted under three perspectives: institutional, student's and instructor's; each of these spheres having specific needs and expectations and, for instance, factors that enhance success (WHITE, 2007). Many studies in the literature found significant dimensions affecting distance education outcomes; some are exhibited on Table 2.

Table 2. Critical success factors found in the literature

\begin{tabular}{|c|c|c|c|}
\hline Author & Dimensions & $\begin{array}{l}\text { Success/effectiveness } \\
\text { variable }\end{array}$ & Main focus \\
\hline VOLERY (2001) & $\begin{array}{l}\text { Technology } \\
\text { Instructor } \\
\text { characteristics } \\
\text { Student characteristics }\end{array}$ & $\begin{array}{l}\text { Student performance: } \\
\text { student involvement and } \\
\text { participation; cognitive } \\
\text { engagement; technology } \\
\text { self-efficacy; perceived } \\
\text { usefulness of the } \\
\text { technology employed; } \\
\text { relative advantage of } \\
\text { online delivery }\end{array}$ & $\begin{array}{l}\text { Student } \\
\text { perspective }\end{array}$ \\
\hline
\end{tabular}




\begin{tabular}{llll}
\hline Author & Dimensions & $\begin{array}{l}\text { Success/effectiveness } \\
\text { variable }\end{array}$ & Main focus \\
\hline BENSON SOONG & Human factors & Students use and enjoy to & Student \\
et (2001) & Technical & use DE & perspective \\
competences & Students consider DE & Instructor \\
& Mindset about & helpful and interesting & perspective \\
& learning & Instructors consider DE & \\
& Level of collaboration & improves learning & \\
& IT (information & & \\
technology) & & \\
& infrastructure and & & \\
& technical support & & Student \\
& Instructor & & \\
& characteristics & & \\
\hline SELIM (2007) & Student characteristics & & \\
& Information & & \\
& technology & & \\
& University's support & & \\
& based SELIM (2007), BENSON SOONG et al (2001), VOLERY
\end{tabular}

Source: By the author, based on SELIM (2007), BENSON SOONG et al. (2001), VOLERY (2001).

The study of critical success factors emerged on management field in the 1980's and helps researchers to find out why an organization/business had a better outcomes than the others (SELIM, 2007). As mentioned earlier, the environment for the educational institutions is complex and highly competitive; in this sense it is important to implement a marketing orientation that enables these institutions to unveil the market needs and react with strategies which improve students learning experience (JAGER; GBADAMOSI, 2009; ŠIMIĆ; ČARAPIĆ, 2008). Marketing as a research field is involved on studying some main constructs such as satisfaction, loyalty, perception of quality, image and attitudes, which are very useful to discover what (on the matter of a product or service) is more important to the consumer and how his/her experience with the service was.

Education in general and specifically distance education certainly cannot be considered a pure or a traditional service, as discussed earlier in this chapter, but marketing dimensions along with the variables pointed by distance education literature, assist the college and university managers to understand how their audiences feel and what they think about DE model and about the institution itself. As a consequence, it is possible to develop stronger and more effective management strategies. 
Thus, educational evaluation may add marketing theory constructs, developing adapted models that study dimensions not included before. On the behalf of marketing theory, despite of the relevance of DE products to higher education institutions portfolios and its advantages for education in general, the students' perceptions about quality and satisfaction with the course are not always clear (POHL et al, 2007).

Quality is a key factor to guarantee competitiveness and sustainability for both distance and traditional institutions. The concept of services quality is abstract and is related to the individual attitudes, his/her satisfaction and experience with the service. There are some methods to assess quality; the most popular compares the perceived and the expected quality (ŠIMIĆ; ČCARAPIĆ, 2008). Cheng (2011) emphasizes the concept of quality is related to the stakeholders; that is, the groups or individuals who have a legitimate interest in higher education quality, such as development agencies, the government, employees, faculty, students and alumni, each one owning different expectations regarding education. Quality, in this sense, is understood as the education transformation through student's empowerment (students take responsibility for their own education process) (CHENG, 2011).

According to Šimić and Čarapić (2008), many studies about quality assessment took place during the 1980's and the 1990's resulting in some assessment models. Among the most popular models are SERVQUAL by Parasuraman, Zeithalm and Berry (1988) and SERVPERF by Cronin and Taylor (1992); each of them can be applied to many different businesses. Then, these models can be adapted to meet the research needs of each business field.

In higher education, quality can be considered as meeting the standards imposed, achieving student transformation or even obtaining return on the investments (CHENG, 2011). The present research will consider for quality assessment student perception of the course experience. Service delivery and student satisfaction depend on the interaction between them and institution staff, both faculty and support team. The choice between one and another institution is highly related to its infrastructure, student support structure, institutional image, academic issues, location and accessibility and quality of the contents delivered (JAGER; GBADAMOSI, 2009). 
Higher education colleges have been working on their marketing strategies trying to become differentiated in the market, to reduce attrition rates and to increase student loyalty. Attrition leads to high costs and high inefficiency for both education institutions and society. Thus, it is important to attract students whose expectations can actually be met, because it leads to a reduction on attrition and external transfer rates (LIN; TSAI, 2008).

A student may decide to leave his/her course anytime; so if he/she has a low quality perception, there is a great attrition probability (LIN; TSAI, 2008). Retention policies help institutions develop a solid financial basis (even public or private institutions). Retention is important for private institutions because the tuition fees represent their main fund source. For the public institutions, retention is relevant as the amount of resources (came from government or support agencies) depends on the number of active students (LIN; TSAI, 2008).

It is important to notice that a satisfied student may become loyal; that is, this student may become motivated to conclude the course or, after graduation, recommend the institution to his/her network. Loyalty can also lead a student to donate resources or take another course in the same institution (LIN; TSAI, 2008).

Although instructors have a different role in distance education programs their relevance to a successful course is recognized. They are no longer experts who teach passive students, just like it happens on face-to-face lectures. Instead, teachers become advisors who guide their students on their educational path, respecting their needs and stimulating critical thinking (CHENG, 2011).

In this modified scenario, teaching skills must be reviewed and teachers must be trained; so they can perform satisfactorily in a high technology environment, where students are located in different places all over the world. The online instructors should own different skills, comparing to traditional instructors, to perform well online, such as technology literacy, capability of motivating students etc. Hunter (2011) points out there is a difference between students and instructors' perceptions in educational context. In her opinion, students and faculty value different aspects from educational environment, for instance, students value communication, organization, fairness, knowledge and credibility when they evaluate learning 
experience; faculty, instead, value the possibility of stimulating critical thinking and achievement of learning goals (HUNTER, 2011).

As a result of this current scenario, and considering the relevance of instructors' perceptions and behaviors to a successful program, it is important to comprehend their attitudes and behavior in online environment; it means, their perception of technology, and how these variables influence students' and program's outcomes.

Finally, it is essential to remark the role of institutional strategies and policies to a successful higher education distance program. Empirical studies with online students show that distance education main advantages are its time and space flexibility - since student can accomplish the required activities anytime, anywhere - and its interactivity - since student can interact with his/her peers, professors and contents, and the latter must be designed and developed for DE purposes (POHL et al., 2007). In this sense, institution must create a specific structure, design proper activities and contents and train staff team and distance instructors to deal with online students. These measures are important as they have a direct influence on the programs outcomes (POHL et al., 2007):

- training and support for staff and teachers impact their motivation and how they perform online;

- technology adopted, online and face-to-face activities and communication structure impact on student's perceptions and performance on the program;

- teachers and staff motivation and skills impact on student's perceptions about the course;

- influence of student's perceptions and performance impact on institution's outcomes (reaching the standards, image to the market, attrition rates etc.).

So, in order to understand and evaluate a distance program, it is necessary to consider not only the students point of view, but also instructor's and institutional perspectives and their relations (Figure 3). 


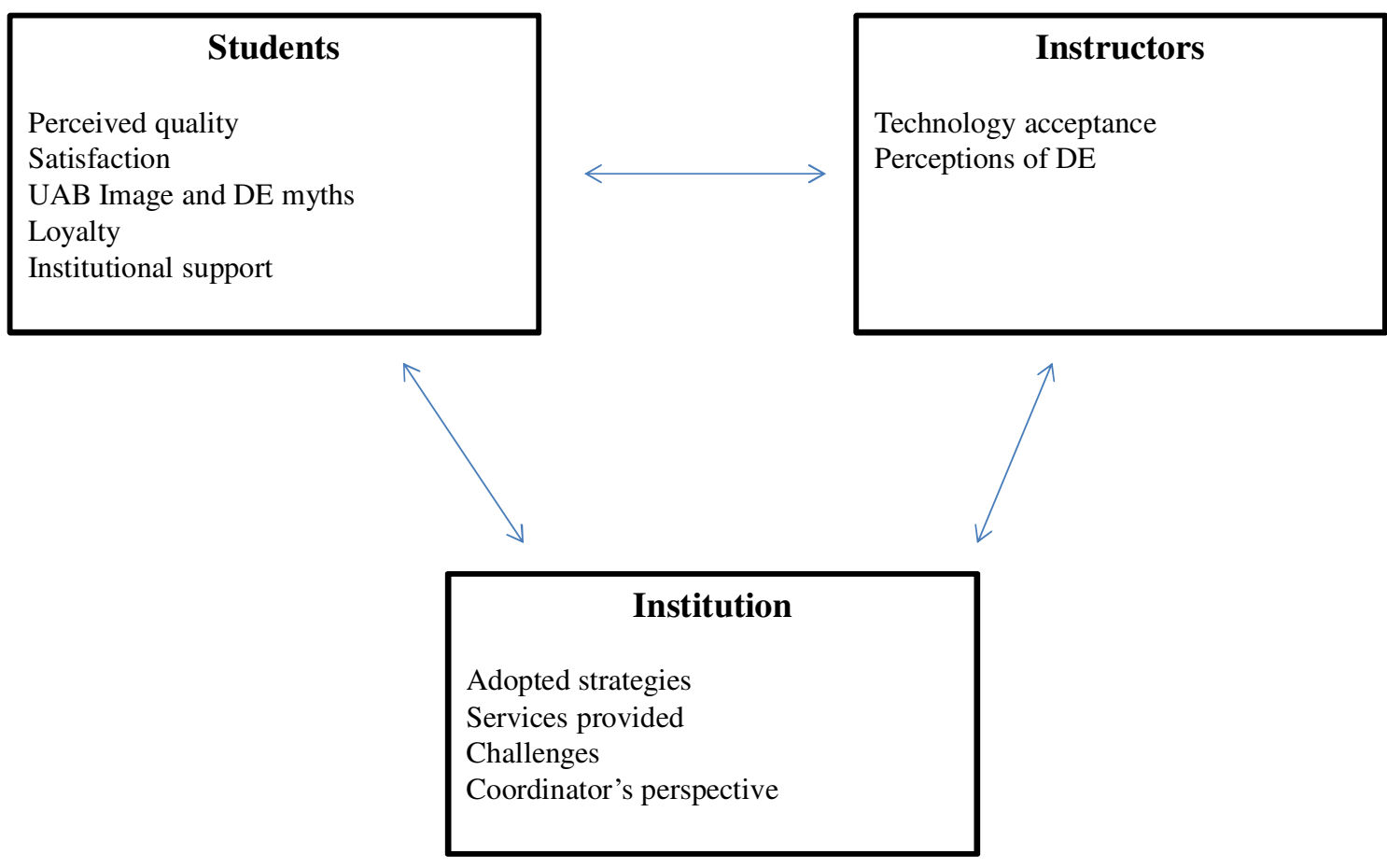

Figure 3. Student's, instructor's and institutional perspectives

\subsection{Rationale}

The fast growing of DE in Brazil during the last decade and the social structure and geographic dimension of this country provide a powerful juncture to disseminate national education. Therefore, evaluating distance programs outcomes is important, and considering the high levels of competition in higher education, with the increasing number of credentialed schools and new courses, using a market-oriented vision seems to be appropriate. For this purpose, educational evaluation models can add some marketing dimensions (such as loyalty, image, perceived quality and satisfaction) to expand their analysis and generate insights for education managers and decision makers.

Brazilian education is regulated by the federal government through the Ministry of Education (MEC - Ministério da Educação), which is responsible for accrediting HEI, authorizing the creation of new programs, inspecting their work and evaluating their outcomes, in order to guarantee quality standards are met. Higher education is evaluated, since 2004, through a system SINAES (Sistema Nacional de Avaliação da Educação Superior/ National System for Evaluation of Higher Education) which includes an exam (ENADE - Exame Nacional de 
Desempenho de Estudantes/ National Exam of Students' Performance) run by INEP (Instituto Nacional de Pesquisas e Estudos Educacionais Anísio Teixeira/ National Institute of Educational Research and Studies Anísio Teixeira) to a sample of students. This is a mandatory exam and aims to acquire student's performance and, as a result, program's quality. In addition, SINAES evaluates the programs and HEI considering also faculty, staff; social responsibility, infrastructure, research activities etc. In case the program does not meet the standards, Ministry of Education can withdraw its accreditation and its activities are interrupted.

Specifically distance education has its own laws and processes (these laws are summarized on the Appendix A) and started to be considered in the national education in 1996 by Law no. 9,394 from 12/20/1996 (Lei de Diretrizes e Bases). However, DE expansion started in 2006, as exhibited earlier in this chapter, which coincides with the creation of the Open University. The Open University of Brazil (Universidade Aberta do Brasil - UAB) has been created in 2006 (Decree no. 5,800, 06/08/2006) by the Brazilian Government to disseminate higher education over the country and, consequently provide accessibility; social inclusion and develop qualified workforce. UAB system's priority is to qualify basic education level teachers, managers and workers in general (who are involved in the basic level) (UAB, 2012). Thus, full degree courses in education/pedagogy field represent an important role for UAB. The Open University is present on the five regions of the country and uses the infrastructure of traditional Brazilian public universities, which are funded by public resources, to provide the courses. São Paulo State Universities are not involved in UAB system, only federal universities (UFSCAR - Federal University of São Carlos, UFABC - Federal University of ABC, UNIFESP - Federal University of São Paulo State) offer UAB undergraduate and graduate courses; an explanation for this is that São Paulo State Government created in 2008 UNIVESP (Universidade Virtual do Estado de São Paulo - São Paulo State Virtual University) by Decree no. 53,536 from 10/09/2008. UNIVESP, just like UAB, makes use of São Paulo State public universities (University of São Paulo/ USP, São Paulo State University/ UNESP, State University of Campinas/ UNICAMP) structure to expand access to education in the state.

Distance education model adopted by UAB allows people from remote areas of the country, who in many cases could not have a degree, to attend a high quality university. As a consequence, it stimulates development in areas where there is a low level of human and 
education development, reduces migration to central cities and lowers the educational concentration which usually happens in urban areas (UAB, 2012). This fact exposes UAB social concerns, recognizing the need of local sustainable development. In 2011 UAB reached 190,000 students and 618 active centers over the country (UAB, 2011). UAB has some peculiar characteristics:

1) Selection process does not occur every year or every semester. Official announcements are published for each course and each university signed in the system may apply for this announcement. The announcements are published as UAB judges necessary.

2) Student application must choose a face-to-face center where he/she will attend face-toface classes, tests and activities.

3) Curriculum has specific characteristics. For instance, Public Management program is a bachelor degree and focuses on developing managers for public sector on city, state and federal levels.

UAB offers the following benefits to the universities involved (UAB, 2012):

- UAB produces and distributes printed material used in the course.

- Offers the books necessary to compose the universities' libraries.

- Offers ICTs (information and communication technologies) for the interaction activities among instructors, tutors and students.

- Builds pedagogical labs.

- Builds the infrastructure for DE centers in the universities.

- Trains universities' staff.

- Manages face-to-face centers.

- Organizes face-to-face meetings which were planned for the course.

Considering the expansion of DE in the country, the national relevance of UAB for Brazilian education development and its peculiar characteristics, this dissertation focus on studying services marketing dimensions according to student's, instructor's and institutional (coordinator) perceptions of DE, for this specific case of UAB. Conducting this research is justified for the following reasons: 
- Although there is a national system to evaluate higher education in the country, the institutions themselves should have their own evaluation processes; so they can diagnose and correct problems and improve their outcomes.

- Competition in higher education raises the need to a market-oriented approach for HEI. In this sense, it is useful to create an evaluation framework which also considers marketing dimensions. Services marketing constructs and their relations are well known in business literature, but they are not broadly examined on the matter of educational services (KENNEY; KHANFAR, 2009), which reinforces the present study's relevance.

- Evaluation works usually focus on one of the education spheres (student, instructor, institution); nevertheless it is necessary to study the three parts and the relationships among them.

- $\mathrm{UAB}$ is a relevant public initiative for expanding access to education in the country and due to its specific characteristics it deserves to be studied so insights to improve its outcomes can be developed. Thus, its positive characteristics can be implemented by other HEI.

The following contributions are expected as results of this dissertation:

- Offer a market-oriented framework for evaluating distance education programs.

- List the most important constructs and characteristics found for distance education Public Management course; so managers can work on improving these factors.

- Exhibit the relationships and influences among the constructs; so new educational strategies can be designed and competitive advantage can be achieved.

\subsection{Problem statement}

Distance Education (DE) has been growing significantly in Brazilian higher education since the last decade (years 2000), when the government created a law (Lei de Diretrizes e Bases, 1996) which allowed the development of graduate and undergraduate courses in a nontraditional format. Many private and public institutions have been adopting DE tools in their products since then, with blended and fully online disciplines. Within the strategy of improving education through the country and, for instance, qualifying Brazilian workforce, 
the government created the Open University of Brazil, which main purposes are: take higher education to unprivileged people and spread DE over the country. Although DE courses have been growing each year, many problems and myths are related to it, such as attrition rates, a lower quality perception in comparison with face-to-face, isolation due to the distance etc.; which makes its study challenging. Therefore, it is relevant to study which are the characteristics that lead to a successful (effective) DE course. Literature points four main dimensions of effective DE courses: 1) Students Characteristics; 2) Instructors Characteristics; 3) Technology and 4) Institution's support.

Nevertheless, most of the studies found in the literature exposes critical success factors in the students' point of view, ignoring there are other stakeholders involved in DE process, mainly the instructors and the institutions themselves. Each of these parts has its own perception of the educational service. These different perceptions may be related and may influence each other.

In this sense, the three parts of DE process (students, instructors and institutions) and their interactions and influences should be investigated; so actions and corrections on the course design can be taken in order to improve the courses' and institutions' outcomes.

This dissertation aims to identify student's, instructor's and institution's perceptions regarding DE, considering the following dimensions: perceived quality, satisfaction, image, loyalty, technology acceptance, institutional support, which helps to unveil myths about DE for the Brazilian case. Additionally, relationships among the factors identified will be investigated.

\subsection{Research objectives}

This dissertation aims to identify student's, instructor's and institution's perceptions regarding DE, considering the following dimensions: perceived quality, satisfaction, image, loyalty, technology acceptance and institutional support, for UAB Public Management undergraduate course; and investigate the relationships among these factors.

Some specific objectives can be pointed out: 
a) Identifying students' perceptions regarding the distance course (perceived quality, satisfaction, image, loyalty, institutional support)

b) Identifying institution's perceptions regarding the distance course (reflected on the course's coordinators point of view).

c) Identifying instructors' perceptions and acceptance of distance education.

d) Studying the relationships among the identified factors for the three parts (students, instructors, coordinators).

\subsection{Definition of concepts}

In this item the main concepts applied on the dissertation are presented:

- Distance education: educational method through which teaching and learning happen in different places. Technology is used in order to facilitate educational process, although face-to-face moments may be included (MOORE; KEARSLEY, 2008).

- Perceived quality: perceived performance of the service (CRONIN; TAYLOR, 1992) in a multidimensional approach (PARASURAMAN et al. 1988).

- Student loyalty: willingness to recommend the course to other people; willingness to take another distance course (ZEITHAML et al., 1996).

- Student satisfaction: extent to which the student feels the service provided fulfills his/her expectations (UDO et al., 2011). It considers how wise and enjoyable the decision to take that service was (BROWN; MAZZAROL, 2009).

- Image: impression about the organization formed on customer's mind, based on the interactions with the organization and its characteristics (structure, staff, products/services) (WANG, 2010).

- Technology acceptance: intention to use a technology, based on the user attitude toward that technology (DAVIS et al., 1989).

- Attrition: number of students who did not complete their courses, including those who enrolled the course but did not start it; students who started the course but dropped out (SIMPSON, 2003).

- Success/effectiveness: in this dissertation, considering only students' reactions will be measured (learning and performance are not scope of the research), success is defined 
as high scores of perceived quality, satisfaction, image, loyalty and institutional support.

- Stakeholders: for this research three stakeholders will be considered, students, instructors and institution (through its course's coordinator).

\subsection{List of activities}

In order to accomplish the research objectives, some activities were conducted, as stated below:

- Activity 1- Literature review

○ Research and reading of academic papers, books and dissertations about the relevant topics: distance education, services marketing, and technology acceptance models.

○ Development of the research framework.

○ Development of data collection instruments and data analysis plan, based on literature studies reviewed.

○ Sampling plan for UAB Public Management course.

- Activity 2 - Study of Institutions' perceptions regarding PNAP

- Interviews with course's coordinators, based on the sample selected.

○ Document research and analysis.

- Activity 3 - Study of Instructors' perceptions regarding DE.

- Survey with faculty and tutors signed up to UAB program, in order to acquire their attitudes and acceptance of DE.

- Activity 4 - Study of Students' perceptions regarding their experience with PNAP.

- Survey with PNAP undergraduate students in order to acquire their perceptions about services marketing dimensions regarding the distance course. 
- Activity 5 - Relate the dimensions

- Study how dimensions relate to each other. ${ }^{2}$

○ Find how students' perceptions relate to coordinator's perceptions regarding DE.

- Find how instructor's perceptions relate to coordinator's perceptions regarding DE.

\subsection{Chapters organization}

The first chapter has discussed the current context for distance education in Brazil, revealing its increasing relevance to the national education scenario and the need of evaluation of these courses in a market-oriented education reality. Thus, the problem statement, the research objectives, and its rationale are presented. Chapter 2 brings the literature review, which supports the development of the study and includes a discussion about distance education characteristics, myths and distance students profile; additionally, program evaluation models are reviewed as well as the constructs concerning student's, instructor's and institution's perspectives of success: quality perception, loyalty, image, satisfaction, technology acceptance and institutional support.

Chapter 3 presents the research mixed methods framework, including its strategies, data collection techniques, data analysis plan and research hypotheses. Chapter 4 concerns the study results, presenting the sample profile, the case presentation and the data analysis findings.

Finally, chapter 5 exposes the dissertation conclusions and discussions, its limitations and insights for future research in the DE field. Figure 4 presents the topics contained in each chapter.

\footnotetext{
${ }^{2}$ Students' results and instructors' results won't be compared, since literature does not relate the constructs studied (obtained from previous validated instruments); then these analyses are proposed for a future study.
} 


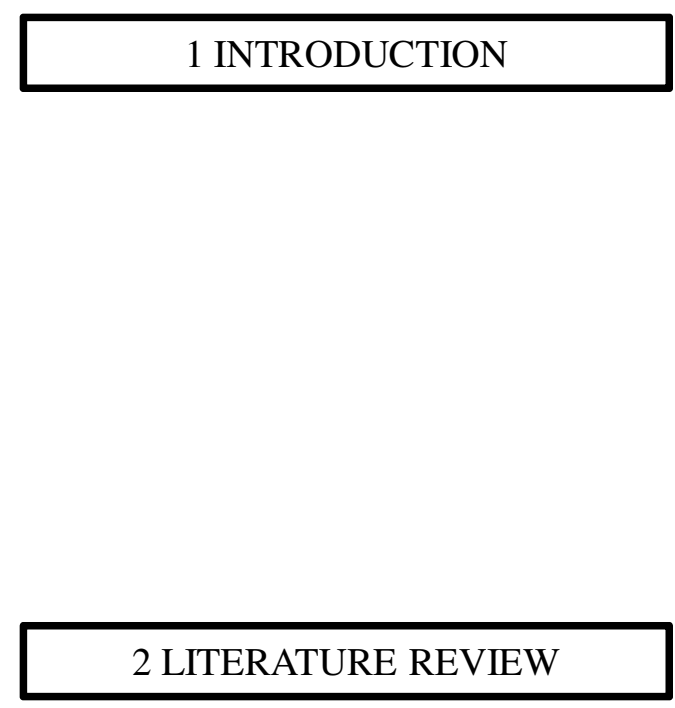

Distance Education Characteristics Generations Learner Profile DE versus Traditional education Trends

Educational evaluation

Student Perspective

Perceived quality

Satisfaction

Loyalty and attrition

Image and myths

Instructor Perspective

Technology acceptance and attitude

Institutional Perspective 


\begin{tabular}{|l|l|}
\hline 3 RESEARCH METHOD & Research design \\
\hline & Research strategy \\
& Research phases \\
& Research model and sampling \\
& Instruments, variables and hypotheses \\
& Validity and reliability \\
& Data collection \\
& Data analysis
\end{tabular}

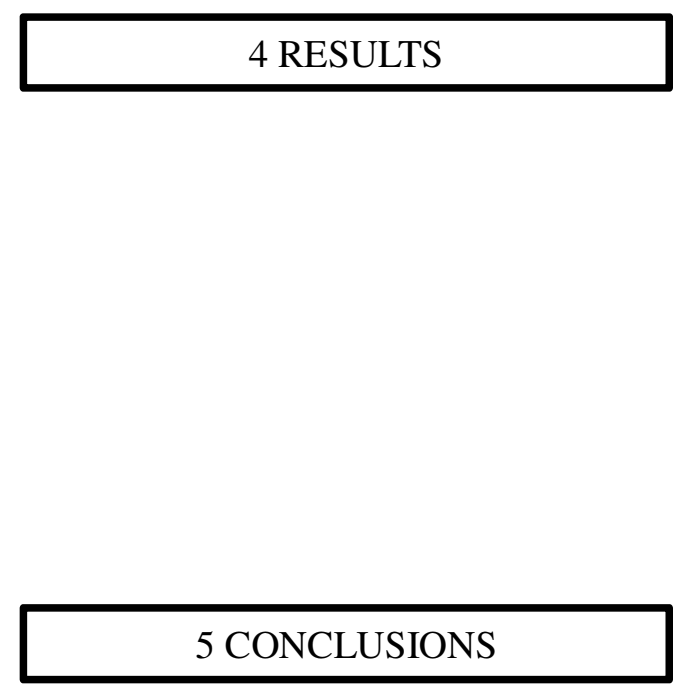

Case description
Sample profile

Student's results

Instructor's results

Institutional results

General considerations

Final considerations

Limitations

Future research

Figure 4. Chapters organization 


\section{LITERATURE REVIEW}

Chapter 2 presents the literature review which gives foundation to the research development, including hypotheses definitions, model definition, instrument development and data analysis. The chapter is structured as exposed by Figure 5.

\begin{tabular}{|c|}
\hline LITERATURE REVIEW \\
\hline Distance Education \\
Characteristics \\
Generations \\
Learner Profile \\
DE versus Traditional education \\
Trends \\
Educational evaluation \\
Student Perspective \\
Perceived quality \\
Satisfaction \\
Loyalty and attrition \\
Image and myths \\
Instructor Perspective \\
Technology acceptance and attitude \\
Institutional Perspective
\end{tabular}

Figure 5. Chapter 2 structure

\subsection{Distance Education}

Moore and Kearsley (2008) define distance education (DE) as a planned form of learning which generally occurs in a different place from where teaching happens. It demands specific techniques for designing the course, conducting, managing and controlling it. They say learning and teaching take place in different locations, but remark that a distance course can have face-to-face moments and face-to-face courses can use technology to help traditional teaching and learning as well. However, in the last case technology just supports education 
while in the first case educational activities depend on the technological tools used for the course, this fact differentiate both models (MOORE; KEARSLEY, 2008).

Keegan (1996) emphasizes distance between learning and teaching acts is central in DE and not the magnitude of geographical separation. This explains the fact a large proportion of distance students come from metropolitan areas and not from remote regions (KEEGAN, 1996).

Garrison (2011) states an educational experience has two purposes: construct meaning from a personal perspective and refine this understanding within a community of learners. It implies the inseparability of teaching and learning which means education is a unified transactional process (GARRISON, 2011).

In this perspective responsibility is shared between teacher and learner; teacher is responsible for creating cognitive and social conditions that will facilitate meaningful learning; learners can dialogue about their outcome expectations, learning activities and so on (GARRISON, 2011).

Moore (2007) emphasizes that DE is a pedagogical concept by which students and instructors, separated for time and space, interact and because of the distance, will perform specific behaviors. Psychological and communication barriers resulting from the separation must be overcome and, this context is known as transactional distance (MOORE, 2007). Distance students are goal-oriented and active, characteristics that make them more likely to appreciate the value added by the educational process, which means they are not a simple product from the educational system (UDO et al., 2011).

In the 1980s Keegan defined six main characteristics for DE: 1) separation between instructor and students; 2) influence of the educational institution on the process, differentiating it from private study at home (students receive specially prepared materials and support from the institution); 3) students and instructor are connected through medias; 4) two way communication; 5) occasional meetings are possible; 6) introducing a new way of industrializing education (DE is compared to the industrial production of goods) (KEEGAN, 1996). 
Spector (2009) considers that the emergence of social media (web 2.0 tools, like social networks, virtual reality worlds, blogs etc.) and their use for education purposes are an expression of the third, fourth and fifth dimensions proposed by Keegan. Technology makes it possible to overcome geographic barriers and reinforces connection among people, making the individual characteristics more relevant and making adaptation of the courses for individual needs crucial (SPECTOR, 2009). Hong and Jung (2010) researched the necessary competences for a successful distance learner; it means a student must develop some specific characteristics in order to perform well in a distance course. For them, competence may be understood as the skills, attitudes, ability and knowledge a student owns and which enable him/her to perform well and benefit from studying at a distance (HONG; JUNG, 2010). In this sense, students profile characteristics will be discussed later in this chapter, as well as the use of social media as a trend in education market.

It is important, in this moment of the discussion, differentiate terms used as synonyms to define DE:

- Blended learning: combines face-to-face and online teaching tools in the same course or program (RUDESTAM; SCHOENHOLTZ-READ, 2010). It combines the strengths of faceto-face and distance models in a way the outcomes are greater than the best results possible from each approach (GARRISON, 2011).

- Open learning: is a kind of DE which focuses on satisfying local and individual needs. It is flexible, learner-centered and focuses on learning, instead of teaching. In general, open learning consists of short term courses, seminars, conferences, workshops and training programs (DABBAGH, 2005).

- Distributed learning: it is described as "education anytime, anywhere, using none; some or many technology artifacts. Students engage on the course following their own pace and developing their own routine, what is known as "pull model" (DABBAGH, 2005).

- Distance learning: the process of learning at a distance, where student is empowered and becomes the center of the process. This term can be used to define the use of electronic technology in DE. However, Keegan (1996) emphasizes distance learning is just a part of the distance educational process, which also includes distance teaching (KEEGAN, 1996). 
- Distance teaching: focuses on the teaching methods and didactic strategies applied in teaching at a distance. Just as distance learning focuses on the students, distance teaching focuses on the institutional responsibility of educational process (KEEGAN, 1996).

- Online education: any way of teaching and learning that occurs through a computer network (local network, intranet, web etc.) (KEARSLEY, 1998).

- E-learning: instructional contents are distributed to remote areas through the Internet, Intranet, Extranet, audio, video, interactive TV, satellite transmission and CD-ROM (RUDESTAM; SCHOENHOLTZ-READ, 2010). It uses tools delivered through the Internet and other web based technology, in order to enhance learning and knowledge building by relevant interactions (DABBAGH, 2005).

Using technology in classroom does not imply innovation. Innovation leads to radical changes that transform and significantly improve teaching and learning experience. In order to consider a technology as an innovation, it is necessary to create an open mind environment which supports a new approach; in this sense, DE could be considered an innovation in educational field (CELSI; WOLFINBARGER, 2002).

Innovation adoption happens in waves and requires a paradigm change. The first wave takes place when technology is used to support course's backstage activities; so technology has an incremental role in educational system. In the second wave technology is used to reproduce traditional practices, for instance, lectures contents are posted in a LMS (learning management system). Finally, in the third wave, a rupture happens and educational paradigm changes; so there is a change on the meaning of the classroom, with teachers and students functions also changing (CELSI; WOLFINBARGER, 2002).

Thus, DE concerns teaching and learning in a planned and guided context; it means incidental learning (what is learned unintentionally searching through the Internet) cannot be considered DE. DE implies the learner is willing to learn, with the guidance of a facilitator who is responsible for creating the adequate learning environment (MOORE; KEARSLEY, 2008). A DE system includes, according to Moore and Kearsley (2008), some basic elements: 
- Teach and learn content: the contents must be selected by the educational institution. This decision must take into account market's needs and demands, considering what the target is interested or willing to learn.

- Instructional design: knowledge must be turned into modules; that is, contents and learning activities.

- Delivery technologies: Internet and computer based technologies are the most used, but CDROM, audio, video, video-conference and print material can also be employed.

- Instruction staff: defining the staff (teachers and tutors), who will interact with learners. This contact makes the instruction more personal and meaningful. Interaction level depends on the institution's characteristics, technology employed, module characteristics and students maturity. Developing high quality contents and delivery medias has high cost; thus, institutions must have enough students in order to guarantee their return on investment. In addition, students will interact with the support team as well, which is responsible to help students with technical issues and other problems that may disturb student's performance.

- Content format: distance learner may study everywhere; which means they can access their courses from home, from work, from the airport and so on. In this sense, institution must consider possible distractions students may face along the way. In order to reduce distraction effects, contents must be planned in segments (small and complete segments of content, including summary, review and linking theory and student daily practice), which help them acquire the required competences for distance studying.

- Evaluation system: which allows institutions and managers to detect problems and react to them. Evaluation and control in DE are complex, because they involve collecting target needs (target is geographically dispersed); allocating resources (investments are done long before course can effectively be sold); quality must be continuously assessed (works and activities should be regularly employed and teacher's feedback about the activities should be reported to the manager, in order to provide information and allow corrective actions when needed). 
- Interdependent system: all of the elements listed above are related and influence each other; thus, investing in technology but ignoring the other dimensions involved in DE will not bring the expected outcomes.

According to Moore and Kearsley (2008) DE may be considered a process by which some inputs are added, processed and transformed into outputs, as showed in Figure 6.

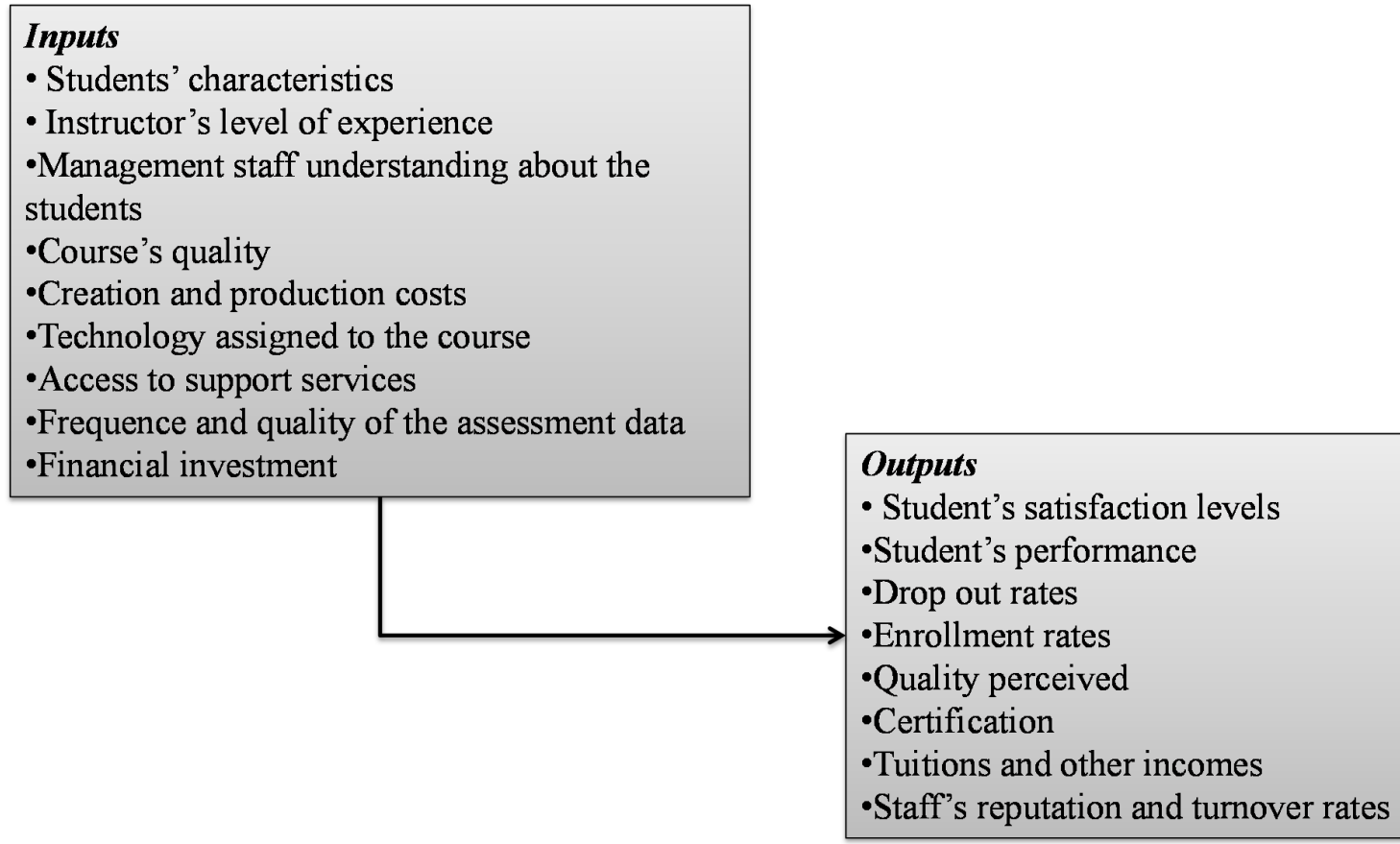

Figure 6. DE process inputs and outputs

Source: Adapted from Moore and Kearsley (2008, p.21)

Literature brings some different approaches to explain education development process. Varlamis and Apostolakis (2006) propose a four step model:

- Design: acquire students' characteristics, define ability, skills and competences the course aims to develop, state educational goals institution wishes to achieve.

- Production: contents, activities and learning environment are produced.

- Delivery: the contents/activities/environments produced in the prior phase are delivered to the students. 
- Evaluation: students are assessed as well as the educational process is evaluated, providing feedback to the whole process.

ADDIE model is an alternative to the prior presented above and is widespread in the literature. It is an instructional design model comprising five phases: analysis, design, development, implementation and evaluation. This model allows the development of instructional modules based on needs evaluation. It is a cyclic approach which includes in each phase (KONERU, 2010):

- Analysis: learner needs, instructional needs, goal analysis.

- Design: define learning goals and objectives, contents, assessment activities.

- Development: actual development of the learning modules designed in the previous phase.

- Implementation: the modules are delivered through the media chosen.

- Evaluation: evaluate course design and contents, learning effectiveness, assessing student skills.

Keegan (1996) proposed an evaluation framework that guides DE systems appraisal. The evaluation emphasizes: the quantity; the quality, the status and the relative cost of the learning achieved:

- Quantity: attrition rates, quantity of output relative to input, time demanded to produce the output, success in satisfying the needs.

- Quality: quality of the produced contents, extension to which DE is appropriate for teaching certain modules, system effectiveness.

- Status: acceptance of the DE courses' certificates, reputation of the institution, extension to which other institutions accept DE credits for transferring students, employability of distance students.

- Cost: cost efficiency compared to traditional education, opportunity cost. 
In $\mathrm{DE}$ the learner becomes the center of the educational process; thus, teaching becomes a support for learning; in other words, student is empowered and must define when and how much study. It may be necessary to align student's expectations about the HEI and about his/her own skills in the educational context (MOORE; KEARSLEY, 2008). Successful instructors in the transformation environment share some common points: offer up to date content; help students identify their learning needs; encourage motivation and involvement; make teaching exciting; help students develop their cognitive abilities and creativity. In addition, teacher must master content, own appropriate didactic skills, own good communication skills, create experimentation opportunities, provide feedback, empower students becoming just a facilitator (CHENG, 2011).

According to Moore and Kearsley (2008), distance students in higher education are usually adults, who have specific individual characteristics that influence their learning experience. Adult learner characteristics will be discussed later in this chapter; however, it is important to remark that they appreciate having their learning activity under control, need to believe on the content's relevance, wish to participate on decisions concerning the course, appreciate the use of real examples and have intrinsic motivation to learn.

Positive emotions may enhance learning as well as negative emotions may inhibit it. Emotions are relevant for adult and non-traditional learners, because they influence motivation. Learning environments should stimulate the expression of emotions (ZEMBYLAS, 2008). On his study in an online class Zembylas (2008) identified diverse emotions among students:

- Positive emotions: enthusiasm, excitement about the course's flexibility, proud for being able to attend the course, surprise with the characteristics online communication.

- Negative emotions: fear and anxiety in the beginning of the course, alienation feeling, stress, guilty for having difficulty in balancing education and other life roles (family and career).

Anxiety is common in the beginning of the course; however it can reduce student's performance and increase dropout probability. Teachers must watch the group and identify these cases, in order to help students (MOORE; KEARSLEY, 2008). 
For Zembylas (2008) DE students do not have homogeneous profile, concerning gender, age and marital status and that is the reason they have different experiences and problems during the online course.

In addition Dabbagh (2007) highlights that distance learners are becoming more heterogeneous, since younger generations are enrolling higher education. It will make distance learner younger, more dynamic and reactive to technology changes. Distance learners may have common characteristics, especially situational and affective variables, but they own diverse learning styles and belong to different generations (DABBAGH, 2007). Student's profile variables will be discussed in details later, but what is important to stress now is that heterogeneity brings pedagogical consequences to HEI, since it requires the courses' design to be reevaluated.

Dabbagh (2007) points out some critical success factors for the online student:

- Strong academic self-concept (academic progress self-control).

- Online education technology literacy.

- Good communication and inter-relational skills.

- Understand and value interaction and collaboration.

- Self-control.

- Self-direct learning skills.

- Need to belong to a group (association need).

Online student has a strong sense of self-regulation, that is, learning is influenced by his/her own thoughts, feelings, behaviors and strategies. Self-regulation makes the student adapt beliefs, behaviors and even cognition in order to optimize his/her learning. Thus, the student is responsible for his/her education process, building his/her own meaning, goals and strategies (ARTINO; IOANNOU, 2008).

Garrison (2011) proposes in his book an e-learning framework which is based on the community of inquiry concept, meaning a community of learners is crucial for the educational experience, when higher level learning is expected. Community of inquiry can be understood as a group of people who engage in a cooperative and critical discussion, in order to establish personal meanings and mutual confirmation to those meanings. This process includes three 
different dimensions that must be developed: social, cognitive and teaching presence (Figure 7) (GARRISON, 2011).

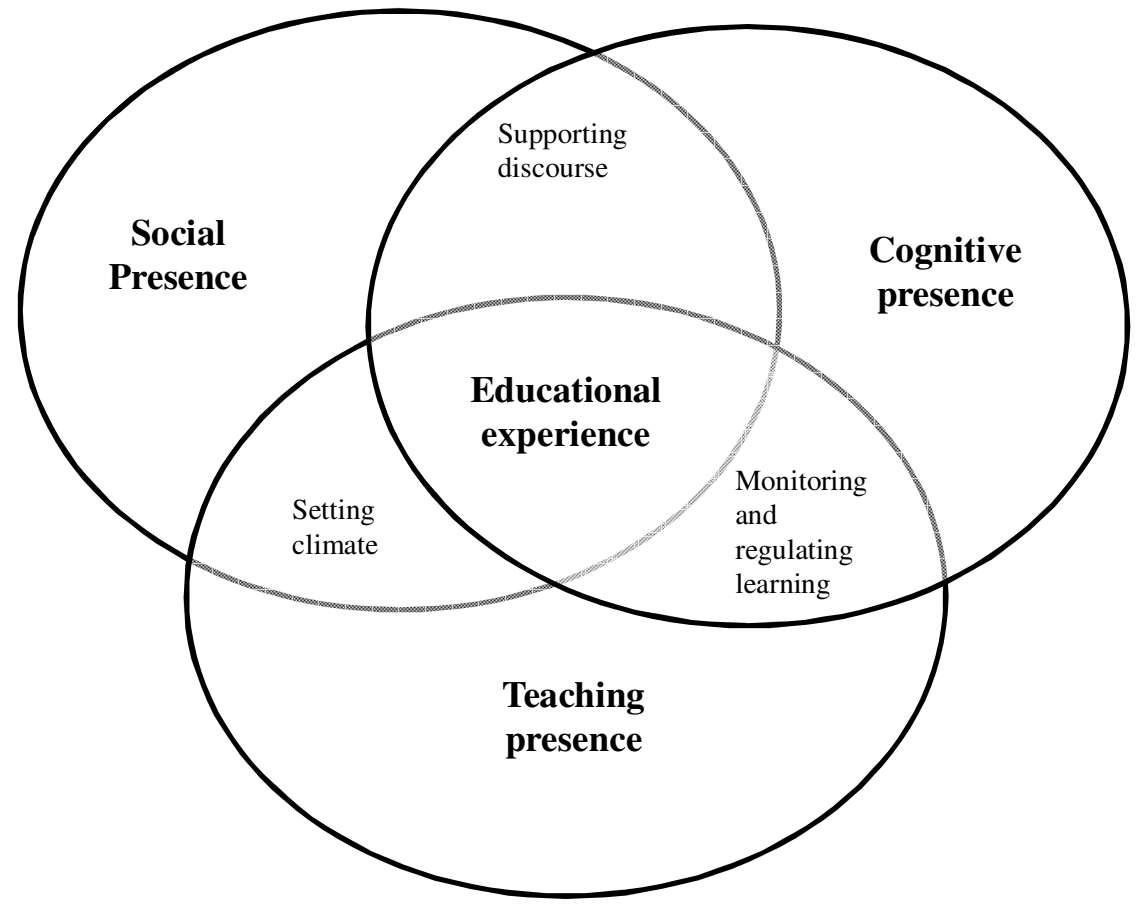

Figure 7. Community of inquiry

Source: (GARRISON, 2011, p.23)

The community of learners includes teachers and students who interact aiming to facilitate, build and confirm understanding and to develop skills that will help future learning; in this sense, the community stimulates cognitive independence and social interdependence at the same time (GARRISON, 2011).

Principles surrounding community of inquiry are (GARRISON, 2011):

- creating open and trustful communication;

- creating opportunity for critical thinking and discussion;

- building community and cohesion;

- creating inquiry dynamics; 
- establishing an environment of respect and responsibility;

- creating assessment methods that are consistent with the expected outcomes.

According to Garrison (2011), social presence is the ability of creating identity with group, meaningfully communicate in a trustful environment where it is possible to express personality and build affective relations. In turn, cognitive presence is the possibility to develop and validate meaning through reflection and discussion in a community of inquiry. Finally, teaching presence concerns the design, facilitation and guidance of cognitive and social processes in order to develop meaningful learning. All of the three constructs draw attention to the relevance of communication in the educational process.

Communication is crucial and can be considered as critical success factor in a distance course. Most common medias are: press media, audio, video, radio and TV, teleconference and the web. Press media is still broadly used in DE and may assume different formats, such as: books, papers, manuals, notes and study guides. Both students and instructors are familiar with print material and do not face any troubles on its use. Good print material enhances learning (MOORE; KEARSLEY, 2008).

Audio and video demand high specialized knowledge in their production, thus their costs are high. Many institutions do not use these medias due to their high costs; nevertheless, they could be effectively used, for instance to explain text material and guiding software usage steps (MOORE; KEARSLEY, 2008).

TV and radio, when combined with other media, enhance student's motivation. TV increases course's credibility, but has high costs. Radio has far reaching and lower costs if compared to TV. Teleconference may assume four different approaches: audio conference, audio graphic, videoconference and web conference (MOORE; KEARSLEY, 2008).

Medias should be chosen based on their strengths and weaknesses, on the course's characteristics (what are the most appropriate medias for that specific content?), and on the audiences traits (MOORE; KEARSLEY, 2008). 


\subsubsection{Distance education generations}

Distance education emerged on the XIX century and since then, it has been transformed through time, reaching its fifth generation (Figure 8), each one of them owning specific characteristics.

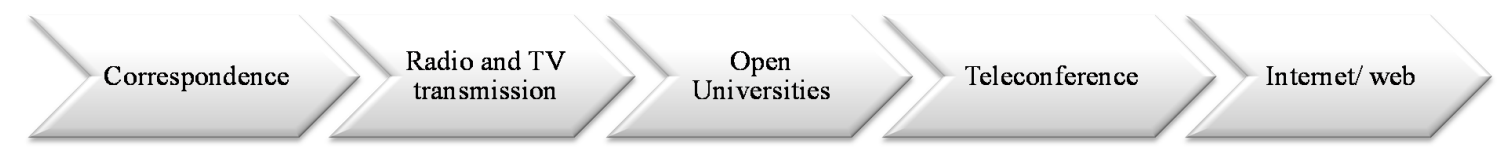

Figure 8. DE generations

Source: (MOORE; KEARSLEY, 2008, p.26)

First generation started in the 1840s in England and was defined by the correspondence study, also known as home study and independent study. In the USA DE started in 1880 and had as its main principle the use of technology to reach people who would not be able to study in other terms. This audience included women, who had an important role in the DE history (MOORE; KEARSLEY, 2008).

In the beginning of XX century the second generation took place, with the emergency of radio technology. The emergence of radio caused excitement among researchers in the universities; however, its use for educational purposes was not diffused. In 1934 educative TV emerged and in 1972 cable channels for telecourses started being created (MOORE; KEARSLEY, 2008).

Between late 1960s and the beginning of 1970s DE suffered deep changes, as new technologies emerged. By that time third generation took place and was remarked by the Project of Articulated Instruction Media (AIM) which aimed to articulate different technologies and support offering high quality and low cost learning. Different media usage means offering more appropriate and adapted content to people with diverse learning styles (MOORE; KEARSLEY, 2008).

Still in this generation, Open University (United Kingdom) was created. It has got scale economies and gathered such a large amount of students, which made it a super-university 
(universities with a great number of students). In the XXI century, the Open University is considered one of the most important institutions in the UK; a student graduated in the Open University costs $40 \%$ of the amount of a student graduated in a traditional university. The Open University has the following principles: anyone can enroll no matter what is his/her background; student defines where to study (convenience); contents are develop by experts; interactions with the students are conducted by an expert team (which is not the same that developed the content); large scale in national level; economy of scale; high amounts of public investments; diverse technologies; high quality (MOORE; KEARSLEY, 2008).

In the 1980s DE started using teleconference and, for instance, focused on group studying. The fourth generation changed education paradigm, as now students were able to interact synchronously with teachers. In the 1990s videoconference use in education had increased (MOORE; KEARSLEY, 2008).

The fifth and current generation focuses on the computer and web usage. Each generation brings innovations but incorporates the technologies from the former generations, for example, correspondence courses in the XXI century may use online resources (MOORE; KEARSLEY, 2008).

\subsubsection{Distance learner profile}

Literature shows students' characteristics such as gender and age may influence their perceptions, satisfaction, opinion and performance in educational context. This research examined gender and age relationships with perceived quality, image, loyalty and satisfaction in DE. For this reason, both variables are discussed as it follows.

\subsubsection{Gender}

In her book titled "The third shift", Kramarae (2001) studied the relationship between the growth of online education and the increasing participation of women in this educational model. At the moment her research was carried out, women were the primary users of distance education in the USA; they were the majority of students of the correspondence 
courses in the twentieth century as well. One of the possible causes for this fact is that DE reduces some barriers female face in their academic lives: they usually need to balance professional life with home tasks, child and family care and educational responsibilities; online education makes it possible to study at home; so balance among the three shifts are more likely to happen (KRAMARAE, 2001). The main reasons women enroll DE courses are (KRAMARAE, 2001):

- acquire a specific degree online: online credential is valued as well as the personal enrichment and knowledge resultant from the online course;

- career development or career change;

- become lifelong learners.

In addition, half of the women interviewed showed preference for online education due to their family and professional situation, that is, DE allows them to manage the diverse roles of their lives; so they do not need to fit their lives into a traditional course's schedule. Other reasons for this result are the flexibility of online learning and the empowerment it gives them (manage their time and agenda and work in their own pace); the reduced travelling time and costs; reduction of child care costs (studying online makes it unnecessary to contract additional help for child care), DE meets special characteristics (physical or psychological conditions). Finally; some interviewees reported to prefer DE simply for being enthusiastic of this model. On the other hand, most of the participants pointed out DE is their last resort; it means, it is their only option for getting educational development (KRAMARAE, 2001). Sen and Samdup (2009) also reinforce the idea of the double or triple workload faced by women and the conflicts emerged from these situations make DE suited for them (SEN; SAMDUP, 2009).

Face-to-face classroom was preferred over online education by some women, because of the interaction and social aspects of traditional space; of the classroom structure planned for learning; and of immediate feedback from teachers (KRAMARAE, 2001).

Bhushan (2008) studied women access to technology in India, considering distance learning students; that society has cultural barriers which leads to gender prejudice. Empirical data involved 48 respondents and showed $90 \%$ of male students had their own computer, while only $50 \%$ of women had a computer at home. However, even those women who had a computer could not use it at their own convenience, since male in the family had priority use. 
Women who did not have a computer, accessed the course from a public facility and were allowed to go there only if accompanied by a male, for security and cultural reasons (BHUSHAN, 2008).

Another finding from Bhushan (2008) research was male usually decide about technology purchase without consulting any family member, female in turn are not decision makers for technology purchase, it is a responsibility of a male family member. There is difference also on technology skills acquaintance for male and female; male reported to learn how to use a computer by themselves; female, in most cases needed a family member support or a training course; male showed more technology self-efficacy (BHUSHAN, 2008).

Enoch and Soker (2006) state DE in the web-based format is usually seen as an inclusive educational method, since it adds time and space flexibility and may take high quality education contents and lectures to people located far from the big educational centers. However, these authors also assert DE may be excluding for those groups which are known as unprivileged (women, mature people, low income people, people living in remote areas), since they do not have broad access to technology and in many cases are not able to keep up with technology advances. In addition, they state, remote areas in general have Internet access difficulties, especially in developing countries (ENOCH; SOKER, 2006), like Brazil.

Empirical data collected in the Open University of Israel showed technology use increased in period from 1995 to 2002 . However, this increase was significantly higher within younger students. Gender also showed significant difference; male students had more Internet use than female students in the period of study (ENOCH; SOKER, 2006).

Kim et al. (2011) studied relationships among learner profile characteristics and satisfaction and social presence. Their study states men and women have different behaviors in educational contexts; women are more active, interact more and value social contact more than men; then women tend to be more satisfied than men in online courses. Time of enrollment also affects satisfaction, since students enrolled for more time tend to be more satisfied; contact with instructors also influences satisfaction (KIM, J. et al., 2011).

Marley (2007) pointed out some dimensions women and men have different perceptions and behavior in DE. Genders are different in motivation for enrolling a distance course; male 
ranked as the main motivations to enroll a distance course "the opportunity to improve technology skills" and "fast and effective assistance". Female in turn value flexibility, cost and institution reputation (MARLEY, 2007). Learning styles (women are more interested in interaction), attitude toward technology (male are more satisfied and use more technology) and attrition (proportion of male dropout on DE is higher than female) are also different for genders (MARLEY, 2007).

\subsubsection{Age}

DE attracts mature students who usually have many other activities in their routine and are conscious of the efforts invested in a course (TRICKER et al., 2001). Githens (2007) studies myths related to age in online education. For him, older adults are generally evaluated under a stereotype of rigidness. Older adults are considered rigid and not open to learn due to their ages; other factors such as personality and background are usually ignored. In the USA a large percentage of baby boomers are familiar with technology and as they age, more elder people will be familiar with it. It happened because they felt learning computer skills was a primary condition to be a plain member of the society. It means that the needs addressed to older people in the present (they need to learn basic computer skills) will no longer be a problem in the future. On the other hand, education developers must consider the unprivileged older adults who really do not master any technology, creating solutions for them, since they can be a market segment (GITHENS, 2007).

Online courses are appreciated by older adults, since they allow them to construct and maintain a social network (which can be tough on traditional environment after retirement). Another point is that online learning provides education experiences even for people with health or mobility limitations. This phenomenon helps these people to have a workforce option, since many of them plan to keep an active and busy life. In other words, education developers should consider older adults as a segment, which means, age is not always a proxy for interest in online opportunities (GITHENS, 2007).

Digital natives (Net generation or Millenials, born in 1980-2000) are considered technology savvy generation, who owns sophisticated skills on digital technologies and new cognitive capacities and learning styles. These new characteristics include mastery of multimedia tools, 
value of communication and expression opportunities and learning based on collective research and contribution. In this sense, current education models are not able to accommodate the needs of this generation. In order to meet these demands institutions invested in staff development, plant expansion and technology update. However, it is important to understand the effective role of technology in learning process is to guarantee pedagogical purposes are met. Margaryan et al. (2011) point that there are many studies focusing on the extent students used technology for education, but neglecting the purpose of using this technology. According to them, there is no homogeneity in the adoption patterns; which means, being a digital native is not necessarily a synonymous of knowing how to use technology to improve learning experiences (MARGARYAN et al., 2011).

In addition, the authors state that skills like writing an email, participation of a chat room or interacting in a forum is part of a regular student life and may not indicate special new skills and the higher willing to engage in discussion may be exaggerated. Students essentially use a basic tool kit for learning purposes; they do not frequently use social networks and wikis for learning, for instance. Yet, the preference for experiential learning, computer literacy and connectedness may not be characteristics of a particular generation. Personal characteristics; socioeconomic background, discipline and variables related to the course (online pedagogy, assessment methods) should be taken into account and help to explain technology use in a deeper way than just classifying people by their generation (MARGARYAN et al., 2011). Finally, they found that the course's nature influence the use of technology; that is, students of technical courses use more technology than social sciences students. The results suggest students may not understand the full potential of technology tools for education purposes. Students' attitudes toward technology in education are influenced by teaching approach, and instructors interviewed by the authors showed little understand of the uses of technology for teaching. In resume, other variables should be considered, rather than age to explain technology adoption (MARGARYAN et al., 2011).

A qualitative study conducted in three universities (two in Canada and one in Spain) corroborates the arguments posted by Margaryan et al. (2011): there was no significant difference on technology use and learning characteristics across net generation and non-net generation (MORGAN; BULLEN, 2011). 
Despite of these initial considerations, many studies in the literature indicate generations of learners have divergent characteristics and interests. Worley (2011) states generations are different in life experiences, expectations, technological expertise and learning styles. Thus, educational institutions as well as instructors and administrators should be aware of these differences and create a learning environment which supports different generations and provide learning opportunities to all of them (WORLEY, 2011). The author presents some differences among the generations as exposed on Table 3. Hanson et al. (2010) reinforce these ideas commenting millennials are highly interested in communication and spend a large amount of daily time on the telephone and texting, including during classes, which may disturb their learning experience and performance (HANSON et al., 2010).

Werth B.E.P. and Werth L. (2011) in order to enrich educational experience for net generation, propose some effective changes on course designs: empowerment of students letting them participate on the planning of the syllabus; designing team work; avoid lectures; implement engaging activities such as games, discussions, problem solving activities; integrate technology used in daily life (wiki, blog; social networks) into classroom for pedagogical uses; show which skills will be developed during the learning activities and privilege those skills valued by students (WERTH, B. E. P.; WERTH, L., 2011).

Table 3. Generations' characteristics

\begin{tabular}{l|l}
\hline Generation & Characteristics \\
\hline Baby boomers (1946-1964) & Individualists \\
& Strong work ethic \\
& Competitive \\
& Self-sufficient \\
& Strong sense of responsibility \\
& Uncomfortable with technology \\
\hline Generation X (1965-1981) & Self-sufficient \\
& Independent \\
& Environmentally conscious \\
& Somewhat comfortable with technology \\
& Challenge authority \\
& Question the government \\
\hline Generation Y (1982-2002) & Technology advanced \\
& Sheltered/protected \\
& Sense of entitlement \\
& Diverse \\
& Extremely social \\
& Close relationship with their parents \\
\hline
\end{tabular}




\begin{tabular}{l|l}
\hline Generation & Characteristics \\
\hline & Education oriented \\
& Self-confident \\
& Multitasking \\
& Impatient \\
& Materialistic \\
& Self-centered \\
\hline
\end{tabular}

Source: (WORLEY, 2011, p.32)

\subsubsection{Distance learning versus traditional learning}

Community colleges have an import role in American distance education system. Half of the online higher education students are enrolled in a community college (ASHBY et al., 2011). These colleges offer developmental modules, which are non-credit disciplines required for college level disciplines; students enrolled in these courses are usually older than traditional learners, are usually employed and have to balance career, family and education. All of these variables impact their success in online environment. Ashby et al. (2011) compared student success in a developmental mathematics course, offered in face-to-face, online and blended formats. Success was measured by student's grades (on test, final exam and course's grade). In addition, they aimed to identify student's performance on the course and attrition rates. The sample was composed by 167 students, $38 \%$ enrolled online environment, $35 \%$ in face-to-face course and $28 \%$ in the blended classes. The sample is considered heterogeneous, because it mixes younger and older students, gender (58\% are female), ethnicity (49\% Caucasian; 43\% African-American) and kind of enrollment (48\% full-time; 52\% part-time). Specifically the online group was significantly older and mainly composed by female students (71\%). In regard of attrition rates, face-to-face group had 5\% of missing grades (students who did not perform the assessment activities); blended group had $23 \%$ and online group had $18 \%$ of missing grades. As a result, the researchers found through ANOVA, blended students had significant lower performance on assessment activities. Face-to-face students had the best outcomes, while online students performed better only compared to blended students (ASHBY et al., 2011).

Considering gender and age in the analysis, they did not found a relationship between those characteristics and performance in the different learning approach. When dropout students were removed from the sample, performance statistics changed; face-to-face students became 
the lowest performers in the assessment activities. In addition, among students who completed the course, they observed $85 \%$ of online students got passing grades, while $69 \%$ of blended and $63 \%$ of face-to-face students achieved this result (ASHBY et al., 2011).

In the view of the presented results, effectiveness in different learning approaches diverge: when considering the whole sample blended students have the lowest success chance (highest attrition rate); when considering the students who completed the course, face-to-face students have the lowest success probability (lowest attrition rate). This means success depends on the attrition rates. In summary, attrition is higher in non-traditional environments and when it is taken into account performance in these cases are better (ASHBY et al., 2011).

Learning outcomes in online education is one of the main concerns surrounding this modality; which means, performance and retention of knowledge is a controversial issue. Drouin and Vartanian (2010), in this sense, studied the influence of the sense of community in students' outcomes. They report that the higher sense of community, the higher are the learning performance and retention; however; social presence perception may vary even in the same group and this difference is related to profile characteristics: women report higher sense of community; graduate students have a stronger feeling of relatedness to classmates than undergraduate. On the other hand, the authors state that sense of community is important but not all the students desire to experience it in their education environments (DROUIN; VARTANIAN, 2010).

Considering these controversial issues, Drouin and Vartanian (2010) investigated the level of desired sense of community and the factors that influence the desire and perception of community, considering online and face-to-face students. The sample was composed by 119 online students and 79 face-to-face students; 54\% was enrolled in an introductory course; $55 \%$ were under the age of $22,29 \%$ were $23-30 ; 10 \%$ were $31-40$ and $6 \%$ were over 41 years; most of the students were women (72\%) and Caucasian (78\%). Considering the learning environment, online students were older than their face-to-face colleagues. In addition, they took less credit hours, worked more weekly hours, and had higher computer skills. There was no difference between the two groups concerning to the satisfaction with social presence in the course (both were satisfied), grades and level of learning. Face-to-face students expressed significant higher desire of higher social presence in their other modules. In summary, faceto-face and online students are different in diverse characteristics: demographic (online 
students are older, had higher computer literacy, and had worked more weekly hours) and level of connectedness (online students feel less connected to their peers than face-to-face students). There are also some similarities: both online and face-to-face students reported similar levels of learning, only a few students desired a sense of community (47\% of face-toface and 30\% of online) (DROUIN; VARTANIAN, 2010).

The multiple regression analysis showed individual characteristics influence desire for community and feelings of connectedness. For face-to-face, the course level (introductory or higher) and the ability to communicate with colleagues and teachers influence the feelings of connectedness; only the amount of working hours influenced their desire for more sense of community (the higher the hours, the higher is the desire for community). For online students the perceived ability to communicate, the amount of hours worked outside home and enrolled credit hours influence connectedness; no variables influence online student's desire for community (DROUIN; VARTANIAN, 2010).

Lim et al. (2003) investigated differences in achievement and satisfaction among online, faceto-face and hybrid students. The sample had 153 undergraduate students (54\% were female, $20 \%$ were online students, $54 \%$ face-to-face and $26 \%$ were hybrid, were 18 to 55 years old). Online and hybrid groups were detained by women (LIM et al., 2003).

Achievement concerns the skills students are expected to master due to the module; the results showed online and hybrid students had better achievement than face-to-face; no differences were found between online and hybrid students. In regard to satisfaction with the course, hybrid students showed significant higher satisfaction than face-to-face students; no differences were found between online and hybrid groups. For the three groups quality of learning was positively rated, but the online group scored higher than face-to-face group. Similarly, the three groups rated the quality of the course positively, but online and hybrid groups attributed higher scores than face-to-face students (LIM et al., 2003).

No differences were found in teacher's encouragement and help; online students considered they were likely to take another online course; and that they had worked harder in the online course (compared to traditional modules they had taken). Online group also showed high satisfaction with the course's accessibility and pointed that the reason to choose this modality 
was its convenience and flexibility. These findings indicate a well-designed online course may accomplish great outcomes (LIM et al., 2003).

\subsubsection{Trends in Education}

Web 2.0 consists of the technology tools which enhance communication, interaction and collaboration through the Internet. These tools allow the users to voluntarily share experiences and information about their interest topics. It means each user is a creator and a consumer of information and knowledge. The main Web 2.0 tools are the social networks (Facebook, Twitter, YouTube, MySpace etc.), blogs, wiki and virtual reality worlds (Second Life etc.). These tools have been used for marketing strategies by companies from different economic sectors and are, now, also being used in education.

Although web 2.0 tools are not specifically projected for educational purposes; some studies in the literature report the use of blogs; social networks, wiki and second life in higher education. Kaplan et al. (2010) state these tools enrich educational activities as they promote experiential learning and help the development of soft skills, such as communication, selfexpression, creativity, critical thinking and collaboration. For Dale and Povey (2009) web 2.0 technologies stimulate the learner to generate content; which means, learners create the content they will consume and share with others. These technologies empower them and change education perspective, as students can be assessed for the content generated, but the content will be accessed by other people (colleagues and even unknown people, since contents may be freely accessed on the Internet), not only by the professor; in a traditional view, students would be assessed for a seminar, a report or a test to which no one would have access (DALE; POVEY, 2009).

Cheng and Chau (2011) complement this idea, pointing out that learning through discussion, as it happens on blogs, wikis and forums, has strong effects on critical thinking development and deep learning achievement (CHENG; CHAU, 2011).

In addition, as the use of social media is becoming more common on daily basis, their use in education can influence students' perceptions about their educational experiences. On the other hand, experiences published in education literature are not conclusive; it means some 
studies found deep benefits from the use of social medias, but others could not find significant improvement on the learning experience (CHENG; CHAU, 2011). In this sense, it is relevant to study the reported social media experiences as educational strategies to enhance learning, including their strengths and weaknesses, because they can be used as an innovation approach to market differentiation.

Cheng and Chau (2011) compared the differences in interaction levels between wiki and blog communication. They considered a class composed of 18 postgraduate students from the Hong Kong Institute of Education. All of the participants were required to read and critically discuss an article, but half of the group was required to use wiki for the discussion, while the other part was signed to use a blog. During the four weeks of activity, the blog group generated more messages than the wiki group, and according to the content analysis, achieved a higher level of knowledge co-construction. One of the reasons for the difference is that blog structure naturally stimulates debate; it means the opportunity to send a message and receive replies and engage in a discussion is similar to a forum structure. Wiki, in turn, allows participants to edit contributions of others; its structure stimulates the co-authoring more than debate, which leads to independent writing contributions. These findings suggest guidance and clear instructions about the use and expected performance should be provided to students (CHENG; CHAU, 2011).

Churchill (2009) studied blog usage in a postgraduate class in a university in Hong Kong as well. He investigated the ways a blog could be used to enhance learning experience. A blog was developed and previewed the following activities: access to course's contents, reflections posting, reacting to colleagues' contributions and regular participation over a semester. In addition, each student had his/her own blog. The researcher observed the blog activity over the semester, surveyed and interviewed some students in the end of the period. As a result, he observed students felt blogging facilitated their learning experience and created a sense of community. They classified as the positive aspects of the course: the opportunity to access others' work; receiving feedback on their work and the involvement of the instructor, whose blogging activity encouraged them to blog. On the other hand, they pointed out their main motivation to blog was the requirement of the task; it means they were assessed (graded) based on that activity (CHURCHILL, 2009). 
On the teacher's perspective, the use of the blog technology increased his effectiveness, as it allowed him to share his perceptions and ideas about emerging issues with his students and hear from them (their own perceptions, questions and reflections). In his point of view the experience was successful due to: 1) activities were required regularly; 2) students were graded for their contributions; 3) instructor was present and blogged regularly. On the other hand, he pointed although it was important each student had his/her own blog, controlling all of the activity at the blogosphere and giving feedback was time consuming (CHURCHILL, 2009).

Gale and Povey (2009) studied an undergraduate tourism discipline called "heritage management" which used podcasting for learner generated content. The objective of podcasting is involving students in their learning process by engaging them in content generation and sharing this content with their peers (DALE; POVEY, 2009).

The authors point out podcast technology can be used in different perspectives, for instance, for lecture delivery and information delivery (students' support services and information). In their paper, they focus on the content creation perspective as a strategy for improving learning experience. For them, its main potentials are: meet a broad range of students' needs and styles, develop critical thinking and reflection. Besides of recording podcasts, students were signed to create and post their individual experiences with podcasting in a blog. As a result, the researchers found that, though students were familiar with podcast technology in their daily lives, its use in college made them insecure in the beginning, especially because many of them had never created a podcast before or were unfamiliar with the software applied. These findings show students should not be assumed to master technology, since they need guidance and orientation to guarantee the learning objectives will be met (DALE; POVEY, 2009).

In opposition, students showed enthusiasm with the opportunity to do something new in class. Thus, creating the podcasts stimulated them to study the content deeply to ensure a good material would come out and helped developing employability skills (more practical perspective of the management activity and creativity) (DALE; POVEY, 2009).

Deed and Edwards (2011) studied the use of an unrestricted non-graded blog in a module of education course at the Liverpool Hope University. An unrestricted blog is a free environment 
where students can post and discuss their ideas with no intervention from the instructors. This approach was adopted in order to evaluate students' behaviors and cognitive strategies in a free academic context; the activity developed through the blog was designed to enhance higher order thinking. Students formed small groups and had to choose an education related theme that they would analyze and interpret through the blog. Students were expected to autonomously create the blog and perform the analysis task using mostly the online interaction (although face-to-face interaction was possible and allowed) (DEED; EDWARDS, 2011).

The authors discovered that most of the students were familiar with the 2.0 technologies, such as social networks and YouTube, but only $19.4 \%$ reported a frequent use of blogs. In order to evaluate the contributions to the blog, a modified version of Bloom's Taxonomy was applied. The taxonomy has six levels (DEED; EDWARDS, 2011):

- Remembering: posting one's own personal opinion.

- Understanding: explaining a previous post or asking clarifying questions.

- Applying: extrapolating the group's posts.

- Analyzing: finding connections among the posts and organizing the ideas into a deeper level.

- Evaluating: comparing the posts arguments against the theoretical framework found in the literature.

- Creating: coming up with new ideas, creating a final product.

The posts resulted from the discipline were mostly analysis content (26.3\%); followed by evaluating (20.2\%), remembering (18.2\%); understanding (16.7\%); applying $(12.1 \%)$ and creating $(6.5 \%)$. Looking closer to the blog contents, the researchers sampled three blogs and examined the contributions in each of them. They found that one of the cases was predominantly a novice level blog (43\% remembering; $29 \%$ understanding); the second case had a higher level of discussion (29\% remembering; 22\% understanding; 34\% applying) and the third case had a deeper level of interaction (37\% analyzing; $10 \%$ evaluating; $16 \%$ creating). In this sense the authors concluded that: 1) the knowledge building was not vigorously pursued by the students due to the superficial levels of the discussion; 2) it is not reasonable to assume that the digital generation will be naturally able to engage in blogs for educational purposes; 3) social media can stimulate a casual attitude toward information, 
which can turn the educational journey complex; 4) educational activities need guidance and careful design (DEED; EDWARDS, 2011).

Hou et al. (2010) run a content analysis in blogs developed for primary and secondary school teachers in Taiwan. Each teacher could have his/her own blog and could access and interact through their peers' blogs. The coding scheme used in this study, like the study published by Deed and Edwards (2011), applied a revised version of the Bloom's Taxonomy. They observed $46.6 \%$ of the messages were unrelated to their teaching topics which indicates teachers used the blogs not only for professional needs. This can be a healthy event, since the group could be considered a community of practice and the spontaneous climate enhances knowledge sharing. On the other hand, this phenomenon should be monitored, since it can cause undesirable effects (HOU et al., 2010). In light of their findings, the authors propose appropriate online discussion strategies should be designed to guarantee meaningful knowledge will be shared (HOU et al., 2010).

Kang et al. (2011) studied the blog usage in two graduate education classes in Korea (Kyung Hee University), totalizing 24 students. Both of the classes were involved in blogging, which was applied in order to promote discussion. The instructor used her blog to post class assignments and reflections; students were required to share information in their own blogs. This dynamic enhanced the sense of community and shared responsibility for learning, among the students and the teacher. In the authors' view, a blog fosters a multilayered interaction and socialization among the participants, but first of all, a blog is an online journal where people share opinions, thoughts and reflections. One of the findings of their study concerns the fact that teacher's blog became only one more blog in the blogosphere of the class; that is, both students and instructor visited each other blogs, promoting a decentralization of power, the instructor's blog is a part of the blogosphere, not more important or relevant than the others (KANG et al., 2011).

The main results reported by the authors are: 1) blogs stimulate community of practice development, in a proactive communication activity among the participants; 2) knowledge building happens through a social process; 3) allows a self-representation or identity construction (KANG et al., 2011). 
Papastegiou et al. (2011) studied blog usage on undergraduate sports education. They point blogs main potentials as: enhance student active participation on his/her knowledge building through social interaction; support individual self-representation and collective interaction; offer a space for creativity expression and divulgation to a real audience; incorporation of multimedia sources; develop reading, writing and reflection skills (PAPASTERGIOU et al., 2011).

Their study used blog to promote content creation among sports education students (University of Thessaly - Greece). The content created concerned basketball and aimed to promote better learning outcomes about basketball knowledge and technology literacy. The sample was composed by 70 students divided in two groups: 35 in a blogging group and 35 in a non-blogging group (which used a content repository website). A blog was developed and access was provided only for the blogging group; the first few posts aimed to orient students about what would be discussed in the blog and what assignments they were expected to perform (PAPASTERGIOU et al., 2011).

As a result they found out that initially there was no significant computer literacy difference between the groups, but the pre-test reveled blogging group had better previous basketball knowledge. The post-test showed the blogging group considered blogging activity to increase their multimedia processing skills, since they worked hard to produce high quality content; however, they did not exhibited a higher knowledge level compared to the non-blogging group (PAPASTERGIOU et al., 2011).

Kaplan et al. (2010) implemented blog in a marketing undergraduate module, aiming to encourage soft skills development, such as communication, self-expression, creativity, collaboration and critical thinking. Students were required to search for interesting, current topics related to marketing and post them at their blogs. Then teacher could assess their contributions and they could interact with their colleagues and external users. As a result, the researchers noticed students had an especial care with their writing (since colleagues and external users could read what they published) and had a deeper involvement with the module. The students considered the experience positive and learning enriching (KAPLAN et al., 2010). 
Wever et al. (2011) used wiki in a first year educational sciences undergraduate course (Ghent University). They aimed to evaluate students' contribution through a peer assessment framework. Wiki is used in education for content creation purposes and to enhance cooperative work, as education is considered an active, situated and collaborative knowledge building process, by which meaning is attributed based on multiple perspectives (WEVER, et al., 2011).

The class was divided in eight or nine student groups which were required to create two or three wikis along the semester and; then, assess their colleagues' participation under four criteria: contribution relevance, level of discussion, active participation, level of cooperation and interaction. This assignment was graded (40\% of the final grade). In order to evaluate peer assessment reliability, the authors calculated an intra-class correlation coefficient, which finds the agreement coefficient among the students. They discovered that peer assessment is reliable and feasible; wiki enhances responsibility among the participants and can be appropriately used for education purposes (WEVER, et al., 2011).

Huang and Nakazawa (2010) investigated wiki usage in a graduate online course. The authors remark, besides the collaborative group knowledge construction, wikis motivate student learning, as they keep participants and instructor connected and allow teachers to monitor the content development progress (HUANG; NAKAZAWA, 2010).

They observed learner-learner interaction happened in a higher level than learner-instructor interaction; this might be due to a change of roles, where teacher becomes one more participant of the discussion. Students distributed workload in the beginning of the course, which indicates they did not switch roles during the semester. In addition, instructors interventions are crucial, to stimulate student participation (writing, reviewing and revising their contributions), since they might not be intrinsically motivated or used to participate in this kind of environment for education purposes (HUANG; NAKAZAWA, 2010).

Jones (2010) studied wiki usage in a social work undergraduate module (James Cook University - Australia), as a tool for collaborative knowledge creation, increasing course's flexibility. He remarks social media tools can be very useful in higher education, but instructors should evaluate their real potential to increase learning and not adopt them just because of the innovation they represent (JONES, 2010). 
Students were divided in small groups and assigned to interact and construct collective material through the wiki. Students reported some frustrations along the process, firstly because most of them were not familiar with wiki technology (instructors provided directions and scaffolding to reduce these problems) and because of group process difficulties (some groups had trouble working collectively since some member did not contribute appropriately, which required teacher's intervention). On the other hand, benefits were related to the wiki experience: deeper understanding of the material and increased computer and technology literacy (JONES, 2010).

Lending (2011) studied wiki usage in an introductory Management System course (in a College of Business in the USA). Students were required to create new wiki pages on topics of their interest and revise and edit someone else's material. As a result, the class (28 students) developed a 70 page study guide and the students showed a positive attitude toward the activity. However, teacher's guidance on collaborative team work was necessary (LENDING, 2011).

North and Moreland (2010) investigated the pedagogical uses of wiki in order to enhance learning experience, according to four dimensions: learning experience, motivation, group interaction and technology. Pedagogical value of wiki was not related to prior web design experience; score was higher for students with less work experience; male students scored a higher pedagogical value for the wiki than female students; age did not influence pedagogical value of wiki (younger student did not show better scores than older students). During the regression analysis, researchers found only work experience and gender are significant predictors of pedagogical value of wiki (NORTH; MORELAND, 2010).

Andreas et al. (2010) used second life as an educational tool in order to enhance experiential learning, stimulate risk taking, test of new ideas and learning from their own mistakes. In their experience with post-graduate students, a specific space was chosen (two different kinds of classrooms), gesture codes were defined (for example, for asking permission to speak, an avatar should raise hands) and specific clothing was determined (shirts and hats of different colors were designated to each group of students, which made possible to differentiate students from diverse groups and teachers and students). The group did not have experience in interacting in virtual reality worlds, neither for entertainment nor for education. Some 
classes were conducted through second life along the semester. As a result students reported the rules imposed for the interactions were efficient; they showed positive feelings about the innovative approach, but pointed some weaknesses: limited interaction, difficulties in discussion coordination and the hardware requirements (ANDREAS et al., 2010).

In addition, students reported collaboration through second life is less effective than traditional interaction; traditional methods were considered easier, more direct and more useful, but second life methods were considered more interesting. They concluded second life cannot substitute traditional interaction but can complement it (ANDREAS et al., 2010).

Burgess et al. (2010) point out that second life, in the context of education, provides a constructivist space appropriate for socialization, collaboration and creativity. They also remark that virtual reality environments are different from other types of educational software, like Learning Management Systems, since the firsts allow telepresence (BURGESS et al., 2010).

They examined learning experience through second life according to the community of inquiry model, which states that learning happens by the interaction among social presence, cognitive presence and teaching presence. The sample included ten graduate students, enrolled in an online instructional technology class. The results show students scored high levels of social, cognitive and teaching presence (scores over 4 in a 1-5 scale) in their second life experience (BURGESS et al., 2010).

Cheong (2010) studied the use of second life for teachers education enrolled in a "teaching methods and educational technologies" in a University in Korea. The activities included a preparation phase (preparation for teaching in second life), a practice phase (teach a planned content to the group; act as a student in the colleagues classes) and a reflection phase (videos recorded were analyzed and the teacher who performed the practice was required to justify the reason he/she chose that teaching strategy). The author observed no significant difference in teaching outcome expectancy after the second life experience; on the other hand, it had positive influence on the personal teaching efficacy (CHEONG, 2010).

Halvorson et al. (2011) studied the second life usage in a marketing graduate course, considering two classes of 45 students each (in Australia). One group had the full discipline 
conducted through second life; the second group had a less intense use of the tool. The second life full class students reported as positive aspects of that experience: the convenience of attending classes online; engagement with the activities; empowerment; being part of a community. The second group expressed some frustration in online discussions, due to their perception of inability with the tool or the lack of participation; within this group some students were skeptical about the uses of second life and others were supportive and considered it to be fresh and innovative (HALVORSON et al., 2011).

On his experimental course, Baran (2010) created a Facebook group to which students were require to enroll, build and discuss about interest topics. Most of the students were already registered on Facebook before the class; however, only one-third of them accessed it on a daily basis; after the course the access frequency increased; $43.6 \%$ of the participants indicated they would prefer a traditional course over a Facebook based module; however, most of them agreed that the tool could be used for knowledge construction and sharing in education and that the communication with their peers motivated learning (BARAN, 2010).

Other point of view indicates students appreciated to have a closer contact with the instructors and access their personal information through Facebook. Thus, they showed excitement when teacher commented their profile postings. Facebook was considered an important tool for peer interaction as well (BARAN, 2010).

Hew (2011) investigated Facebook usage reported in the literature. The author ran a literature review, finding 539 articles which had studied its usage. The papers could be clustered into three different categories: 1) student's usage profile; 2) effects of the usage; 3) student's attitude toward the tool. Students use Facebook primarily to keep in touch with friends, low educational activity was reported in the literature. They disclosed more personal information on this tool than in other social media and their trust on the teacher increases when he/she shares personal information through Facebook. Facebook is mostly seen as an entertainment tool instead of a serious platform (HEW, 2011).

Lowe and Laffey (2011) used Twitter in a Marketing module. They created a profile for the module in the micro blog site and the instructor used this account to post news concerning the course and the content itself. Students were free to react and post their perceptions in the profile. However, the use of Twitter was not mandatory or graded; in addition; some students 
were not familiar with the social network and others reported an uncomfortable feeling of having to identify themselves in order to interact. In this sense there were low interaction activity during the semester, but in general, students considered the experience positively (LOWE; LAFFEY, 2011).

On the other hand, discussions in Twitter were not moderated, and it was considered a negative characteristic. Thus, instructors should monitor the activity, guide the students and correct their mistakes and misunderstanding. Another negative point was the poor written skills showed by the students, which can be due to the characters restriction (messages can have up to 140 characters) (LOWE; LAFFEY, 2011).

Finally, Lowe and Laffey (2011) remark Twitter's strengths: 1) the reduced extension of the messages stimulates the development of synthesis skill; 2) including links to other websites make the course dynamic; 3) mobile access to Twitter makes the course more convenient; 4) Twitter is popular among young people, which makes its use adequate for undergraduate modules (LOWE; LAFFEY, 2011).

Rinaldo et al. (2011) studied the use of Twitter for marketing education, stating it is a useful tool to develop relevant skills in business students and promote experiential learning. Their study was conducted over two semesters. In the first semester, they noticed most of the teacher's messages were related to course's activities or were directed to the students; most of the students did not have experience on Twitter, but in general, they reported a good experience with it; and people with technology interest showed a better attitude toward Twitter adoption (RINALDO et al., 2011).

The second study was conducted on the next semester and, based on the former experience, instructors offered an orientation section to help students use the tool; the messages posted became more course related, and a survey was implemented in order to measure the relationship between technology adoption and Twitter usage in the classroom. As a result, this group showed similar perception about the benefits of Twitter in the course (RINALDO et al., 2011).

Focus groups ran with students revealed Twitter increased their involvement with the class; affected satisfaction with the course and enhanced learning of the proposed content. In 
opposition, negative comments raised, such as, "Twitter was a waste of time", which indicates a barrier. In order to reduce resistance, authors suggest the benefits of social media in the business professional carriers should be reinforced (RINALDO et al., 2011).

Jones and Cuthrell (2011) investigated the use of YouTube videos in formal kids learning. According to them, YouTube videos can be used as part of the instruction activity; use the video contents to propose an additional activity in class may also be interesting (JONES, T.; CUTHRELL, 2011).

Clifton and Mann (2011) pointed out that YouTube is more than a video repository and has a great potential in education. In their study about nursing education they found YouTube videos increased students' engagement in the course, facilitated deep learning and raised critical thinking skills (CLIFTON; MANN, 2011). 


\subsection{Educational Evaluation}

In educational literature the term "educational evaluation" is understood as "the process of making judgments about the merit, value or worth of educational programs" (GALL et al., 2003 , p. 542). It is a specific research design named "evaluation research". It is worth to clarify the present dissertation is not an evaluation research and does not propose to run an educational evaluation (in the sense considered by education literature), although the word evaluation is sometimes used in the text. The word evaluation is simply used in the study in order to define the results obtained from services marketing dimensions measured.

In spite of that, it is relevant to briefly discuss educational evaluation approach and situate the research within this literature. Therefore, Kirkpatrick model and Scriven approach are briefly presented in the next section.

\subsubsection{Directions for evaluation}

The concept of evaluation regards the performance of the object evaluated and the standards by which the performance is studied; that is, the evaluator is responsible for describing the performance of a program in a way that allows it to be compared to the fixed standards. Performance can be understood as the accomplishments of a program. In order to gather information about performance; social research methods may be applied (ROSSI et al., 1999).

Rossi et al. (1999) point out that program evaluation can concern different kinds of programs, but it usually focuses on social programs, which can be defined as a set of actions that aims to address a social problem or to react to a social need providing some extent of human service (ROSSI et al., 1999).

Program evaluation may involve the following phases: definition of the need for the program; program's design; program implementation and service delivery; program's outcomes; cost effectiveness (ROSSI et al., 1999).

Evaluation may be conducted according different objectives: program improvement (formative evaluation); accountability (summative evaluation; which means, checking if the 
program meets the expectations); knowledge creation; public relationships (evaluation is conducted in order to provide a good impression on the stakeholders) (ROSSI et al., 1999).

Roberts et al. (2005) point out the most common approach for higher education evaluation are formative evaluation (occurs during the educational activity and helps continuous improvement) and summative evaluation (occurs after educational activity ends, in order to acquire its outcomes, compared to the objectives previously fixed). Usually institutions apply a summative evaluation at the end of courses and disciplines to find out students opinions, and ask them to express their perceptions about course content, materials and instructional methods (ROBERTS et al., 2005).

Summative/ formative classification was proposed by Scriven in 1967 and has been considered for professionals and researchers in any kind of programs evaluation. Scriven (1991) describes the formative evaluation as the activities to make sure program goals are being met. He also points out formative evaluation aims to give a preview of summative evaluation and if all the goals were found to be accomplished, summative evaluation is likely to be favorable (SCRIVEN, 1991).

It has been also criticized and discussed. Patton (1991) asserts evaluation is broader than this dichotomy classification, since in Scriven's perspective, formative (improvement oriented) evaluation is the previous step, to get the program ready to go through a summative (judgment oriented) evaluation (PATTON, 1991). Patton (1991) defends evaluation is a source of knowledge that can be used to clarify a program model, test a theory, figure out how to measure outcomes, redefine a target population and so forth.

Bryson et al. (2011) state evaluation should consider each stakeholder involved, including their needs, interests, concerns, priorities and intentions. All these inputs should drive the evaluation design in order to build credible and applicable approach (BRYSON et al., 2011).

Roberts et al. (2005) comment Kirkpatrick four-level model is largely used, particularly evaluations on the first level, since evaluations in the other three levels are difficult to conduct. HEI usually use the first level of Kirkpatrick model (measurement of students' reactions and opinions regarding the course) (ROBERTS et al., 2005). 
Kirkpatrick, D.L. and Kirkpatrick, J.D. (2006) describe some steps should be watched during the planning and implementation of training programs: determining needs; setting objectives; determining subject content; selecting participants; determining the best schedule; selecting appropriate facilities; selecting appropriate instructors; selecting and preparing audiovisual aids; coordinating the program; evaluating the program. Evaluation is considered an important step of any training program, since it shows how the program contributes to an organization goals achievement, it adds relevant information that lead to modifications and even discontinuance of the training (KIRKPATRICK, D.L.; KIRKPATRICK, J.D., 2006).

The training evaluation model developed by Kirkpatrick in 1996 involves four levels (reaction, learning, behavior, results) of evaluation and, although criticized has been applied to many contexts by several researchers. Level one considers participants' reactions to the program; it is a measure of customer satisfaction. In order to warrant effectiveness and, for consequence, learning, the program must enhance customer satisfaction; thus measuring reactions is critical to provide feedback and improve the program (KIRKPATRICK, D.L.; KIRKPATRICK, J.D., 2006).

Level two considers learning during the training; that is, how much they changed or improved attitudes, skills and knowledge as a consequence of the training. Measuring learning is more difficult than measuring reaction, but it is critical, as a behavioral change will happen only if learning takes place. The author suggests the use of a control group (which did not receive the training) and the measurement of knowledge, skills and attitudes before and after the program (in order to compare changes after the training), using the appropriate tools for each of them (i.e. knowledge can be assessed by a theoretical test; attitude can be assessed by a survey; skills may be tested in practical tests) (KIRKPATRICK, D.L.; KIRKPATRICK, J.D., 2006).

Behavior is evaluated on level three, and measures the change in participants' behaviors due to the training. It is relevant to remark change will happen only if: 1) participant wants to change; 2) participant knows what to do and how to do it; 3) the work climate is favorable; 4) changing must be rewarded (intrinsically or extrinsically) (KIRKPATRICK, D.L.; KIRKPATRICK, J.D., 2006).

In case no behavior change can be observed, it is important to evaluate levels one and two. If reaction to the program was favorable and learning happened, it is likely the organization did 
not stimulate behavioral change. It is not a weakness of the program, but a problem in the organization (reward, climate, willingness to change etc.). The opposite is also possible; behavior change will not happen if the program wasn't effective on providing satisfaction and learning (KIRKPATRICK, D.L.; KIRKPATRICK, J.D., 2006).

Finally, level four evaluates the training results; it means the final outcomes resultant from participation in the program. Some results may be: increased production; improved quality; cost reduction; reduction on accident rates; increase sale; diversity tolerance etc. Each program must state objectives in these terms; they may be tangibles or intangibles (KIRKPATRICK, D.L.; KIRKPATRICK, J.D., 2006).

This research, although is not classified as an educational evaluation research, aims to evaluate distance students' perceptions of their Public Management distance course. This kind of approach could be placed into the first level of Kirkpatrick model (reaction) and, since its objective is to provide information for decision making and course improvement, can also be seen as a formative evaluation. 


\subsection{Student's perspective}

\subsubsection{Quality perception}

Quality has started being investigated in the operations field where quality of a tangible product means the lack of defects and conformity with the production requisites. When services came into place, that approach was not able to measure services quality, since services own specific characteristics which differentiate them from the products: intangibility, heterogeneity and inseparability (PARASURAMAN et al., 1985).

Intangibility concerns the impossibility of counting, measuring, inventorying and testing the service before its performance. Heterogeneity means that the service performance varies according to different suppliers, consumers, situations and so on. Finally, inseparability means production and consumption of a service happen at the same time, inseparably. All of these aspects make it difficult for the client to assess quality and for the company to comprehend consumer's perceptions about the services provided. In addition, quality is even harder to assess when the consumer has intense participation on the service performance, such as it happens during medical appointments and in education (PARASURAMAN et al., 1985). Services quality concerns perception of quality; in other words, quality will be defined by the customer's judgment about the overall level of excellence owned by a service; it is an expression of attitude which is related but not synonym of satisfaction (PARASURAMAN et $a l ., 1988)$. Quality in services happens during their delivery, during interaction between who provides the service and who receives the service (ZEITHAML et al., 1988).

"Quality in higher education is a complex and multifaceted concept" (GRUBER et al., 2010, p.107); then its interpretation depends on the stakeholders points of view and those, in turn, are influenced by their particular needs. Thus, each stakeholder owns a particular perception of the service, driven by their own needs (GRUBER et al., 2010).

Due to their intangibility - in general, the only tangible aspects available are provider's infrastructure, staff and technology employed - services assessment needs additional evidence. In this sense, Parasuraman et al. (1985) propose quality perception is measured through the difference between performance and expectations (quality= service performance - 
expectations about the service). Thus, quality evaluation, besides of considering the final outcome, also takes into account the service delivery process (PARASURAMAN et al., 1985). For these authors expectations lay in two levels: 1) desired service, which is the level of service the customer believes could and should be offered;2) adequate service, which consists of the minimum level of service accepted by the costumer. Between these two levels there is a tolerance zone which determines the levels of services considered satisfactory (PARASURAMAN; ZEITHAML; et al., 1994b).

In order to define key attributes for service quality, Parasuraman et al., (1985) ran a qualitative research with clients and executives from different sectors (retail banking, credit card, security brokerage, product repair and maintenance). They found that regardless of the kind of service assessed, consumers used the same evaluation criteria, which can overlap (PARASURAMAN et al., 1985):

- reliability: means the company perform the service correctly at the first time and honor its promises;

- responsiveness: concerns the staff readiness and willingness to perform the service; that is, service and assistance are provided immediately;

- competence: means the staff owns the required knowledge and skills to provide a high quality service;

- access: concerns the ease of contact including easy contact channels (telephone, email, chat etc.), reduced waiting time, convenient assistance hours, convenient located assistance facilities;

- courtesy: involves politeness, respect and friendliness of contact staff;

- communication: concerns keeping the client informed, adapting language and style to his/her reality and listening to the consumers;

- credibility: concerns the company's reputation, honesty and trustworthiness which means, company has the clients' interest as a priority;

- security: includes physical and financial security and confidentiality;

- understanding: means the company make hard efforts to know and meet clients' needs;

- tangible: includes the tangible aspects of the service, that is, company facilities, staff appearance, technology employed in the service performance etc. 
Parasuraman et al. (1985) research originated the five dimension SERVQUAL questionnaire and a quality gap model which are presented and discussed later in the chapter. SERVQUAL and the gap model have been used in various studies since its creation in the 1980's, including in the educational field, which is this dissertation study object.

"Service quality enhances perceived value which contributes to customer loyalty" (PARASURAMAN; GREWAL, 2000, p.168). Perceived value of the service may have different forms: acquisition value, transaction value, in-use value, redemption value (PARASURAMAN; GREWAL, 2000). Although perceived quality is related to satisfaction, there is a remarkable difference over the concepts. Satisfaction is situational; it is the emotional response to the consumed service and results from the comparison between expectations and perception of the service in a specific transaction. Perceived quality is attitudinal; it is more long-term oriented and refers to a general experience with a service, it relates to the customer's evaluation of the superiority of the service. Thus, both constructs are related, satisfaction events over time will lead to perception of quality of a service (PARASURAMAN, A. et al., 1988).

It is usual to consider quality as an antecedent to customer loyalty in services industry. Specially intangible variables of services quality perception may have a strong influence on loyalty, such as reliability, empathy, assurance and responsiveness, which are dimensions from SERVQUAL (BLOEMER; RUYTER; WETZELS, 1998).

Brady and Cronin (2001) criticize SERVQUAL gap approach, presenting an alternative hierarchical model. They also ran a qualitative research in eight different industries (amusement parks, restaurants, health care, hair salons, automobile care facilities, dry cleaning, jewelry repair, photo developing), getting 391 completed surveys. The questionnaire asked the respondents to specify attributes they felt influenced interactions, environment and outcomes on recent services experiences. For each of the three primary dimensions they found three sub-dimensions, which means, in their perspective, overall quality perception is formed by a multilevel perception of factors related to the service (BRADY; CRONIN, 2001).

Despite of criticizing SERVQUAL, Brady and Cronin (2001) recognized the five dimensions proposed by Parasuraman et al. (1985) are important in order to evaluate a service quality; then each of their nine sub-dimensions are measured in terms of reliability, responsiveness 
and empathy (SERVQUAL dimensions). It is worth to notice, tangibles and assurance are not retained in the hierarchical multilevel model. Tangibles dimension is comprehended as a subdimension of outcomes quality and assurance was found to load on different factors, depending on the industry studied (BRADY; CRONIN, 2001). Figure 9 shows multilevel model and its attributes. Interaction quality consists of the interactions that happen during a service delivery and which strongly affect quality perception. The services interactions are determined by staff's attitudes, behaviors and expertise during the service delivery. In turn, service environment considers the surrounding environment during the service delivery. Environment perception includes ambient conditions (temperature, music playing, lighting), facility design (architecture and layout) and social factors (noise, disturbance, hygiene). Outcome quality refers to what lasts to the customer after the service is finished; it is composed by the waiting time needed, tangible aspects and valence (extent to which the customer considers the service good or bad) (BRADY; CRONIN, 2001).

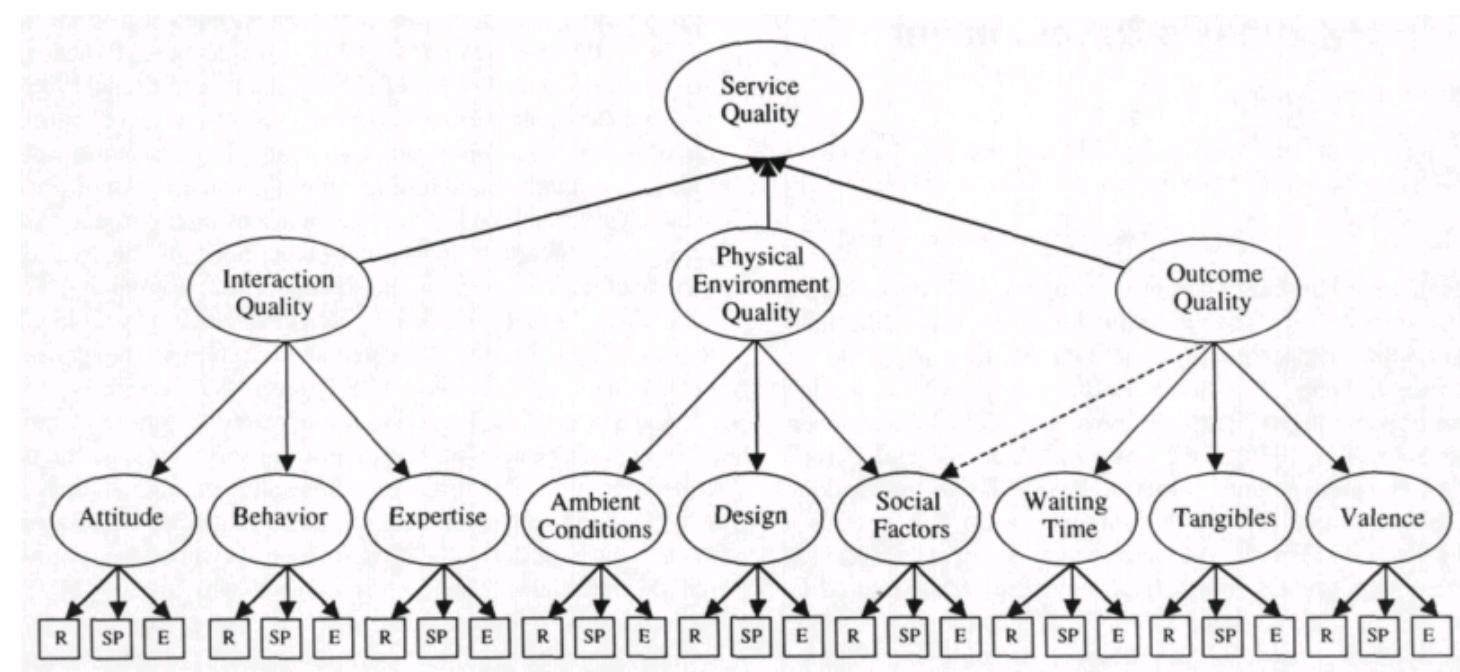

Note: $\mathrm{R}=$ a reliability item, $\mathrm{SP}=\mathrm{a}$ responsiveness item, $\mathrm{E}=$ an empathy item. The broken line indicates that the path was added as part of model respecification.

Figure 9. Hierarchical multilevel model

Source: (BRADY; CRONIN, 2001, p.34)

A quantitative study was conducted (35 items; 4 industries, 1,133 cases) in order to test the theoretical model proposed and some findings emerged from the structural model (BRADY; CRONIN, 2001):

- Attitudes, behavior and expertise affect interaction quality. 
- Interaction quality affects service quality perception.

- Ambient conditions, facilities design and social factors affect environment perception.

- Environment perception influences service quality perception.

- Waiting time, tangibles and valence affect services outcome.

- Outcome quality influence service quality perception.

- Social aspects also influence outcome quality.

- Empathy, responsiveness and reliability are relevant in order to provide high quality services.

Zeithaml et al. (1996) proposed services quality has an import effect on behavioral intentions and, as a consequence, on financial outcomes (Figure 10) (ZEITHAML et al., 1996). Their model showed service quality is related to behavioral intentions, which means perceived quality determines whether a customer will keep business or leave the company. When quality is high, behavioral intention is favorable and there is a higher probability customers will strength relationships with the company (ZEITHAML et al., 1996).

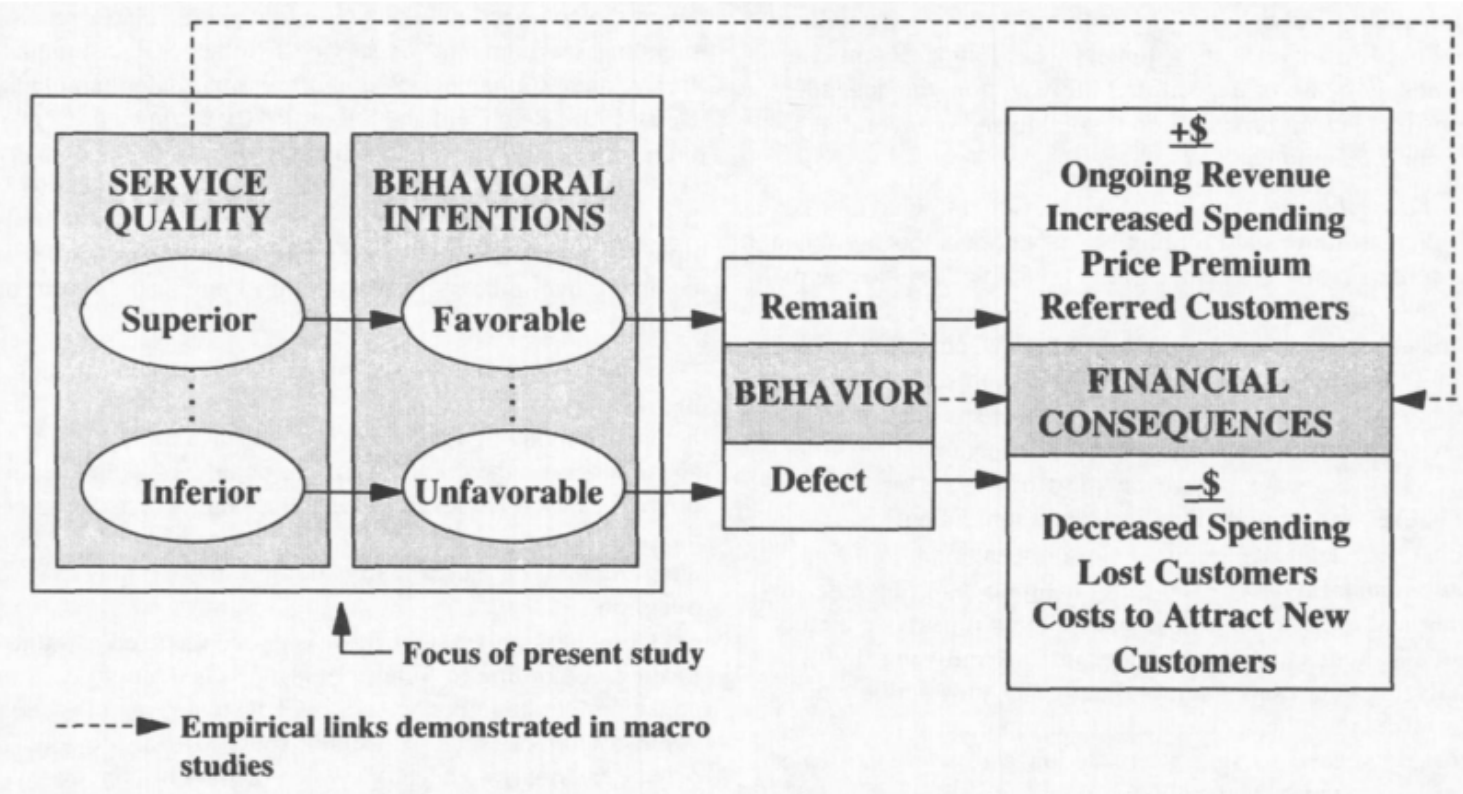

Figure 10. Behavioral and financial consequences of service quality

Source: (ZEITHAML et al., 1996, p.33)

Stella and Gnanam (2004) remark the relevance of discussing quality in DE and ways to guarantee it. In the past DE courses used to be considered inferior to face-to-face courses and to have poor quality; distance students were also considered to have lower requisites to start 
the course. This idea has been changing over time as face-to-face courses have been adopting technology to enhance learning, which is leading to a convergence between online and traditional education (STELLA; GNANAM, 2004).

Distance education is just an educational method that may be effective or not, like traditional educational methods. Effectiveness depends on how it is conducted. Using distance education tools to provide a high quality program is a complex issue since quality assessment and standards creation are hard to define (STELLA; GNANAM, 2004).

Kassim and Zain (2010) define service quality as a source of competitive advantage for HEI. Institutions must monitor quality to guarantee stakeholders' expectations and needs are met. In their opinion, students are the stakeholders who should evaluate service quality, since they receive the service (KASSIM; ZAIN, 2010).

There are three elements on service quality: service product, service environment and service delivery. Service product concerns the specifications of the provided service. Service environment concerns internal (organizational culture and strategies) and external environment (policies adopted to deal with the customers). Service delivery concerns the direct interaction between customers and the company's staff. In education these three elements are present, for example:1) product may be considered the materials and equipment employed; 2) environment may be considered educational policies and practices adopted by the institution; 3) delivery concerns the interaction with faculty during classes, advising sections etc. (KASSIM; ZAIN, 2010).

Ortiz-Rodríguez et al. (2005) studied student perceptions of distance learning quality in an American University. They selected a sample of students (214 students) who listed the main factors they considered important in a DE course. Communication was found to be the most important variable affecting DE quality on students' point of view. It includes many forms of communication, such as peer-to-peer interaction, student-instructor interaction; student-staff interaction; access to support; timely feedback. In addition, they found within undergraduate students $72 \%$ of female considered communication important against $56 \%$ of male students; for graduate students $70 \%$ of male considered communication important while $57 \%$ of female students (ORTIZ-RODRÍGUEZ et al., 2005). These findings suggest gender, educational level and age may influence quality perception. 
Chaney et al. (2007) developed a scale to measure quality of DE courses in the health field offered by a southern university in the USA. Their research revealed 14 dimensions that evaluate quality for DE: student-teacher interaction; prompt feedback from instructor; program evaluation and assessment; clear analysis of audience; documented technology plan to ensure quality; institutional support and institutional resources; course structure guidelines; active learning techniques; respect to diverse ways of learning; faculty support services; strong rationale for distance education that correlates to the mission of the institution; appropriate tools and media; reliability of technology; implementation of guidelines for course development and review of instructional materials (CHANEY, et al., 2007).

The proposed model contained 22 items and four dimensions named: student-teacher interaction; student support services; student technical assistance; evaluation and course structure. As a result, from a sample of 567 students, they found that quality perception is impacted by administrative process, technology ease of use, quality of instructional methods and quality of course materials, as it may be seen on Figure 11 (CHANEY, et al., 2007).

In 2009 Chaney et al. published a paper which proposed to review the literature about quality in distance education and selected critical dimensions brought by those studies (CHANEY, et al., 2009): student teacher interaction; active learning techniques; prompt feedback; respect to diverse ways of learning; student support services; faculty support services; program evaluation and assessment; clear analysis of audience; appropriate tools and media; documented technology plan; institutional support and institutional resources; course structure guidelines; strong rationale for DE that correlates to the institutional mission; reliability of technology; implementation of guidelines for course development and review of instructional materials (CHANEY, et al., 2009).

Chen (2009) in turn proposes DE quality (through the e-learning courseware certification program from Taiwan) should be assessed across four aspects: content, navigation, instructional design and instructional media. Content means institution should provide accurate, clear and organized content in order to facilitate learning. Navigation concerns the technological tools applied to the course in order to facilitate learning. Instructional design includes well-designed learning activities, clear objectives, adequate learning strategies, student feedback, adequate assessment activities and stimulation to interaction. Instructional 
media includes the media employed to DE in order to accomplish learning objectives (CHEN, 2009). He also comments quality may be assessed (by the e-learning service certification program from Taiwan) considering student support, faculty support, curriculum development, instructional design and processes, organizational technology support, assessment and evaluation methods (CHEN, 2009).

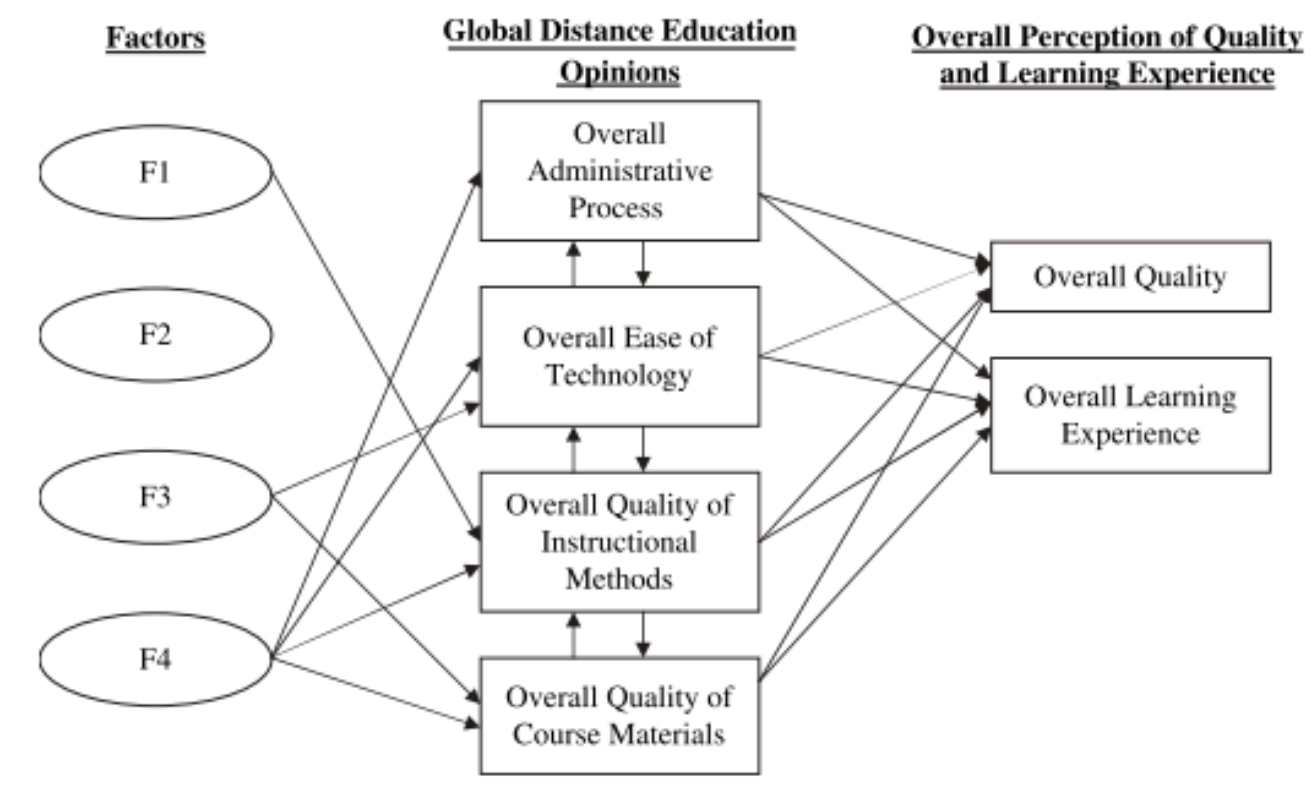

Figure 11. Chaney et al. (2007) model for quality assessment in DE for health education Source: (CHANEY et al., 2007, p.160).

Šimić and Čarapić (2008) studied quality in Croatia higher education, as they see it as mandatory to create a competitive, market-oriented institution and to satisfy customers. Study was conducted at the Faculty of Economics of Osijek in Croatia and used a sample of 150 former students and 273 current students. Their questionnaire was based on an adapted version of SERVQUAL, which was more consistent with Croatian reality. Three aspects were

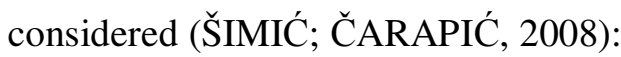

1) Organization and capabilities: organization of studies; adequacy of resources; opening hours and schedule; faculty quality, politeness, credibility, knowledge and capability; staff quality, politeness, knowledge and capability. 
2) Acquired knowledge: quality of the program; extent to which knowledge meets expectations; extent to which knowledge meets needs; extent to which knowledge leads to personal development; extent to which knowledge is useful for future work.

3) Study success: average grade on graduation.

Šimić and Čarapić (2008) found, for the former students sample, that the course main strengths were: knowledge and capabilities of faculty; opening hours and schedules; reputation of the college. The main weaknesses were: politeness of staff; quality of staff work; extent to which knowledge acquired meets expectations. For the current students, main strengths were faculty knowledge; opening hours and schedule; applicability of knowledge. The weaknesses were politeness of staff, study success, knowledge of staff (ŠIMIĆ; ČARAPIĆ, 2008).

Jager and Gbadamosi (2009) also studied perceived quality in education, selecting a sample from two Management Universities in South Africa (391 students). They found 13 dimensions for education quality measurement: internationalization; marketing and support; access to services; international students and staff; academic reputation; student focused; academic quality; variety and reach; location and logistics; accommodation and scholarship; sports reputation and facilities; safety and security and parking. All the dimensions explained $60 \%$ of variance and had Cronbach's Alpha ranging from $0.57-0.82$. In addition, the factors, satisfaction, intention to leave the university and trust in management and support also had satisfactory reliability (intention $=0.7$; trust $=0.86)($ JAGER; GBADAMOSI, 2009).

Peltier et al. (2007) studied drivers for successful online education and proposed six quality dimensions and a model that relates these quality determinants. Quality dimensions identified by the authors were: student-student interaction; student-instructor interaction; instructor support and mentoring; lecture delivery quality; course content; course structure (PELTIER et $a l ., 2007)$. Study was conducted in a USA Midwest university, specifically with students from an online MBA (299 students in the sample). They found only course structure, course content and instructor mentoring influence perceived quality of learning experience, which means quality perception in education is a complex issue (PELTIER et al., 2007). From the paths of their theoretical model (Figure 12) they found the following relationships to be significant (PELTIER et al., 2007): 
- Course structure influences quality of learning experience.

- Student-student interaction influences perception of course content.

- Instructor-student interaction influences perception of course content.

- Course content influences quality of learning experience.

- Course structure influences perception of course content.

- Course structure influences instructor-student interactions.

- Instructor mentoring influences quality of learning experience.

- Instructor mentoring influences course structure perception.

- Instructor mentoring influences student-student interactions.

- Instructor mentoring influences instructor-student interactions.

- Instructor mentoring influences perception of course content.

- Lecture delivery quality influences instructor mentoring.

- Lecture delivery quality influences perception of course structure.

- Lecture delivery quality influences perception of course content.

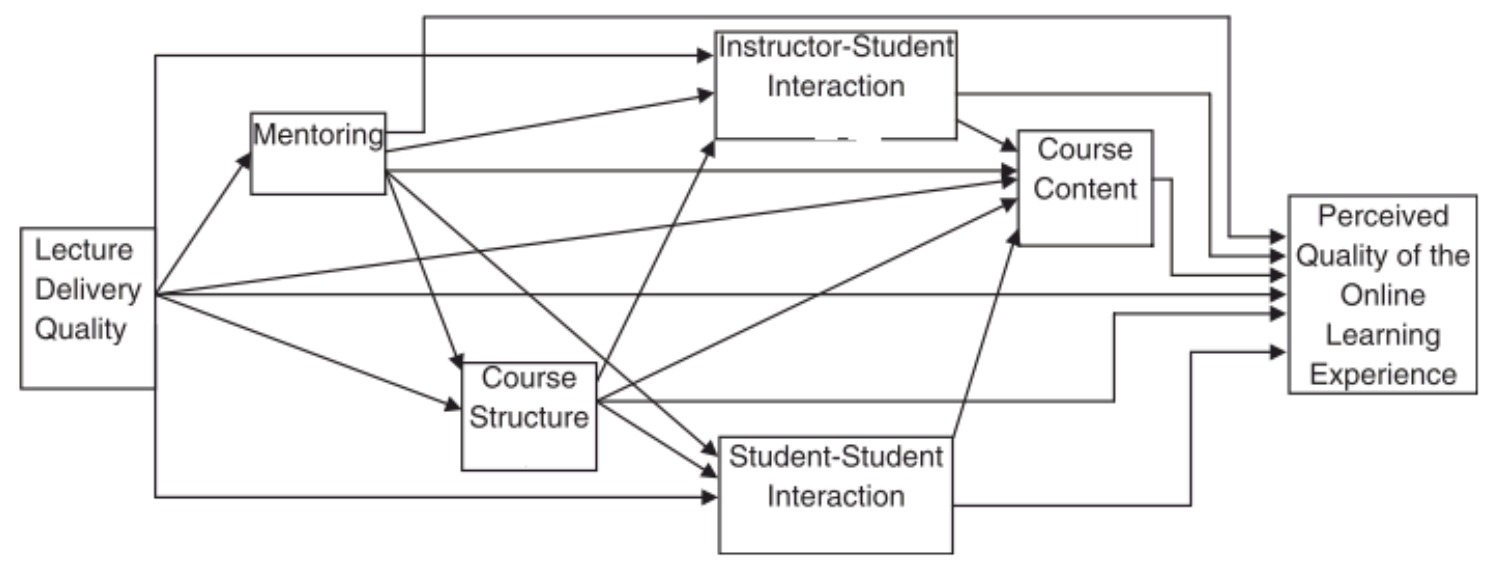

Figure 12. Quality perception model - Peltier et al. (2007)

Source: (PELTIER et al., 2007, p.142)

Evaluating DE quality is important to all parts involved, since attrition in DE is high (25$40 \%$ ) and may be partly explained by low quality perception (UDO et al., 2011). Measuring variables that influence DE helps increasing quality perception, student satisfaction and better decision making conditions for educational institutions (UDO et al., 2011). 
The authors point out quality perception leads to student satisfaction and is determined by the relationships and contact between students and instructors, administrators and staff. Satisfaction in turn is also influenced by technology issues and interactivity conditions (UDO et al., 2011).

Nesset and Helgesen (2009) studied the determinants of student loyalty and considered quality perception as a driver to the feelings regarding the educational object as well as to student satisfaction. For them, quality owns three different dimensions: perception of learning quality, facility quality and information technology quality, which include the elements studied for SERVQUAL five dimensions model. The dimension "learning quality" includes elements from the dimensions assurance, reliability, responsiveness and empathy, focusing the analysis on the interaction with instructor as the driver of quality perception. The dimensions "information technology (IT) quality" and "facility quality" include elements from the SERVQUAL dimension tangibles. All the three dimensions are considered as positive related to positive feelings and negatively related to negative feelings. Thus satisfaction is positively influenced by the three dimensions (NESSET; HELGESEN, 2009).

Udo et al. (2011) applied a modified version of SERVQUAL, as well, to measure student's perceptions in e-learning courses. For these authors SERVQUAL has been broadly used in many different kinds of services but within educational field it remained unexplored until recently (UDO et al., 2011). Their version uses adapted assurance, empathy, responsiveness and reliability questions to evaluate instructors' relations and performance. Tangibles dimension had its name altered to "website content", as in their point of view, physical facilities and equipment (evaluated by tangibles) are less important for DE; then contents, audio, video and every material posted on the course's website are evaluated by the dimension "website content". This dimension includes the quality of information provided, appropriateness of the amount of information available, kinds of media and image employed and website appearance (UDO et al., 2011).

In addition, Udo et al. (2011) defend student's performance expectation influences his/her perception about the course quality (UDO et al., 2011). This dimension will be also examined in the dissertation.

Rojas-Méndez et al. (2009) argument that educational staff is more empowered than employees in other sectors of business, because they own more autonomy and higher level of 
interaction with their clients (students). As a consequence, interaction plays a strong part of services quality perception in education. For these authors quality perception concerns "what the consumer feels a firm should provide" (ROJAS-MÉNDEZ et al., 2009, p.24). In their study, perceived quality is determined by five dimensions: service quality of the instructors, service quality of the program director, service quality of secretaries, service attitude and competence development. It means student's perception of educational services quality is fundamentally affected by the competence of instructors and staff, during the educational experience (ROJAS-MÉNDEZ et al., 2009).

Service quality, in Kenney and Khafar (2009) point of view, is achieved when the service provider offers reliable service that meets or exceeds customer's expectations. Perceived quality is considered as a determinant to satisfaction and also: impacts repurchase intentions, helps retaining customers and attracting new clients (KENNEY; KHANFAR, 2009). Organizations certainly should pursue high service quality level, but it is unrealistic to expect no breakdowns, even because, breakdowns do not have to lead to customer dropout. What the organization does after a breakdown determine the outcomes of that situation; in other words, if a problem is promptly solved, customers will probably not dropout. Then, managers should anticipate possible breakdowns and formulate a reaction strategy, in order to reduce their impacts over the company (KENNEY; KHANFAR, 2009).

Kuo and Ye (2009) bring a different perspective; in their opinion quality measurement in educational organizations often refers to pedagogical aspects of teaching-learning process. However, this approach may be ineffective for management purposes, since it focuses on pedagogical instead of administrative variables (infrastructure, support services etc.) (KUO; YE, 2009).

In higher education institutions, quality evaluation is mainly based on student's perceptions about their instructors. These perceptions are impacted not only by an instructor knowledge and competence, but also by his/her interpersonal skills, communication and by interaction provided (KUO; YE, 2009).

In this sense, they propose an adaptation of SERVQUAL from Parasuraman et al. (1988) in which the five dimensions become: a) tangibles: level of maintenance of facilities and equipment and how effective technology is used by instructors to enhance learning; b) 
reliability: ability of instructors and staff to perform their tasks in a dependable and accurate way; c) responsiveness: staff members service willingness; d) assurance: staff politeness and instructor's level of knowledge; e) empathy: individualized attention provided to students by staff members (KUO; YE, 2009).

Kassim and Zain (2010) used a modified version of SERVQUAL in order to measure business students' service quality perception. They observed students attributed high expectation scores to all the five dimensions. Total perceived quality score was lower than expectation score, which means there was a quality gap in the overall educational experience (course did not meet student's expectation). Quality gap was negative to the five dimensions. Empathy had the bigger gap, followed by responsiveness, assurance, tangibles and reliability (KASSIM; ZAIN, 2010).

Regression analysis was conducted to evaluate the influence of each dimension (independent variables) on the overall quality (dependent variable). Empathy and assurance had significant influence on quality; responsiveness, reliability and tangibles did not have significant influence on quality perception (KASSIM; ZAIN, 2010).

Brown and Mazzarol (2009) in their study measured quality through two dimensions: humanware $^{3}$ and hardware; it means perceived service quality has a human and a technological component. Similarly to SERVQUAL, humanware represents responsiveness, assurance, empathy and reliability, while hardware concerns tangible aspects of the service. They considered, in their initial model, quality perception influences service perceived value. However, their data basis (Australian students) did not show strong relationships between perceived quality and value; which they considered an indeterminate relationship between quality and perceived value (BROWN; MAZZAROL, 2009).

Kenney and Khanfar (2009) also mention SERVQUAL as the most popular instrument for service quality evaluation; however, they point out SERVPERF may be a more appropriate scale, because it measures customer's real perceptions about the service consumed, while SERVQUAL assesses the gap between customer's expectations and customer's perceptions regarding the service (KENNEY; KHANFAR, 2009). Kuo and Ye (2009) corroborate Kenney

\footnotetext{
${ }^{3}$ The expression "humanware" is proposed by Brown and Mazzarol (2009) in their published article.
} 
and Khanfar (2009) saying that in educational field, students will evaluate their educational experience based on their actual experience; that is, expectations will be biased by real situations lived by students during the long period they spent at school. For this reason, Kuo and Ye (2009), just like Kenney and Khanfar (2009), recommend the collection of perceptions, as a measure of perceived quality, instead of the difference between expectations and perceptions (proposed in the original SERVQUAL model) (KUO; YE, 2009).

Kassim and Zain (2010) comment the criticism over SERVQUAL due to the use of the difference between expectations and perceptions in order to measure quality. They also point out SERVQUAL has been broadly used in many kinds of industries, but researchers rarely are successful in maintaining the 22 items and the five dimensions of the validated scale, because of the diverse nature of the different industries (KASSIM; ZAIN, 2010). Brown and Mazzarol (2009) also reinforce that idea saying many studies in the literature which applied SERVQUAL found different number of dimensions (more or less than five) due to the diverse nature of the services (BROWN; MAZZAROL, 2009). Parasuraman et al. (2005) assume from empirical standpoint there is controversy on defining quality as the gap between expectations and performance of the service; the existence of five distinct dimensions for measuring services quality; and the relations across perceived quality and perceived value and behavioral intentions (PARASURAMAN, A. et al., 2005). Table 4 summarizes the results found by some similar quality studies found in the literature.

Table 4. Quality perception in education studies - Summary table

\begin{tabular}{|c|c|c|c|}
\hline Authors & Sample profile & Quality dimensions & Main findings \\
\hline $\begin{array}{l}\text { (KASSIM; ZAIN, } \\
2010)\end{array}$ & $\begin{array}{l}\text { Business students } \\
78.8 \% \text { female } \\
90.1 \% \text { Age } 18-24 \\
82.3 \% \text { single } \\
93.6 \% \text { full time } \\
\text { students } \\
87.9 \% \text { intention to } \\
\text { continue course } \\
78.7 \% \text { intention to } \\
\text { recommend the course }\end{array}$ & $\begin{array}{l}\text { SERVQUAL } \\
\text { - Empathy } \\
\text { - Reliability } \\
\text { - Responsiveness } \\
\text { - Assurance } \\
\text { - Tangibles }\end{array}$ & $\begin{array}{l}\text { Negative quality gap, } \\
\text { college fails to meet } \\
\text { student's expectations. } \\
\text { Empathy and } \\
\text { responsiveness have } \\
\text { the stronger gaps. } \\
\text { Regression analysis } \\
\text { showed empathy and } \\
\text { assurance impact } \\
\text { quality perception. }\end{array}$ \\
\hline $\begin{array}{l}\text { (CHANEY, BETH } \\
\text { HENSLEIGH et al., } \\
2007)\end{array}$ & $\begin{array}{l}\text { Southern university } \\
\text { students } \\
83.3 \% \text { female } \\
86 \% \text { white } \\
33.6 \% \text { education and } \\
\text { human development } \\
25.2 \% \text { liberal arts }\end{array}$ & $\begin{array}{l}\text { Created a new scale } \\
\text { - Student-teacher } \\
\text { interaction } \\
\text { - Student support } \\
\text { services } \\
\text { - Student technical } \\
\text { assistance }\end{array}$ & $\begin{array}{l}\text { SEM indicated student- } \\
\text { teacher interaction and } \\
\text { evaluation and } \\
\text { assessment explain } \\
\text { quality of instructional } \\
\text { methods. Student } \\
\text { support does not }\end{array}$ \\
\hline
\end{tabular}




\begin{tabular}{|c|c|c|c|}
\hline Authors & Sample profile & Quality dimensions & Main findings \\
\hline & & $\begin{array}{l}\text { - Evaluation and course } \\
\text { structure }\end{array}$ & $\begin{array}{l}\text { influence perceived } \\
\text { quality and student } \\
\text { technical assistance } \\
\text { explains technology } \\
\text { ease of use (negative } \\
\text { influence) and quality } \\
\text { of course material. } \\
\text { Evaluation and } \\
\text { assessment explained } \\
\text { all DE constructs. }\end{array}$ \\
\hline $\begin{array}{l}\text { (ŠIMIĆ; ČARAPIĆ, } \\
\text { 2008) }\end{array}$ & $\begin{array}{l}\text { Croatian students from } \\
\text { an Economics college } \\
14 \% \text { management } \\
56 \% \text { marketing } \\
28 \% \text { finance } \\
11 \% 0-1 \text { years of } \\
\text { employment } \\
41 \% 1-5 \text { years of } \\
\text { employment } \\
23 \% 5-10 \text { years of } \\
\text { employment } \\
25 \% \text { more than } 10 \\
\text { years }\end{array}$ & $\begin{array}{l}\text { Adapted a scale: } \\
\text { - Organization and } \\
\text { capabilities } \\
\text { - Acquired knowledge } \\
\text { - Performance }\end{array}$ & $\begin{array}{l}\text { Current students have a } \\
\text { better perception of the } \\
\text { aspects evaluated } \\
\text { except for: organization } \\
\text { of studying; quality of } \\
\text { staff; politeness of } \\
\text { professors and } \\
\text { performance. }\end{array}$ \\
\hline $\begin{array}{l}\text { (JAGER; } \\
\text { GBADAMOSI, 2009) }\end{array}$ & $\begin{array}{l}\text { South Africa } \\
\text { Management } \\
\text { University } \\
59 \% \text { female } \\
43 \% \text { first year of the } \\
\text { course } \\
25 \% 18-19 \text { years old } \\
31 \% \text { 20-21 years old } \\
18 \% \text { over } 22 \text { years old }\end{array}$ & $\begin{array}{l}\text { Scale based on } \\
\text { literature review } \\
52 \text { items for quality } \\
5 \text { items for trust in } \\
\text { management and } \\
\text { support } \\
4 \text { items for intention to } \\
\text { leave } \\
1 \text { item for satisfaction }\end{array}$ & $\begin{array}{l}13 \text { factors were found } \\
\text { in order to measure } \\
\text { quality in HE (higher } \\
\text { education) }\end{array}$ \\
\hline (PELTIER et al., 2007) & Online MBA students & $\begin{array}{l}\text { Scale based on } \\
\text { literature review } \\
47 \text { items } \\
\text { - Lecture delivery } \\
\text { quality } \\
\text { - Mentoring } \\
\text { - Course structure } \\
\text { - Instructor-student } \\
\text { interaction } \\
\text { - Student-student } \\
\text { interaction } \\
\text { - Course content }\end{array}$ & $\begin{array}{l}\text { Model goodness of fit } \\
\text { (GoF): } \\
\text { GFI (goodness of fit } \\
\text { statistic) }=0.99 \\
\text { AGFI (adjusted } \\
\text { goodness of fit } \\
\text { statistics) }=0.89 \\
\text { CFI (comparative fit } \\
\text { index) }=0.99 \\
\text { IFI (incremental fit } \\
\text { index) }=0.99 \\
\text { Only course content, } \\
\text { course structure and } \\
\text { mentoring influence } \\
\text { directly quality. }\end{array}$ \\
\hline
\end{tabular}

In this dissertation, adapted version of SERVQUAL applied by Udo et al. (2011) was used in order to measure PNAP students' perceptions of Public Management course. However, the study considered only the actual perception in order to measure quality, instead of considering 
the gap between expectations and perceptions, as proposed by the original scale. This approach was also employed by other researchers in similar studies (KENNEY; KHANFAR, 2009; KUO; YE, 2009; UDO et al., 2011). Variables used in the present study are shown in chapter 3 .

Considering the relevance of SERVQUAL and SERVPERF for service quality research and their status as the most used scales for quality measurement, both of them will be better described in the next sections.

\subsubsection{SERVQUAL}

After proposing the gap model for services quality evaluation, Parasuraman et al. (1988) proposed a scale named SERVQUAL which intends to measure perceived quality in five different dimensions as already mentioned: assurance, empathy, reliability, responsiveness and tangibles. It consists of a scale with 22 items, which asks the respondent to classify his/her expectation about a determined service and his/her actual perception of the service (after experience); quality will be measured by the gap between expectations and real perceptions (PARASURAMAN et al., 1988).

Initially 97 items were created and affirmatives were formulated to measure both expectations and actual perception of the service assessed; using a 7 point Likert scale. These items considered the quality dimensions found by the research conducted in 1985 (ten dimensions). The instrument refinement was conducted in two phases. The first phase consisted of a data collection which gathered a sample of 200 customers from five different services (repair, retail banking, long distance telephone, credit card and brokerage). Firstly Cronbach's Alpha was calculated for each of the ten quality dimensions, considering the gap between perceptions and expectations regarding the service; values ranged from 0.55 to 0.78 (PARASURAMAN et al., 1988). Then some items (which had a low item-to-total correlation) were deleted resulting in 54 items and values of Cronbach's Alpha ranging from 0.72 to 0.83 . These items were submitted to a factor analysis with a prior decision of 10 factors solution. Since many items loaded in more than one factor; some of them were excluded and oblique rotation was ran (allows intercorrelation among the factors). Seven dimensions were extracted 
totalizing 34 items with Cronbachs's Alpha varying from 0.72 to 0.85 (PARASURAMAN, A. et al., 1988).

A second data collection was conducted considering four companies (a bank, a repair company, a credit card company and a long-distance telephone company). A sample of 200 cases was extracted from each company; Cronbach's Alpha was calculated as well as a seven factor solution was applied to each of the four samples. For both collections, only clients who had a three months experience with the service and the company were selected. These new data showed lower reliability which led to a new refinement with the exclusion of some other items. The final solution kept 22 items and found five dimensions, which compose SERVQUAL scale (PARASURAMAN et al., 1988):

- Tangibles (four items): physical facilities, technology employed and people appearance.

- Reliability (five items): performing the service dependably and correctly.

- Responsiveness (four items): prompt service and willingness to help.

- Assurance (four items): level of knowledge and politeness of the staff.

- Empathy (five items): care and attention provided to customers.

Empathy and assurance include items from seven original dimensions, which means although SERVQUAL kept only five dimensions, they represent the content from the ten original dimensions. Final Cronbach's Alpha ranged from 0.72 to 0.86 . Regression analysis was conducted in order to evaluate the importance of SERVQUAL dimension on overall quality perception. The author found reliability was the most important dimension for the four companies studied; assurance is the second most important dimension and empathy is the least important. In addition, R-square ranged from $27 \%$ to $52 \%$ (PARASURAMAN et al., 1988).

Parasuraman et al. (1988) suggested considering demographic and profile variables in order to evaluate SERVQUAL results; then it is possible to identify weaknesses and create an action plan. The scale can be used for different kinds of services and may be adapted in order to provide better measurement for a specific industry. 
In 1991 the authors published another paper in which they discuss a replication of SERVQUAL to three other industries: telephone repair, insurance and retail banking. Five companies were surveyed totalizing 1,936 customers. Original scale had six statements negatively worded which showed to be problematic; in addition; some expressions used on the original items caused a confused interpretation. Then some modifications were performed in order to refine the scale (PARASURAMAN et al., 1991).

Data analysis showed similar results to the original study. However two differences were found: 1) tangibles were divided in two new factors; 2) responsiveness and assurance overlapped and merged into one factor. When considering only expectations scores, four factors are extracted and tangibles did not split into two factors; it indicates customers have quite different expectations and perceptions of tangibles aspects of the service. Considering only perceptions scores, the authors found that customer's perceptions of assurance and responsiveness overlap (PARASURAMAN et al., 1991).

A five factor solution was held and tangibles still divided into two dimensions while assurance and responsiveness overlapped. Then a six factor solution was conducted and tangibles still had two dimensions; however, responsiveness and assurance showed differentiation. Then, the authors concluded the basic multidimensional structure found by the original scale is valid. Regression analysis was ran in order to find most important dimensions for each company surveyed and for four of them reliability is the most important dimension (for one insurance company assurance was the most important dimension). Each company had a specific dimension ranking, showing factor relevance varies depending on the case. Rsquare ranged from $57 \%$ to $71 \%$. Then the authors concluded results obtained are consistent with the original study (PARASURAMAN et al., 1991).

Since its development SERVQUAL have been applied by many researchers and criticized for its multidimensionality (five dimensions) and its gap approach (difference between expectations and perceptions). In 1993 the authors responded to a critique to the gap approach, saying the use of perceptions for measuring quality is not appropriate since it does not allow the researcher to find out possible reasons for the change of attitudes over time (PARASURAMAN et al., 1993). 
In 1994, also responding to those critiques, the authors pointed out the gap approach was based on an extensive literature study and on their focus group held with organization's executives. In addition, they defended multidimensionality and oblique rotation (allows the factors to be intercorrelated). They argument Cronin and Taylor (1992) research found one factor which explains less than $50 \%$ of variance; it means the one-dimensional approach fails on representing the 22 items of services quality measurement. In addition, the authors reinforce SERVQUAL obtained reliability and validity that were satisfactory and compatible with results found by other papers published in the literature (PARASURAMAN; ZEITHAML; et al., 1994a).

More recently, Parasuraman et al. (2005) developed a scale adapted to measure e-services quality, more specifically e-commerce services (focus on online purchase sites). They developed two scales: 1) E-S-QUAL, 22 items divided in four dimensions, named efficiency (ease of using and accessing the site), fulfillment (extent to which the store's promises are fulfilled), system availability (correct technical functioning) and privacy (extent to which the site protects customers' information); 2) E-RecS-QUAL, 11 items, three dimensions named responsiveness (effectiveness on dealing with problems), compensation (extent to which the site compensates the customer for problems), contact (availability of assistance services) applied to customers who had sporadic relation to websites services (PARASURAMAN et $a l ., 2005)$. In their point of view e-services are different in nature from offline services; so adapting a regular services quality scale would not be effective. Perceptions of online services is affected by the interactions occurred during the service experience and also by postinteraction services. A previous qualitative study revealed 11 dimensions which define a website attributes: reliability; responsiveness; access; flexibility; ease to navigate; efficiency; assurance; privacy; price knowledge; site appearance; customization (PARASURAMAN et $a l ., 2005)$.

Initially 121 items were created in order to measure those 11 dimensions. Insights from a focus group with target customers (people who used online stores for three months and had made three purchases during that period) led to the exclusion of some items (113 items were maintained) and to the decision of using a 5 point Likert scale. The refined scale was administered and obtained a sample of 549 customers. Confirmatory factor analysis and reliability analysis were conducted and the authors refined the instrument to a version with 22 items divided in the four dimensions already mentioned. Since many customers had not used 
recovery services, such as returning goods, exchanging goods, help to solve a problem etc., a second scale was created to measure the quality of this modality (E-RecS-QUAL). This scale has 11 items in three dimensions. For both scales reliability was satisfactory (Alpha for E-SQUAL ranging from 0.83 to 0.94 ; Alpha for E-RecS-QUAL ranging from 0.77 to 0.88 ) as well as factor analysis indices. The instrument also measured overall quality and overall value of the site. They found both scales correlate positively with overall quality and value (PARASURAMAN et al., 2005).

\subsubsection{SERVPERF}

Cronin and Taylor (1992), as commented on the previous item, criticized SERVQUAL scale (PARASURAMAN et al., 1988) and proposed an alternative instrument named SERVPERF. As already mentioned they suggested the gap approach for measuring quality is inappropriate, since in their opinion, there is no empirical evidence that perception gap is basis for perceived quality, which makes a pure performance approach more effective (CRONIN; TAYLOR, 1992).

Their research focused on trying different approaches for measuring services quality; they used SERVQUAL 22 items and conducted four different analysis (CRONIN; TAYLOR, 1992):

1) Services quality $=$ performance - expectation

2) Services quality $=$ importance $*$ (performance - expectation)

3) Service quality $=$ performance

4) Service quality $=$ importance $*$ performance

With this study they aimed to prove an unweighted performance approach is more appropriate to measure services quality. This unweighted approach is denominated SERVPERF. Data was collected from a 660 cases sample (from the industries: pest control, banking, dry cleaning and fast food) and it was used SERVQUAL instrument including expectations and performance questions with addition of adapted questions to measure perceived importance of each variable. Results showed the five dimensions from the original scale were not confirmed 
to that sample; so a unidimensional solution was tried and obtained satisfactory reliability (CRONIN; TAYLOR, 1992).

In addition, they found, through regression analysis, the unweighted SERVPERF solution explained more variance than the other possible approaches (Extracted variation for SERVPERF: bank $=41.1 \%$; pest control $=57.5 \%$; dry cleaning $=42.6 \%$; fast food $=29.1 \%$; Rsquare for SERVPERF: bank=47.9\%; pest control=38.8\%; dry cleaning=44.7\%; fast food $=47.6 \%)($ CRONIN; TAYLOR, 1992).

The authors also investigated the relations across quality, satisfaction and purchase intention (loyalty). They found service quality has a significant effect on satisfaction; satisfaction has a significant effect on purchase intentions; service quality does not have a significant effect on purchase intention (CRONIN; TAYLOR, 1992).

In 1994 Cronin and Taylor published another paper responding to critiques posted by Parasuraman, Zeithaml and Berry earlier on that year (they had criticized performance based approach and the goodness of the model obtained by Cronin and Taylor in 1992). In this work Cronin and Taylor (1994) clarify: 1) studying customer's expectations is relevant; 2) defining quality as the difference between expectations and performance is not appropriate on their point of view; 3) satisfaction has a stronger influence on loyalty than service quality. In this sense, they reinforce those findings obtained in 1992 and conclude performance and unidimensional approach seems to be a more adequate way to measure quality in services (CRONIN; TAYLOR, 1994).

\subsubsection{Service quality gap models}

Parasuraman et al. (1985) started research about quality in services, since they have specific and different characteristics if compared to products, as discussed earlier in this chapter. As a result, they found out there were gaps between executives perceptions about quality and consumers' perceptions about the same service quality, which gave rise to a five gap model, presented in Figure 13. 


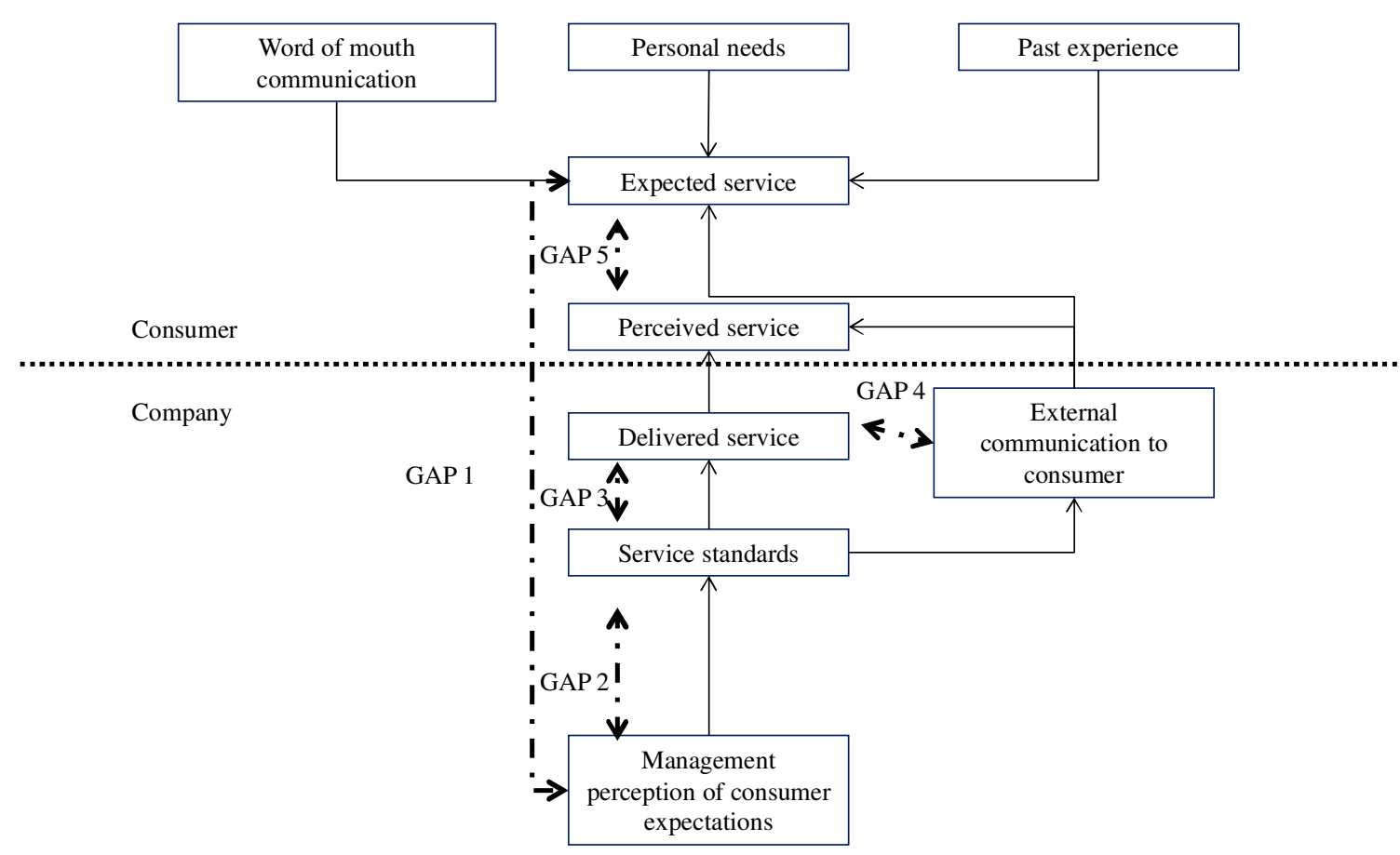

Figure 13. Parasuraman et al. (1985) Five-gap model

Source: Parasuraman et al. (1985, p.44)

Gap 1 indicates de different perceptions between managers and clients, that is, managers may misunderstand the attributes valued by their consumers, which should define the services characteristics. This gap may reduce the quality perception, as the services provided do not meet clients' needs (PARASURAMAN et al., 1985).

Gap 2 concerns the difference between managers' perceptions about consumer's needs and the services real specifications. This gap results from the difficulty on providing services which match the consumers' expectations in many dimensions (PARASURAMAN et al., 1985).

Gap 3 concerns the difference between services specifications and what is actually delivered. Even when the services attributes are clear and match consumers' expectations, it is not guarantee a high quality service will be performed, since employees behavior strongly impacts the service and, as a consequence, the consumer's perception of quality (PARASURAMAN et al., 1985). 
Gap 4 deals with the difference between the service delivered and what was communicated about the service. Communication at the media creates expectation; when the company communicates more than it can really deliver, gap 4 takes place. In this sense, company should communicate its efforts to serve consumers appropriately and meet consumers' needs, since it makes clients perceive the service in a more favorable way (PARASURAMAN et al., 1985).

Finally, gap 5 concerns the difference between consumers' expectations about the service and their real perceptions regarding the service delivered. Then, a service which exceeds consumers' expectations causes a favorable quality perception and a service which does not meet clients' expectations, causes frustration and an unfavorable quality perception (PARASURAMAN et al., 1985). Gap 5 is a function of the other four gaps (LUK; LAYTON, 2002); that is, each gap impacts on service quality; then consumers' quality perception is a function of the gaps 1, 2, 3 and 4 .

In 1988 Zeithaml et al. (1988) published a paper that extends the original five-gap model presenting variables and services attributes that define each gap. Since gap 1 measures the discrepancy between consumer's expectations and the managers' perceptions of these expectations, variables that measure this relation may be (ZEITHAML et al., 1988):

- Marketing research orientation: amount of marketing research conducted by the organization; extent to which research data is applied; degree to which marketing research focuses on service quality issues and the level of interaction between the managers and the organization's customers.

- Upward communication: level of communication between employees and managers; level of communication between contact personnel and managers and how this information is used.

- Levels of management: number of layers between contact personnel and managers may make difficult communication.

Gap 2 (difference between managers' perceptions of customer's expectations and services specifications) is a function of (ZEITHAML et al., 1988): 
- Management commitment to service quality: amount of resources and policies that show commitment to quality; existence of internal quality programs; management perception of recognition to quality commitment.

- Goal-setting: formal process for quality goals creation.

- Task standardization: use of technology in order to standardize the operation as much as possible.

- Perception of feasibility: extent to which managers feel customer's expectations can be met; adoption of systems that help meeting specifications.

Gap 3 (difference between specifications and the service delivered) is a function of (ZEITHAML et al., 1988):

- Teamwork: extent to which employees see their peers as customers; extent to which contact staff feels managers care for them; extent to which contact staff feels they cooperate with the organization and other departments; extent to which employees feel committed to the organization.

- Employee job fit: ability to perform the tasks; effectiveness of selection process.

- Technology job fit: adequacy of technologies employed to perform the tasks.

- Perceived control: extent to which employees feel they control their jobs; extent to which contact staff feels they have flexibility to deal with the consumers; extent to which demand is predictable.

- Supervisory control systems: extent to which employees' whole performance is assessed (not only quantitative results). 
- Role conflict: conflict between customer's expectations and organization's expectations; existence of management policies that do not match services specifications.

- Role ambiguity: perceived quality of goals and expectations (quality of downward communication, feedback); perceived level of competence and confidence (training programs).

Gap 4 (difference between delivered service and external communications) is a relationship of (ZEITHAML et al., 1988):

- Horizontal communication: extent to which inputs from operation personnel are taken into account for advertising planning and execution; extent to which contact personnel is aware of external communications; level of communication between contact and operation employees; standardized procedures across different departments.

- Propensity to overpromise: extent to which the organization feels its competitors overpromise.

Finally, gap 5 is a function of the first four gaps, and is measured through SERVQUAL five dimensions (assurance, reliability, empathy, responsiveness and tangibles). The extended model is presented by Figure 14 and, as recommended by the authors, a structural equation model may be employed to evaluate the results (ZEITHAML et al., 1988). 


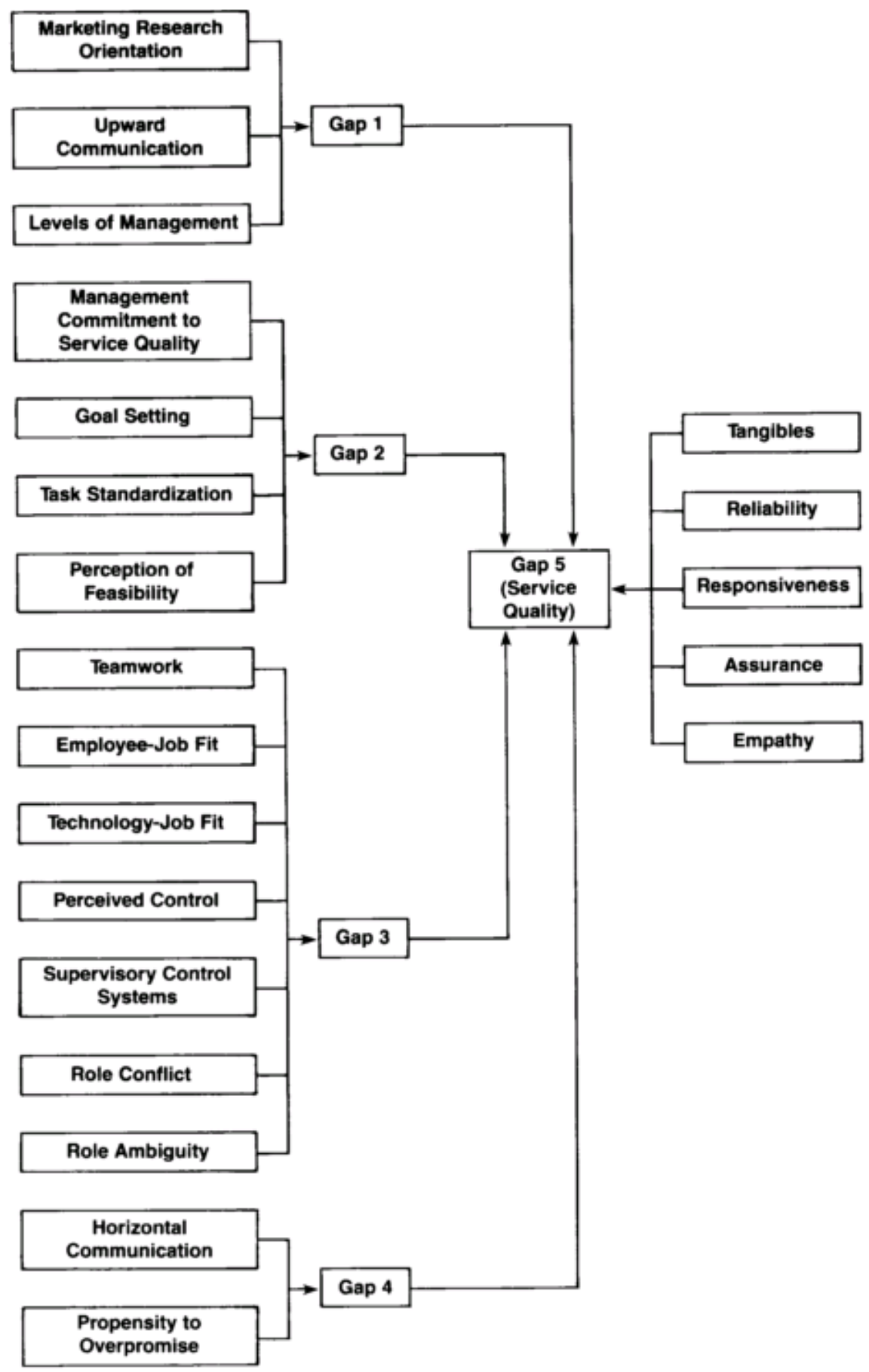

Figure 14. Extended model for service quality (ZEITHAML et al., 1988)

Source: (ZEITHAML et al., 1988, p.46)

Luk and Layton (2002) proposed two additional gaps to Parasuraman et al. (1985) model. In their approach, employees impact significantly on the consumers' perceptions of quality; thus employees' perceptions about consumers' expectations was included in the model and 
generated the additional gaps 6 and 7 (Figure 15). Gap 6 measures the difference between employee's perceptions about consumer expectations and consumer's real expectations regarding the service. Gap 7 concerns the difference between manager's perceptions about consumers' expectations and the employees' perceptions about customer's expectations (LUK; LAYTON, 2002).

In order to evaluate the modified model, the authors applied the proposed version to a room service. They applied an adapted version of SERVQUAL which comprehended 24 items, to three different samples of room services providers (51 employees), managers (21 managers) and guests (108 guests), including expectations and real perceptions of the service (as recommended by the original model by Parasuraman et al. (1985)) (LUK; LAYTON, 2002).

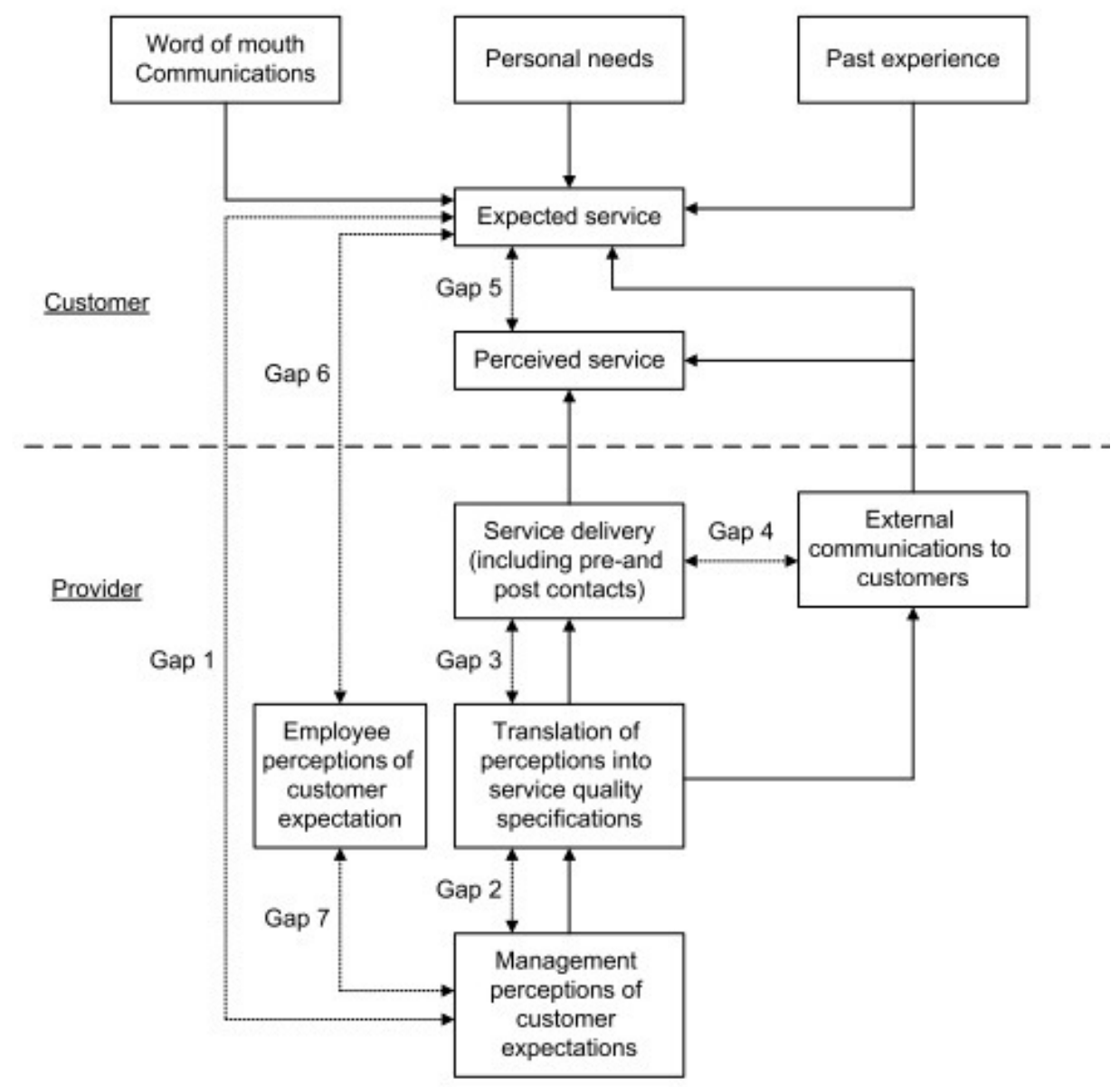

Figure 15. Seven-gap Model

Source: Luk and Layton (2002, p.113) 
Shanin and Samea (2010), in turn, came with a modified model which adds new gaps to the original framework developed by Parasuraman et al. (1985) and already modified by Luk and Layton in 2002 (SHAHIN; SAMEA, 2010). Changes concern the following aspects (SHAHIN; SAMEA, 2010):

- ideal standards;

- management perceptions of consumers perceptions;

- employees perceptions of customer perceptions;

- service quality strategy and policies;

- translation of strategy and policies into service quality specifications.

The new gaps proposed were submitted to 16 experts in order to acquire their opinions. The authors found most of the researchers agreed to the new model proposed, which includes five new variables and eight new gaps to the original model. Organizational strategy and policies are added to the model, since these elements guide people inside the company, define how the organization positions itself in the market and how it defines quality (SHAHIN; SAMEA, 2010). This means a company which does not own a service quality strategy will not be able to offer costumer oriented services; then problems to communicate strategy leads to a service quality gap (gap 2) (SHAHIN; SAMEA, 2010).

In addition, it is worth to remember quality strategies will be effective if they are properly translated into service specifications; when companies fail in this process another quality gap takes place (gap 3). Shahin and Samea (2010) also point out that costumers usually create an ideal standard level in their minds, which they expect the service to meet. When the specifications of the service provided do not meet these mental standards, gap 4 takes place (SHAHIN; SAMEA, 2010).

External communications are relevant to acquire costumers' opinions about services standards they value and then develop service specifications and also to communicate and persuade consumers about already existent services specifications. When the organization fails to communicate its specifications, gap 5 happens (SHAHIN; SAMEA, 2010). 
Sometimes managers fail to understand customer's expectations which leads to gap 1, but they may also have problems to comprehend consumers real perceptions of the service consumed which leads to gap 11 (SHAHIN; SAMEA, 2010).

In this sense, manager's perceptions of consumer's actual perceptions of the service are useful in order to define or correct strategies and policies. However, when consumer's perceptions are not properly understood, gap 12 occurs (SHAHIN; SAMEA, 2010).

As well as Luk and Layton (2002), Shahin and Samea (2010) also consider employees important on the service delivery process. Then, when employees fail to comprehend consumers' perceptions of the provided service, gap 13 happens. In synthesis, the new model included gaps $2,3,4,5,11,12,13$ and 14; however, it is important to say the model was not applied to a real data basis; so it is necessary to validate it in order to evaluate its accuracy (SHAHIN; SAMEA, 2010).

The 14 gaps are summarized below and can be observed on Figure 16.

- Gap 1: difference between employees' perceptions of customer's perceptions and the service delivered.

- Gap 2: difference between management perception of customer expectations and quality strategy.

- Gap 3: difference between quality strategy and service quality specifications.

- Gap 4: difference between costumer's ideal standards and services actual specifications.

- Gap 5: difference between external communications and services specifications.

- Gap 6: difference between service specification and service delivered.

- Gap 7: difference between external communication and service delivered.

- Gap 8: difference between expected service and perceived service.

- Gap 9: difference between expected service and employees' perceptions of customer's expectations.

- Gap 10: difference between employees' perceptions of consumer's expectations and management perceptions of customers' expectations.

- Gap 11: difference between consumer's perceptions of the service and manager's perceptions of customer's perceptions. 
- Gap 12: difference between managers' perceptions of customer's perceptions and service strategy.

- Gap 13: difference between customer's perceptions about the service and employees' perceptions about customers' perceptions.

- Gap 14: difference between management perceptions of customer's perceptions and employees' perceptions of customer's perceptions.

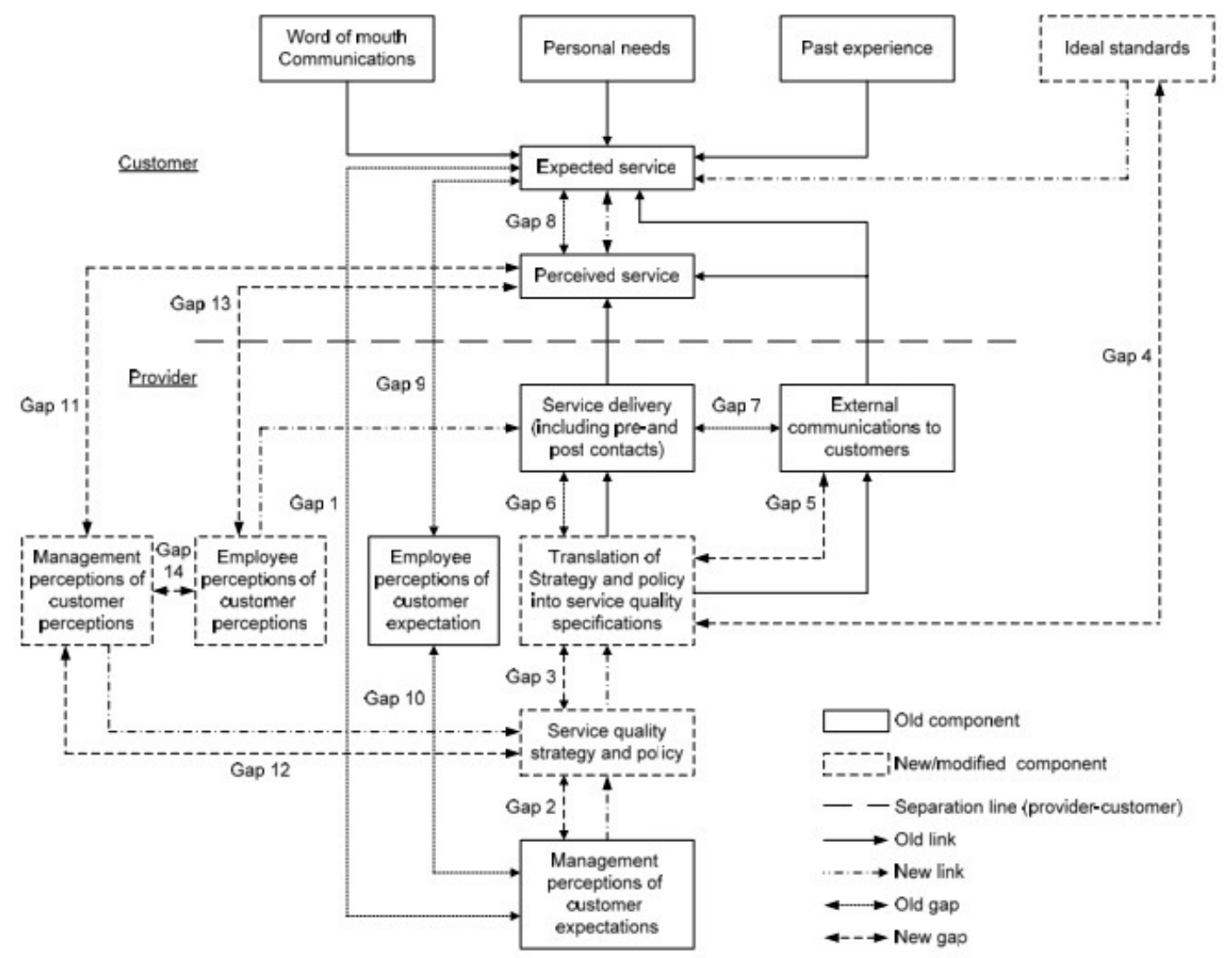

Figure 16. 14 Gap model

Source: (SHAHIN; SAMEA, 2010, p.11)

\subsubsection{Satisfaction}

There is no consensus regarding the definition of satisfaction among the researchers in the field (ROJAS-MÉNDEZ et al., 2009). Nevertheless, every author proposes a definition that is appropriate for his/her research objectives. Nesset and Helgesen (2009) define satisfaction as the customer's total experience with a product/service/company, which means, satisfaction 
results from the utility perception about the object. It is an individual judgment, in which the customer compares his/her experience with the product/service and his/her initial expectations. In education, satisfaction can be seen as the student attitude toward the course, which resulted from the evaluation of the experience with the educational service (NESSET; HELGESEN, 2009). In their model, Nesset and Helgesen (2009) consider satisfaction influences positively student loyalty and, as a consequence, business (institution and course) performance. In addition, the authors propose that positive and negative feelings concerning the educational object influences satisfaction, positively and negatively respectively (NESSET; HELGESEN, 2009).

Udo et al. (2011) define satisfaction as a customer's response to received service, the degree to which a consumer believes the provided service may lead to positive feelings. Their study in online education considers satisfaction is associated to student perceived quality and, in turn is related to student retention (UDO et al., 2011). Gruber et al. (2010) define student satisfaction as the evaluation of the learning experience and propose a satisfied student may help attract new students through word of mouth communication and may take another course from the same institution (loyalty behavior) (GRUBER et al., 2010).

In order to create a satisfaction measurement scale, Gruber et al. (2010) proposed 15 dimensions (based on literature review) covering educational services which influences student experience: administrative and student services; atmosphere among students; attractiveness of surrounding city; computer equipment; courses; library; lecturers; lecture theaters; cafeteria; relevance of teaching to practice; reputation of the university; school placements; support from lecturers; presentation of information and university buildings (GRUBER et al., 2010).

Two samples of students were extracted (374 students for pilot study; 544 students for main study) from a German university. For both the pilot and the main studies, students were more satisfied with "school placements", while their main dissatisfaction was due to "lecture theaters" and "university buildings". When correlations between overall satisfaction and each dimension were analyzed, the authors found "positive outlook on life" did not correlate to overall satisfaction on the pilot study. Regression analysis showed R-square $=44 \%$ (pilot) and $53 \%$ (main), which they considered satisfying indices. For the pilot study "relevance to practice", "lecturer support", "presentation of information", "courses", "lecturer theaters" and 
"number of semesters" influence significantly satisfaction. For the main study, "lecturers", "university buildings", "relevance to practice", "presentation of information", "courses", "reputation", "lecture theaters" and "number of semesters" influenced general satisfaction (GRUBER et al., 2010).

Satisfaction is also influenced by personal and situational characteristics, such as student performance (GRUBER et al., 2010), and should be observed. For this reason, this dissertation included a variable in order to measure students' expectations of performance.

Bloemer and Ruyter (1998) define satisfaction as an evaluation process comparing expectations and perceived performance of a service. The evaluation process may be more or less structured depending on the customer's ability to evaluate and his/her awareness regarding his/her expectations. For this reason, satisfaction is considered in a continuum; on one side there is conscious and high elaborated satisfaction and on the other side there is latent satisfaction (customer is no conscious of his/her satisfaction, since he/she is not able or motivated to evaluate a service) (BLOEMER; RUYTER, 1998).

Luk and Layton (2002) consider satisfaction feeling happens when the customer compares his/her initial expectations about the service and his/her real experience with the service. For them, quality perception determines satisfaction (LUK; LAYTON, 2002).

In their turn, Rojas-Méndez et al. (2009) define satisfaction as a cumulative construct that includes satisfaction with specific products/services and other characteristics of the company such as infrastructure, staff etc. In their point of view satisfaction derives from trust, since the latest is a predictor of future intentions. In education, trust is defined as the confidence student has on the institution integrity and reliability, and it is built through the experience student lives at school. Similarly, commitment is considered a mediator between satisfaction and actual behavior, and may be characterized as the involvement between the student and the institution, both academically and socially. Satisfaction is the first dimension to emerge (short-term), followed by trust (medium-term) and commitment (long-term) (ROJASMÉNDEZ et al., 2009).

Kenney and Khanfar (2009) describe satisfaction as the situation in which the customer has his/her expectations met; and when it happens, there is a higher probability he/she will 
perform a repurchase. When expectations are not met, client is more likely to engage in switching behaviors. Sometimes, nevertheless, satisfied customers may dropout, which raises a challenge to managers; in other words, although satisfaction is correlated to repurchase intention, it is not the only cause to this intention (KENNEY; KHANFAR, 2009).

Bowden (2011) adds satisfaction as an overall emotional and cognitive evaluation of the services consumed; then highly satisfied customers indicate the organization meets the standards promised and the customer trusts on the organization's reputation (BOWDEN, 2011).

Specifically in educational field, student's satisfaction is related to the quality of the course design, instructors' performance and the relationship among the classmates. In their research, Kuo and Ye (2009) consider training program student's satisfaction as a construct of five attributes, namely curriculum content, classroom climate, pricing, access to facilities and infrastructure (KUO; YE, 2009). These authors, finally, point out that on the matter of education, student satisfaction is crucial to maintain a solid relationship between the HEI and the student and to enhance learning. In order to increase satisfaction, they suggest the offer of high quality services and the adequate promotion of institution image; both will impact in student satisfaction and, in consequence in student loyalty and retention (KUO; YE, 2009). Bowden (2011) reinforces Kuo and Ye (2009) argumentation, saying that fostering student satisfaction is relevant since it is strongly related to positive recommendation to other people and to the willingness to take another course from the same institution (loyalty) (BOWDEN, 2011). In addition, as satisfaction is considered a strong predictor to loyalty, HEI should ensure they have a deep and clear understanding of student's expectations and needs before they enroll a course; so managers would have more information to plan activities and create value to students (BOWDEN, 2011).

For Vander Schee (2011) satisfaction is analyzed in individual level; it means for each course or discipline student takes; in opposition loyalty is built based on the overall college experience. Thus satisfaction is obtained in the short-term and loyalty is a long-term construct (VANDER SCHEE, 2011).

Brown and Mazzarol (2009) considered student satisfaction has two different components, evaluative and emotional. Evaluative satisfaction considers student's perceptions regarding 
how wise his/her decision of choosing that institution was or how right this decision feels. Emotional component considers student interests, enjoyment and surprise about the course (BROWN; MAZZAROL, 2009).

Letcher and Neves (2010) studied business senior students from American institutions. They applied a survey instrument named "Undergraduate Business Exit Assessment" which aims to assess students' opinions about their course in the moment of graduation. They collected 1,212 responses. Factor analysis found the following dimensions: self-confidence; curriculum, instruction and classes; teaching; extra-curricular activities and career opportunities; advising; feedback quality; technology and equipment; interaction with peers (LETCHER; NEVES, 2010). Regression analysis showed self-confidence; extra-curricular activities and teaching quality are the significant predictors for senior students satisfaction in the American case (LETCHER; NEVES, 2010).

A literature review study conducted by Sinclaire (2011) showed potential dimensions to determine student satisfaction in online education: 1) interaction with colleagues and instructors; 2) comparison between expected and real learning experience; 3) advising, registration and access to materials ; 4) guidance to study online; 5) perceived outcomes that are useful to career and human development (SINCLAIRE, 2011). He summarizes his findings proposing student satisfaction in a distance context will be determined by levels of interaction, communication, as well as course design, learning environment, technology selfefficacy; time management (SINCLAIRE, 2011).

Hunter (2011) considers student satisfaction in online education can be enhanced by the way the instructors use technology in the course. She points three kinds of influence strategies, namely soft, rational and strong. Soft influence happens when instructor creates empathy with students; for instance, female instructors are found to be more empathic than male. Strong influence consists on coercive or punishment behavior. Rational influence consists on the quality of the explanations and interactions in class. All these three kinds of power influence satisfaction, but only soft and rational influence affect positively student satisfaction in online environment (HUNTER, 2011). It means, from this study contribution, instructors learning strategies and behaviors are important on defining and understanding student satisfaction in online education. 
Maceli et al. (2011) studied how gender influences students' satisfaction on learning environment. These authors point out women and men have different learning needs and ways to express themselves (i.e. women are more verbal; men are more visual); then it is reasonable to consider student satisfaction is also influenced by gender. Besides the students' gender, student satisfaction is also influenced by instructors' gender (MACELI et al., 2011).

Their empirical research considered a sample of 328 students ( $40 \%$ female) from a business college of a university in the USA and aimed to study student satisfaction with their teachers. Results showed both men and women were lowly satisfied with instructors; t-test showed men were less satisfied then women. In addition, instructors' gender was found to be more important to female students than for male (MACELI et al., 2011).

\subsubsection{Loyalty and attrition rates}

Higher education institutions are becoming more market-oriented, which makes student loyalty an important business strategy variable, as it helps them deal with an increasing student mobility, an increasing global competition and scarce resources (NESSET; HELGESEN, 2009). In order to deal with an increasingly competitive market, managers must create programs to promote, develop and maintain successful long-term relationship with current and former students. Such programs should have a deep understanding of how these relationships are formed and nourished in an educational context (ROJAS-MÉNDEZ et al., 2009).

Loyalty concept emerged from services marketing literature and are still poorly explored in the educational field (BOWDEN, 2011). Sudhahar et al. (2006) define loyalty as the development and maintenance of a long term relationship with customers, which gives the company sustainable competitive advantage. For these authors, loyalty is obtained through the interaction between attitudes toward a company's product/service and the willingness to consume that product/service continuously; it means loyalty is composed by attitudes, behavior and cognitive factors (SUDHAHAR et al., 2006). Similarly, Rojas-Méndez et al. (2009) describe loyalty as an identifiable intention to behave a repurchase of a product/service/brand (ROJAS-MÉNDEZ et al., 2009). 
Sudhahar et al. (2006) developed a loyalty measurement scale named SERVLOYAL which includes seven dimensions: behavioral (disposition of recommending the company, purchasing new products/services, word of mouth), attitudinal (disposition in keep business with the organization even if there is price raise or service change), cognitive (long-term relationship, consider the organization superior over the competitors, keep business exclusively with the organization), conative (organization superiority over the competitors), affective (satisfaction with the services consumed), trust (empathy with the organization and its staff) and commitment. The scale was applied to a sample of 137 bank clients and obtained high reliability (Cronbach's Alpha >0.8) (SUDHAHAR et al., 2006). Although SERVLOYAL was conceived for banking services, it can be applied to other nature services, like education.

Zeithaml et al. (1996) defined behavioral intentions in five different dimensions: loyalty (say positive things about the service; recommend the service; consider the service as the first choice); switch (intention to do more or less business with the provider; do business with the provider's competitors); pay more (willingness to pay a little more to stay with that provider); external response (switch to a competitor if one has a problem with the current provider; in case of problems willingness to complain to friends and external agencies); internal response (complain to the provider staff in case of problems) (ZEITHAML et al., 1996).

Bloemer and Ruyter (1998) studied loyalty to retail stores and in their perspective, loyalty is strongly defined by commitment. The commitment relation happens in a continuum; on one side there are highly loyal customers, who are truly committed and on the other side are the spuriously loyal customers whose repeated store visit is not based on commitment to the organization or the brand (BLOEMER; RUYTER, 1998). These considerations make loyalty definition and study important and complex.

Bloemer, Ruyter and Wetzels (1998) consider loyalty in services industry is a multidimensional variable, affected by behavior (repurchase action), attitudes (willingness to recommend the service to other people) and cognition (the customer's first choice among a set of possible alternatives) (BLOEMER; RUYTER; WETZELS, 1998). They considered in their study, SERVQUAL dimensions in order to measure quality perception and word of mouth, price sensitivity, complaining behavior and purchase intention as loyalty dimensions. Data was collected from four different industries (entertainment, fast food, supermarket, health 
care) totalizing 708 cases. They found quality dimensions relate differently to loyalty components depending on the industry studied; for example, for entertainment industry purchase intention is affected by reliability, responsiveness and tangibles; for fast food it is influenced by assurance and empathy (BLOEMER; RUYTER; WETZELS, 1998). These findings reinforce the importance of studying different kinds of services industries such as education which owns specific characteristics.

It seems reasonable that satisfied customers become loyal and, loyal people are more likely to repurchase products/services. However, in fact these relationships are complex and not completely understood, since customer has his/her own cognitive process which impacts his/her perceptions of the products/services experienced (KENNEY; KHANFAR, 2009). In this sense, the authors consider satisfaction and loyalty to be influenced by diverse variables, such as demographic characteristics and culture (KENNEY; KHANFAR, 2009).

On the matter of the educational field loyalty can be understood as the retention of enrolled students as well as the relationship with former ones; it means loyalty concerns the relationship between students and institution during and after the study period (NESSET; HELGESEN, 2009; NICHOLS, 2010; BOWDEN, 2011; VANDER SCHEE, 2011) in a way current students will be retained until graduation and former students will be attracted back to the institution (ROJAS-MÉNDEZ et al., 2009). Student loyalty may be seen as a source of competitive advantage, since looking for new students has a higher cost than maintaining the current ones and the relationship development may be worth as the former students (alumni) may continue supporting the institution in many ways: word of mouth, financial offerings and job opportunities for current students (ROJAS-MÉNDEZ et al., 2009), as well as decreased relationship costs and less price sensitivity (KENNEY; KHANFAR, 2009). Vander Schee (2011) points out that investments on loyalty actions in higher education are justified by the long relationship and lifelong association with the students (VANDER SCHEE, 2011).

Nichols (2010) considers student retention is on both the institution and the student best interests, since economic costs as well as emotional costs may be high (dropping out may reduce student confidence and demotivate future educational initiatives) (NICHOLS, 2010).

For Bowden (2011), students play several roles during their time enrolled in an educational institution. They may assume a customer role since they are students and consume the 
institution's services and products; a supplier role, since they provide the university with financial resources; a donor role after graduation. For these reasons the relationship between student and institution may help the development of a positive image of the university in the market and deserves to be examined carefully (BOWDEN, 2011).

In addition, Kuo and Ye (2009) reinforce loyalty has two phases, short-term and long-term. The latest refers to solid relationships, while short-term concerns immediate relations; so customers will switch to another organization if that shows them any valuable advantages, or if the current organization provides them with unsatisfactory services/products repeatedly. For an educational organization, the authors comment some characteristics of loyalty: repurchase intentions, voluntary recommendation of the organization to other people, tolerance to price changes, frequency of purchase of services/products from the organization (KUO; YE, 2009).

Ueda and Nojima (2012) propose an additional characteristic of student loyalty to his/her university, namely university citizenship behavior (student commitment to his/her college). The authors attribute that commitment to some factors: student will be branded by the institution name after graduation; student spend a lot of time involved in academic activities, especially in face-to-face courses, they spend much time on campus and develop friendship relations (UEDA; NOJIMA, 2012). This vision of loyalty involves the voluntary promotion of the organization's interest (customer identifies him/herself to the organization); that is, customer stimulate his/her influence circle to purchase organization's products and services; cooperation, meaning helping the organization staff to provide high quality services; making constructive contributions. More specifically in education, student loyalty takes place, for example, when they recommend positively the institution to target candidates or when they do not bother classes with inappropriate behavior (UEDA; NOJIMA, 2012).

Bowden (2011) presents loyalty definition as a voluntary commitment; then loyalty is determined by satisfaction, trust and commitment. This approach is consistent to that applied by Rojas-Méndez et al. (2009). In addition, Bowden (2011) found that satisfaction and affective commitment are significant predictors of student loyalty. Affective commitment is considered important to quality perception as well. This means HEI should develop affective relationships with students, for example promoting an affiliation feeling, friendship and rapport climate (BOWDEN, 2011). Affective variables are important, because students face their interaction with an institution as a free will relationship rather than a purely relation of 
evaluating costs and switching. This study offers a new perspective to research of student's loyalty, since it highlights the significance of affective aspects when other studies reinforced rational aspects of student-institution relation (such as costs involved and advantages provided) (BOWDEN, 2011).

It is important to notice that students' performance (their grades and learning) cannot be comprehended through a customer lens, but their behavior can be examined from a consumer behavior perspective. Thus, students are considered customers of a higher education institution, since they consume educational services (ROJAS-MÉNDEZ et al., 2009).

Nesset and Helgesen (2009) recognize that it is not trivial, although useful, using services marketing dimensions in educational context. Loyalty is usually assumed as positively related to business performance, which reinforces the importance of studying its determinants and relationships to other marketing dimensions (NESSET; HELGESEN, 2009), such as satisfaction, perception of quality and image as proposed in the present dissertation.

Rojas-Méndez et al. (2009) propose in their study of loyalty in higher education that loyalty is determined by perception of service quality, satisfaction, trust and commitment. For them loyalty involves long-term relationships and these relationships start during school years (ROJAS-MÉNDEZ et al., 2009). Bowden (2011) also points out trust is a strong determinant of student loyalty, since it is the base for a long-term relationship which ensures education is not viewed as a commercial transaction (BOWDEN, 2011). Customers evaluate the advantages of entering or leaving a relationship; so successful loyalty programs must go farther than superficial promotional actions (i.e. offering gifts or discounts) (KENNEY; KHANFAR, 2009).

A controversial finding from Bowden (2011) research is that trust was not a significant predictor of loyalty in his sample. The author explains that education is a standard regularized kind of service with inherently owns a noble mission; it makes education a low risk service; then trust is not a strong variable for loyalty prediction (BOWDEN, 2011).

Kenney and Khanfar (2009) studied repurchase intention (a consequence from loyalty) on DE college students and argument that in the highly competitive market for distance education, even a little reduction on dropout may result in significant returns for the institution. In other 
words, Kenney and Khanfar (2009) relate student loyalty to decreasing attrition rates. Other antecedents to loyalty are image, trust, perceived quality and switching costs (KENNEY; KHANFAR, 2009).

Udo et al. (2011) studied behavioral intentions in e-learning and define this dimension as student's intentions to continue with the DE course. In their point of view, the more satisfying the learning experience, the greater is the chance student stays in the course (UDO et al., 2011).

It is worth to point out that satisfied customers may dropout and unsatisfied and non-loyal customers may engage on repurchase behavior. This contradiction brings a great challenge to managers and reinforces the relevance of loyalty studies, as policies to satisfy and enhance loyalty in clients may not be as effective as planned (KENNEY; KHANFAR, 2009).

Udo et al. (2011) still discuss there is no strong evidence in the literature to prove which construct causes loyalty (service quality or satisfaction) or even which of them causes the other (satisfaction $\rightarrow$ service quality or service quality $\rightarrow$ satisfaction); some authors even argument there is no cause relation between them (UDO et al., 2011). Despite of this controversy, the present dissertation will test this relation (service quality influences satisfaction and loyalty) as research hypotheses, which may be or not confirmed.

\subsubsection{Attrition}

Attrition concerns the number of students who do not complete their courses. However, it is difficult to measure dropout rates, since students may leave the course in different ways: enquiring about a course but not starting it; failing the course, transferring to another institution or leaving before finishing it (SIMPSON, 2003). Attrition may be seen as a failure, but, when it concerns DE, managers should evaluate it carefully, due to the specific characteristics and conditions faced by distance students (they are more affected by external variables than face-to-face students). It is worth to say that internal and external variables ${ }^{4}$ interact with each other; so a student with an external limitation is more likely to dropout

\footnotetext{
${ }^{4}$ Internal variables refer to course's characteristics; external variables concern problems not directly related to the course.
} 
when he/she faces an internal problem (i.e. a students with little time to study, will be more likely to dropout when they get no feedback from the instructors) (PARK; CHOI, 2009).

For Tinto (1982) attrition may not be completely controlled by the institutions, as students enter a HEI owning a set of interests, abilities, skills, values and commitments, but these sets are not always sufficient to take the individual to complete his/her course. Sometimes, one may not have appropriate skills, commitment or interest in finishing a higher education degree and in these cases, institution cannot intervene effectively (TINTO, 1982).

In order to study attrition, two main questions should be answered: who dropout and why. Park and Choi (2009) mention high dropout rates as a concerning problem for organizations which provide online education; that is, schools face difficulty retaining online students (PARK; CHOI, 2009). Simpson (2003) proposes some variables that may be observed and which are related to attrition rates: level of the course, credit rating of the course, previous educational level, age, gender, term-time job hours, financial worries, family responsibilities, course area (social sciences, arts, education, mathematics, health etc.), courses enrolled. Other more qualitative factors can also influence attrition, such as intelligence, learning skills, organizational skills (time management and personal issues control), emotional skills (dealing with stress, motivation, self-confidence, personality, attitudes etc.). These questions may be assessed through a survey, but the accuracy of the results depends on the student ability and disposition to answer it properly (SIMPSON, 2003). Tinto (1988) asserts time is an important variable on studying attrition, since it is usually higher in the first year of college; in addition, dropout in the beginning of the course has different reasons comparing with dropout that happens later in the course (TINTO, 1988); probability of leaving the course decreases as the course progresses (GUTTMAN; OLKIN, 1989).

Vander Schee (2011) highlights the importance of providing an appropriate first semester experience, since attrition happens mostly in the beginning of the course. For him the longer a student stays in the institution the lower is the probability of dropping out. This is because the higher the investment on time and efforts, the higher is the intention to conclude the degree (VANDER SCHEE, 2011).

An adequate first semester experience is not only related to classroom activities, but also extra activities and socialization opportunities. These factors help students to feel connected and 
build high quality relationships. In order to guarantee satisfying relationships, institution should pay attention to instructors and staff relations with students. Students will be more engaged if they feel unique and valued by teachers and employees in the institution. Finally, the author points out a good semester experience impacts quality perception and satisfaction (VANDER SCHEE, 2011).

Park and Choi (2009) research considered three dimensions in order to study attrition: individual characteristics (age, gender, educational background, employment status) external factors (family support and organizational support) and internal factors (motivation; social and academic integration and technology usability issues) (PARK; CHOI, 2009). Their sample of 147 students (33.3\% had dropped out online courses; $66.7 \%$ completed the course) found, as a result, dropped out students and persistent students have different perceptions about organizational and family support. Thus, they showed different levels of motivation in terms of satisfaction and perceived relevance (PARK; CHOI, 2009). Logistic regression was run in order to determine whether individual characteristics and motivation could predict dropout behavior; as a result the model showed that student's perception of organizational support and course's relevance are determinants to dropout in online education; meaning there's a higher probability of attrition when students do not perceive a high level of support from his/her organization and when the course is not related to his/her personal interests. Individual characteristics did not result a significant influence on the dropout decision. External factors have a strong influence on attrition once the course is in progress; this fact must be taken into account by managers and instructors, since these variables may lead to student interruption and are difficult to control. A simple way to reduce external variables effects is to provide additional support for students if needed. Finally increasing satisfaction is an effective way to reduce or prevent dropout; it can be done by providing materials that make the content meaningful and applicable to real life (PARK; CHOI, 2009).

Aitkens (1982) proposes student attrition is a function of a set of variables related to his/her learning experience: student satisfaction with academic program; student satisfaction with living environment; student performance; level of involvement on extra-curricular activities; external factor. He points out student performance has a strong influence on attrition (AITKEN, 1982). 
Nichols (2010) points that colleague and instructor presence is important to retention. He also comments some common reasons for attrition in DE students (found in his study with New Zealand students): course workload, increase in personal or professional activities, difficulties in time management and life changes. Then it is important the institution to have clear information of students' characteristics and technology skills before enrollment (NICHOLS, 2010). The author also gives some reasons pointed by students for successful completion: financial reasons (student did not want to waste resources); the course was worth to be completed; materials kept student interest; personal determination; interaction with colleagues and instructors; family and classmate support; friendly institutional contacts (encouraging email and phone calls) (NICHOLS, 2010).

Finally Nichols' study suggests support services are "hygiene factors" in DE; it means, when they are not offered there is a negative effect on student's perceptions of the course; but, when they are offered, they are not always used by students and attrition is not attributed to them (NICHOLS, 2010).

It is important to accept that some students will dropout, for many reasons, such as change of aspirations and circumstances (NICHOLS, 2010). When asked about what could be done to avoid dropping out, students listed some measures: improve teaching quality; offer detailed feedback; offer exam support; stimulate more empathy from institution's staff; provide additional resources (contents and structure); offer clearer instructions about what is required and expected in assignments; offer clearer course's description; reduce the workload (SIMPSON, 2003); instructors relationship development may also improve retention (NICHOLS, 2010).

Simpson (2003) also exposes the relation between course's recruitment (process by which students are attracted to the institution) and dropout rates. For him, the more successful the recruitment process, the greater is the dropout probability, since, the first, in order to sell the course, may communicate course's characteristics and required skills inappropriately (SIMPSON, 2003).

Simpson (2003) suggests the model Attention-Relevance-Confidence-Satisfaction (ARCS) as an approach to increase retention in distance education. Attention refers to keeping student's attention and interest to the course, which is possible, providing intriguing contents, well 
planned interaction and motivating activities. Relevance considers the extension to which the course meets student's personal needs, future goals and social environment. Confidence concerns student's self-efficiency (high expectation of success takes to higher performance, motivation and confidence). Satisfaction is the comparison between student's outcomes and expectations regarding the course. According to this approach, interaction and motivational messages are crucial for DE success (SIMPSON, 2003). Simpson (2003) proposes some actions to reduce dropout, as presented by Table 5 .

Table 5. System for increasing retention

\begin{tabular}{|c|c|c|c|}
\hline Stage & $\begin{array}{l}\text { Importance in terms } \\
\text { of retention }\end{array}$ & Activity & Effectiveness \\
\hline \multirow[t]{5}{*}{ Integration (pre-course) } & \multirow{5}{*}{$\begin{array}{l}\text { There is some evidence } \\
\text { that the pre-course } \\
\text { period is by far the } \\
\text { most important in } \\
\text { terms of retention }\end{array}$} & $\begin{array}{l}\text { Pre-course individual } \\
\text { contact possibly by } \\
\text { phone }\end{array}$ & $\begin{array}{l}\text { High. There is very } \\
\text { little self-selection } \\
\text { effect, so it reaches the } \\
\text { 'quiet students' }\end{array}$ \\
\hline & & Preparatory work & $\begin{array}{l}\text { High but unclear how } \\
\text { far this is due to 'self- } \\
\text { selection' }\end{array}$ \\
\hline & & $\begin{array}{l}\text { Mentoring of new } \\
\text { students by existing } \\
\text { students }\end{array}$ & $\begin{array}{l}\text { High but also some } \\
\text { evidence of 'self- } \\
\text { selection' }\end{array}$ \\
\hline & & $\begin{array}{l}\text { Peer and mentoring of } \\
\text { support online. } \\
\text { Conferencing }\end{array}$ & $\begin{array}{l}\text { This could be high if } \\
\text { the effectiveness is } \\
\text { similar to mentoring }\end{array}$ \\
\hline & & $\begin{array}{l}\text { Family and friends } \\
\text { support. Employer } \\
\text { support }\end{array}$ & $\begin{array}{l}\text { There is evidence that } \\
\text { family and friends } \\
\text { support is the most } \\
\text { valued by students but } \\
\text { the retention effect is } \\
\text { very difficult to assess }\end{array}$ \\
\hline \multirow[t]{3}{*}{$\begin{array}{l}\text { Course choice (pre- } \\
\text { course) }\end{array}$} & \multirow[t]{3}{*}{$\begin{array}{l}\text { Considerable evidence } \\
\text { that this is critically } \\
\text { important in retention } \\
\text { in full-time education; } \\
\text { little is known } \\
\text { regarding its } \\
\text { importance in DE }\end{array}$} & $\begin{array}{l}\text { Self-diagnostic } \\
\text { materials - course - } \\
\text { and knowledge - } \\
\text { related }\end{array}$ & $\begin{array}{l}\text { Only likely to be } \\
\text { successful for } \\
\text { mathematics, science, } \\
\text { technology, language } \\
\text { and computing? Less } \\
\text { easy for arts; social } \\
\text { sciences etc. Evidence } \\
\text { of effectiveness not } \\
\text { very clear in science } \\
\text { courses }\end{array}$ \\
\hline & & $\begin{array}{l}\text { Self-diagnostic } \\
\text { materials - aptitude - } \\
\text { or circumstance-related }\end{array}$ & $\begin{array}{l}\text { There is not much } \\
\text { evidence of } \\
\text { effectiveness in DE, } \\
\text { although they have } \\
\text { been used in full-time } \\
\text { learning with some } \\
\text { success with a tutor as } \\
\text { a mediator }\end{array}$ \\
\hline & & Course previews & There is some evidence \\
\hline
\end{tabular}




\begin{tabular}{|c|c|c|c|}
\hline Stage & $\begin{array}{l}\text { Importance in terms } \\
\text { of retention }\end{array}$ & Activity & Effectiveness \\
\hline & & & $\begin{array}{l}\text { that previews do } \\
\text { change students' } \\
\text { choices. There is no } \\
\text { evidence that the } \\
\text { students are unduly put } \\
\text { off such materials }\end{array}$ \\
\hline & & $\begin{array}{l}\text { Other students' views } \\
\text { of courses }\end{array}$ & $\begin{array}{l}\text { The evidence is that } \\
\text { such views are popular } \\
\text { with new students but } \\
\text { there has been no study } \\
\text { yet to detect course } \\
\text { changes as a result }\end{array}$ \\
\hline & & $\begin{array}{l}\text { Direct advice by phone, } \\
\text { letter or email }\end{array}$ & $\begin{array}{l}\text { There is evidence that } \\
\text { students will reduce the } \\
\text { number of courses they } \\
\text { are taking as a result of } \\
\text { advice but they will not } \\
\text { necessarily change } \\
\text { their choice otherwise }\end{array}$ \\
\hline & & 'Taster course' & $\begin{array}{l}\text { No evidence known in } \\
\text { DE }\end{array}$ \\
\hline $\begin{array}{l}\text { Retention on course } \\
\text { Course start }\end{array}$ & & \begin{tabular}{|l|}
$\begin{array}{l}\text { Individual contact from } \\
\text { the tutor }\end{array}$ \\
\end{tabular} & \\
\hline \multirow[t]{2}{*}{$\begin{array}{l}\text { Before the first } \\
\text { assignment }\end{array}$} & \multirow[t]{2}{*}{$\begin{array}{l}\text { Probably the most } \\
\text { important retention on } \\
\text { course activities }\end{array}$} & Contact from the tutor & $\begin{array}{l}\text { Studies indicate a 3\% } \\
\text { increase in assignments } \\
\text { submitted }\end{array}$ \\
\hline & & $\begin{array}{l}\text { Contact from } \\
\text { institution }\end{array}$ & $\begin{array}{l}\text { Studies indicate a } 2.7 \% \\
\text { increase in assignments } \\
\text { submitted }\end{array}$ \\
\hline $\begin{array}{l}\text { Before subsequent } \\
\text { assignments }\end{array}$ & $\begin{array}{l}\text { Probably much less } \\
\text { important than the first } \\
\text { assignment }\end{array}$ & $\begin{array}{l}\text { Contact from either the } \\
\text { tutor or the institution }\end{array}$ & Little evidence known \\
\hline Mid-year & $\begin{array}{l}\text { Depends on course } \\
\text { structure }\end{array}$ & $\begin{array}{l}\text { Contact from either the } \\
\text { tutor or the institution } \\
\end{array}$ & Little evidence known \\
\hline $\begin{array}{l}\text { Before the exam, if } \\
\text { there is one }\end{array}$ & $\begin{array}{l}\text { Probably highly valued } \\
\text { by the students }\end{array}$ & $\begin{array}{l}\text { Contact from either the } \\
\text { tutor or the institution }\end{array}$ & Little evidence known \\
\hline $\begin{array}{l}\text { Retrieval } \\
\text { Contact after first } \\
\text { assignment aimed at } \\
\text { non-submitted or failed } \\
\text { assignments }\end{array}$ & & $\begin{array}{l}\text { Contact from either the } \\
\text { tutor or the institution }\end{array}$ & $\begin{array}{l}\text { Although the retrieval } \\
\text { effect is probably low } \\
\text { this may also be } \\
\text { important in terms of } \\
\text { reclamation as this is } \\
\text { the first and probably } \\
\text { only sign of passive } \\
\text { withdraw }\end{array}$ \\
\hline $\begin{array}{l}\text { Contact after } \\
\text { subsequent } \\
\text { assignments }\end{array}$ & & $\begin{array}{l}\text { Contact from either the } \\
\text { tutor or the institution }\end{array}$ & As above \\
\hline $\begin{array}{l}\text { Contact after a failed } \\
\text { exam }\end{array}$ & & $\begin{array}{l}\text { Contact from either the } \\
\text { tutor or the institution } \\
\end{array}$ & $\begin{array}{l}\text { Some evidence of a } \\
\text { reclamation effect }\end{array}$ \\
\hline $\begin{array}{l}\text { Contact after withdraw } \\
\text { at any stage }\end{array}$ & & $\begin{array}{l}\text { Contact from either the } \\
\text { tutor or the institution }\end{array}$ & $\begin{array}{l}\text { Some evidence of a } \\
\text { retrieval of } 2-3 \% \text { if fast } \\
\text { enough. Possibly a }\end{array}$ \\
\hline
\end{tabular}




\begin{tabular}{l|l|l|l}
\hline Stage & $\begin{array}{l}\text { Importance in terms } \\
\text { of retention }\end{array}$ & Activity & Effectiveness \\
\hline & & & $\begin{array}{l}\text { reclamation effect as } \\
\text { well }\end{array}$ \\
\hline $\begin{array}{l}\text { Reclamation } \\
\text { after course finish }\end{array}$ & & $\begin{array}{l}\text { Contact from the } \\
\text { institution }\end{array}$ & Possibly around 5\% \\
\hline
\end{tabular}

Source: (SIMPSON, 2003, p.153-157).

\subsubsection{Image perception and myths about $\mathrm{DE}$}

Wang (2010) defines image as the general impression formed on customer's minds; this impression results from the interaction between customer and company and from physical and behavioral aspects (organization name, products and services provided, buildings etc.). When switching costs are high, unsatisfied customers are more likely to keep a service provider even if it has unfavorable image. It means image has a stronger influence on loyalty when switching costs are low. Similarly, image has strong influence on customer's satisfaction in low switching costs situation (WANG, 2010).

For Nesset and Helgesen (2009) image is a synonym of reputation and concerns the general perception of an organization, including what people associate to that organization and what they may expect from its products and services. Reputation results from the interaction between the organization and its stakeholders, which reflects the history of past experiences. In education, understanding students' perceptions of reputation is helpful, since image relates positively to loyalty and a positive perception about the institution may influence student's attraction and retention (NESSET; HELGESEN, 2009).

Kuo and Ye (2009) define image as the ability of an organization to position itself in its customers mind. Image has an emotional and a functional aspect. The latter refers to the analysis of tangible aspects of the organization performance. Emotional attributes, in turn, concern the subjective perception about the organization, which includes feelings and attitudes, resulting from the interaction between the customer and the company (KUO; YE, 2009). 
In their perspective, an institution is not only a service/product provider, but a society member which is expected to contribute to its development. Image is related to the level the company is able to meet customer's needs with high quality services (KUO; YE, 2009).

Image is a relevant variable in business context since it influences organizational success. A positive image helps an organization keep a market position. A customer will create a picture of the company in his/her mind based on past experiences and the organization's attributes will be evaluated considering this mental image formed. Then image influences customer loyalty through evaluative constructs (quality perception and satisfaction). It means expectations will be built based on the client's image perception (BLOEMER; RUYTER; PEETERS, 1998).

In their study on banking services, Bloemer, Ruyter and Peeters (1998) found through factor analysis image is a multidimensional construct, composed by: customer contact; expertise in investment advising; relationship orientation; position in the market (innovation, advertisement, presence in the market); commitment to society; prices (BLOEMER; RUYTER; PEETERS, 1998).

Bloemer and Ruyter (1998), in their retail store study, define image as the customer's perceptions about the salient attributes of the store, such as location, price, merchandise, staff friendliness (BLOEMER; RUYTER, 1998).

Brown and Mazzarol (2009) studied institutional image as one determinant construct of student satisfaction and loyalty. In their point of view, image has three components: 1) study environment which concerns institution's friendliness, innovation, support and student focus; 2) practicality which measures how practical and job focused the course offered is; 3 ) conservativeness, meaning how traditional or prestigious the institution is (BROWN; MAZZAROL, 2009).

Back (2005) studied image congruence and its relations to customer satisfaction and loyalty, for accommodation industry. Image congruence theory states perceived image is based on personal self-image. Self-image has four dimensions: actual self-image (how someone really perceives him/her-self); social self-image (how someone is perceived by other people), ideal self-image (how someone would like to see him/herself) and social ideal self-image (how 
someone would like to be seen by other people). In his point of view social and ideal social self-image have stronger influence on customer's behavior (BACK, 2005).

Thus, Back (2005) proposed image congruence (social and ideal social) affects customer satisfaction, as well as, satisfaction is related to loyalty (image congruence has an indirect effect on loyalty). Empirical data showed (BACK, 2005):

- Social image influences customer satisfaction.

- Ideal social image influences customer satisfaction and loyalty.

- Customer satisfaction influences loyalty.

Kabadayi and Ozkiris (2011) also studied the influence of image congruence on customer's satisfaction. They studied a bank customer sample (449 customers) in Turkey. Image congruence concerns the customer identification to a brand; in other words the individual characteristics, preferences and personality lead to identification and, as a consequence, helps to predict preference, loyalty and satisfaction with a brand, a provider and a service (KABADAYI; OZKIRIS, 2011). Their empirical study used an image scale which is divided in five dimensions: 1) sincerity; 2) excitement; 3) competence; 4) sophistication; 5) peacefulness. In addition, they adapted services quality dimensions and created other dimensions for image congruence measurement (functional congruity) for bank services: physical characteristics, interest rates, staff, promotion, access, services and products. Image will be better perceived when the functional characteristics of the bank match the ideal image of a bank in customer's opinions (KABADAYI; OZKIRIS, 2011).

Image is an important marketing tool, since it helps a company positioning in the market. In the educational field, image defines how the institution is perceived in comparison to its competitors and how it is perceived by its stakeholders. Thus, studying image perception over a period of time is critical for identifying changes and formulating corrective actions (if the actual image is different from the ideal image, an image gap happens) (STEVENS et al., 2008).

Institutional image is defined by what is communicated regarding the institution and by its actions (STEVENS et al., 2008). Stevens et al. (2008) conducted a longitudinal image study in a business college from an American university. The first data collection occurred in mid- 
1990's (university and its administrators had a favorable reputation in the community); second collection happened ten years later. During this period the university had suffered negative publicity and had its administration substituted. Sample was composed by 375 business people from the university area for the first collection and 31 people for the second collection. As result they found the overall image improved over time. However, when asked about the willingness to recommend the university to other people, respondents were less optimistic in the last study (STEVENS et al., 2008).

\subsubsection{Myths}

Literature in distance education field brings some myths surrounding this learning model, especially concerning online learning and e-learning. Myths should be studied since they may help to understand social behavior; in addition, they embody social values (COX, 2005). Many articles studied the subject and are summarized in Table 6 bellow. In general, myths about DE are related to: 1) DE effectiveness compared to traditional education (KEARSLEY, 1998; CLARK, 2002; GAYTAN, 2009); 2) Institutions' motivations to start DE programs (mainly market competition) (COX, 2005; GAYTAN, 2009; MARKEL, 1999; NJENGA; FOURIE, 2010); 3) Belief that online learning has lower cost than traditional education (NJENGA; FOURIE, 2010); 4) DE is a second option, online education is chosen when traditional education is not available (COX, 2005; LI; AKINS, 2004; POWELL; KEEN, 2006; VADILLO, 2010); 5) Computer literacy is required to online education (KEARSLEY, 1998;COX, 2005; LI; AKINS, 2004; VADILLO, 2010) ; 6) Isolation of online environments (KEARSLEY,1998; CLARK, 2002; LI; AKINS, 2004; NJENGA; FOURIE, 2010); 7) It is easy to cheat online (GAYTAN, 2009; LI; AKINS, 2004); 8) DE is about technology (CLARK, 2002; COX, 2005; LI; AKINS, 2004).

Although myths may help to understand perceptions regarding distance education they should be carefully analyzed, since the literature consulted concerns American, Canadian and European cases. In this sense; some myths may have a different interpretation in Brazilian case, which justifies their investigation. For instance, Powell and Keen (2006) studied the Athabasca Open University (Canada) and found that, though the university's main objective was to provide democratic access to education for unprivileged people, in reality, most of the students were "visitor students" it means, they took some courses at Athabasca (for various 
reasons) but never intended to conclude the course. Considering the heterogeneous levels of regional development in Brazil, maybe the access expansion is a reality and not a myth. The specific characteristics of Brazilian economy, culture and sociopolitical development make the study of these myths relevant. 
Table 6. Myths about distance education courses

\begin{tabular}{|c|c|c|}
\hline Reference & Myth & Reality \\
\hline \multirow[t]{3}{*}{ Kearsley (1998) } & Learning environment is impersonal & $\begin{array}{l}\text { Effective use of communication tools make online environment interactive, dynamic and } \\
\text { personal }\end{array}$ \\
\hline & $\begin{array}{l}\text { High technology literacy is necessary } \\
\text { in order to be successful in online } \\
\text { courses }\end{array}$ & $\begin{array}{l}\text { Software applied are usually simple; therefore, basic computer skills are enough to attend } \\
\text { an online course }\end{array}$ \\
\hline & $\begin{array}{l}\text { Online courses are easier than their } \\
\text { traditional equivalents }\end{array}$ & $\begin{array}{l}\text { Distance courses, in general, demand more participation, intense communication and } \\
\text { involvement which may make them more demanding than traditional courses }\end{array}$ \\
\hline \multirow[t]{4}{*}{ Clark (2002) } & $\begin{array}{l}\text { E-learning is just another delivery } \\
\text { method }\end{array}$ & $\begin{array}{l}\text { Education in any nature should be based on solid principles of the psychology of learning. } \\
\text { In this sense, e-learning must consider the changes of educational perspective which is } \\
\text { now more learner-centered. Thus, e-learning forces educational researchers to rethink } \\
\text { education and address fundamental issues in psychology of learning, such as, retention, } \\
\text { motivation, cognitive engagement, learning pre-requisites (does e-learning deliver the } \\
\text { right learning to the right people at the right time?). }\end{array}$ \\
\hline & $\begin{array}{l}\text { E-learning is less effective than } \\
\text { traditional education }\end{array}$ & $\begin{array}{l}\text { According to the author, e-learning tends to be more effective, since interactivity leads to } \\
\text { higher levels of participation. Participation in turn, leads to higher cognitive engagement } \\
\text { and for instance retention is enhanced. Another important variable related to online } \\
\text { effectiveness is its self-paced model which allows student to stop, repeat, reflect and } \\
\text { integrate learning to his/her current knowledge structure. It is important to remark that this } \\
\text { positive cycle strongly depends on course design, content quality and faculty and staff } \\
\text { training. }\end{array}$ \\
\hline & $\begin{array}{l}\text { E-learning cannot support different } \\
\text { types of learners }\end{array}$ & $\begin{array}{l}\text { Any course will have a heterogeneous group with different levels of experience, } \\
\text { background, personality types and motivation. Thus, perceptions regarding the course will } \\
\text { be impacted by these personal characteristics. In order to reduce the problems arising } \\
\text { from students' diversity, it is essential to cater individual needs. It is easier to deal with } \\
\text { diversity when student assumes responsibility for his/her educational process. Student } \\
\text { empowerment should certainly come after a need and profile diagnosis, which will show } \\
\text { what kind of training is adequate to that target. }\end{array}$ \\
\hline & E-learning is demotivating & $\begin{array}{l}\text { Learning is essentially enhanced by intrinsic motivation; that is, the motivation for } \\
\text { learning is driven fundamentally by personal goals rather than external factors. In } \\
\text { addition, motivation increases when student has the opportunity to reflect, makes } \\
\text { judgments and choices and feels control about the whole process. Finally, on demand } \\
\text { access is seen as more effective in motivation than fixed-time classroom experience, since }\end{array}$ \\
\hline
\end{tabular}




\begin{tabular}{|c|c|c|}
\hline \multirow[t]{7}{*}{ Reference } & Myth & Reality \\
\hline & & $\begin{array}{l}\text { learning happens through incremental steps on the study journey (as mental models are } \\
\text { built and adapted along the way). This structure of education is enhanced by e-learning. }\end{array}$ \\
\hline & E-learning is not engaging & $\begin{array}{l}\text { Cognitive engagement is necessary for a successful learning experience, in any kind of } \\
\text { delivery method. Interactivity and the exchange of experience among teacher and } \\
\text { participants lead to engagement. High quality content, meaningful, personal (self- } \\
\text { reference effect, how does it apply to me?) and organized content also helps increasing } \\
\text { engagement. }\end{array}$ \\
\hline & $\begin{array}{l}\text { E-learning fragments the learning } \\
\text { experience }\end{array}$ & $\begin{array}{l}\text { Psychology of learning advocates retention is higher when learning is delivered in small } \\
\text { and frequent doses. Access on demand allows this structure and does not force student to } \\
\text { absorb lots of knowledge in concentrated sessions, which reduces retention. }\end{array}$ \\
\hline & $\begin{array}{l}\text { E-learning is not realistic due to the } \\
\text { intense use of technology }\end{array}$ & $\begin{array}{l}\text { The author states that once someone gets used to technology it becomes part of real life. } \\
\text { Besides, there are some measures that help online experience, such as, politeness, flattery } \\
\text { (watch how to give feedback), use of multimedia resources, group interaction. }\end{array}$ \\
\hline & E-learning retention is lower & $\begin{array}{l}\text { Retention is a memory issue, but immediately reinforcing theory into practice helps } \\
\text { increasing retention. Many e-learning characteristics contribute to retention increase, such } \\
\text { as on demand access and online networking built during the course. }\end{array}$ \\
\hline & $\begin{array}{l}\text { E-learning takes the same time as } \\
\text { traditional learning }\end{array}$ & $\begin{array}{l}\text { His article considering medical education arguments that students studying online learn } \\
\text { faster than traditional students, due to the intensive use of multimedia. Audio, video and } \\
\text { image help students in their learning process, which reduces its time. }\end{array}$ \\
\hline \multirow{2}{*}{ Cox $(2005)$} & $\begin{array}{l}\text { Market competition compels } \\
\text { institutions involvement with distance } \\
\text { education }\end{array}$ & $\begin{array}{l}\text { Competitive pressures in higher education leads to a stronger market-oriented approach } \\
\text { which aims to attract funding, student enrollment and status. In this context, the business } \\
\text { world rhetoric that internet savvy education is crucial to obtain significant market share } \\
\text { took many institutions to start their online programs, with no realistic demand forecast } \\
\text { and marketing research. }\end{array}$ \\
\hline & $\begin{array}{l}\text { Online education enhances } \\
\text { technological literacy }\end{array}$ & $\begin{array}{l}\text { Online courses are considered to develop technology skills needed in workplace. In this } \\
\text { vision, web-based technologies included in higher education online courses would, } \\
\text { supposedly, conduct students to pursue a high-tech career. The truth is technological skills } \\
\text { needed for online courses are basic. In addition, this myth brings to light an excessive } \\
\text { concern to the technology itself while the way it could improve education experience and }\end{array}$ \\
\hline
\end{tabular}




\begin{tabular}{|c|c|c|}
\hline Reference & Myth & Reality \\
\hline \multirow{3}{*}{ Gaytan (2009) } & $\begin{array}{l}\text { Administrators believe online model } \\
\text { allows the enrollment of a larger } \\
\text { number of students. }\end{array}$ & $\begin{array}{l}\text { In fact; some courses, for example, for research sections, less students should be enrolled } \\
\text { to guarantee a high quality experience. Thus, online education demands in some cases } \\
\text { additional sections, hiring additional faculty, providing faculty with incentives (such as } \\
\text { extra payment, an assistant help, release time), which increases the institution's budget. }\end{array}$ \\
\hline & $\begin{array}{l}\text { Students have trouble on time- } \\
\text { management, discipline and honesty } \\
\text { online. }\end{array}$ & $\begin{array}{l}\text { There is no consensus about cheating in online education; it means; some authors claim it } \\
\text { is easier to cheat online, but others could not find evidence about that or argument it is } \\
\text { simpler to discover dishonesty online than in traditional environment. Anyway, there are } \\
\text { some software helping faculty in this task }\end{array}$ \\
\hline & $\begin{array}{l}\text { The development of new online } \\
\text { courses is stimulated by the } \\
\text { administrators }\end{array}$ & $\begin{array}{l}\text { They recognize that designing an appropriate online course is more time consuming than } \\
\text { traditional education }\end{array}$ \\
\hline \multirow{2}{*}{ Li and Akins (2004) } & $\begin{array}{l}\text { Online learning is limited to content } \\
\text { learning }\end{array}$ & $\begin{array}{l}\text { Students get much more than content from online learning; they learn from the } \\
\text { interactions among each other and with the instructor, establishing a collaborative } \\
\text { relationship (community), building friendship that lasts out of class. }\end{array}$ \\
\hline & Online education leads to isolation & $\begin{array}{l}\text { If the course is not designed to provide interaction and collaboration opportunities, the } \\
\text { process can indeed cause isolation. In this sense course's design should include tools and }\end{array}$ \\
\hline
\end{tabular}




\begin{tabular}{|c|c|c|}
\hline Reference & Myth & Reality \\
\hline & $\begin{array}{l}\text { Learner and instructor must be } \\
\text { proficient in technology }\end{array}$ & $\begin{array}{l}\text { This view focuses online learning on technology rather than on an education model; } \\
\text { technology is just a tool. In addition, although some technology skills are required, they } \\
\text { are basic and cannot be considered a "mastery of all technologies". }\end{array}$ \\
\hline & $\begin{array}{l}\text { Online learning is just for people in } \\
\text { remote locations }\end{array}$ & $\begin{array}{l}\text { It is true in many cases, but there are many online students who enroll an online course } \\
\text { because it matches their busy schedules, it allows conciliation among education, work and } \\
\text { family, it provides rich interaction opportunities and builds networking. }\end{array}$ \\
\hline & Online learning is for everyone & $\begin{array}{l}\text { This view considers that despite of student's background, self-efficacy and individual } \\
\text { preferences, everyone can learn the same content online, in the same amount of time. The } \\
\text { reality is that attrition rates in online education are high and in order to be successful, } \\
\text { students need to be motivated, have discipline, persistence and commitment. Many } \\
\text { reasons lead to attrition, such as work and family lives balance, finance, lack of focus, } \\
\text { lack of reasons to complete the course, inefficient instructor's guidance, unclear view of } \\
\text { what is expected from the student etc. }\end{array}$ \\
\hline & Online learning will substitute teachers & $\begin{array}{l}\text { Technology is just a tool; education is a human process and teachers will always be } \\
\text { needed in order to plan, design and facilitate learning experiences. }\end{array}$ \\
\hline & $\begin{array}{l}\text { Expensive equipment are required } \\
\text { from students in order to participate }\end{array}$ & $\begin{array}{l}\text { The institution's technological structure is in fact sophisticated and expensive, but } \\
\text { students themselves generally need only a computer and internet access. }\end{array}$ \\
\hline & $\begin{array}{l}\text { Question-and-answer is the best } \\
\text { approach for discussion }\end{array}$ & $\begin{array}{l}\text { Threaded discussion is one of the most used tools in online education, because it provides } \\
\text { opportunity to interaction, exchange of ideas and presentation of multiple perspectives. } \\
\text { The question-and-answer format is widely used and can be effective in many cases; } \\
\text { however, this format can make students feel bored. To avoid this effect, discussions } \\
\text { should be planned in different formats to stimulate interest (for example, debates in small } \\
\text { groups). }\end{array}$ \\
\hline & Online learning is quick and easy & Despite of its higher flexibility, online education has a workload for both students and \\
\hline
\end{tabular}




\begin{tabular}{|c|c|c|}
\hline Reference & Myth & Reality \\
\hline & $\begin{array}{l}\text { Learner's comments in a discussion } \\
\text { must be corrected when posted }\end{array}$ & $\begin{array}{l}\text { Students may be afraid of posting their opinions in online discussion (fear of not meeting } \\
\text { teacher's expectative, of posting a wrong comment, of having his/her comment recorded } \\
\text { etc.). Teachers should help students overcome the fear, value their contributions, and } \\
\text { moderate discussion redirecting attention to important points. Discussion must be a safe } \\
\text { environment for the free expression of ideas. }\end{array}$ \\
\hline & $\begin{array}{l}\text { Online learning is a one-way learning } \\
\text { process, teacher to student }\end{array}$ & Online education change focus from teacher, to student. \\
\hline & $\begin{array}{l}\text { Assessment should consider quantity } \\
\text { of messages posted }\end{array}$ & $\begin{array}{l}\text { Participation can consider the messages posted but other evaluation techniques are crucial. } \\
\text { Students must have the evaluation criteria clear. }\end{array}$ \\
\hline & Cheating online is easier & $\begin{array}{l}\text { There are many tools that ensure authentication of student works. Students should be } \\
\text { educated about issues surrounding plagiarism, in order to avoid it. }\end{array}$ \\
\hline Markel (1999) & $\begin{array}{l}\text { Many administrators consider distance } \\
\text { education as a market strategy to } \\
\text { attract hundreds of students to the } \\
\text { institution }\end{array}$ & $\begin{array}{l}\text { In reality, online education demands a higher level of interaction in order to guarantee a } \\
\text { successful learning experience. In this context, classes should be smaller and } \\
\text { infrastructure should be enough to support these students. Considering teaching time is } \\
\text { also higher in online education, costs may be substantial. Markel (1999) states that } \\
\text { literature claims for a new pedagogy for distance education, which differs substantially } \\
\text { from bad traditional education, but in his opinion, face-to-face is bad only if the lecture, } \\
\text { passive format is considered; on the other hand there are other kinds of effective } \\
\text { approaches for traditional education. Anyhow, distance learning breaks teacher/student } \\
\text { hierarchy and engages student in his/her educational process, which should also happen } \\
\text { face-to-face. }\end{array}$ \\
\hline \multirow[t]{3}{*}{$\begin{array}{l}\text { Njenga and Fourie } \\
(2010)\end{array}$} & $\begin{array}{l}\text { E-learning is a savior, every institution } \\
\text { should adopt it }\end{array}$ & $\begin{array}{l}\text { Impacts of this adoption where wrongly considered by administrators. E-learning should } \\
\text { be adopted only if it has a real potential to improve educational experience, not because } \\
\text { every institution is doing it. }\end{array}$ \\
\hline & $\begin{array}{l}\text { E-learning can replace human } \\
\text { interaction }\end{array}$ & $\begin{array}{l}\text { Many institutions believe that one teacher can reach dozens of students at once, but the } \\
\text { truth is that this belief is unrealistic, since teachers are responsible to facilitate learning } \\
\text { and watch students along the way. Technology does not replace interaction, it claims for a } \\
\text { higher level of interaction. }\end{array}$ \\
\hline & E-learning cuts costs of education & E-learning is expensive, the infrastructure needed to begin an online course is complex \\
\hline
\end{tabular}




\begin{tabular}{|c|c|c|}
\hline Reference & Myth & Reality \\
\hline & & $\begin{array}{l}\text { and high cost. E-learning is cheaper than traditional education only when economy scales } \\
\text { are conquered. The myth also states that investing in e-learning will make the institution } \\
\text { save money, but it is not necessarily true. }\end{array}$ \\
\hline & $\begin{array}{l}\text { Providing innumerous courses and } \\
\text { abundance of information is beneficial }\end{array}$ & $\begin{array}{l}\text { This idea is due to the belief student will construct knowledge by him/herself. However, } \\
\text { information does not naturally become knowledge without guidance. In addition, not all } \\
\text { knowledge can be packaged; tacit knowledge is transmitted through interaction. } \\
\text { Technology is just a tool. }\end{array}$ \\
\hline & $\begin{array}{l}\text { Entertainment and learning are } \\
\text { separate activities }\end{array}$ & $\begin{array}{l}\text { Technology should be used to improve learning experience of the young net generation } \\
\text { and to meet their needs for interaction, communication and collaboration. }\end{array}$ \\
\hline & $\begin{array}{l}\text { Creating the infrastructure is the most } \\
\text { difficult part }\end{array}$ & Resistance to change and other people related issues are more complex than infrastructure \\
\hline & $\begin{array}{l}\text { E-learning can decrease absenteeism } \\
\text { and attrition rates }\end{array}$ & $\begin{array}{l}\text { Absenteeism is difficult to measure because of the time and space flexibility and many } \\
\text { studies show attrition is a main concern in online education. }\end{array}$ \\
\hline \multirow[t]{2}{*}{$\begin{array}{l}\text { Powell and Keen } \\
\text { (2006) }\end{array}$} & $\begin{array}{l}\text { DE aims to reach excluded people } \\
\text { (second chance university) }\end{array}$ & $\begin{array}{l}\text { The truth is, just a little percentage of the students represent excluded people (for } \\
\text { geographic barriers; social and financial limitations); the majority of them were visitor } \\
\text { students testing their skills, or looking for pre-requisites for entering programs in other } \\
\text { institutions; it means, they did not intend to finish the course. }\end{array}$ \\
\hline & DE is a substitution for real education & It is considered a second, inferior choice, but in fact it is a new model \\
\hline \multirow[t]{5}{*}{ Vadillo (2010) } & Courses should look like courses & $\begin{array}{l}\text { Courses should innovate, using games, virtual reality and other resources as long as } \\
\text { learning experience is valuable. }\end{array}$ \\
\hline & $\begin{array}{l}\text { Online education is second best to } \\
\text { face-to-face }\end{array}$ & $\begin{array}{l}\text { Many believe online should be used only if face-to-face is not available, but online } \\
\text { learning has a great potential and fits many learning styles. }\end{array}$ \\
\hline & $\begin{array}{l}\text { An unique format should be adopted to } \\
\text { avoid confusion }\end{array}$ & $\begin{array}{l}\text { Adaptability and flexibility should be fostered and format should be decided according to } \\
\text { the courses characteristics. }\end{array}$ \\
\hline & Student must be graded & Learning activities may increase motivation even though they are not on their grades. \\
\hline & $\begin{array}{l}\text { Technologies should be gradually } \\
\text { introduced, to make sure students get } \\
\text { used to them }\end{array}$ & Technology skills required are basic and do not represent a limitation. \\
\hline
\end{tabular}




\subsubsection{Constructs relations}

This item presents some models found in the literature which relate services marketing constructs considered in the dissertation. The results found by these studies help interpreting data from the PNAP case.

Nesset and Helgesen (2009), in their study about the determinants of student loyalty, propose the following model in which loyalty (dependent variable) is determined by student satisfaction and perceived reputation (independent variables). The independent variables are impacted by affective dimensions and quality perception, as shown on Figure 1.

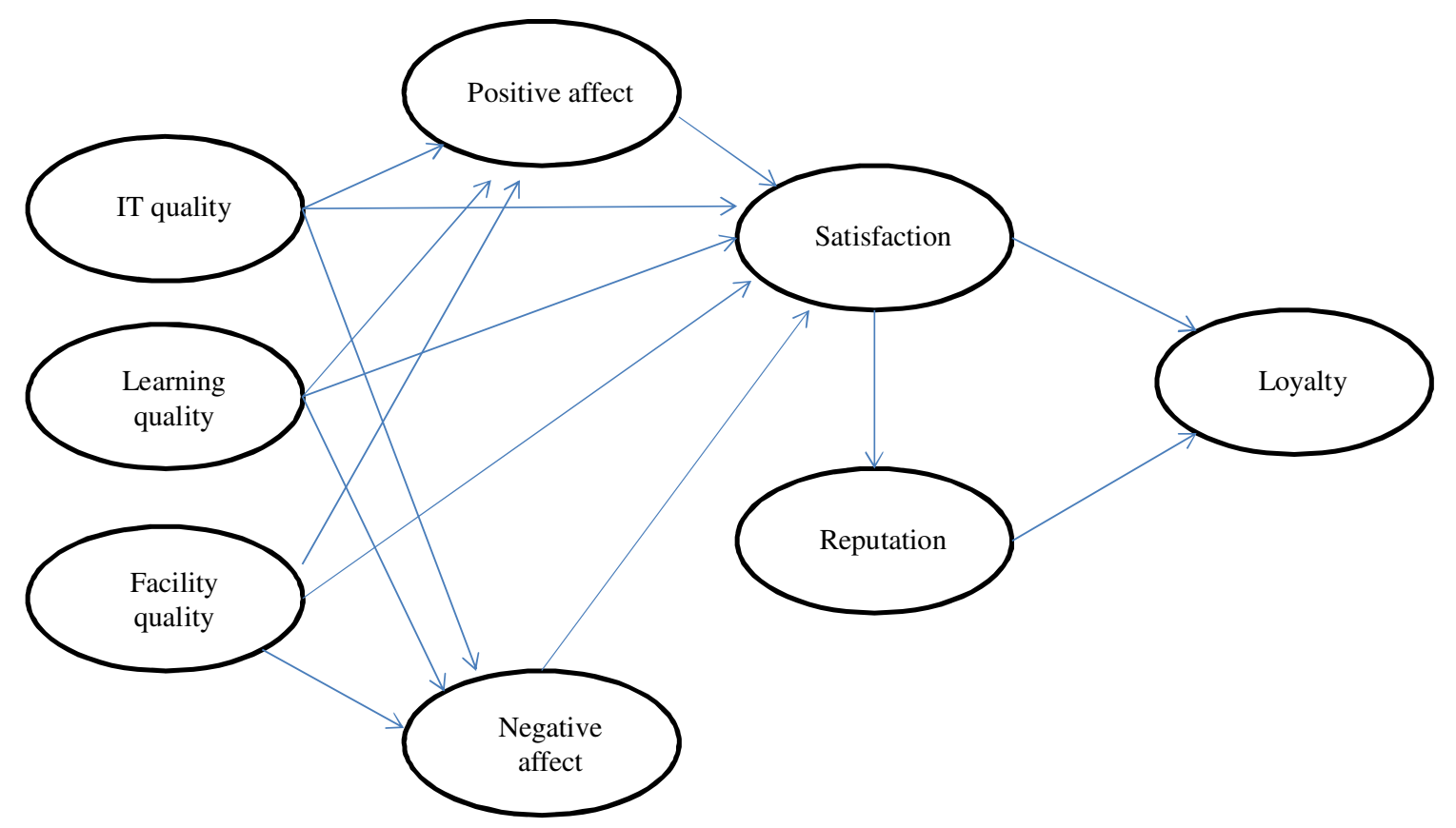

Figure 17. Nesset and Helgesen Model

Source: (NESSET; HELGESEN, 2009, p.329).

Data analysis showed (NESSET; HELGESEN, 2009):

- Reputation influences loyalty positively.

- Satisfaction influences loyalty positively.

- Satisfaction influences reputation positively.

- Positive affect influences satisfaction positively. 
- Negative affect influences satisfaction negatively.

- Learning quality influences positive affect positively.

- Learning quality influences negative affect negatively.

- Learning quality influences satisfaction positively.

- Facility quality influences positive affect positively.

- Facility quality influences negative affect negatively

- Positive affect has indirect and positive influence on reputation.

Rojas-Méndez et al. (2009) proposed the following theoretical model in order to understand student's behavior in higher education and define loyalty. For them, loyalty is explained by commitment, which is influenced by trust, which is explained by satisfaction, which is, finally, defined by perception of quality in the long-term relationship, as exposes Figure 18. It is different from the model proposed by Nesset and Helgesen (2009), which states student's loyalty is influenced by reputation and satisfaction.

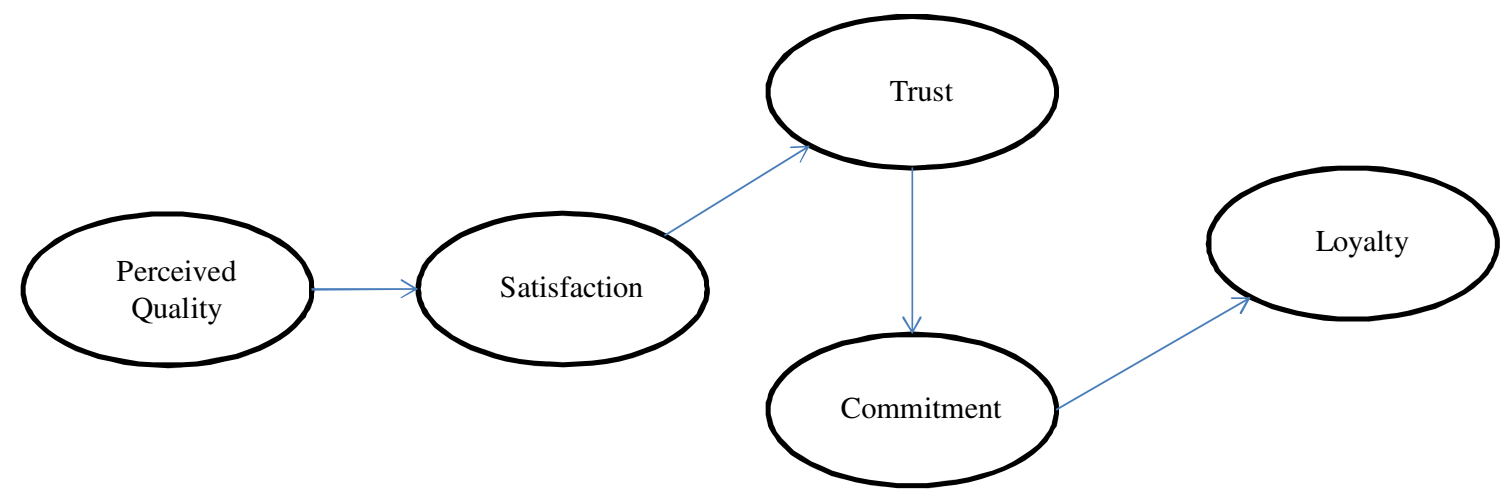

Figure 18. Rojas-Méndez et al. (2009) model for determinants of loyalty Source: (ROJAS-MÉNDEZ et al., 2009, p.27)

As a result of their study, they found that only commitment has a direct effect on student's loyalty, while perceived quality, satisfaction and trust have an indirect effect (ROJASMÉNDEZ et al., 2009):

- Perceived quality has a significant effect on satisfaction.

- Satisfaction has a significant effect on trust.

- Commitment has a significant effect on loyalty.

- Trust has a significant effect on commitment. 
Similarly to the previous studies mentioned, Kenney and Khanfar (2009) proposed the model shown in Figure 19. The authors add some propositions: satisfaction has a direct effect on repurchase intention; perceived quality has a direct effect on repurchase intention; switching costs have direct effect on repurchase intention; satisfaction has an indirect effect on repurchase intention; perceived quality has an indirect effect on repurchase intention. It's relevant to observe that in their view, repurchase intention theoretically results from loyalty. However, since the authors did not test the model, it is not possible to discuss about the propositions (KENNEY; KHANFAR, 2009).

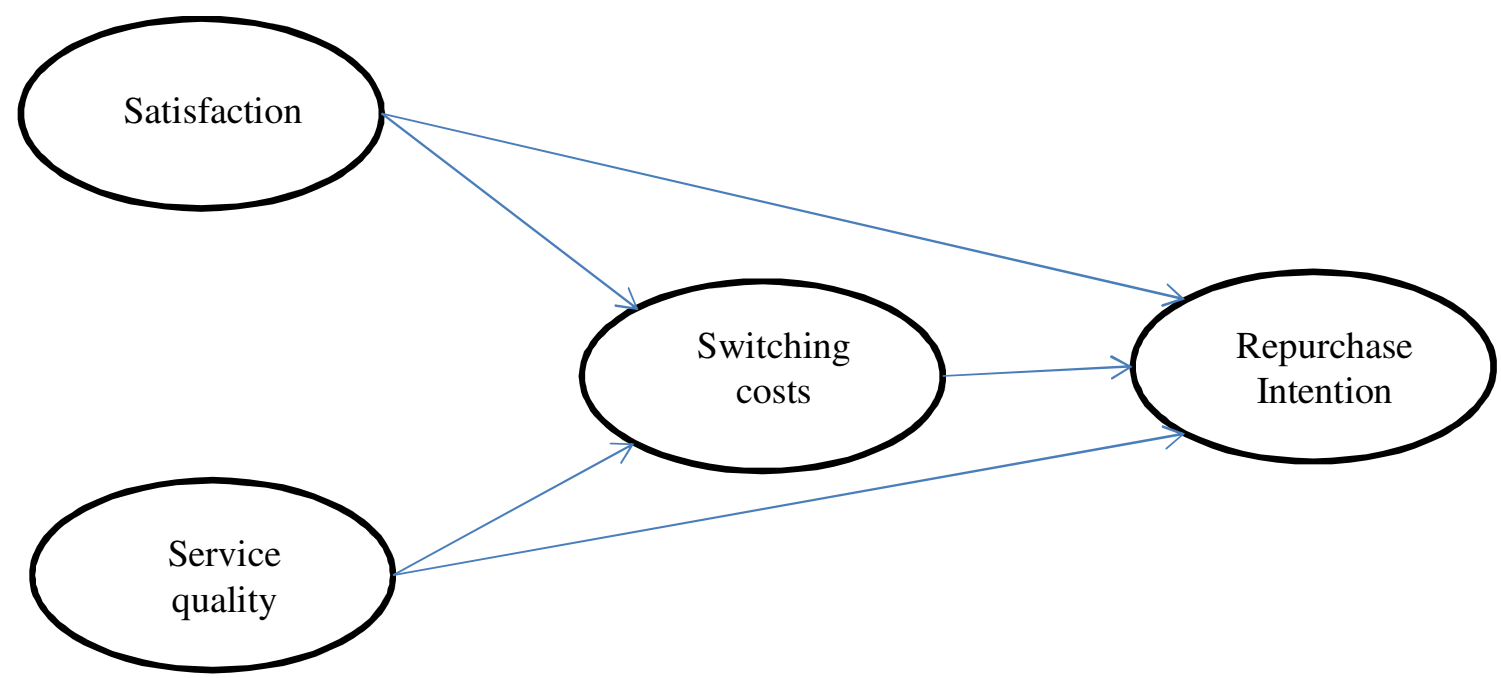

Figure 19. Kenney and Khanfar (2009) model

Source: (KENNEY; KHANFAR, 2009, p.280)

In their study of training students in Taiwan, Kuo and Ye (2009) propose a model which considers perceived quality and organization's image as predictors of student's satisfaction, which, in turn, influences student's loyalty (Figure 20). 


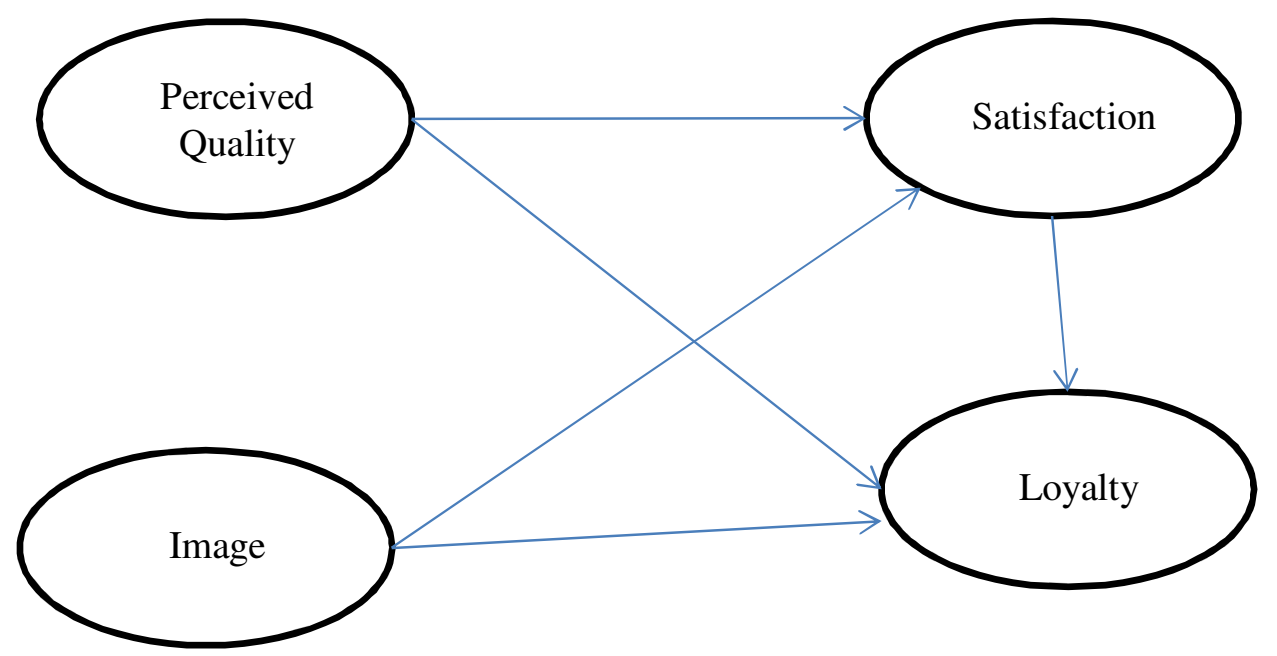

Figure 20. Kuo and Ye model

Source: (KUO; YE, 2009, p.754)

As a result Kuo and Ye (2009) found:

- Service quality significantly influences student satisfaction;

- Service quality has an indirect effect over loyalty, through satisfaction;

- Image significantly impacts student satisfaction;

- Image has an indirect effect over loyalty, through satisfaction;

- Satisfaction significantly influences student loyalty.

Udo et al. (2011), as mentioned before, applied a modified version of SERVQUAL in order to evaluate student's perceptions of e-learning quality. In their model, e-learning quality is determined by five dimensions (assurance, empathy, responsiveness, reliability and web site content). Quality, in turn, determines behavioral intentions and satisfaction. Satisfaction also impacts behavioral intentions. Their model is presented on Figure 21. 


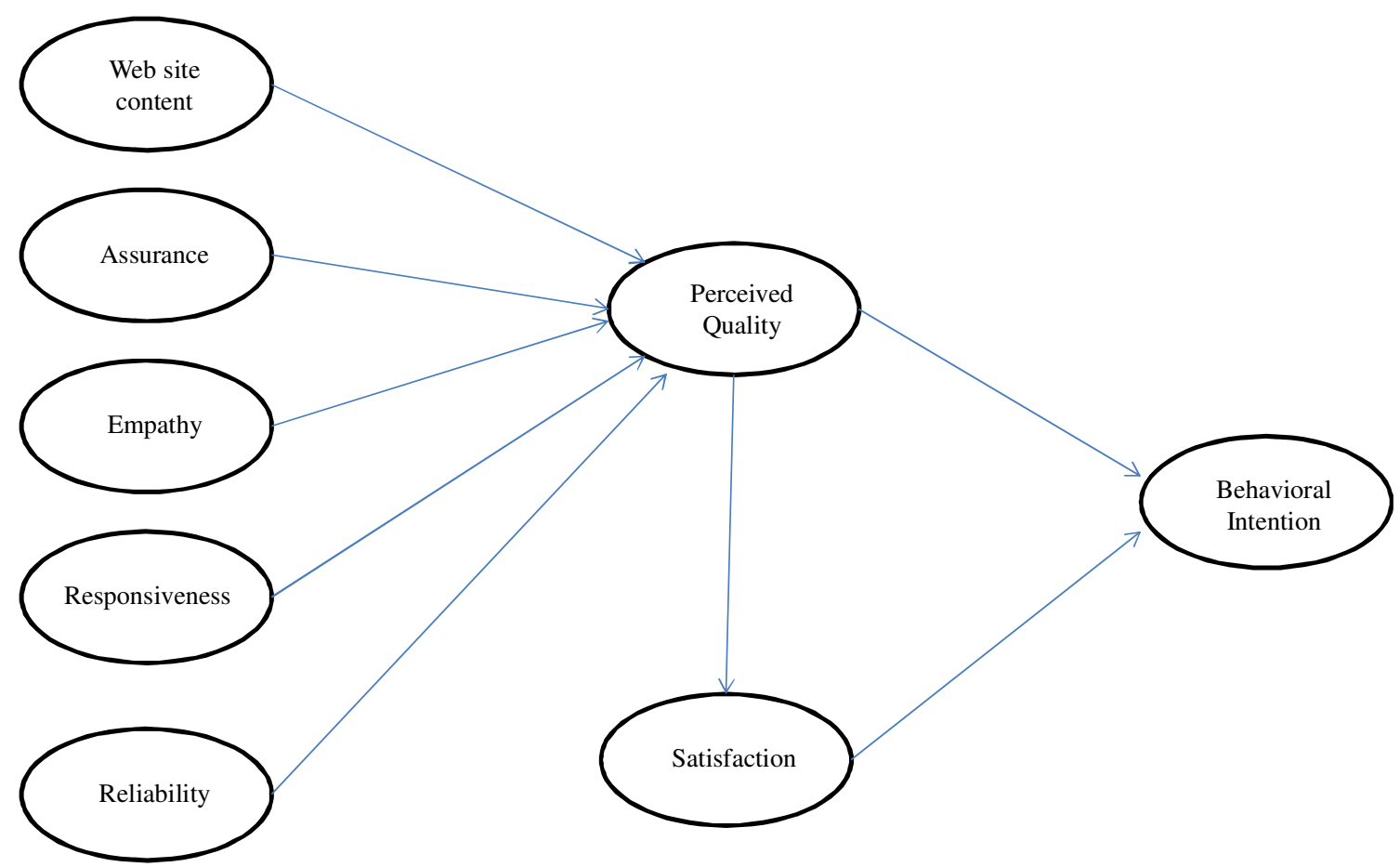

Figure 21. Udo et al. Model (UDO et al., 2011).

Results showed that all indicators (variables) provided good measure of their constructs. In addition, they found (UDO et al., 2011):

- Assurance has a positive influence on perceived quality.

- Empathy has a positive influence on perceived quality.

- Responsiveness has a positive influence on perceived quality.

- Reliability has not a significant relation to perceived quality.

- Website content has a positive influence on perceived quality.

- Perceived quality has a positive influence on satisfaction.

- Perceived quality has not a significant influence on behavioral intentions.

- Perceived quality has an indirect effect on behavioral intentions when is mediated by satisfaction.

- Performance expectation has a positive influence on student satisfaction (performance expectation was analyzed independently of the model).

Brown and Mazzarol (2009) adapted a model from services marketing literature to use it for the case of higher education in Australia. In their approach, student loyalty is determined by satisfaction, perceived value, institutional image and perceived quality of human aspects 
(named software) and of technology (named hardware). The hardware dimension concerns SERVQUAL tangibles; while software dimension concerns SERVQUAL reliability, responsiveness, assurance and empathy. Partial Least Square (PLS) showed the following results (BROWN; MAZZAROL, 2009):

- Image has a significant strong relation with perceived value.

- Image has a significant weak relation with satisfaction.

- Perceived value has a significant strong relation with satisfaction.

- Perceived value has a significant weak relation with loyalty.

- Satisfaction has a significant strong relation with loyalty.

- Quality perception has an indeterminate relation with perceived value. Relation was defined as indeterminate, because perceived quality had significant path only with one sub-dimension of perceived value.

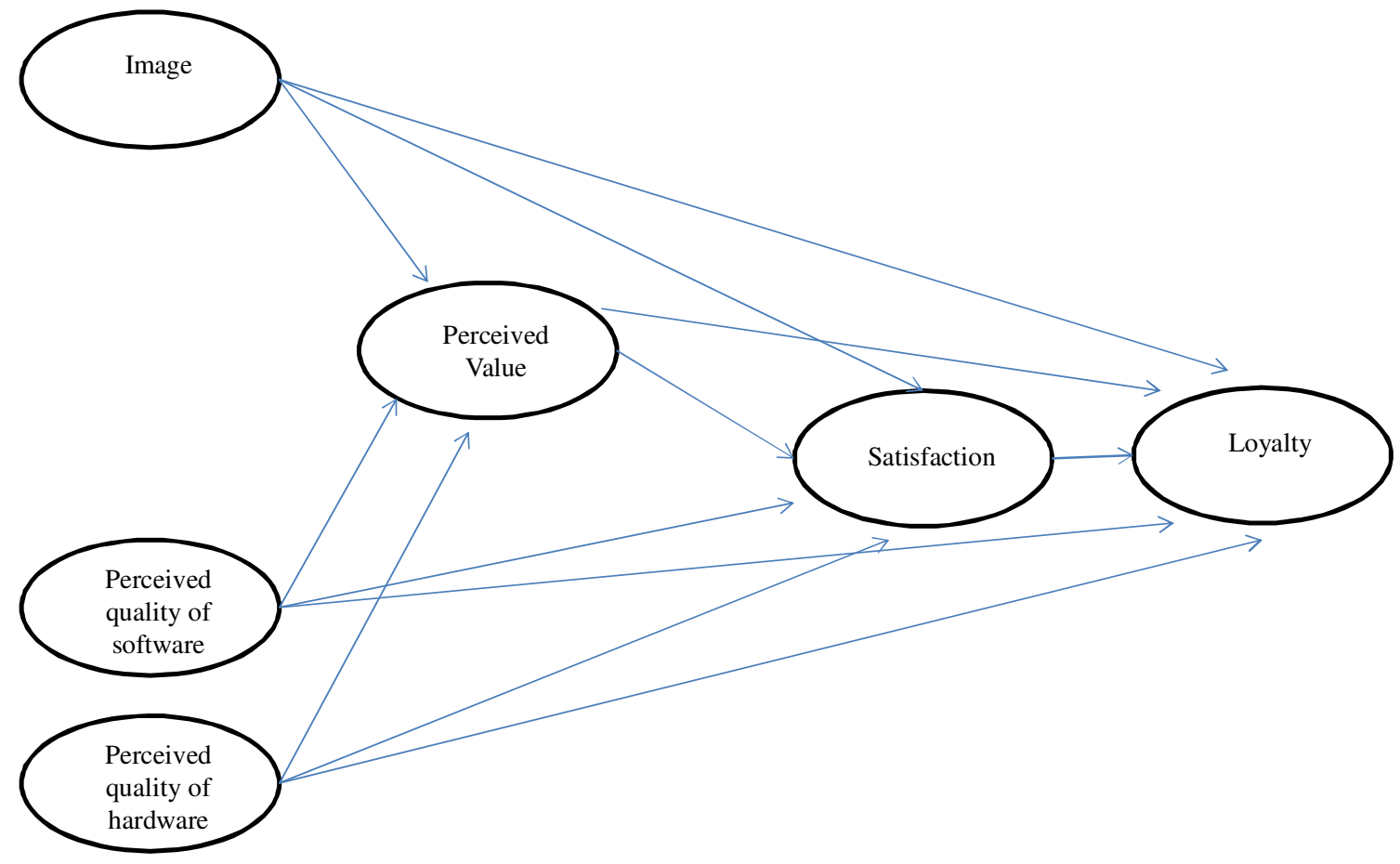

Figure 22. Brown and Mazzarol (2009) model

Source: (BROWN; MAZZAROL, 2009, p.84)

Bloemer et al. (1998) studied the relationship among customer's loyalty, satisfaction, perceived quality and image in the specific context of banking services. Although this dissertation proposes to study educational service, it is useful to present Bloemer, Ruyter and 
Peeters (1998) model since the previous models mentioned in this item share similarities with this last model. The authors, despite of controversies already exposed in the text, define quality perception is a determinant of satisfaction, which is, in turn determinant of loyalty. Institutional image also affects loyalty, but it is mediated by evaluative judgments in constructs such as services quality and satisfaction (BLOEMER; RUYTER; PEETERS, 1998). Their model (Figure 23) proposes customer loyalty is directly determined by quality and satisfaction and indirectly determined by image. Empirical data showed all the constructs are significantly positively correlated. Multiple regression showed loyalty is a function of quality and satisfaction (R-square $=53 \%$ ), image has no significant effect on loyalty. In order to evaluate image's indirect effect on loyalty, another regression was ran (satisfaction as dependent variable) and the authors found only quality has a significant effect on satisfaction (R-square $=30 \%$ ). A third model was conducted (quality as dependent variable) and image showed significant influence on quality (R-square=34\%). Summarizing, the authors found the following relationships (BLOEMER; RUYTER; PEETERS, 1998):

- Quality has a direct and an indirect effect on loyalty, through satisfaction.

- Satisfaction has a direct effect on loyalty.

- Image has a direct effect on quality.

- Image has an indirect effect on satisfaction through quality.

- Image has an indirect effect on loyalty through quality. 


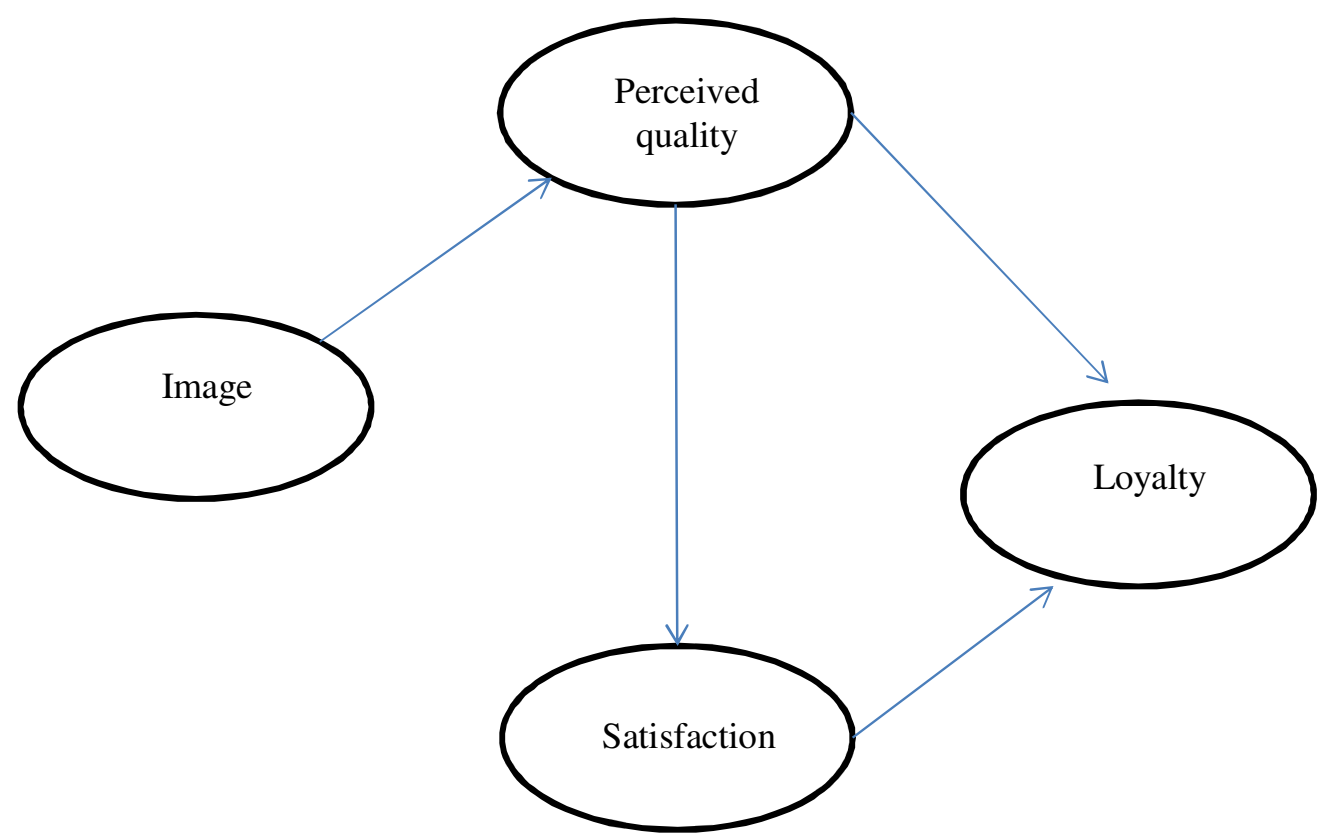

Figure 23. Bloemer et al. (1998) model for banking services

Source: (BLOEMER et al., 1998, p.281)

Bloemer and Ruyter (1998) studied the relation between loyalty, satisfaction and image on retail stores. Clients from a department store in Swiss were surveyed (124 cases); the scale included the construct elaboration, which measures customer motivation and ability to evaluate a service (Figure 24). They found satisfaction, loyalty and image are positively related. In addition, satisfaction was found to influence loyalty; image does not have a direct effect; image has an indirect influence on loyalty through satisfaction. 


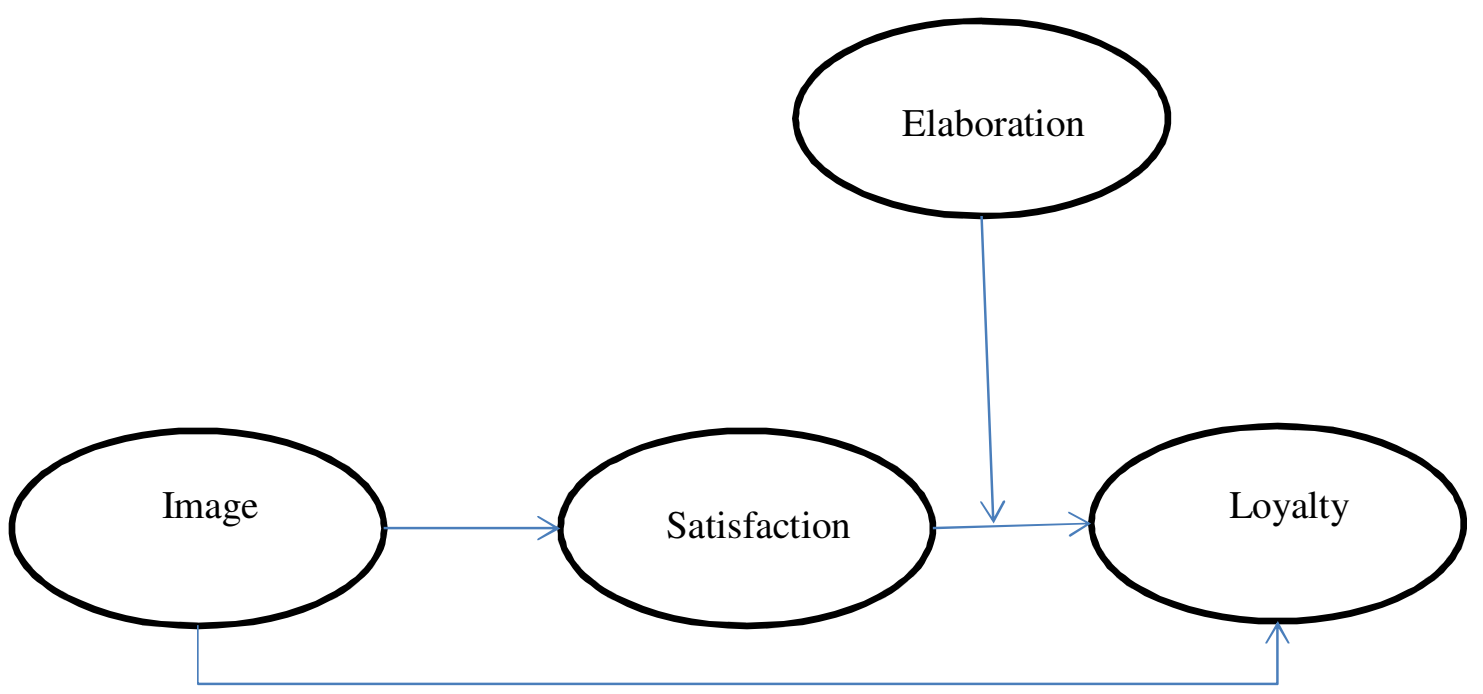

Figure 24. Bloemer and Ruyter (1998) model for retail store

Source: (BLOEMER; RUYTER, 1998, p.503).

Table 7 summarizes results found on similar studies in literature, which helped to develop the present research model and hypotheses.

Table 7. Sample profile and models goodness of fit of the educational studies considered in the literature review

\begin{tabular}{|c|c|c|}
\hline Study & Sample profile & Model goodness of $\mathrm{fit}^{5}$ \\
\hline $\begin{array}{l}\text { (NESSET; } \\
\text { HELGESEN, 2009) }\end{array}$ & $\begin{array}{l}240 \text { engineering students } \\
\text { Aalesund University College } \\
\text { Norway } \\
\text { Bachelor degree } \\
58 \% \text { full time students } \\
\text { Mean age }=24.9 \text { years old } \\
87 \% \text { male }\end{array}$ & $\begin{array}{l}\text { SEM: } \\
\text { RMSEA }=0.049 \\
\text { CFI }=0.95 \\
\text { SRMR }=0.053 \\
\text { R-square for satisfaction and } \\
\text { loyalty }=75 \% \\
\text { R-square for image }=42 \% \\
\text { R-square positive affect }= \\
35 \% \\
\text { R-square negative affect }= \\
21 \%\end{array}$ \\
\hline $\begin{array}{l}\text { (ROJAS-MÉNDEZ et } \\
a l ., 2009)\end{array}$ & $\begin{array}{l}752 \text { students } \\
\text { Public Chilean University } \\
33.5 \% \text { Accounting students } \\
57.4 \% \text { Business students } \\
\text { 7.6\% Psychology students } \\
55.3 \% \text { female } \\
43.5 \% \text { male } \\
25.5 \% \text { freshman } \\
\end{array}$ & $\begin{array}{l}\text { SEM: } \\
\text { RMSEA under } 0.05 \\
\text { GFI } \sim 0.9 \\
\text { AGFI } \sim 0.9 \\
\text { CFI above } 0.9 \\
\text { Cronbach's alpha ranging } \\
0.74-0.92 \\
\text { R-square for loyalty }=83 \%\end{array}$ \\
\hline
\end{tabular}

${ }^{5}$ RMSEA: Root Mean Square Error of Approximation; CFI: Comparative Fit Index; SRMR:

Standardized Root Mean Square Residuals; R-square: coefficient of determination. 


\begin{tabular}{|c|c|c|}
\hline Study & Sample profile & Model goodness of fit ${ }^{5}$ \\
\hline & $\begin{array}{l}17.6 \% \text { sophomore } \\
20.6 \% \text { junior } \\
34.2 \% \text { senior } \\
21.9 \%<20 \text { years old } \\
70.1 \% \text { between } 20 \text { and } 24 \\
6.1 \% \text { between } 25 \text { and } 29 \\
0.7 \% \text { more than } 30 \text { years old }\end{array}$ & $\begin{array}{l}\text { R-square for commitment } \\
=59 \% \\
\text { R-square for trust }=95 \% \\
\text { R-square for satisfaction = } \\
40 \%\end{array}$ \\
\hline (KUO; YE, 2009) & $\begin{array}{l}\text { 321 students } \\
\text { Taiwanese training institute } \\
\text { students }\end{array}$ & $\begin{array}{l}\text { SEM: } \\
\text { RMSEA =0.049 } \\
\text { GFI =0.94 } \\
\text { AGFI=0.92 } \\
\text { Cronbach's Alpha ranging } \\
0.32-0.66\end{array}$ \\
\hline (UDO et al., 2011) & $\begin{array}{l}203 \text { Students from a mayor public } \\
\text { University in USA enrolled in e- } \\
\text { learning classes } \\
56 \% \text { female } \\
65.2 \% \text { are }>24 \text { years old } \\
22.3 \% \text { are from } 24-35 \text { years old } \\
12.4 \% \text { are }<35 \text { years old } \\
\text { Online course: } \\
\text { Undergraduate level - } 80 \% \\
\text { Graduate level }-9.2 \% \\
\text { Non-degree }-10.7 \% \\
\text { Mayor: } \\
\text { Business }-42 \% \\
\text { Health sciences }-16.6 \% \\
\text { Art and sciences }-10.7 \% \\
\text { Engineering }-2 \% \\
\text { Others }-26.8 \% \\
\text { Incomes: } \\
<\$ 20,000-29.8 \% \\
<\$ 40,000-28.3 \% \\
<\$ 60,000-21.5 \% \\
>\$ 60,000-20.4 \%\end{array}$ & $\begin{array}{l}\text { SEM: } \\
\text { AVE for constructs varied } \\
\text { from } 0.797-0.955 \\
\text { Composite reliability varied } \\
\text { from } 0.87-0.98 \\
\text { Cronbach's Alpha varied from } \\
0.81-0.97 \\
\text { R-square quality }=0.706 \\
\text { R-square satisfaction }=0.631 \\
\text { R square loyalty }=0.886\end{array}$ \\
\hline $\begin{array}{l}\text { (BROWN; } \\
\text { MAZZAROL, 2009) }\end{array}$ & $\begin{array}{l}373 \text { students from } \text { Australian } \\
\text { universities }\end{array}$ & $\begin{array}{l}\text { Exploratory factor analysis in } \\
\text { order to test the proposed } \\
\text { constructs: } \\
\text { Image } \rightarrow 3 \text { components } \\
\text { - Study environment } \\
\text { - Practicality } \\
\text { - Conservativeness } \\
\text { Humanware quality } \rightarrow 2 \\
\text { components } \\
\text { - Responsiveness/reliability } \\
\text { - Assurance/empathy } \\
\text { Hardware quality } \rightarrow \\
\text { component } \\
\text { - Tangibles }\end{array}$ \\
\hline
\end{tabular}




\begin{tabular}{|c|c|c|}
\hline Study & Sample profile & Model goodness of fit ${ }^{5}$ \\
\hline & & $\begin{array}{l}\text { Perceived value } \rightarrow 4 \\
\text { components } \\
\text { - Emotional } \\
\text { - Social } \\
\text { - Price/value } \\
\text { - Quality/performance } \\
\text { Satisfaction } \rightarrow 2 \text { components } \\
\text { - Evaluative } \\
\text { - Emotional } \\
\text { Loyalty } \rightarrow 1 \text { component } \\
\text { - Loyalty } \\
\text { PLS Structural equation model } \\
\text { R-square evaluative satisf. = } \\
\text { 41\% } \\
\text { R-square emotional satisf. = } \\
50 \% \\
\text { R-square loyalty = } 72 \%\end{array}$ \\
\hline
\end{tabular}




\subsection{Instructor's perspective}

\subsubsection{Attitudes and acceptance of technology and $\mathrm{DE}$}

Quality in DE depends a lot on instructors' involvement and commitment to this method. Instructors are critical to a successful educational initiative and, for this reason, institution's administrators need to understand their motivations and behaviors in order to facilitate and stimulate their participation in educational programs, either online or face-to-face (TABATA; JOHNSRUD, 2008).

Technology is broadly used by instructors in order to conduct their daily professional activities; however, resistance is found when technology is about to be used on instructional delivery, as it happens in the DE method. In most of the cases, resistance emerges from many factors such as workload, technology competences, institutional support, reward and incentives, quality of instruction and learning etc. (TABATA; JOHNSRUD, 2008).

The study of technology acceptance appeared in the late 1980, in the organizational context for investigating adoption of information systems by employees. Davis et al. (1989) investigated the reasons people in the organizations rejected information system, that were conceived to improve organizational performance. Beliefs and attitudes and external factors like systems characteristics drive users' acceptance of the system. Based on the theory of reasoned action (TRA) by Fishbein and Ajzen (1975), Davis (1986) proposed a technology acceptance model (TAM) which aims to explain technology usage behavior (DAVIS. et al., 1989). System usage is determined by user behavioral intention, as well as perceived usefulness, as presented on Figure 25. Attitudes, in turn, are defined by perception of utility and ease of use. Perceived usefulness influences behavioral intention directly and indirectly through attitude. Ease of use also affects attitude directly and indirectly through usefulness. Both usefulness and ease of use are influenced by external variables and are forms of beliefs. Perceived usefulness is defined as how likely that system is, in the user's opinion, to improve his/her performance in the organization. Perceived ease of use consists of the degree the user perceives the use of the system will be free of effort. It means, if the user considers the system easy to use, he/she will feel more comfortable in using it and will develop feeling of control. This will influence his/her attitude toward the system as well as the perception of utility of the 
system. The function of both perceptions determine attitudes toward the system and, as a consequence, intention of use and actual use (DAVIS, F. D. et al., 1989).

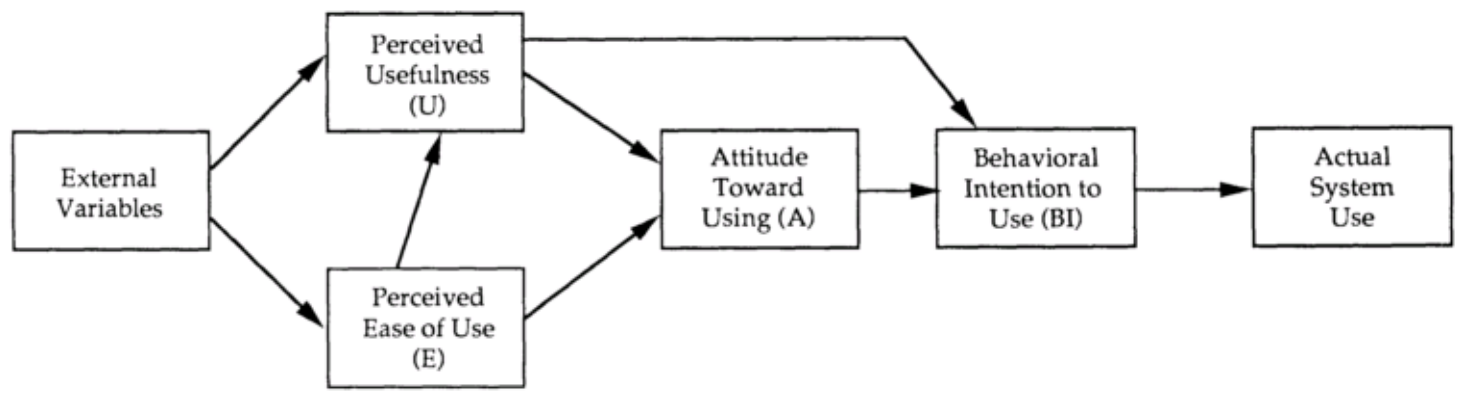

Figure 25. TAM Model

Source: (DAVIS et al., 1989, p.985)

Venkatesh and Davis (2000) proposed an extension to TAM in which perceived usefulness is explained in terms of diverse variables including social influence and cognitive process. Social influence processes include subjective norms, image and voluntariness (VENKATESH; DAVIS, 2000):

- Subjective norms consist of the individual perception that people important in his/her life consider he/she should perform the behavior in analysis. Then, people may perform a behavior even if they are not favorable to that or do not want to perform it, when reference people think they should.

- Voluntariness concerns the obligation to use a system. When the use is mandatory subjective norms influence directly intention to use.

- Image concerns the fact people have some behaviors aiming to create or keep a positive image in their group of influence. Subjective norms influence image, since if reference people think someone should perform determinate behavior, performing that behavior will increase their image inside the group. Image, on the other hand, influences perception of usefulness.

- Experience with the system reduces the subjective norms influence on behavioral intention and perception of usefulness. That is because the more familiar people are with the system the more knowledge they will acquire and, consequently, their behavior will be based on experiential information. 
Cognitive variables also influence system acceptance (VENKATESH; DAVIS, 2000):

- Job relevance consists of the extent to which the user considers the system relevant to perform his/her job. The more relevant system, the higher the usefulness perception.

- Output quality concerns the quality of the system; it means how well it performs its tasks. The better the perception of outputs quality, the better will be the perception of usefulness of the system.

- Result demonstrability consists to the extent to which the user is able to attribute job performance to the use of the system. The more the user is able to attribute his/her performance to the usage of that technology, the better will be his/her perception of usefulness.

- Perceived ease of use consists of the perception of needed effort to use a system. The easier the system, the better will be user's perception of usefulness.

The modified model is named TAM 2 and the constructs relationships are exposed on Figure 26.

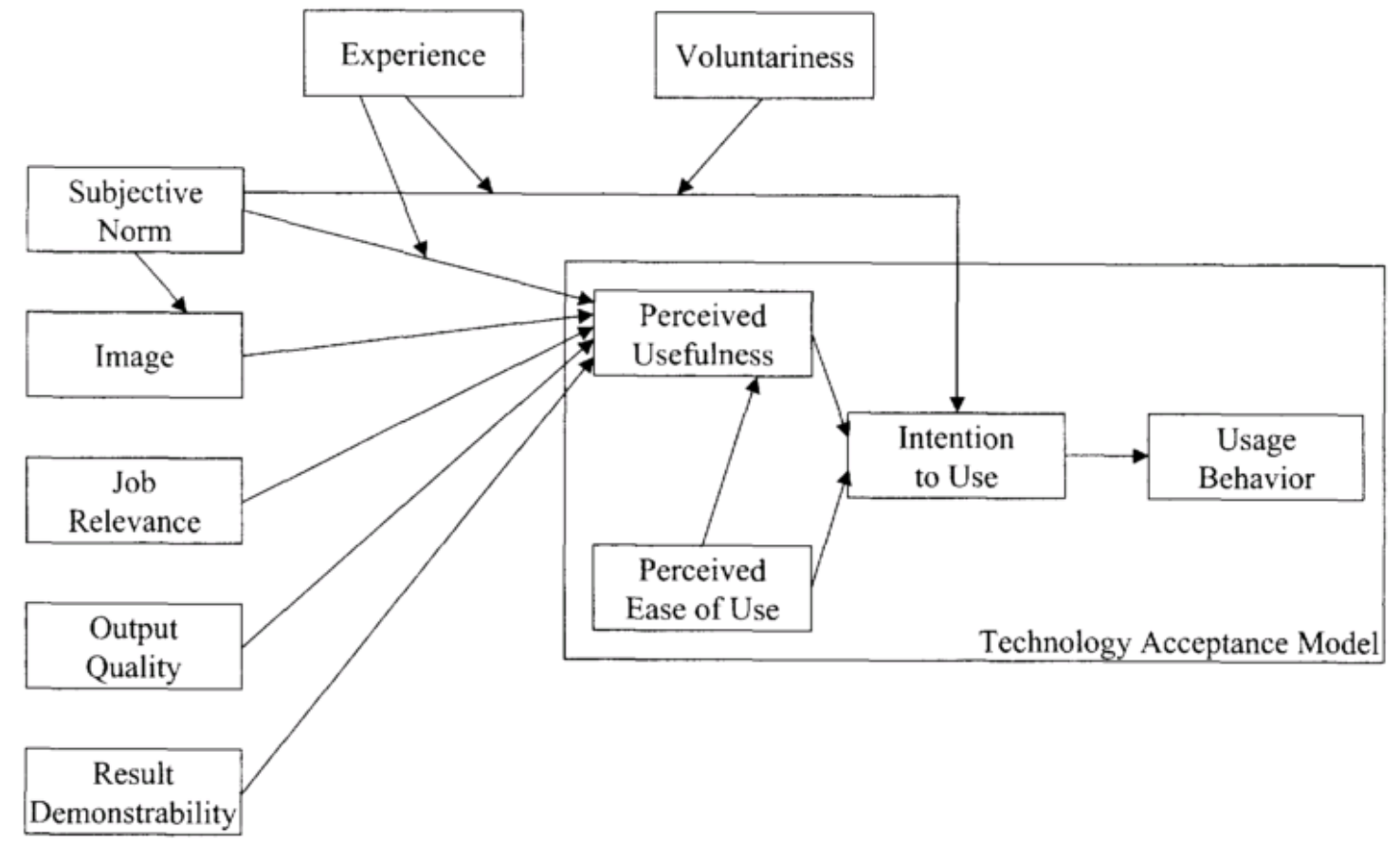

Figure 26. TAM 2 Model

Source: (VENKATESH; DAVIS, 2000, p. 187) 
Venkatesh et al. (2003), based on the review of existing model for studying technology acceptance, proposed the unified theory of acceptance and use of technology (UTAUT) exposed on Figure 27. In their perspective four constructs influence system usage intention: performance expectancy, effort expectancy, social influence and facilitating conditions, with moderation of the variables gender, age, experience and voluntariness of use. (VENKATESH et al., 2003).

Performance expectancy concerns the perception that the use of the system will bring gains in job performance. Its influence on behavioral intention will be moderated by age and gender; influence is stronger for men and young men specifically (VENKATESH et al., 2003).

Effort expectancy refers to the ease of use associated to the system. Its influence will be moderated by age, gender and experience; influence is higher for women, specifically younger women with less experience with the system (VENKATESH et al., 2003).

Social influence consists of the degree someone believes reference people think he/she should use the system. Its influence will be moderated by age, gender, experience and voluntariness of use (VENKATESH et al., 2003).

Facilitating conditions consist of the perception someone has that the organization provides adequate structure to the appropriate use of the system. It influences the use and is moderated by age and experience (VENKATESH et al., 2003). 


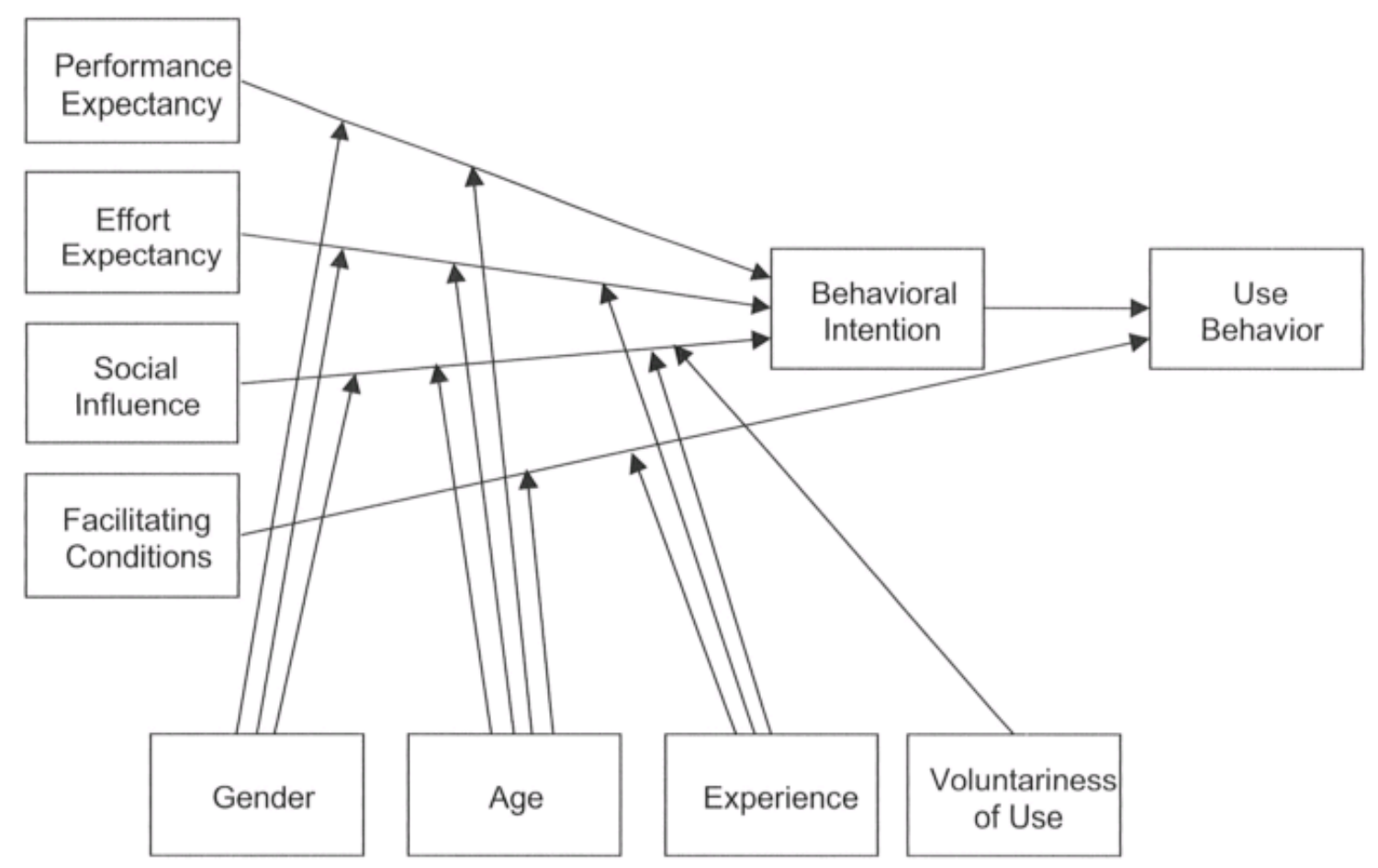

Figure 27. UTAUT Model

Source: (VENKATESH et al., 2003, p.447)

Although the models described in this section were conceived to be used in organizational contexts, researchers have been applying them to different contexts such as education. Considering the increasing usage of ICTs in educational field and the relevance of instructors to a successful course, studying technology acceptance is this context is appropriate. Zhou (2011) applied a modified version of UTAUT to evaluate mobile internet usage. He found from empirical data ${ }^{6}$ (ZHOU, 2011):

- Performance expectancy has no influence on user satisfaction.

- Performance expectancy has significant influence on technology usage.

- Effort expectancy has significant influence on user satisfaction.

- Effort expectancy has no influence on technology usage.

- Social influence has significant influence on technology usage.

- Facility conditions have significant influence on technology usage.

- Perceived enjoyment has significant influence on technology usage and user satisfaction.

\footnotetext{
${ }^{6}$ Zhou (2011) added to UTAUT model the constructs "perceived enjoyment" and "satisfaction".
} 
- Satisfaction has significant influence on technology usage.

Sánchez and Hueros (2010) applied TAM to evaluate MOODLE acceptance in a distance course. They supposed technical support and computer self-efficacy affect MOODLE acceptance in the University of Huelva. A sample of 226 students showed (SÁNCHEZ; HUEROS, 2010):

- Technical support influences perceived ease of use and perceived usefulness.

- Perceived usefulness influences attitude.

- Perceived ease of use influences attitude.

- Perceived ease of use influences Moodle usage.

- Perceived usefulness influences attitude.

- Attitude influences Moodle usage.

Bolliger and Wasilik (2009) studied faculty satisfaction with DE. They defined faculty satisfaction as the perception that online learning is effective and adds value to faculty job. As faculty satisfaction influences course quality, the authors created a scale to measure faculty satisfaction, considering three dimensions (BOLLIGER; WASILIK, 2009):

- Student related factors: access to higher education, student engagement in interactive communication.

- Instructor related factors: performance expectancy, intrinsic reward, interest in using technology to enhance work.

- Institution related factors: policies and support to DE usage.

Tabata and Johnsrud (2008) studied the factors that influence instructor participation in distance education. In their model technology use, attitude toward technology, attitude toward distance education and adoption of innovation determine faculty willingness to participate in distance education courses, as well as demographic characteristics (Figure 28) (TABATA; JOHNSRUD, 2008).

A faculty that perceives technology has a positive effect on his/her job is more likely to use it; the more technology is used, the more skillful becomes the faculty, which increases the likelihood of trying a different technology. Technology use and self-efficacy influence faculty 
attitudes toward DE and the probability to participate in a DE program. However, resistance to DE may happen for many reasons (TABATA; JOHNSRUD, 2008):

- Time investment: the amount of time needed to learn how to use a new technology and develop appropriate skills.

- Workload: the effect of DE in their workload.

- Lack of institutional support: inappropriate support for developing distance courses may lead to resistance.

- Lack of training and institutional support: providing training, workshops and support encourage faculty participation on distance course.

- Lack of rewards and incentives: if the participation on DE is not recognized and rewarded resistance may happen.

- Perception of learning quality: participation is stimulated if the faculty perceives outcomes of DE are positive.

\section{Demographic characteristics}

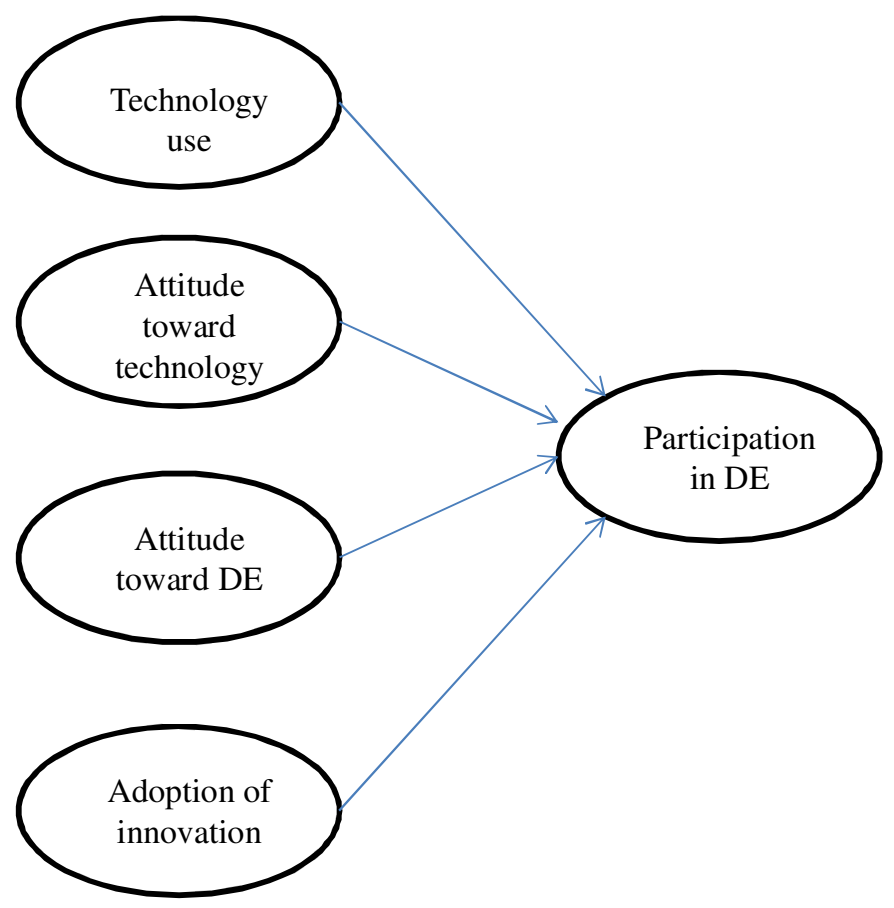

Figure 28. DE acceptance model

Source: (TABATA; JOHNSRUD, 2008, p.629). 


\subsection{Institutional perspective}

Competition and the need for a more cost effective education led many institutions to adopt strategic marketing approach. In order to be successful, institutions should find niches and formulate strategies to attract and keep these customers. However, strategic planning involves the "clarification of the institutional mission, identification of core capabilities, and examination of competitive environment" and quality assurance which is critical for successful strategy implementation (MOWEN; PARKS, 1997, p.28). This model suggests six steps should be watched in order to implement quality market-oriented strategy (Figure 29) (MOWEN; PARKS, 1997).

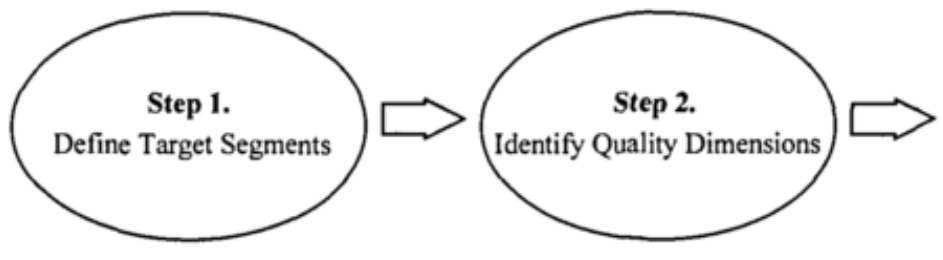

Step 3.

Assess the performance of specific quality dimensions through SERVQUAL

- Program Quality

- Service Quality

- Reputation for Quality

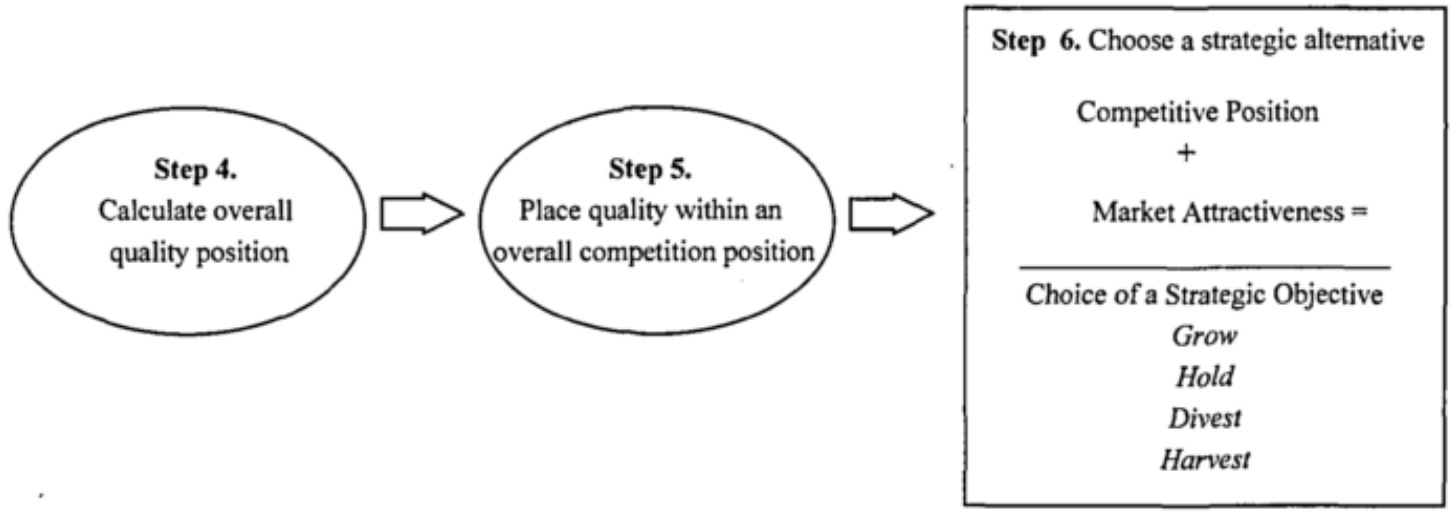

Figure 29. Marketing strategy for education

Source: (MOWEN; PARKS, 1997, p.30)

According to Garrison (2011) e-learning is an innovation in the educational market and may add a competitive advantage to the HEI. However, it must be clear that competition in higher education concerns quality, not technology adoption itself. Thus, e-learning fosters competition when it improves learning experience. Institution and faculty values and vision 
must be taken into account when formulating a strategic direction, or there is a great risk DE will face resistance inside the organization (GARRISON, 2011).

Kramarae (2001) based on the findings of her gender research gives some recommendations regarding distance education policies: distance learners should be treated as active learners; older students enrolled in DE are less homogeneous than face-to-face groups; so their situation should be taken into account; women ${ }^{7}$ exercising the function of course or institution administrators, students and teachers should participate in the online course's planning process; institution's mission should be clearly stated, including DE objectives; online programs should be continuously evaluated; create opportunities so online students can interact face-to-face in some situations; find ways to make female students feel welcome online; interview students who dropped out; ensure that the promotional materials and the course contents provide relevant information and sufficient guidance; develop policies and conduct codes for online education and make it available as part of the course content; train instructors for online communication and moderation; make the learning needs addressed by the program clear; use methods that give students an opportunity to engage in the course (KRAMARAE, 2001).

Online education became central in higher education discourse, due to its promise of providing access to higher education, increasing learning engagement and developing student's technological literacy. However, many institutions join distance education model, just because it is a market trend; it means, technology is largely available, cost efficacy and convenience are highly valued and demand for education is raising; distance learning raises from these set of events. On the other hand, considering competition is fierce in education market, schools feel compelled to join DE (COX, 2005).

In general distance education starts with the adhesion of a few professors who usually are technology early adopters. Creating appropriate structure for online education may be very costly (high technology investments, technology support and student support services), even though the institution may have small numbers of online students in the beginning. After organizing the basic structure for $\mathrm{DE}$, adherence of other professors is needed in order to expand operation; in this sense; some issues, such as compensation, intellectual property and

\footnotetext{
${ }^{7}$ It is important to include women coordinators on the planning process, since female students have great participation in DE.
} 
evaluation come to light. For the purpose of expansion it is necessary to coordinate six dimensions: administrative commitment, online student support services, full-time online coordinator, adequate faculty participation, online professional development, financial and technological support (COX, 2005).

Institutional theory explains how organizations respond to environmental conditions, environment considered the whole set of institutional rules that guide their work, as exposes Figure 30 .

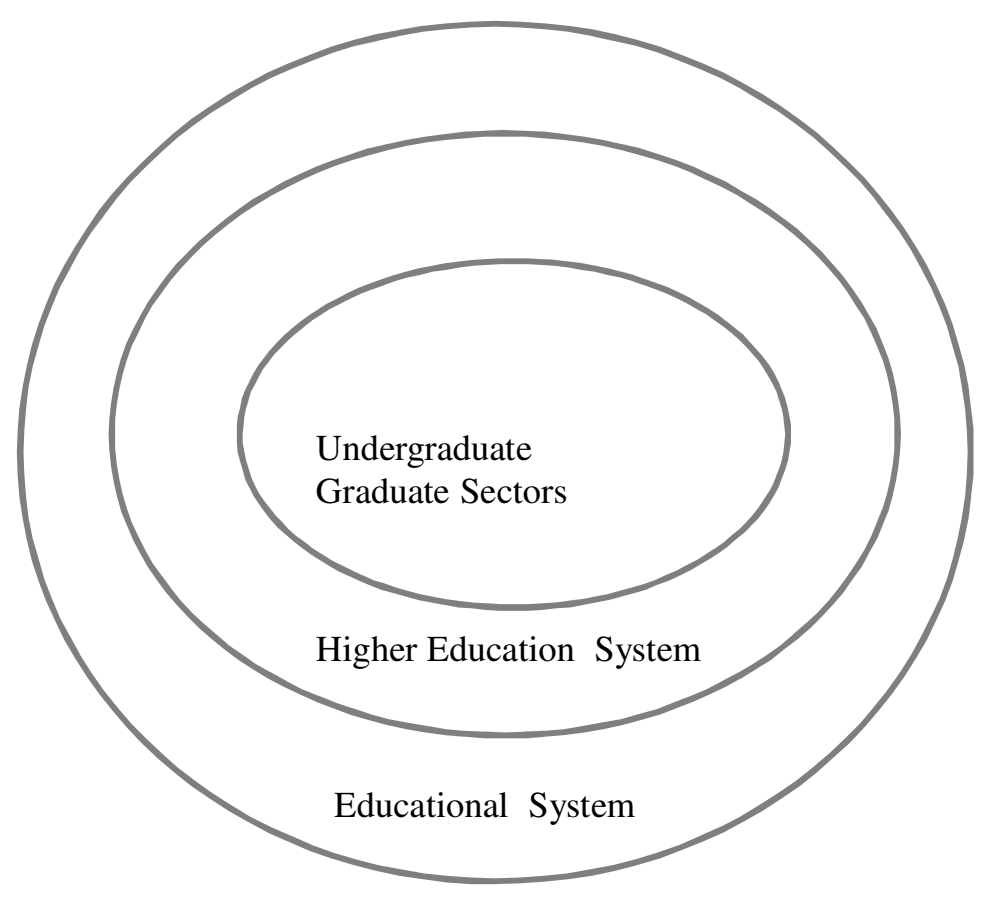

Sociopolitical System

Figure 30. Institutional theory model

Source: Adapted from (COX, 2005).

Njenga and Fourie (2010) point a compulsive enthusiasm about distance education in higher education. For them institutions should step back and reflect about the critical factors involved in the use of technology in education. Educational technology was presented as a source of benefits and market opportunities to schools. Nevertheless, teachers and educational researchers were denied the time and opportunity to investigate the motivation, potential, application and possible consequences of the use of technologies in teaching and learning. 
This phenomenon created a false belief that the simple use of technology leads to meaningful knowledge creation, which mixes the concepts of knowledge and information (NJENGA; FOURIE, 2010).

The authors state that many instructors cannot define e-learning clearly, confusing it with the use of technology to enrich classroom experience, which shows an excessive focus on technology rather than on education itself (NJENGA; FOURIE, 2010).

White (2007) suggests technology usage in higher education does not keep up with technology used in daily life and that's the reason DE courses have trouble in achieving success. Then DE must come through a strategic planning and policies definition. This means institution must provide directions for effective distance teaching and learning, including quality standards (WHITE, 2007).

Despite of the controversy about the adoption of DE by HEI and its motivation, it is important to discuss on the university point of view the factors that drive effective DE, named critical success factors in the literature. Selim (2007) points out four categories of critical success factors for distance education courses (SELIM, 2007):

- Instructor: technology self-efficacy, teaching style, attitude toward DE.

- Student: time management skills, computer skills, attitude toward DE.

- Information technology (IT): appropriate structure; reliable and high quality systems and tools (video, audio, Internet access, learning management system (LMS) etc.).

- Institutional support: technical and administrative support.

Benson Soong et al. (2001) define success occurs in DE when: student uses and enjoys using the resources; student considers the resources rich and helpful; instructors consider the resources add value to educational process. They suggest five critical success factors (Figure 31) (BENSON SOONG et al., 2001):

- Human factors: interaction and motivation skills from both students and instructors.

- Technology self-efficacy.

- Attitude toward DE.

- Level of collaboration: student active participation. 
- $\quad$ IT structure.

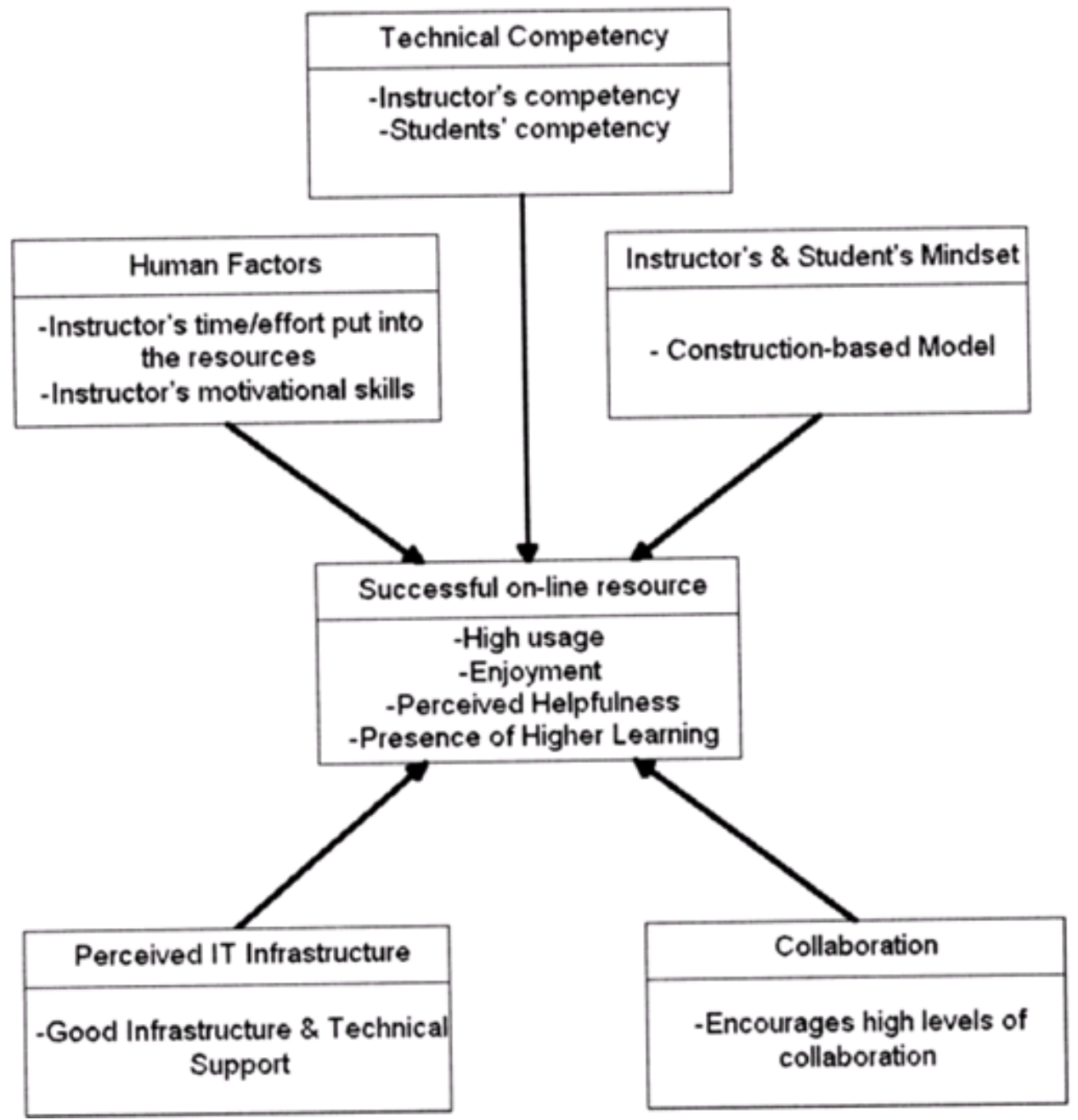

Figure 31. Critical success factors for DE

Source: (BENSON SOONG et al., 2001, p.108).

The topics discussed in chapter 2 give foundation to the study development. 


\section{RESEARCH METHOD}

This chapter presents the research structure, as exposes Figure 32. Initially mixed method design is presented; then case study strategy, chosen for the research, is described. The following items present the study phases, model and sampling, the instruments, variables and hypotheses, validity and reliability procedures, data collection and analysis techniques.

\begin{tabular}{|l|}
\hline \multicolumn{1}{|c|}{3 RESEARCH METHOD } \\
Research design \\
Research strategy \\
Research phases \\
Research model and sampling \\
Instruments, variables and hypotheses \\
Validity and reliability \\
Data collection \\
Data analysis
\end{tabular}

Figure 32. Chapter 3 structure.

\subsection{Research design}

The present item exposes the research method framework selected for this dissertation in order to make the study conduction possible and to help accomplishing research objectives appropriately.

A research may assume different designs in a continuum which varies from a pure qualitative to a pure quantitative design. Between both extremes there are the mixed methods designs which include qualitative and quantitative approaches. The decision for the design should be based on the problem's characteristics, on the prior experiences of the researcher in charge and on the characteristics of the research report audience (CRESWELL, 2009). Mixed 
methods, is a set of research methods which guides data collection and analysis, mixing qualitative and quantitative approach during research process. It is an interesting approach because mixing data leads to a deeper understanding of the research problem and help answering questions that could not be appropriately responded through one single approach (either qualitative or quantitative) (CRESWELL; CLARK, 2007). Greene (2007) highlights qualitative data is frequently used to explain quantitative findings. Usually, mixed methods approaches apply different methods separately (collection, analysis and conclusions are independent), and then correlations and comparisons are made among the sets of results (GREENE, 2007).

Once the design is selected, the researcher should choose the strategy that better fits the study objectives. Quantitative strategies include experimental studies, quasi-experimental studies and survey studies; qualitative strategies include phenomenological studies, ethnographic studies, grounded theory and case studies. Finally, mixed strategies are those that put quantitative and qualitative strategies together in the same study (CRESWELL, 2009). In addition, quantitative data includes closed-ended information, such as those found on perception, attitude and behavioral instruments; qualitative data, in turn, concerns open-ended variables, gathered through interview, observation and documentary records (CRESWELL; CLARK, 2007).

Mixed method strategies can be sequential, concurrent or transformative. Sequential strategies (represented in Table 8 by $\rightarrow$ symbol) aim to use an additional research strategy after a first one has been applied, in order to expand the results obtained by the first research strategy; for example, in case an exploratory focus group is followed by a survey, it would be considered a sequential strategy (CRESWELL, 2009).

Concurrent strategies (+ symbol) use both qualitative and quantitative methods simultaneously for data gathering and analysis. Finally, transformative strategies use a theoretical framework in the study which may include sequential $(\rightarrow)$ and concurrent $(+)$ data gathering methods (CRESWELL, 2009).

Creswell (2009) adds that quantitative studies, for instance, try to compare or relate variables and constructs while qualitative research aims to explore, discover or understand a phenomenon, concept or idea. In addition, in qualitative studies researcher collects data 
through observation, document analysis or even conducting a personal interview; interaction with the objects is very relevant for this kind of studies (CRESWELL, 2009).

In cases qualitative or quantitative methods are not enough to answer the research questions or when the phenomenon in focus is highly complex to be comprehended through a unique method, mixed methods approach may be an appropriate framework. According to Morse (2003) mixed methods approach implicates the conduction of diverse related projects within the same research study, in order to solve a larger and complex problem. Though, there is a dominant direction in each study (quantitative or qualitative), mixed methods approach makes it possible to use both methods, respecting their sampling requisites and their validity and reliability characteristics as well (MORSE, 2003). Morse (2003) presents eight different types of mixed method designs, as presented on Table 8.

Table 8. Mixed method designs

\begin{tabular}{l|l|l}
\hline Orientation & Design & Definition \\
\hline Inductive & QUAL+qual & $\begin{array}{l}\text { Two qualitative methods are simultaneously applied, one of } \\
\text { them is dominant or is the basis for the whole project }\end{array}$ \\
\cline { 2 - 3 } & QUAL $\rightarrow$ qual & $\begin{array}{l}\text { Two qualitative methods are sequentially applied, one of } \\
\text { them is dominant or is the basis for the whole project }\end{array}$ \\
\cline { 2 - 4 } & QUAL+quan & $\begin{array}{l}\text { A qualitative and a quantitative method are simultaneously } \\
\text { applied, qualitative method is dominant }\end{array}$ \\
\cline { 2 - 4 } & QUAL $\rightarrow$ quan & $\begin{array}{l}\text { A qualitative and a quantitative method are applied } \\
\text { sequentially, qualitative method is dominant }\end{array}$ \\
\cline { 2 - 4 } Deductive & QUAN+quan & $\begin{array}{l}\text { Two quantitative methods are simultaneously applied, one of } \\
\text { them is dominant or is the basis for the whole project }\end{array}$ \\
\cline { 2 - 4 } & QUAN + qual & $\begin{array}{l}\text { Two quantitative methods are sequentially applied, one of } \\
\text { them is dominant or is the basis for the whole project }\end{array}$ \\
\cline { 2 - 4 } & $\begin{array}{l}\text { A quantitative and a qualitative method are simultaneously } \\
\text { applied, quantitative method is dominant }\end{array}$ \\
\hline
\end{tabular}

Source: By the author, based on MORSE (2003).

Considering the complexity of the problem studied in this dissertation: evaluate services marketing dimensions in distance education, considering three different perspectives (students', instructors' and institutional perceptions) and investigating the relationships among these factors, it is appropriate to conduct some subprojects simultaneously in order to answer the research questions; then mixed methods approach was selected, in the QUAN+qual design. This means, the research has a quantitative orientation and uses both 
qualitative and quantitative strategies in order to achieve the study objectives. Table 9 summarizes the subprojects included in the research.

Table 9. Research subprojects

Research problem: What are the perceptions of students, instructors and coordinators of service marketing dimensions in a distance education course?

Dominant orientation: Quantitative

Project a: survey with PNAP students. Aims to identify their perceptions Quantitative

of course quality, satisfaction, loyalty and image and their profile.

Project b: interviews with coordinators in order to understand course Qualitative dynamic and their perceptions about the course.

Project c: survey with PNAP instructors (professors and tutors). Aimed at Quantitative identifying their attitudes and acceptance of technology and DE.

Project $\mathrm{d}$ : study of UAB and PNAP characteristics, based on Qualitative documentary records

Project e: relate constructs and triangulate data

Quantitative and qualitative

It is worth to comment Creswell and Clark (2007) propose a different classification for mixed methods design: triangulation, embedded, explanatory and exploratory design. Triangulation seems to be adequate to the present study, since it aims to use both qualitative and quantitative information in order to better understand the research problem. It is used when the researcher needs to compare quantitative results with qualitative results, as exposed on Figure 33 (CRESWELL; CLARK, 2007). Then the present dissertation applies a QUAN+qual (MORSE (2003) classification) triangulation design (CRESWELL; CLARK (2007) classification).

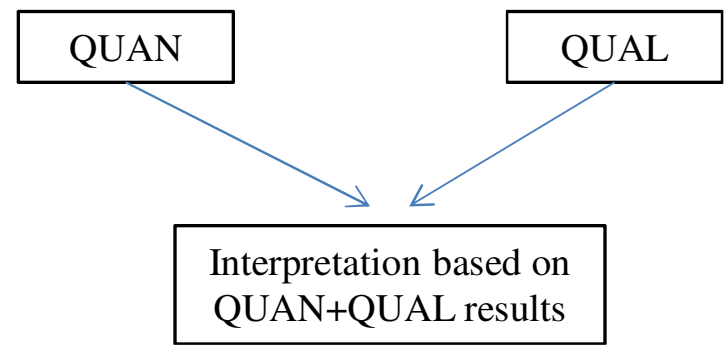

Figure 33. Triangulation design.

Source: (CRESWELL; CLARK, 2007, p.63)

Within educational field, research is important because it helps to "develop new knowledge about learning, teaching and educational administration" (GALL et al., 2003, p.3). The 
present study may be understood under the educational research approach, since its objective is to provide information about marketing dimensions in a DE course, in order to foment educational management and decision making.

According to Gall et al. (2003), research may provide description knowledge, that is, describing a phenomenon (its structure, relations, activities etc.) through the use of a set of data collection instruments (questionnaires or interviews). Description studies are a kind of quantitative research that aims to respond "what is" kind of questions (GALL et al., 2003). This dissertation is a descriptive study that describes the phenomenon of interest at one point in time. The following item describes the research strategies used in the study.

\subsection{Research strategies}

Each phase of study makes use of a different research strategy, which defines it as a mixed method design. Since PNAP was chosen as the case for this dissertation case study strategy is used in order to provide deep understanding of the object. Survey strategy is applied to the study within PNAP students and PNAP instructors and adds information to the case. Documentary research is used with the objective of analyzing UAB and PNAP missions and processes and offers useful information that could not be accessed by other kinds of research design. Figure 34 shows strategies applied to this study. 


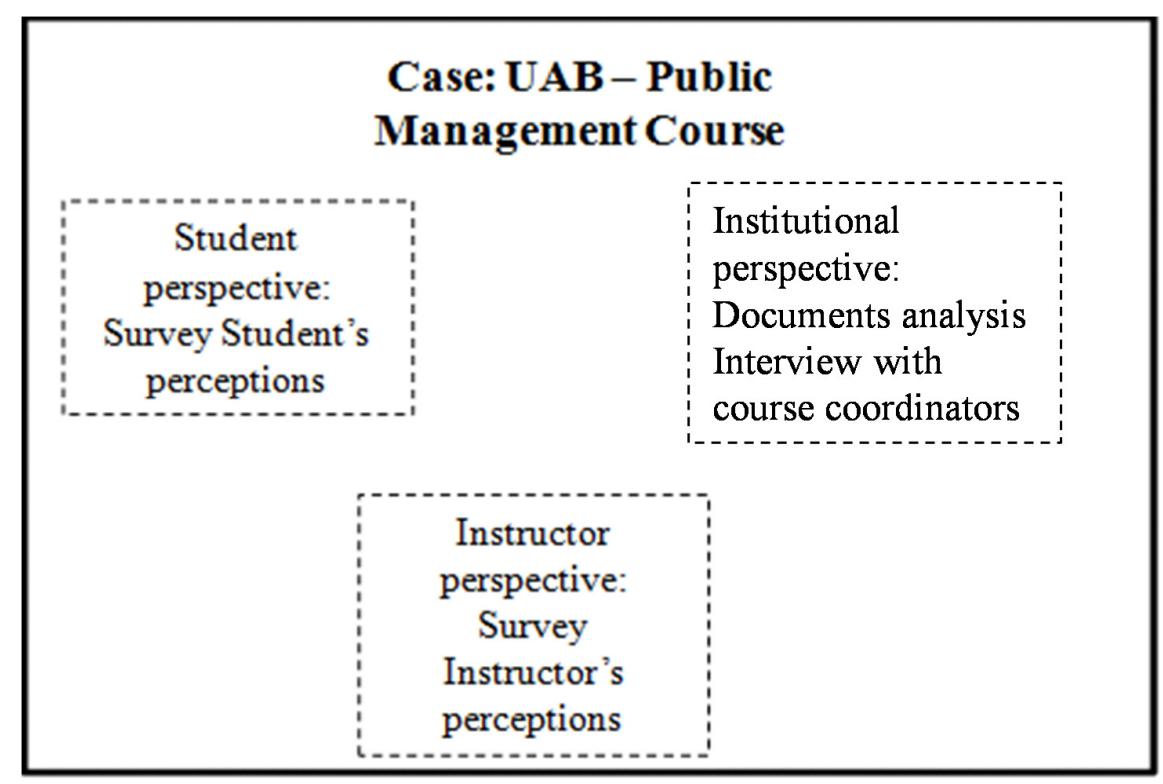

Figure 34. Research strategies scheme

\subsubsection{Case study}

According to Yin (2005), a case study is a kind of empirical investigation which analyses a phenomenon in its real context. The phenomenon may be a process, people, an event, or anything that interests to the researcher. After the phenomenon is clear, a case may be selected; that is, a case is an instance of the whole phenomenon (GALL et al., 2003). In addition, the researcher cannot control the behavioral events; so data collection and analysis have specific characteristics. Researcher seeks to capture the whole situation and then, describe, comprehend and interpret the case complexity, revealing deep analysis (MARTINS, 2006).

Case studies usually handle a large number of variables, making triangulation necessary. Thus, theoretical propositions should be previously created, in order to guide data gathering and analysis; for this reason case study may be considered a broad research strategy (YIN, 2005). This strategy aims to provide understanding about complex social phenomenon and answer questions such as "how" and "why" (YIN, 2005).

Case studies may assume two variations: unique and multiple. Single case study is appropriate when the case represents the most adequate option for testing a theory or for testing a set of 
propositions. In addition, it is also useful when the case represents a rare or an extreme case, a representative or a typical case, a revealing or a longitudinal (the same case is studied in two different time occasions) case (YIN, 2005). In opposition, a multiple case study develops more than one unique case (YIN, 2005). This research is considered a single case study, since it studies only PNAP undergraduate course.

\subsubsection{Survey}

Survey was used in two phases of the study: 1) to assess student's perceptions about their experience in the distance course and 2) to assess instructors' attitudes toward technology and distance education.

According to Fowler (1988) and Fink (1995a) a survey owns the following characteristics:

- Aims to describe some interesting aspects of the population (FOWLER, 1988) or to compare or explain a phenomenon, attitudes or behaviors (FINK, 1995a).

- Data gathering happens through the use of questionnaires administered to a sample from the interest population (FOWLER, 1988).

- A sample is extracted in order to provide information about the population (FOWLER, 1988).

- Usually involves a few phases: sampling, instrument development, data collection (FOWLER, 1988), data analysis e reporting (FINK, 1995a).

In order to develop an effective survey some points need to be observed (FINK, 1995a):

- Clear objectives: objectives should be expressed in a simple and clear manner, with no ambiguities that could induce to different interpretations.

- Well formulated questions: questions must allow the extraction of meaningful information. Thus, they need to be well written, bring just one subject at once, do not be repetitive, must set clear the relationship between the question and the research objectives. In order to guarantee all these aspects are met, questions may be evaluated by experts and by a group of subjects from the target population, before data gathering. Open-ended questions may be interesting if the objective is to explore an 
unknown subject or to capture the target view. However, open-ended questions are difficult to categorize and interpret.

- Appropriate design: involves the survey planning process.

- Representative sampling: in order to guarantee high levels of response rate, trained interviewers must be employed. In addition, it is necessary to stimulate target interest about the research subject, keep information under confidentiality, keep up with the answers, sending stimulus to the questionnaire completion.

- Instruments must be valid and reliable: a reliable instrument brings the same content every time it is applied; a valid instrument provides accurate information, measuring appropriately what it was meant to measure.

- Adequate analysis and reporting of the findings.

According to Creswell (2009) a survey may assume a cross-sectional form, when data is collected at a defined point of time; similarly, it may be longitudinal when data is collected more than once, in order to follow the sample for a period of time (CRESWELL, 2009). The present dissertation conducted cross-sectional surveys with both UAB students and instructors.

Fink (1995c) provides some directions to prevent bias on cross-sectional surveys:

- Researcher must consider the possibility of unexpected events during the data collection. These events may cause bias to the study (i.e. curriculum change during the collection may change student's perception about the course).

- Maturation of the individuals may occur during a long data collection; it means people may change their perceptions and behavior with possible bias to the study.

- Randomness must be pursued in order to guarantee generalized of the findings (external validity).

- Missing data must be evaluated and patterns searched.

Plenty of techniques may be applied for data gathering in survey design, such as selfadministrated questionnaire (the individual fills out the form by him/herself) or interview (interviewer reads the questions to the individual and takes notes of his/her answer) (FOWLER, 1988; CRESWELL, 2009). The choice for one technique or another depends on 
the costs involved, deadlines, and population profile. The last, concerns the population members reading and writing skills and technology skills etc. (FOWLER, 1988).

\subsection{Research phases}

Study was conducted in three phases simultaneously. First phase concerns institutional perspective study, which included interviews with course coordinators and documentary analysis. Second phase consisted of a survey applied to PNAP instructors (professors and tutors) in order to capture their attitude and acceptance of technology and DE. Third phase consisted of a survey applied to PNAP students. This survey aimed to identify their profile (gender, age, family and employer support, dedication to course etc.) and their perception of services marketing dimensions studied by this dissertation: perceived quality, loyalty, UAB image, DE image, course satisfaction. Figure 35 illustrates research phases.

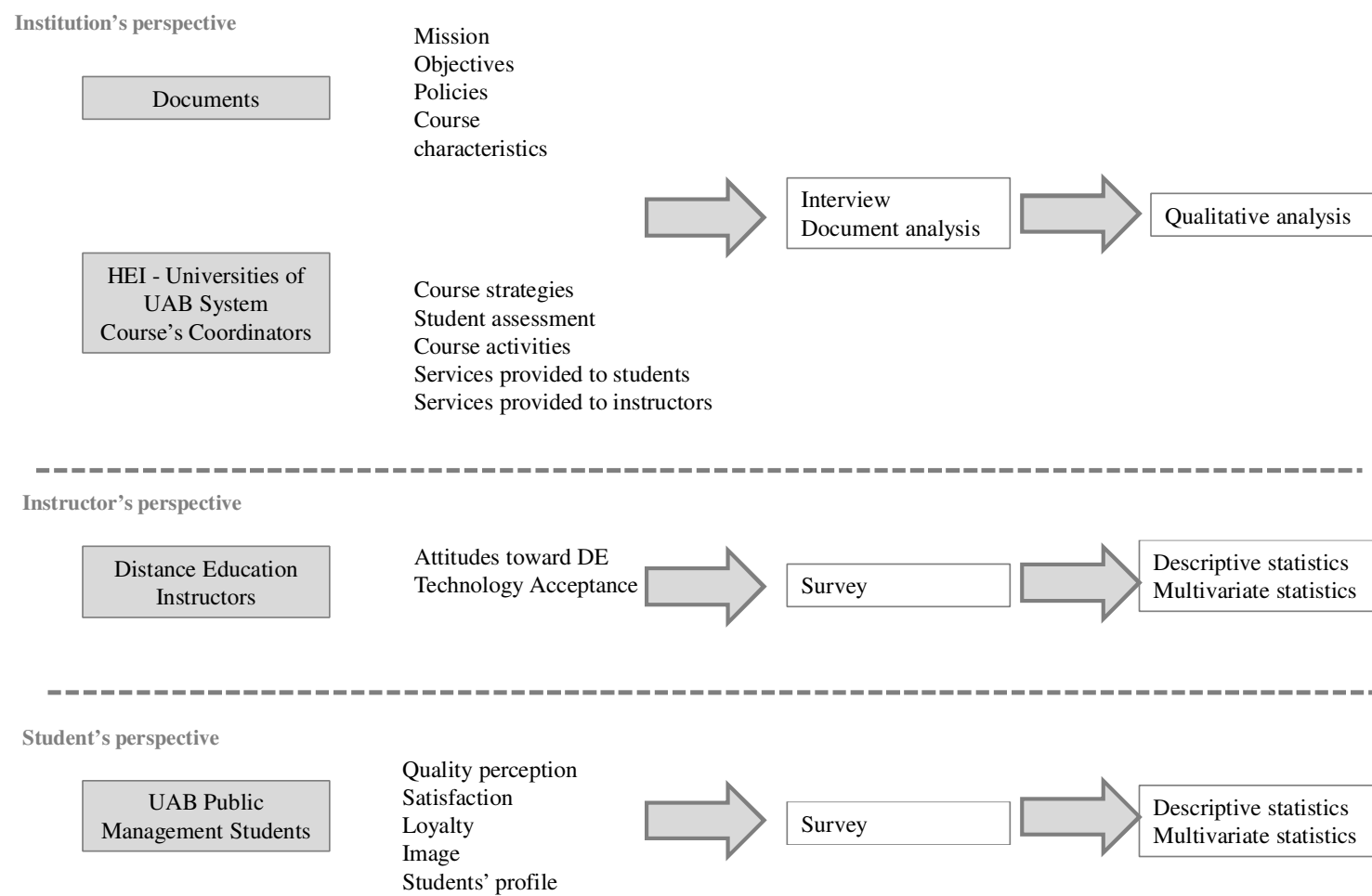

Figure 35. Research phases

Each research phase is further discussed on the following items. 


\subsubsection{Institutional perspective}

Institutional perspective was acquired through course coordinators perceptions and documentary analysis. Sampling will be described on item 3.4, but it is important to explain that all PNAP members were invited to the research. However, only ten institutions actually agreed to participate on data collection. For each of these institutions students, instructors and coordinators were researched. Coordinators were chosen for the study, because they work as course administrators; that is, they have institution and UAB best interests in mind, which drive their decisions and strategies. They also have direct contact with students, who are consumers of educational services and instructors, who provide educational services, and as seen in the literature review, strongly impact on student's perceptions of the course and, consequently, on the course results. Interview script can be found on Appendix E.

In addition, documents found on UAB and institution's websites were analyzed in order to comprehend better how UAB system works and what is the specific dynamics of PNAP undergraduate course.

\subsubsection{Instructor's perspective}

As discussed on chapters 1 and 2, instructors' involvement and relationships with students are a central dimension in educational services, especially in distance courses, it is even defined as a critical success factor by some authors. Bolliger and Wasilik (2009) and Mitchell and Geva-May (2009) highlight the importance of understanding instructor's perceptions and attitudes toward DE, as a pedagogical model. In their point of view this analysis is important because instructors' perceptions and attitudes affect students' perceptions of course quality, their satisfaction and performance (BOLLIGER; WASILIK, 2009).

For these reasons a survey was conducted with professors and tutors from PNAP in order to acquire their attitudes and acceptance of technology and DE. Both professors and tutors are mixed in the same sample and were included since they have a relevant participation in student's educational experience; professors are responsible for planning learning activities 
and giving lectures; online tutors are responsible for solving doubts, controlling students' performance and participation and helping both students and professors with technical problems that may take place on the LMS. Questionnaire can be found on Appendix D.

\subsubsection{Student's perspective}

In a market-oriented view students are consumers of educational services; so their expectations and needs must be clear and met. Therefore, knowledge of students' perceptions of quality, their satisfaction, their perception of institution's image as well as DE image and their loyalty to course is essential for educational administration and decision making. Thus, a survey was conducted with students from the ten universities members of PNAP and included, besides of profile variables, agreement questions concerning to the dimensions described above and structural aspects of the course. Instrument can be seen on Appendix C.

\subsection{Research model and sampling}

This item presents sampling procedures and research models adopted for results analysis.

\subsubsection{Sampling}

The Open University of Brazil (UAB) was chosen as a case study for this dissertation, specifically PNAP bachelor degree course. This choice, as argued on chapter 1, was based on the following evidences:

- it is a public initiative that involves federal and state institutions all over the country, which is strongly relevant to the country's development;

- UAB mission is to expand education to remote unprivileged locations where face-to-face education is not available;

- these institutions offer open access to their data, for the fact they are public and interested on having their courses evaluated; 
- Public Management course is related to business field and aims to prepare people to work on public institutions; it means the objective is to improve workforce to act in public companies and departments.

Only PNAP bachelor degree was studied for many reasons:

- Graduate and undergraduate courses are different in nature and student profile, which makes it inappropriate to mix both in the same work.

- Although there are many undergraduate courses provided by UAB system, mixing different courses would be inadequate, since each one has a specific design, different activities and student profile.

- Initial idea was to study business bachelor degree course, since business education is a field of personal interest of the researcher and of the graduate program where this dissertation is under development and will be defended (FEA Business Department to which the researcher is affiliated). However, this course is available in a small number of UAB institutions, which could complicate data gathering. Public management, although differs in many ways, has many disciplines in common with business course, which makes its study interesting for both the researcher and the business graduate program.

Considering the research model proposed for the study, the appropriate sampling framework would be stratified cluster sampling, which is a double sampling technique or two-phase sampling (COCHRAN, 1977; THOMPSON, 1992). A double sampling design extracts a unit sample in order to obtain additional information and from these initial units a second sample is selected. The purpose of this framework is to obtain better results, since the relations between the first and the second samples are taken into account (THOMPSON, 1992).

This framework initially stratifies the population into strata, which would be Brazilian geographic areas. Then, the universities in each stratus, which offer Public Management undergraduate course in 2012, are selected composing the sample (first sample). Finally, for each university enrolled in the research, a convenience sample of students and instructors was selected, which results in the second sample. Figure 36 presents the theoretical scheme for a stratified cluster sampling approach. 


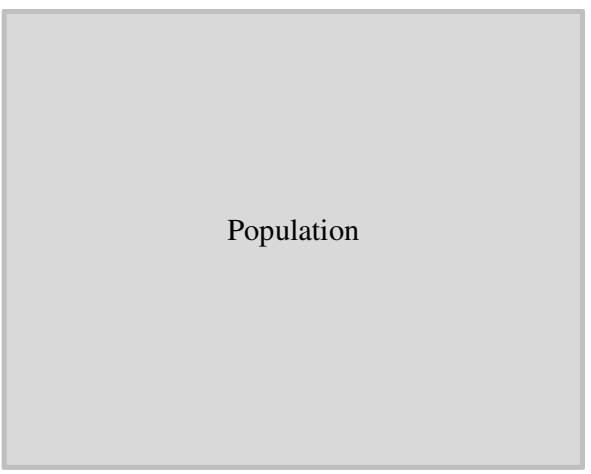

\section{Stratus A}

\section{Stratus B}

Stratus C

Stratus D

Stratus E

Figure 36. Stratified cluster sample scheme

There are 36 institutions currently offering Public Management undergraduate course through UAB system (see Appendix B) in the five regions of Brazil. To compose the sample all of the institutions were invited to participate of the study. The request was placed through an invitation letter (see Appendix F) explaining the research objectives and guaranteeing confidentiality for those which agreed to participate. The letter was sent by email on May $2^{\text {nd }}$ 2012 to UAB and PNAP coordinators. From the total, 17 institutions answered positively to the letter and proposed to support the study; the links to the electronic questionnaires (GOOGLE DOCS $($ ) were emailed to them. Only ten universities actually divulged the questionnaires to their students and instructors and asked for their participation.

Collection occurred from May $2^{\text {nd }}$ to $30^{\text {th }}$ and the final sample totalized 593 valid responses (from a total of 600 questionnaires) from students and 120 valid responses (from a total of 130 questionnaires) from instructors. Thus, nine coordinators ${ }^{8}$ were interviewed: one by Skype ${ }^{\circledR}$, four by telephone, two by email and two in person. Final composition of the sample is illustrated on Table 10. In order to keep confidentiality, the institutions will be named A to $\mathrm{J}$ and the states where they belong to will not be mentioned, since in some states there is only one institution member of PNAP.

\footnotetext{
${ }^{8}$ Coordinator from institution B was not available for the interview.
} 
Table 10. Sample composition

\begin{tabular}{|c|c|c|c|c|c|}
\hline \multicolumn{2}{|c|}{ Institution } & \multirow{2}{*}{\begin{tabular}{|l|} 
Region \\
South \\
\end{tabular}} & \multirow{2}{*}{\begin{tabular}{|r|}
$\begin{array}{r}\text { Instructors } \\
\text { Frequency }\end{array}$ \\
45 \\
\end{tabular}} & \multirow{2}{*}{\begin{tabular}{|c|c|}
$\begin{array}{c}\text { Students } \\
\text { Frequency }\end{array}$ \\
70
\end{tabular}} & \multirow{2}{*}{\begin{tabular}{|l} 
Coordinator \\
Email
\end{tabular}} \\
\hline & A & & & & \\
\hline & $\mathrm{B}$ & Southeast & 5 & 112 & $\begin{array}{l}\text { Not } \\
\text { interviewed }\end{array}$ \\
\hline & $\mathrm{C}$ & Northeast & 8 & 65 & Email \\
\hline & D & Northeast & 7 & 46 & Skype \\
\hline & $\mathrm{E}$ & Midwest & 1 & 37 & In person \\
\hline & $\mathrm{F}$ & Southeast & 8 & 131 & Telephone \\
\hline & $\mathrm{G}$ & Northeast & 6 & 24 & Telephone \\
\hline & $\mathrm{H}$ & Northeast & 9 & 23 & Telephone \\
\hline & $\mathrm{I}$ & South & 29 & 85 & Telephone \\
\hline & $\mathrm{J}$ & South & 0 & 0 & In person \\
\hline & Total & 4 regions & 118 & 593 & 9 \\
\hline Missing & & region north & 2 & 0 & 1 \\
\hline Total & & 4 regions & 120 & 593 & 10 \\
\hline
\end{tabular}

\subsubsection{Research models}

According to research objectives and the literature review, research models were defined as follows.

\section{- Student's perspective}

Data from student survey allowed hypotheses testing through a structural equation model (Figure 37) and other kinds of statistical analysis. Student's perspective data analysis tested hypotheses: $\mathrm{H} 1$ to $\mathrm{H} 16$ and $\mathrm{H} 18$ to $\mathrm{H} 23$. 


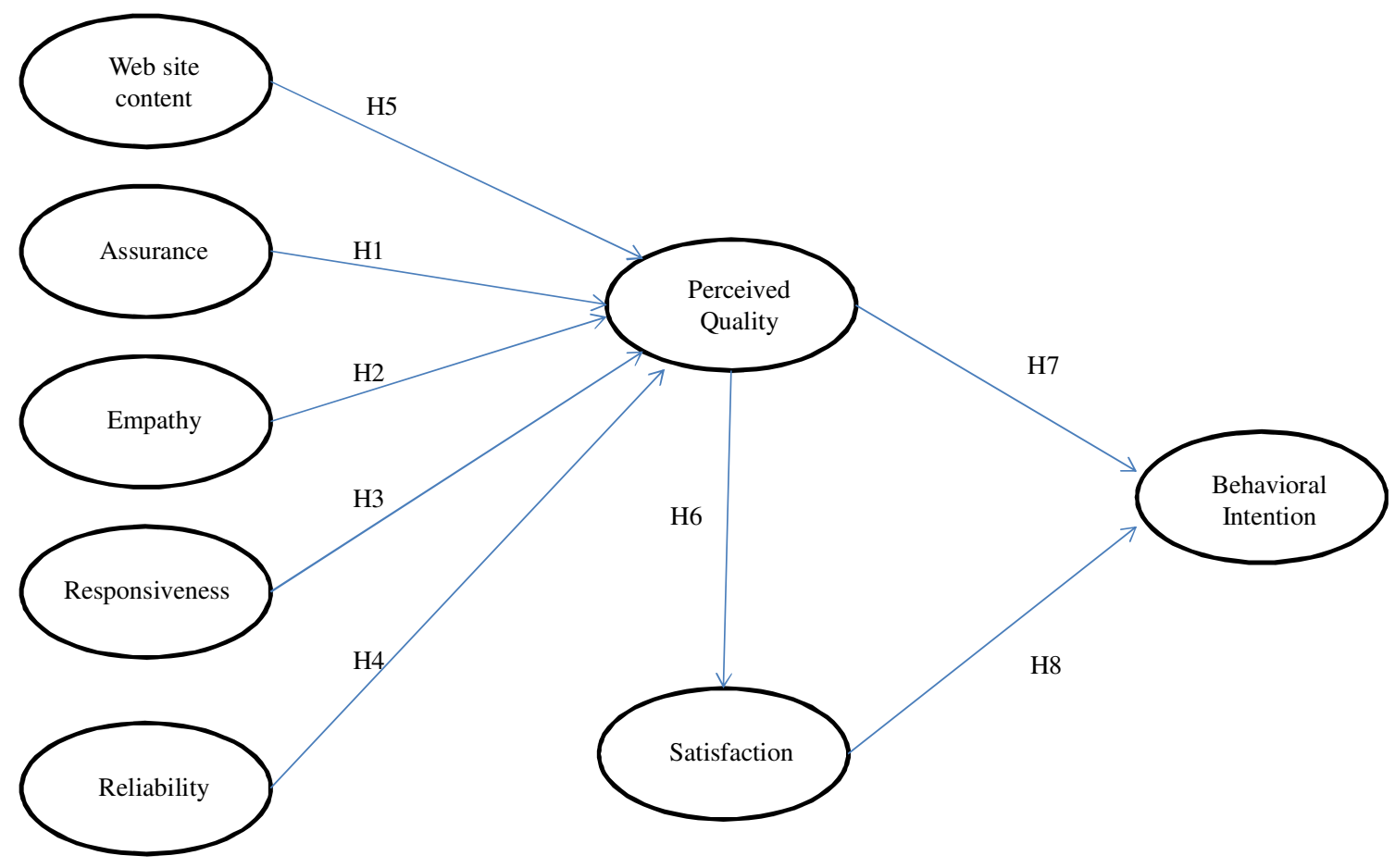

Figure 37. Research model for student's perspective

Source: (UDO et al., 2011).

\section{- Instructor's perspective}

Instructors' data provided evidence for testing hypotheses H25 to H31. The path model presented by Figure 38 will test hypotheses H25 to H28. 


\section{Demographic characteristics}

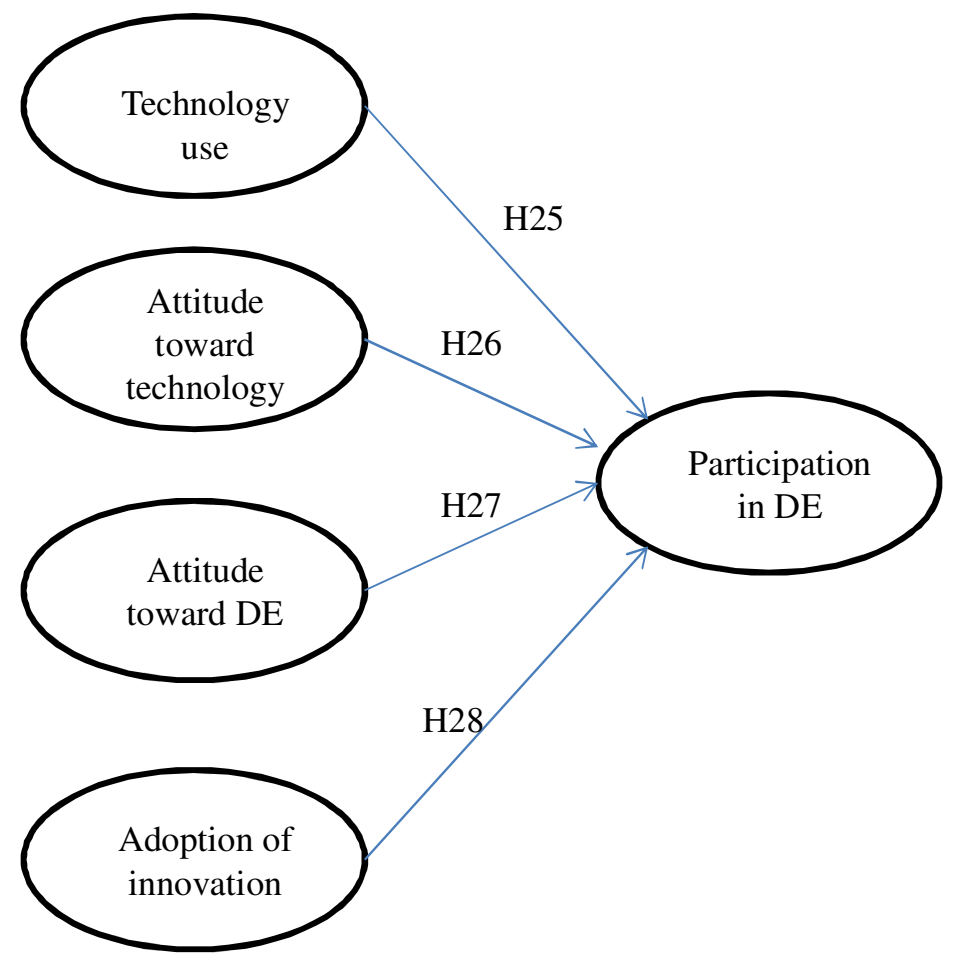

Figure 38. Research model for instructors' perspective

Source: (TABATA; JOHNSRUD, 2008).

\section{- Coordinator's perspective}

Qualitative data obtained from interviews provided evidence for testing hypotheses H17, H32 to $\mathrm{H} 35$, through qualitative description and content analysis.

\section{- Gap model (student's x coordinator's perspective)}

In order to compare perceptions of students and coordinators a quality gap analysis - based on Shahin and Samea (2010) model - was conducted:

Gap 2: Difference between manager perceptions of student's expectation and institutional strategy and policies (H36). 
Gap 6: Difference between translation of institutional strategy and policies into specifications and service delivered (H37).

Gap7: Difference between service delivered and external communications to students (H38).

Gap 11: Difference between managers' perceptions of students' perceptions and students' actual perceptions $(\mathrm{H} 24)$.

- Comparative analysis (instructor's x coordinator's perspective)

This analysis compares coordinators' perceptions and instructors' acceptance of DE (H39).

All these hypotheses are presented in Table 13.

\subsection{Instruments, variables and hypotheses}

The research community has not found a consensus about the measurement of the concepts quality, loyalty, image positive and negative affect (NESSET; HELGESEN, 2009). As mentioned before in this chapter, this dissertation makes use of different kinds of data gathering strategies. For the survey instruments, applied for both students and instructors, the researcher opted to utilize Likert scale to measure the variables. Likert is one of the most common scales (DEVELLIS, 2012). This scale implies the presentation of an affirmative sentence (question) followed by answer options that indicate degrees of agreement; these options may or may not include a neutral point. It is widely used in questionnaires that propose to measure opinion, beliefs and attitudes (DEVELLIS, 2012). Although this scale may be questioned by some researchers in the field, most of the studies basing this dissertation development used Likert scale in their questionnaires, as presented on Table 11. In this sense, a five point Likert scale was applied, including a neutral point, where: $1=$ strongly disagree; $2=$ mildly disagree; $3=$ neither agree or disagree; $4=$ mildly agree; $5=$ strongly agree. 
Table 11. Likert scale use in similar studies

\begin{tabular}{|c|c|c|}
\hline Study & Scale & Data Analysis \\
\hline $\begin{array}{l}\text { (NESSET; } \\
\text { HELGESEN, 2009) }\end{array}$ & $\begin{array}{l}7 \text { point Likert scale }-1=\text { least } \\
\text { favorable alternative; } 7=\text { most } \\
\text { favorable alternative } \\
\text { The responses were converted to a } 0 \\
\text { to } 100 \text { point scale }\end{array}$ & $\begin{array}{l}\text { SEM (Structural Equation } \\
\text { Model) }\end{array}$ \\
\hline $\begin{array}{l}\text { (ROJAS-MÉNDEZ et } \\
\text { al., 2009) }\end{array}$ & $\begin{array}{l}7 \text { point Likert scale }-1=\text { strongly } \\
\text { disagree; } 7=\text { strongly agree }\end{array}$ & SEM \\
\hline (KUO; YE, 2009) & 5 point Likert scale & SEM \\
\hline (BOWDEN, 2011) & $\begin{array}{l}7 \text { point Likert scale }-1=\text { strongly } \\
\text { disagree; } 7=\text { strongly agree }\end{array}$ & SEM \\
\hline $\begin{array}{l}\text { (SUDHAHAR } \text { et al. } \\
\text { 2006) }\end{array}$ & $\begin{array}{l}\text { Construction of a loyalty } \\
\text { measurement scale (SERVLOYAL) } \\
5 \text { point Likert scale }-1=\text { strongly } \\
\text { agree; } 5=\text { strongly disagree }\end{array}$ & $\begin{array}{l}\text { Confirmatory factor } \\
\text { analysis (CFA) }\end{array}$ \\
\hline (UDO et al., 2011) & $\begin{array}{l}7 \text { point Likert scale }-1=\text { strongly } \\
\text { disagree; } 7=\text { strongly agree }\end{array}$ & SEM \\
\hline (KASSIM; ZAIN, 2010) & $\begin{array}{l}6 \text { point Likert scale }-1=\text { strongly } \\
\text { disagree; } 6=\text { strongly agree; no } \\
\text { neutral point }\end{array}$ & $\begin{array}{l}\text { Exploratory factor analysis } \\
\text { CFA }\end{array}$ \\
\hline $\begin{array}{l}\text { (ŠIMIĆ; ČARAPIĆ, } \\
\text { 2008) }\end{array}$ & $\begin{array}{l}5 \text { point Likert scale }-1=\text { poor; } 5= \\
\text { excellent }\end{array}$ & $\begin{array}{l}\text { Significance tests between } \\
\text { former students and current } \\
\text { students }\end{array}$ \\
\hline $\begin{array}{l}\text { (JAGER; } \\
\text { GBADAMOSI, 2009) }\end{array}$ & $\begin{array}{l}5 \text { point Likert scale }-1=\text { very } \\
\text { important; } 5=\text { not important at all } \\
\text { or } \\
1=\text { strongly agree; } 5=\text { strongly } \\
\text { disagree }\end{array}$ & Exploratory factor analysis \\
\hline (PELTIER et al., 2007) & $\begin{array}{l}5 \text { point Likert scale }-1 \text { strongly } \\
\text { disagree; } 5=\text { strongly agree }\end{array}$ & SEM \\
\hline (GRUBER et al., 2010) & $\begin{array}{l}5 \text { point Likert scale }-1=\text { statement } \\
\text { does not apply to me at all; } 5= \\
\text { statement always applies to me }\end{array}$ & $\begin{array}{l}\text { Correlation and regression } \\
\text { analysis }\end{array}$ \\
\hline
\end{tabular}

Data collection instruments (student and instructors surveys) used variables found in the literature or adapted from other researches. Table 12 shows study constructs, variables and their sources. 
Table 12. Instruments variables and sources ${ }^{9}$

\begin{tabular}{|c|c|c|}
\hline Dimension & Variable & Source \\
\hline \multicolumn{3}{|c|}{ - Student Survey Instrument } \\
\hline \multirow{4}{*}{$\begin{array}{l}\text { Quality } \\
\text { 1)Assurance }\end{array}$} & V1: The instructors are knowledgeable in their field & \multirow[t]{4}{*}{ (UDO et al., 2011) } \\
\hline & V2: The instructors are fair and impartial in grading & \\
\hline & V3: The instructors answer all the questions thoroughly & \\
\hline & $\begin{array}{l}\text { V4: I am confident the instructors have an expert } \\
\text { understanding of the material }\end{array}$ & \\
\hline \multirow[t]{4}{*}{$\begin{array}{l}\text { Quality } \\
\text { 2) Empathy }\end{array}$} & $\begin{array}{l}\text { V5: The instructors are genuinely concerned about the } \\
\text { students }\end{array}$ & \multirow[t]{4}{*}{ (UDO et al., 2011) } \\
\hline & $\begin{array}{l}\text { V6: The instructors understand the individual needs of } \\
\text { students }\end{array}$ & \\
\hline & V7: The instructors have the student's best interests in mind & \\
\hline & $\begin{array}{l}\text { V8: The instructors encourage and motivate students to do } \\
\text { their best }\end{array}$ & \\
\hline \multirow{4}{*}{$\begin{array}{l}\text { Quality } \\
\text { 3) } \\
\text { Responsiveness }\end{array}$} & $\begin{array}{l}\text { V9: Instructors can be easily accessed out of face-to-face or } \\
\text { synchronous meetings }\end{array}$ & $\begin{array}{l}\text { (AGHAMOLAEI; } \\
\text { ZARE, 2008) }\end{array}$ \\
\hline & $\begin{array}{l}\text { V10:Instructors quickly and efficiently respond to student } \\
\text { needs }\end{array}$ & \multirow[t]{3}{*}{ (UDO et al., 2011) } \\
\hline & $\begin{array}{l}\text { V11: Instructors are willing to go out of their way to help } \\
\text { students }\end{array}$ & \\
\hline & $\begin{array}{l}\text { V12: Instructors always welcomes student questions and } \\
\text { comments }\end{array}$ & \\
\hline \multirow{3}{*}{$\begin{array}{l}\text { Quality } \\
\text { 4) Reliability }\end{array}$} & V13: Instructors consistently provide good lectures & \multirow[t]{2}{*}{ (UDO et al., 2011) } \\
\hline & V14: Instructors are dependable & \\
\hline & $\begin{array}{l}\text { V15: Instructors always provide feedback to the assessment } \\
\text { activities }\end{array}$ & $\begin{array}{l}\text { (AGHAMOLAEI; } \\
\text { ZARE, 2008) }\end{array}$ \\
\hline \multirow{8}{*}{$\begin{array}{l}\text { Quality } \\
\text { 5) Website } \\
\text { content }\end{array}$} & V16: The website uses audio elements properly & (UDO et al., 2011) \\
\hline & V17: The website uses video elements properly & (UDO et al., 2011) \\
\hline & $\begin{array}{l}\text { V18: The website uses multimedia elements (animation, } \\
\text { graphics, audio, video) properly }\end{array}$ & (UDO et al., 2011) \\
\hline & V19: The website provides useful information & (UDO et al., 2011) \\
\hline & V20: The website provides accurate information & (UDO et al., 2011) \\
\hline & V21: The website provides high quality information & (UDO et al., 2011) \\
\hline & V22: The information on the website is relevant to me & (UDO et al., 2011) \\
\hline & V23: Time flexibility is provided to activity development & $\begin{array}{l}\text { (AGHAMOLAEI; } \\
\text { ZARE, 2008) }\end{array}$ \\
\hline \multirow[t]{5}{*}{ Overall quality } & V24:The instructional website seems to be up to date & (UDO et al., 2011) \\
\hline & V25: The instructional website works well & (UDO et al., 2011) \\
\hline & V26: The instructional website has clear instruction & (UDO et al., 2011) \\
\hline & V27: I'd rather study at a distance than face-to-face & $\begin{array}{l}\text { (SUDHAHAR } e t \\
\text { al. 2006) }\end{array}$ \\
\hline & V28: In my opinion my course has high quality & (UDO et al., 2011) \\
\hline \multirow[t]{4}{*}{ Satisfaction } & $\begin{array}{l}\text { V29: I am satisfied with my decision to enroll in a distance } \\
\text { course }\end{array}$ & (UDO et al., 2011) \\
\hline & V30: My choice to enroll a distance course was a wise one & (UDO et al., 2011) \\
\hline & V31: I feel that may experience with DE has been enjoyable & (UDO et al., 2011) \\
\hline & V32: The course meets my expectations & $\begin{array}{l}\text { (GRUBER } \text { et al., } \\
\text { 2010) }\end{array}$ \\
\hline Loyalty & V33: I would recommend this distance course to my friends & (UDO et al., 2011) \\
\hline
\end{tabular}

\footnotetext{
${ }^{9}$ Profile variables were also included in the instruments, as can be observed on Appendix C,D and E.
} 


\begin{tabular}{|c|c|c|}
\hline \multirow[t]{4}{*}{ Dimension } & Variable & Source \\
\hline & and family & \\
\hline & V34: I would enroll in another distance course & (UDO et al., 2011) \\
\hline & V36: I believe I will finish my course in the regular period & $\begin{array}{l}\text { By the author, } \\
\text { based on } \\
\text { (GRUBER } \text { et al., } \\
\text { 2010) }\end{array}$ \\
\hline $\begin{array}{l}\text { Performance } \\
\text { expectation }\end{array}$ & V35: I am doing well in the distance course & (UDO et al., 2011) \\
\hline \multirow[t]{4}{*}{ Image } & V37: $\mathrm{UAB}$ is reliable & $\begin{array}{l}\text { Adapted from } \\
\text { (KABADAYI; } \\
\text { OZKIRIS, 2011) }\end{array}$ \\
\hline & V38: UAB is innovative & $\begin{array}{l}\text { Adapted from } \\
\text { (KABADAYI; } \\
\text { OZKIRIS, 2011) }\end{array}$ \\
\hline & V39: UAB is a model of DE in Brazil & $\begin{array}{l}\text { Adapted from } \\
\text { (KABADAYI; } \\
\text { OZKIRIS, 2011) }\end{array}$ \\
\hline & V40: UAB is a synonym of education quality & $\begin{array}{l}\text { Adapted from } \\
\text { (KABADAYI; } \\
\text { OZKIRIS, 2011) }\end{array}$ \\
\hline \multirow[t]{5}{*}{ Myths about DE } & V41: The website is dynamic and interactive & $\begin{array}{l}\text { By the author based } \\
\text { on (LI; AKINS, } \\
\text { 2004) }\end{array}$ \\
\hline & $\begin{array}{l}\text { V42: People need to master technology in order to study at a } \\
\text { distance }\end{array}$ & $\begin{array}{l}\text { By the author based } \\
\text { on (KEARSLEY, } \\
1998)\end{array}$ \\
\hline & $\begin{array}{l}\text { V43: A distance course is more demanding than a face-to- } \\
\text { face course }\end{array}$ & $\begin{array}{l}\text { By the author based } \\
\text { on (KEARSLEY, } \\
1998 \text { ) }\end{array}$ \\
\hline & V44: Study at a distance is motivating & $\begin{array}{l}\text { By the author based } \\
\text { on (CLARK, 2002) }\end{array}$ \\
\hline & $\begin{array}{l}\text { V45: In my opinion any person is able to do well in a } \\
\text { distance course }\end{array}$ & $\begin{array}{l}\text { By the author based } \\
\text { on (LI; AKINS, } \\
\text { 2004) }\end{array}$ \\
\hline \multirow[t]{5}{*}{$\begin{array}{l}\text { Course } \\
\text { organization }\end{array}$} & $\begin{array}{l}\text { V46: I was provided with clear statement of course } \\
\text { objectives }\end{array}$ & $\begin{array}{l}\text { Adapted from } \\
\text { (CHANEY, BETH } \\
\text { HENSLEIGH et } \\
\text { al., 2007) }\end{array}$ \\
\hline & $\begin{array}{l}\text { V47: Before starting the course, I was well advised about } \\
\text { the technology I would need to fulfill my requirements }\end{array}$ & $\begin{array}{l}\text { (CHANEY, BETH } \\
\text { HENSLEIGH } \text { et } \\
\text { al., 2007) }\end{array}$ \\
\hline & $\begin{array}{l}\text { V48: Before starting the course I was well advised about the } \\
\text { skills needed to fulfill my course requirements }\end{array}$ & $\begin{array}{l}\text { (CHANEY, BETH } \\
\text { HENSLEIGH } \text { et } \\
\text { al., 2007) }\end{array}$ \\
\hline & $\begin{array}{l}\text { V49: Before starting the course, I was well advised about } \\
\text { the commitment needed to succeed at distance learning }\end{array}$ & $\begin{array}{l}\text { (CHANEY, BETH } \\
\text { HENSLEIGH } \text { et } \\
\text { al., 2007) }\end{array}$ \\
\hline & V52: Workload for this course were appropriate & $\begin{array}{l}\text { Adapted from } \\
\text { (ROBERTS } \text { et al., } \\
\text { 2005) }\end{array}$ \\
\hline $\begin{array}{l}\text { Technical } \\
\text { support }\end{array}$ & V50: Technical support was available in this course & $\begin{array}{l}\text { (ROBERTS et al., } \\
2005)\end{array}$ \\
\hline
\end{tabular}




\begin{tabular}{|c|c|c|}
\hline Dimension & Variable & Source \\
\hline & $\begin{array}{l}\text { V51: Technical support was able to solve the problems } \\
\text { during the course }\end{array}$ & $\begin{array}{l}\text { (ROBERTS et al., } \\
\text { 2005) }\end{array}$ \\
\hline \multirow[t]{2}{*}{ Peers interaction } & V53: There is interaction between students & $\begin{array}{l}\text { Adapted from } \\
\text { (ROBERTS } \text { et al., } \\
\text { 2005) }\end{array}$ \\
\hline & $\begin{array}{l}\text { V54: There was a sense of community among the students in } \\
\text { the course }\end{array}$ & $\begin{array}{l}\text { (ROBERTS et al., } \\
\text { 2005) }\end{array}$ \\
\hline \multirow[t]{2}{*}{$\begin{array}{l}\text { Structure } \\
\text { availability }\end{array}$} & V55: Support services for this course were convenient & $\begin{array}{l}\text { Adapted from } \\
\text { (ROBERTS } \text { et al., } \\
\text { 2005) }\end{array}$ \\
\hline & V56: Appropriate resources were available to the students & $\begin{array}{l}\text { Adapted from } \\
\text { (ROBERTS } \text { et al., } \\
\text { 2005) }\end{array}$ \\
\hline \multicolumn{3}{|c|}{ - Instructor Survey Instrument ${ }^{10}$} \\
\hline \multirow[t]{3}{*}{ Technology use } & $\begin{array}{l}\text { V1: It is important to use hardware equipment in conducting } \\
\text { professional work }\end{array}$ & $\begin{array}{l}\text { (TABATA; } \\
\text { JOHNSRUD, } \\
\text { 2008) }\end{array}$ \\
\hline & $\begin{array}{l}\text { V2: It is important to use software applications in } \\
\text { conducting professional work }\end{array}$ & $\begin{array}{l}\text { (TABATA; } \\
\text { JOHNSRUD, } \\
\text { 2008) }\end{array}$ \\
\hline & $\begin{array}{l}\text { V3: It is important to use online resources in conducting } \\
\text { professional work }\end{array}$ & $\begin{array}{l}\text { (TABATA; } \\
\text { JOHNSRUD, } \\
\text { 2008) }\end{array}$ \\
\hline \multirow[t]{7}{*}{$\begin{array}{l}\text { Attitude toward } \\
\text { technology }\end{array}$} & $\begin{array}{l}\text { V4: Technology is important for conducting professional } \\
\text { work }\end{array}$ & $\begin{array}{l}\text { (TABATA; } \\
\text { JOHNSRUD, } \\
2008)\end{array}$ \\
\hline & V5: I expect to be rewarded for using technology & $\begin{array}{l}\text { (TABATA; } \\
\text { JOHNSRUD, } \\
2008)\end{array}$ \\
\hline & V6: Resources are available to support technology needs & $\begin{array}{l}\text { (TABATA; } \\
\text { JOHNSRUD, } \\
\text { 2008) }\end{array}$ \\
\hline & V7: I am skillful in using technology & $\begin{array}{l}\text { TABATA; } \\
\text { JOHNSRUD, } \\
2008)\end{array}$ \\
\hline & V8: Using technology has little impact on my career $(*)$ & $\begin{array}{l}\text { TABATA; } \\
\text { JOHNSRUD, } \\
2008)\end{array}$ \\
\hline & V9: Institution recognizes those who use technology & $\begin{array}{l}\text { (TABATA; } \\
\text { JOHNSRUD, } \\
\text { 2008) }\end{array}$ \\
\hline & V10: Using technology is stressful $(*)$ & $\begin{array}{l}\text { (TABATA; } \\
\text { JOHNSRUD, } \\
2008)\end{array}$ \\
\hline \multirow[t]{2}{*}{$\begin{array}{l}\text { Attitude toward } \\
\text { distance } \\
\text { education }\end{array}$} & V11: DE training and development is available & $\begin{array}{l}\text { (TABATA; } \\
\text { JOHNSRUD, } \\
\text { 2008) }\end{array}$ \\
\hline & V12: I am motivated to teach DE courses & $\begin{array}{l}\text { (TABATA; } \\
\text { JOHNSRUD, } \\
2008)\end{array}$ \\
\hline
\end{tabular}

${ }^{10}(*)$ these variables had their scores inverted. 


\begin{tabular}{|c|c|c|}
\hline Dimension & Variable & Source \\
\hline & V13: Technical support is available for DE & $\begin{array}{l}\text { (TABATA; } \\
\text { JOHNSRUD, } \\
2008)\end{array}$ \\
\hline & V14: I have DE instructional skills & $\begin{array}{l}\text { (TABATA; } \\
\text { JOHNSRUD, } \\
2008)\end{array}$ \\
\hline & $\begin{array}{l}\text { V15: The quality of DE instruction and learning is as good } \\
\text { as face-to-face }\end{array}$ & $\begin{array}{l}\text { (TABATA; } \\
\text { JOHNSRUD, } \\
\text { 2008) }\end{array}$ \\
\hline & V16: Delivering DE instruction is stressful $(*)$ & $\begin{array}{l}\text { (TABATA; } \\
\text { JOHNSRUD, } \\
\text { 2008) }\end{array}$ \\
\hline \multirow[t]{8}{*}{$\begin{array}{l}\text { Adoption of } \\
\text { innovation }\end{array}$} & V17: Participation in DE is voluntary & $\begin{array}{l}\text { (TABATA; } \\
\text { JOHNSRUD, } \\
\text { 2008) }\end{array}$ \\
\hline & V18: I am able to share the results of using DE with others & $\begin{array}{l}\text { (TABATA; } \\
\text { JOHNSRUD, } \\
\text { 2008) }\end{array}$ \\
\hline & V19: The advantages of DE outweigh the disadvantages & $\begin{array}{l}\text { (TABATA; } \\
\text { JOHNSRUD, } \\
\text { 2008) }\end{array}$ \\
\hline & V20: DE instruction is difficult $(*)$ & $\begin{array}{l}\text { (TABATA; } \\
\text { JOHNSRUD, } \\
\text { 2008) }\end{array}$ \\
\hline & V21: I am able to see results of DE delivery & $\begin{array}{l}\text { (TABATA; } \\
\text { JOHNSRUD, } \\
\text { 2008) }\end{array}$ \\
\hline & V22: DE is compatible with my work style & $\begin{array}{l}\text { (TABATA; } \\
\text { JOHNSRUD, } \\
\text { 2008) }\end{array}$ \\
\hline & V23: I am able to try out DE before deciding to use it & $\begin{array}{l}\text { (TABATA; } \\
\text { JOHNSRUD, } \\
\text { 2008) }\end{array}$ \\
\hline & $\begin{array}{l}\text { V24: My self-image is enhanced by using technological } \\
\text { innovations }\end{array}$ & $\begin{array}{l}\text { (TABATA; } \\
\text { JOHNSRUD, } \\
\text { 2008) }\end{array}$ \\
\hline \multicolumn{3}{|c|}{ - Coordinator Interview Script ${ }^{11}$} \\
\hline \multirow[t]{6}{*}{$\begin{array}{l}\text { Critical success } \\
\text { factor }\end{array}$} & V9: Reasons to sign up to UAB & $\begin{array}{l}\text { Based on (WHITE, } \\
\text { 2007) }\end{array}$ \\
\hline & V10: What were the main difficulties found? & $\begin{array}{l}\text { Based on (SELIM, } \\
\text { 2007) }\end{array}$ \\
\hline & $\begin{array}{l}\text { V11: What are the positive results from PNAP } \\
\text { implementation? }\end{array}$ & $\begin{array}{l}\text { Based on (SELIM, } \\
\text { 2007) }\end{array}$ \\
\hline & V12: Did instructors resist to DE implementation? & \\
\hline & $\begin{array}{l}\text { V13: Does tutor recruitment and selection process find } \\
\text { difficulties? }\end{array}$ & $\begin{array}{l}\text { Based on (SELIM, } \\
\text { 2007) }\end{array}$ \\
\hline & V14: What support services are provided to instructors? & $\begin{array}{l}\text { Based on (SELIM, } \\
\text { 2007) }\end{array}$ \\
\hline
\end{tabular}

\footnotetext{
${ }^{11} \mathrm{~V} 1$ to V8 concern coordinators demographic characteristics (gender, area of expertise, educational level) and course characteristics (number of students, number of professors, number of tutors). The complete version of the instrument can be found on Appendix E.
} 


\begin{tabular}{|c|c|c|}
\hline Dimension & Variable & Source \\
\hline & V15: What support services are offered to students? & $\begin{array}{l}\text { Based on (SELIM, } \\
\text { 2007) }\end{array}$ \\
\hline & $\begin{array}{l}\text { V16: What do students point out as positive factors of } \\
\text { studying at a distance? }\end{array}$ & $\begin{array}{l}\text { Based on (SELIM, } \\
\text { 2007) }\end{array}$ \\
\hline & V17: What do they point out as negative factors? & $\begin{array}{l}\text { Based on (SELIM, } \\
\text { 2007) }\end{array}$ \\
\hline & $\begin{array}{l}\text { V18: What is the attrition rate? What are the reasons for this, } \\
\text { in your opinion? }\end{array}$ & $\begin{array}{l}\text { Based on (TINTO, } \\
\text { 1982) and } \\
\text { VANDER SCHEE } \\
(2011)\end{array}$ \\
\hline & $\begin{array}{l}\text { V19: What technology resources and pedagogical activities } \\
\text { are included in the course }\end{array}$ & $\begin{array}{l}\text { Based on (SELIM, } \\
\text { 2007) }\end{array}$ \\
\hline \multirow[t]{9}{*}{$\begin{array}{l}\text { Perceived } \\
\text { quality }\end{array}$} & V20: How students' expectations are identified? & $\begin{array}{l}\text { Based on } \\
\text { (PARASURAMAN } \\
\text { et al., 1985) }\end{array}$ \\
\hline & V21: What are the differential of the course? & $\begin{array}{l}\text { Based on } \\
\text { (PARASURAMAN } \\
\text { et al., 1985) }\end{array}$ \\
\hline & $\begin{array}{l}\text { V22: Have all the points planned in the initial project been } \\
\text { already implemented? If negative, what has not been already } \\
\text { implemented and why? }\end{array}$ & $\begin{array}{l}\text { Based on } \\
\text { (PARASURAMAN } \\
\text { et al., 1985) }\end{array}$ \\
\hline & $\begin{array}{l}V 23^{12}: \text { Instructors involved in the course are committed to } \\
\text { the course and the method }\end{array}$ & $\begin{array}{l}\text { Based on (UDO et } \\
\text { al., 2011) }\end{array}$ \\
\hline & $\begin{array}{l}\text { V24: Instructors have deep knowledge on the contents they } \\
\text { teach }\end{array}$ & $\begin{array}{l}\text { Based on (UDO et } \\
\text { al., 2011) }\end{array}$ \\
\hline & V25: Instructors are willing to help distance students & $\begin{array}{l}\text { Based on (UDO et } \\
a l ., 2011)\end{array}$ \\
\hline & V26: Instructors are dependable & $\begin{array}{l}\text { Based on (UDO et } \\
\text { al., 2011) }\end{array}$ \\
\hline & $\begin{array}{l}\text { V27: Learning environment is reliable and provides } \\
\text { appropriate resources }\end{array}$ & $\begin{array}{l}\text { Based on (UDO et } \\
a l ., 2011)\end{array}$ \\
\hline & V28: Course has high quality & $\begin{array}{l}\text { Based on (UDO et } \\
\text { al., 2011) }\end{array}$ \\
\hline
\end{tabular}

The constructs studied in the present dissertation aimed to help achieving the study objectives. Thus, some hypotheses were developed and tested. They are presented on Table 13.

\footnotetext{
${ }^{12}$ On questions V23 to V28 coordinators were asked to attribute a concordance level on a 5 point Likert scale.
} 
Table 13. Research hypotheses and dimensions

\begin{tabular}{|c|c|c|c|c|c|}
\hline Hypothesis & Dimension $^{13}$ & Source & Scale & Collection & Analysis \\
\hline $\begin{array}{l}\text { H1: Assurance has a positive relation to } \\
\text { student perceived quality }\end{array}$ & $\begin{array}{l}\text { Assurance } \\
\text { Perceived quality }\end{array}$ & (UDO et al., 2011) & $\begin{array}{l}5 \text { point Likert } \\
\text { scale }\end{array}$ & $\begin{array}{l}\text { Survey } \\
\text { (students) }\end{array}$ & $\begin{array}{l}\text { SEM } \\
\text { CFA }\end{array}$ \\
\hline $\begin{array}{l}\mathrm{H} 2 \text { : Empathy is positively related to student } \\
\text { perceived quality }\end{array}$ & $\begin{array}{l}\text { Empathy } \\
\text { Perceived quality }\end{array}$ & (UDO et al., 2011) & $\begin{array}{l}5 \text { point Likert } \\
\text { scale }\end{array}$ & $\begin{array}{l}\text { Survey } \\
\text { (students) }\end{array}$ & $\begin{array}{l}\text { SEM } \\
\text { CFA }\end{array}$ \\
\hline $\begin{array}{l}\text { H3: Responsiveness is positively related to } \\
\text { student perceived quality }\end{array}$ & $\begin{array}{l}\text { Responsiveness } \\
\text { Perceived quality }\end{array}$ & (UDO et al., 2011) & $\begin{array}{l}5 \text { point Likert } \\
\text { scale }\end{array}$ & $\begin{array}{l}\text { Survey } \\
\text { (students) }\end{array}$ & $\begin{array}{l}\text { SEM } \\
\text { CFA }\end{array}$ \\
\hline $\begin{array}{l}\text { H4: Reliability is positively related to student } \\
\text { perceived quality }\end{array}$ & $\begin{array}{l}\text { Reliability } \\
\text { Perceived quality }\end{array}$ & (UDO et al., 2011) & $\begin{array}{l}5 \text { point Likert } \\
\text { scale }\end{array}$ & $\begin{array}{l}\text { Survey } \\
\text { (students) }\end{array}$ & $\begin{array}{l}\text { SEM } \\
\text { CFA }\end{array}$ \\
\hline $\begin{array}{l}\text { H5: Website content is positively related to } \\
\text { student perceived quality }\end{array}$ & $\begin{array}{l}\text { Website content } \\
\text { Perceived quality }\end{array}$ & (UDO et al., 2011) & $\begin{array}{l}5 \text { point Likert } \\
\text { scale }\end{array}$ & $\begin{array}{l}\begin{array}{l}\text { Survey } \\
\text { (students) }\end{array} \\
\end{array}$ & $\begin{array}{l}\text { SEM } \\
\text { CFA }\end{array}$ \\
\hline $\begin{array}{l}\text { H6: Perceived quality has a positive relation } \\
\text { to student satisfaction }\end{array}$ & $\begin{array}{l}\text { Perceived quality } \\
\text { Satisfaction }\end{array}$ & (UDO et al., 2011) & $\begin{array}{l}5 \text { point Likert } \\
\text { scale }\end{array}$ & $\begin{array}{l}\text { Survey } \\
\text { (students) }\end{array}$ & $\begin{array}{l}\text { SEM } \\
\text { CFA }\end{array}$ \\
\hline $\begin{array}{l}\text { H7: Perceived quality has a positive relation } \\
\text { to student loyalty to the course }\end{array}$ & $\begin{array}{l}\text { Perceived quality } \\
\text { Loyalty }\end{array}$ & (UDO et al., 2011) & $\begin{array}{l}5 \text { point Likert } \\
\text { scale }\end{array}$ & $\begin{array}{l}\text { Survey } \\
\text { (students) }\end{array}$ & $\begin{array}{l}\text { SEM } \\
\text { CFA }\end{array}$ \\
\hline $\begin{array}{l}\text { H8: Satisfaction has a positive relation to } \\
\text { student loyalty to the course }\end{array}$ & $\begin{array}{l}\text { Satisfaction } \\
\text { Loyalty }\end{array}$ & (KUO; YE, 2009) & $\begin{array}{l}5 \text { point Likert } \\
\text { scale }\end{array}$ & $\begin{array}{l}\text { Survey } \\
\text { (students) }\end{array}$ & $\begin{array}{l}\text { SEM } \\
\text { CFA }\end{array}$ \\
\hline $\begin{array}{l}\text { H9: Student performance expectation has a } \\
\text { positive relation to perceived quality }\end{array}$ & $\begin{array}{l}\text { Student } \\
\text { performance } \\
\text { Perceived quality }\end{array}$ & (UDO et al., 2011) & $\begin{array}{l}5 \text { point Likert } \\
\text { scale }\end{array}$ & $\begin{array}{l}\text { Survey } \\
\text { (students) }\end{array}$ & Correlation \\
\hline $\begin{array}{l}\text { H10: Satisfaction level is related (moderated } \\
\text { by) to gender }\end{array}$ & $\begin{array}{l}\text { Gender } \\
\text { Satisfaction }\end{array}$ & $\begin{array}{l}\text { Based on (MACELI } \\
\text { et al., 2011) }\end{array}$ & $\begin{array}{l}\text { Nominal } \\
5 \text { point Likert } \\
\text { scale }\end{array}$ & $\begin{array}{l}\text { Survey } \\
\text { (students) }\end{array}$ & $\begin{array}{l}\text { Descriptive } \\
\text { analysis } \\
\text { Significance tests }\end{array}$ \\
\hline $\begin{array}{l}\text { H11: Women are dominant within UAB } \\
\text { Public Management students }\end{array}$ & Gender & $\begin{array}{l}\text { Based on } \\
\text { (KRAMARAE, } \\
\text { 2001) }\end{array}$ & $\begin{array}{l}\text { Nominal } \\
\text { (male/female) }\end{array}$ & $\begin{array}{l}\text { Survey } \\
\text { (students) }\end{array}$ & $\begin{array}{l}\text { Descriptive } \\
\text { analysis }\end{array}$ \\
\hline H12: Image influences ${ }^{14}$ perceived quality & $\begin{array}{l}\text { Image } \\
\text { Perceived quality }\end{array}$ & $\begin{array}{l}\text { (BLOEMER et al., } \\
\text { 1998) }\end{array}$ & $\begin{array}{l}5 \text { point Likert } \\
\text { scale }\end{array}$ & $\begin{array}{l}\begin{array}{l}\text { Survey } \\
\text { (students) }\end{array} \\
\end{array}$ & $\begin{array}{l}\text { CFA } \\
\text { SEM }\end{array}$ \\
\hline
\end{tabular}

\footnotetext{
${ }^{13}$ Instruments in the original language (Portuguese) can be found on Appendix C, D and E.

${ }^{14}$ Influence among variables is studied in this dissertation as an association relationship; it does not concern a cause-effect relation, since for that, other variables that impact on the study constructs would need to be controlled, which is not objective of the research.
} 


\begin{tabular}{|c|c|c|c|c|c|}
\hline Hypothesis & Dimension $^{13}$ & Source & Scale & Collection & Analysis \\
\hline H13: Myths perception influences image & $\begin{array}{l}\text { Myths } \\
\text { Image }\end{array}$ & $\begin{array}{l}\text { Based on } \\
\text { (KEARSLEY, 1998) }\end{array}$ & $\begin{array}{l}5 \text { point Likert } \\
\text { scale }\end{array}$ & $\begin{array}{l}\text { Survey } \\
\text { (students) }\end{array}$ & Regression \\
\hline H14: Family support influences loyalty & $\begin{array}{l}\text { Family support } \\
\text { Loyalty }\end{array}$ & $\begin{array}{l}\text { Based on (PARK; } \\
\text { CHOI, 2009) }\end{array}$ & $\begin{array}{l}1-10 \text { scale } \\
5 \text { point Likert } \\
\text { scale }\end{array}$ & $\begin{array}{l}\text { Survey } \\
\text { (students) }\end{array}$ & Correlation \\
\hline H15: Employer support influences loyalty & $\begin{array}{l}\text { Employer support } \\
\text { Loyalty }\end{array}$ & $\begin{array}{l}\text { Based on (PARK; } \\
\text { CHOI, 2009) }\end{array}$ & $\begin{array}{l}1-10 \text { scale } \\
5 \text { point Likert } \\
\text { scale }\end{array}$ & $\begin{array}{l}\text { Survey } \\
\text { (students) }\end{array}$ & Correlation \\
\hline H16: Distance students are mature & Age & $\begin{array}{l}\text { Based on } \\
\text { (TRICKER et al., } \\
\text { 2001) }\end{array}$ & Metric & $\begin{array}{l}\begin{array}{l}\text { Survey } \\
\text { (students) }\end{array}\end{array}$ & $\begin{array}{l}\text { Descriptive } \\
\text { analysis }\end{array}$ \\
\hline $\begin{array}{l}\text { H17: Attrition is higher in the first year of } \\
\text { course }\end{array}$ & Attrition & $\begin{array}{l}\text { Based on (TINTO, } \\
\text { 1988) and } \\
\text { VANDER SCHEE } \\
(2011)\end{array}$ & Percent & $\begin{array}{l}\text { Coordinator } \\
\text { interview }\end{array}$ & $\begin{array}{l}\text { Qualitative } \\
\text { analysis }\end{array}$ \\
\hline $\begin{array}{l}\text { H18: Performance expectation is related to } \\
\text { loyalty }\end{array}$ & $\begin{array}{l}\text { Performance } \\
\text { expectations } \\
\text { Loyalty }\end{array}$ & $\begin{array}{l}\text { Based on (AITKEN, } \\
\text { 1989) }\end{array}$ & $\begin{array}{l}5 \text { point Likert } \\
\text { scale }\end{array}$ & $\begin{array}{l}\text { Survey } \\
\text { (students) }\end{array}$ & Correlation \\
\hline H19: Female are more satisfied & $\begin{array}{l}\text { Gender } \\
\text { Satisfaction }\end{array}$ & $\begin{array}{l}\text { Based on (KIM, } \\
\text { 2011) }\end{array}$ & $\begin{array}{l}\text { Nominal } \\
5 \text { point Likert } \\
\text { Scale }\end{array}$ & $\begin{array}{l}\text { Survey } \\
\text { (student) }\end{array}$ & Significance test \\
\hline $\begin{array}{l}\text { H20: Satisfaction is higher for those students } \\
\text { in more advanced stages of the course }\end{array}$ & $\begin{array}{l}\text { Course semester } \\
\text { Satisfaction }\end{array}$ & $\begin{array}{l}\text { Based on (KIM, } \\
\text { 2011) }\end{array}$ & $\begin{array}{l}\text { Ordinal } \\
5 \text { point Likert } \\
\text { scale }\end{array}$ & $\begin{array}{l}\text { Survey } \\
\text { (students) }\end{array}$ & Significance test \\
\hline $\begin{array}{l}\text { H21: Satisfaction increases as interaction } \\
\text { with instructors is higher }\end{array}$ & $\begin{array}{l}\text { Satisfaction } \\
\text { Quality }\end{array}$ & $\begin{array}{l}\text { Based on (KIM, } \\
\text { 2011) }\end{array}$ & $\begin{array}{l}5 \text { point Likert } \\
\text { scale }\end{array}$ & $\begin{array}{l}\text { Survey } \\
\text { (students) }\end{array}$ & Correlation \\
\hline H22: Female are more loyal to DE & $\begin{array}{l}\text { Gender } \\
\text { Loyalty }\end{array}$ & $\begin{array}{l}\text { Based on } \\
\text { (MARLEY, 2007) }\end{array}$ & $\begin{array}{l}\text { Nominal } \\
5 \text { point Likert } \\
\text { scale }\end{array}$ & $\begin{array}{l}\text { Survey } \\
\text { (students) }\end{array}$ & Significance test \\
\hline $\begin{array}{l}\text { H23: Net generation and non-net generation } \\
\text { have the same perception of the course }\end{array}$ & $\begin{array}{l}\text { Age } \\
\text { Quality } \\
\text { Satisfaction } \\
\text { Loyalty } \\
\text { Image }\end{array}$ & $\begin{array}{l}\text { Based on } \\
\text { (MORGAN; } \\
\text { BULLEN, 2011) }\end{array}$ & $\begin{array}{l}\text { Nominal } \\
\text { (generation) } \\
5 \text { point Likert } \\
\text { scale }\end{array}$ & $\begin{array}{l}\text { Survey } \\
\text { (students) }\end{array}$ & Significance test \\
\hline
\end{tabular}




\begin{tabular}{|c|c|c|c|c|c|}
\hline Hypothesis & Dimension $^{13}$ & Source & Scale & Collection & Analysis \\
\hline $\begin{array}{l}\text { H24: There is no gap in quality perception } \\
\text { considering students and coordinators views } \\
\text { (GAP 11) }\end{array}$ & Quality & $\begin{array}{l}\text { (SHAHIN; SAMEA, } \\
\text { 2010) }\end{array}$ & $\begin{array}{l}5 \text { point Likert } \\
\text { scale }\end{array}$ & $\begin{array}{l}\text { Survey } \\
\text { (students) } \\
\text { Interview } \\
\text { (coordinator) }\end{array}$ & Significance test \\
\hline $\begin{array}{l}\text { H25: Technology usage influences instructor } \\
\text { participation in DE }\end{array}$ & $\begin{array}{l}\text { Technology } \\
\text { acceptance }\end{array}$ & $\begin{array}{l}\text { Based on } \\
\text { (TABATA; } \\
\text { JOHNSRUD, 2008) }\end{array}$ & $\begin{array}{l}5 \text { point Likert } \\
\text { scale }\end{array}$ & $\begin{array}{l}\text { Survey } \\
\text { (instructors) }\end{array}$ & $\begin{array}{l}\text { SEM } \\
\text { Factor analysis }\end{array}$ \\
\hline $\begin{array}{l}\text { H26: Attitude toward technology influences } \\
\text { instructor participation in DE }\end{array}$ & $\begin{array}{l}\text { Technology } \\
\text { acceptance }\end{array}$ & $\begin{array}{l}\text { Based on } \\
\text { (TABATA; } \\
\text { JOHNSRUD, 2008) }\end{array}$ & $\begin{array}{l}5 \text { point Likert } \\
\text { scale }\end{array}$ & $\begin{array}{l}\text { Survey } \\
\text { (instructors) }\end{array}$ & $\begin{array}{l}\text { SEM } \\
\text { Factor analysis }\end{array}$ \\
\hline $\begin{array}{l}\text { H27: Attitude toward distance education } \\
\text { influences instructor participation in DE }\end{array}$ & $\begin{array}{l}\text { Technology } \\
\text { acceptance }\end{array}$ & $\begin{array}{l}\text { Based on } \\
\text { (TABATA; } \\
\text { JOHNSRUD, 2008) }\end{array}$ & $\begin{array}{l}5 \text { point Likert } \\
\text { scale }\end{array}$ & $\begin{array}{l}\text { Survey } \\
\text { (instructors) }\end{array}$ & $\begin{array}{l}\text { SEM } \\
\text { Factor analysis }\end{array}$ \\
\hline $\begin{array}{l}\text { H28: Adoption of innovation influences } \\
\text { instructor participation in DE }\end{array}$ & $\begin{array}{l}\text { Technology } \\
\text { acceptance }\end{array}$ & $\begin{array}{l}\text { Based on } \\
\text { (TABATA; } \\
\text { JOHNSRUD, 2008) }\end{array}$ & $\begin{array}{l}5 \text { point Likert } \\
\text { scale }\end{array}$ & $\begin{array}{l}\text { Survey } \\
\text { (instructors) }\end{array}$ & $\begin{array}{l}\text { SEM } \\
\text { Factor analysis }\end{array}$ \\
\hline $\begin{array}{l}\text { H29: Technology acceptance is influenced by } \\
\text { age }\end{array}$ & $\begin{array}{l}\text { Technology } \\
\text { acceptance } \\
\text { Age }\end{array}$ & $\begin{array}{l}\text { Based on } \\
\text { (TABATA; } \\
\text { JOHNSRUD, 2008) }\end{array}$ & $\begin{array}{l}5 \text { point Likert } \\
\text { scale } \\
\text { Nominal } \\
\text { (generations) }\end{array}$ & $\begin{array}{l}\text { Survey } \\
\text { (instructors) }\end{array}$ & Significance test \\
\hline $\begin{array}{l}\text { H30: Technology acceptance is influenced by } \\
\text { experience with DE }\end{array}$ & $\begin{array}{l}\text { Technology } \\
\text { acceptance } \\
\text { Experience }\end{array}$ & $\begin{array}{l}\text { Based on } \\
\text { (TABATA; } \\
\text { JOHNSRUD, 2008) }\end{array}$ & $\begin{array}{l}5 \text { point Likert } \\
\text { scale } \\
\text { Metric (years } \\
\text { teaching DE) }\end{array}$ & $\begin{array}{l}\text { Survey } \\
\text { (instructors) }\end{array}$ & Significance test \\
\hline $\begin{array}{l}\text { H31: Technology acceptance is influenced by } \\
\text { gender }\end{array}$ & $\begin{array}{l}\text { Technology } \\
\text { acceptance } \\
\text { Experience }\end{array}$ & $\begin{array}{l}\text { Based on } \\
\text { (TABATA; } \\
\text { JOHNSRUD, 2008) }\end{array}$ & $\begin{array}{l}5 \text { point Likert } \\
\text { scale } \\
\text { Nominal (male/ } \\
\text { female) }\end{array}$ & $\begin{array}{l}\text { Survey } \\
\text { (instructors) }\end{array}$ & Significance test \\
\hline $\begin{array}{l}\text { H32: Institution evaluates instructor's skills } \\
\text { and attitude toward DE }\end{array}$ & $\begin{array}{l}\text { Critical success } \\
\text { factors }\end{array}$ & $\begin{array}{l}\text { Based on (SELIM, } \\
\text { 2007) }\end{array}$ & Qualitative data & $\begin{array}{l}\text { Interview } \\
\text { (coordinator) }\end{array}$ & $\begin{array}{l}\text { Qualitative } \\
\text { analysis }\end{array}$ \\
\hline H33: Institution offers support to instructors & $\begin{array}{l}\text { Critical success } \\
\text { factors }\end{array}$ & $\begin{array}{l}\text { Based on (SELIM, } \\
\text { 2007) }\end{array}$ & Qualitative data & $\begin{array}{l}\text { Interview } \\
\text { (coordinator) }\end{array}$ & $\begin{array}{l}\text { Qualitative } \\
\text { analysis }\end{array}$ \\
\hline
\end{tabular}




\begin{tabular}{l|l|l|l|l|l}
\hline Hypothesis & Dimension $\mathbf{1 3}$ & Source & Scale & Collection & Analysis \\
\hline $\begin{array}{l}\text { H34: Institution provides support to the } \\
\text { students }\end{array}$ & $\begin{array}{l}\text { Critical success } \\
\text { factors }\end{array}$ & $\begin{array}{l}\text { Based on (SELIM, } \\
\text { 2007) }\end{array}$ & Qualitative data & $\begin{array}{l}\text { Interview } \\
\text { (coordinator) }\end{array}$ & $\begin{array}{l}\text { Qualitative } \\
\text { analysis }\end{array}$ \\
\hline $\begin{array}{l}\text { H35: Institution provides appropriate } \\
\text { technology support }\end{array}$ & $\begin{array}{l}\text { Critical success } \\
\text { factors }\end{array}$ & $\begin{array}{l}\text { Based on (SELIM, } \\
2007)\end{array}$ & Qualitative data & $\begin{array}{l}\text { Interview } \\
\text { (coordinator) }\end{array}$ & $\begin{array}{l}\text { Qualitative } \\
\text { analysis }\end{array}$ \\
\hline $\begin{array}{l}\text { H36: There is no gap between managers' } \\
\text { perceptions of customer expectation and } \\
\text { service strategy and policy (GAP 2) }\end{array}$ & Quality & $\begin{array}{l}\text { Based on (SHAHIN; } \\
\text { SAMEA, 2010) }\end{array}$ & Qualitative data & $\begin{array}{l}\text { Interview } \\
\text { (coordinator) }\end{array}$ & $\begin{array}{l}\text { Qualitative } \\
\text { analysis }\end{array}$ \\
\hline $\begin{array}{l}\text { H37: There is no gap between translation of } \\
\text { strategies and policies into specifications and } \\
\text { the service delivered (GAP 6) }\end{array}$ & Quality & $\begin{array}{l}\text { Based on (SHAHIN; } \\
\text { SAMEA, 2010) }\end{array}$ & Qualitative data & $\begin{array}{l}\text { Interview } \\
\text { (coordinator) }\end{array}$ & $\begin{array}{l}\text { Qualitative } \\
\text { analysis }\end{array}$ \\
\hline $\begin{array}{l}\text { H38: There is no gap between external } \\
\text { communications and the service delivered } \\
\text { (GAP7) }\end{array}$ & Quality & $\begin{array}{l}\text { Based on (SHAHIN; } \\
\text { SAMEA, 2010) }\end{array}$ & Qualitative data & $\begin{array}{l}\text { Interview } \\
\text { (coordinator) }\end{array}$ & $\begin{array}{l}\text { Qualitative } \\
\text { analysis }\end{array}$ \\
\hline $\begin{array}{l}\text { H39: Coordinator perception of instructors } \\
\text { acceptance to DE is compatible with } \\
\text { instructors attitudes toward DE }\end{array}$ & DE acceptance & $\begin{array}{l}\text { Based on (SELIM, } \\
\text { 2007) }\end{array}$ & $\begin{array}{l}\text { Qualitative data } \\
5 \text { point Likert } \\
\text { scale }\end{array}$ & $\begin{array}{l}\text { Interview } \\
\text { (coordinator) } \\
\text { Survey } \\
\text { (instructor) }\end{array}$ & $\begin{array}{l}\text { Qualitative } \\
\text { analysis }\end{array}$ \\
\hline
\end{tabular}




\subsection{Validity and reliability}

Reliability concerns consistence and stability, it reflects "how much a variable influences a set of items" (DEVELLIS, 2012, p.59). Internal reliability relates to the homogeneity of the items on each construct. Cronbach's Alpha is commonly applied in order to measure internal reliability. This index is defined as "the proportion of a scale's total variance that is attributed to a common source, presumably the true score of a latent variable underlying the items" (DEVELLIS, 2012, p.37). It is a criticized measure, because it tends to represent a lower bound for the real reliability; that is, Alpha is a conservative index (DEVELLIS, 2012). It may be calculated by the following equation:

$$
\alpha=\frac{k \bar{r}}{1+(k-1) \bar{r}}
$$

Where $\mathrm{k}=$ number of items; $\bar{r}=$ average inter-item correlation.

Despite of the critiques, Cronbach's Alpha was used as a reliability measure in this dissertation, for its conservatism and because studies that provided foundation to this work also used Alfa; so it gives a basis for model quality comparison.

Validity, on the other hand, determines whether the variable is "the underlying cause of item covariation" (DEVELLIS, 2012, p.59); it means it assesses the scale ability to predict the event it was expected to predict. Carmine and Zeller (1979) and DeVellis (2012) propose three kinds of validity: content, criterion, and construct.

Content validity assesses the items accuracy; to which extent a set of items actually measures the subject it proposed to measure. It may be difficult to assess in researches that aim to measure attitudes and perceptions since in studies of this nature it is hard to determine an ideal number of items to a dimension (DEVELLIS, 2012).

Criterion-related validity is achieved when the item is related to a standard criterion; it means the item (or a set of items) is able to predict the phenomenon, but in a practical, not in a scientific, way (DEVELLIS, 2012). 
Finally, construct validity determines the relation between one variable and other variables; it means that is, it measures an item ability to behave in the same way the construct it measures actually behaves (DEVELLIS, 2012).

In this study, SEM (Structural equation modeling), PLS, was applied as well as CFA (confirmatory factor analysis) as will be described later in this chapter. Thus, reliability is measured by Cronbach's Alpha coefficient and PLS composite reliability; validity was evaluated by criterion-related validity and content validity and was examined as follows:

- Reliability: constructs Cronbach's Alpha and SEM composite reliability.

- Convergent validity (criterion-related validity): factor loads for each variable were examined, in order to acquire if they provided adequate measure to the constructs. In addition, AVE (average variance extracted) values were examined.

- Discriminant validity (criterion-related validity): comparison between constructs correlations and the AVE square root.

- Content validity: accuracy of the items may be considered under the theoretical basis which gave foundation to them. Since the constructs considered in the study and the variables that compose them were based in an extensive literature review, it may be considered content validity was satisfied in this dissertation.

Reliability and validity results for dissertation data will be highlighted and discussed in chapter 4 .

\subsection{Data collection}

As mentioned before in this chapter, the research evaluated distance education from three different perspectives: students', instructors' and course coordinators' (institutional perspective). For each perspective, different techniques were applied; in other words, specific instruments were developed, specific data collection strategies were employed and appropriate data analysis tools were run. Instruments were discussed in item 3.5; in this section, data gathering techniques will be exposed; similarly, data analysis tools will be presented in the next item. 
The surveys conducted with students and instructors from PNAP used questionnaires for data collection; coordinators were interviewed and documentary records from the institutions' websites were analyzed in order to provide additional data to the study. Questionnaires were developed in electronic form, through GOOGLE DOCS $®$, and the links were emailed to students and instructors by their coordinators; some institutions chose to post the links on the first page of the LMS (Learning Management System) MOODLE ®; so students would see them when accessing the course.

Interviews with the coordinators were made by Skype ${ }^{\circledR}$, telephone, email or in person, depending on the preference of each professional. In every case the same script was used. Finally, UAB official website and institutions' websites were accessed to allow more details of the objectives, mission and processes concerning UAB system and PNAP. Each of the collection techniques is discussed in the next items.

\subsubsection{Questionnaire}

A questionnaire is a data collection instrument that may contain open (permit a spontaneous open-ended answer) or closed questions (offer a set of options for response). It may be applied both individually, in groups or self-administered (FOWLER, 1988).

The present dissertation developed two questionnaires, one for measuring student's perceptions of PNAP course and the second for measuring instructor's acceptance and attitude toward technology and DE. Both instruments were electronically self-administered, developed through GOOGLE DOCS ${ }^{\circledR}$ and emailed to the subjects or posted on the course LMS. This format was chosen, since it allows the collection of information from people geographically dispersed, such as students and professors and tutors from UAB. In addition, considering they are distance students and instructors, used to technology in some extent, online format would not be a constraint for the data collection. Finally, both questionnaires used closed questions and on single open-ended question ("general comments"), in which they could freely express their feelings and opinions about the course or give suggestions about the questionnaire. Questionnaire main characteristics are discussed below. 
Bourque and Fielder (1995) define a self-administered questionnaire as an instrument filled out by the respondent him/her-self with or without help from a supervisor. They can be both electronic (usually are not supervised) or on traditional format (may or may not be supervised). Supervised collection may happen individually (an interviewer clarifies respondents doubts) or in groups (collection happens in a room and a supervisor helps the group with their doubts); this approach increases response rates. In turn, non-supervised questionnaire has an average response rate of 30\% (BOURQUE; FIELDER, 1995).

In addition; some precautions must be taken with the development and application of the questionnaires:

- Clear research objectives and questions which help these objectives achievement (FOWLER, 1988).

- Well formulated and easy understanding questions. Respondent's reading skills and daily language must be considered, as well as his/her knowledge about the subject (FINK, 1995b).

- Questions concerning past or future events may be difficult to fill out and should be avoided (FINK, 1995b) as well as the use of "skip question" resource (BOURQUE; FIELDER, 1995).

- Number of questions included in the questionnaire depends on the research objectives and time available for collection (FINK, 1995b). They may be open (allow the respondent free expression, but should not require long answers) or closed (more simple and easy to fill out) (FOWLER, 1988).

- Questions must be specific, including just one subject at a time and determined time period (avoiding adverbs such as recently, lately etc.) (BOURQUE; FIELDER, 1995). Also must be accurate and exact and avoid abbreviations, slangs, technical expressions (unless they are commonly used by the population and it is homogeneous) (FINK, 1995b).

- Questions must not demonstrate judgment, because for this kind of questions, people tend to give answers that preserve their image even if it is not true (FOWLER, 1995).

- Questions concerning feelings and attitudes must be measured in a continuum scale (varying from negative to positive), or giving a concordance degree or even asking for ordering a list of response options (FOWLER, 1995). 
- Questionnaire must leave a space for suggestions and overall comments (BOURQUE; FIELDER, 1995).

- Time for completion must be realistic estimated and reported in the questionnaire (BOURQUE; FIELDER, 1995).

- Using variables developed by former studies is recommended since they have already been tested (BOURQUE; FIELDER, 1995; FINK, 1995b).

- Questions should be ordered starting from the less complicated to the most complicated or delicate. In addition, they must have a logical order. Profile questions must come together, in the first part or in the last part of the questionnaire (BOURQUE; FIELDER, 1995). However, Bourque and Fielder (1995) recommend profile questions come in the last part of the instrument, since some of them can be considered delicate and, if presented in the beginning, can reduce the response rate. In addition, after directions, the questionnaire should present questions directly related to the research objectives (BOURQUE; FIELDER, 1995).

- Concerning the profile questions, age should be asked as the birth date; monthly income should be asked as ranges (FINK, 1995b).

- Complete directions for filling out the questionnaire must be included, especially on non-supervised self-administered instruments (BOURQUE; FIELDER, 1995).

- In order to avoid bias in the answers, confidentiality must be guaranteed; it means questionnaires should not be identified and the responses must be accessed only by the researcher's team (FOWLER, 1995).

- Invitation letter must be formal. It should motivate participation, highlighting study relevance, importance of the respondent participation, incentives to participation (gifts), confidentiality must be guaranteed, contact information must be provided (in case the respondent needs further information) (BOURQUE; FIELDER, 1995).

- Follow up procedure may help increase response rates. They consist of sending a reminding letter or giving a phone call. The first contact should be done ten days after sending the questionnaire and as many times as needed until the sample gets the necessary size (BOURQUE; FIELDER, 1995). 


\subsubsection{Interview}

Interview is a very flexible data collection technique and may assume different forms: structured, unstructured and semi-structured. Structured interview follows a pre-defined script, which contains well formulated and ordered questions. In opposition, unstructured interview does not follow a script; it consists of the interaction between the interviewer and the interviewee in order to capture data that helps research objectives accomplishment. Finally, semi-structured interview owns a list of important subjects that will be introduced by the interviewer, but the interaction is not rigidly defined (GIL, 2002). James and Busher (2009) highlight that an interview aims to capture the meanings attributed by the interviewees to the phenomenon of interest.

Internet has been modifying way research is conducted, since it allows both quantitative and qualitative strategies to be applied. For this application traditional strategies are adapted to be conducted online (JAMES; BUSHER, 2009).

Specifically, online interviews allow text exchange and allow time for reflection, for both interviewer and interviewee; even synchronous interview allows a dialogue (JAMES; BUSHER, 2009). Both traditional and online interviews are compared on the following table (Table 14).

Table 14. Interview characteristics

\begin{tabular}{l|l|l}
\hline Dimension & Online interview & Traditional interview \\
\hline Cost & $\begin{array}{l}\text { Lower cost. May not need } \\
\text { transcription. }\end{array}$ & $\begin{array}{l}\text { High costs (travel costs, } \\
\text { transcription costs etc.). }\end{array}$ \\
\hline Access & $\begin{array}{l}\text { Achieve people } \\
\text { geographically distributed } \\
\text { or people who would not } \\
\text { be accessible by telephone } \\
\text { or in person. } \\
\text { Just people who own } \\
\text { Internet access and } \\
\text { technology skills are able } \\
\text { to participate of this kind } \\
\text { of interview. }\end{array}$ & $\begin{array}{l}\text { May not achieve } \\
\text { geographically disperse } \\
\text { people. } \\
\text { May have trouble when } \\
\text { interviewee has } \\
\text { communication and } \\
\text { expression limitations. }\end{array}$ \\
\hline Time & $\begin{array}{l}\text { May be synchronous or } \\
\text { asynchronous }\end{array}$ & $\begin{array}{l}\text { Are essentially } \\
\text { synchronous and physical } \\
\text { interaction is relevant }\end{array}$ \\
\hline Answer time & Asynchronous: there is & Interaction is deep and \\
\hline
\end{tabular}




\begin{tabular}{|c|c|c|}
\hline Dimension & Online interview & Traditional interview \\
\hline & $\begin{array}{l}\text { time for reflection, but } \\
\text { there is also a high risk of } \\
\text { non-response } \\
\text { Synchronous: answers are } \\
\text { spontaneous }\end{array}$ & relevant \\
\hline Duration & $\begin{array}{l}\text { Asynchronous: may take } \\
\text { weeks to be completed } \\
\text { Synchronous: limited to the } \\
\text { time dedicated to the } \\
\text { collection } \\
\text { External interferences may } \\
\text { happen (out of the } \\
\text { researcher's control) }\end{array}$ & $\begin{array}{l}\text { Time for collection is the } \\
\text { time dedicated to the } \\
\text { interview itself. }\end{array}$ \\
\hline Location & Email and chat & $\begin{array}{l}\text { The location is important, } \\
\text { may be anywhere }\end{array}$ \\
\hline Confidentiality & $\begin{array}{l}\text { Shyness is reduced. } \\
\text { On asynchronous } \\
\text { interviews identification is } \\
\text { not necessary }\end{array}$ & $\begin{array}{l}\text { Personal interaction may } \\
\text { reduce motivation or } \\
\text { increase shyness }\end{array}$ \\
\hline
\end{tabular}

Source: Adapted from (JAMES; BUSHER, 2009, p.14-16).

This dissertation applied interview as the main technique to collect data from the Public Management course coordinators. The interviews were conducted by both, face-to-face,

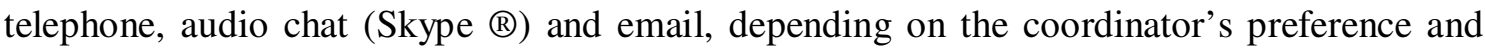
availability.

\subsubsection{Documentary records}

Documentary records were used as the third data collection technique. These documents were collected from UAB official website and from the institution's websites. The documents aim to provide better understanding of UAB processes and individual institutional characteristics. They included public announcements, decrees, course descriptions etc.

According to Selltiz et al. (2005), documentary records may assume many formats:

- Statistical records: demographic, economic; social data.

- Written documents: may be public or internal documents.

- Verbal documents. 
- Mass communications: information published on newspapers, magazines, radio, TV and literary publications.

Content analysis is usually conducted for evaluating documents, but researcher must be careful when establishing relationships between variables. That is because spurious correlations or mistakes in the data are possible. Finally, using documentary records for answering research objectives may be interesting, since costs are low and it is a less complicated data collection method (it is not necessary to get interviewees participation) (SELLTIZ et al., 2005).

\subsection{Data analysis plan}

Data analysis was conducted for each set of data separately and; then a combined analysis was developed, in order to find relations and linkage within the three perspectives. Researcher applied SPSS 17.0® (Statistical Package for Social Sciences) and Smart PLS 2.0 ® for analysis. For both students', instructors' and coordinators' analysis, the following procedures were conducted:

\section{1) Missing values and outliers}

Preliminary analysis included missing values evaluation and outlier cases of students and instructors data basis. Missing values were not a problem in both, students and instructors, data basis since all the questions in the electronic questionnaire were mandatory; it means, respondent could not finish and send the questionnaire if those obligatory questions were not completed. Just profile (category questions) answers were not obligatory, but had massive participation.

Outliers were evaluated through Mahalanobis Distances which were tested by a t-student test (significance level alpha $=0.1 \%$; it is a conservative level, recommended by Hair et al. (1998) and by Tabachnick and Fidell (2001) for outliers detection). T-student test showed no outliers in both data basis; then all cases were kept for subsequent analysis (593 students; 120 instructors). 
All subsequent analysis considered $1 \%$ or $5 \%$ significance level.

\section{2) Variables distribution}

Variables on student and instructor instruments, except for the category ones (profile questions), were measured in a five point Likert scale. Normality of distribution was tested for each individual variable through a Kolmogorov-Smirnov test. The tests showed none of the variables had normal distribution (rejection of the null hypothesis: $\mathrm{H}_{0}$ : variable "a" is normally distributed; $\mathrm{H}_{1}$ : variable "a" does not have a normal distribution). Normality is a requisite for some statistical techniques, especially those focused on inference. In this dissertation, considering the non-normality restriction, non-parametric significance tests were used. In addition, other techniques chosen for data analysis are not impact by non-normality. In factor analysis normal distribution is not required (HAIR et al., 1998), as well as for PLS model (HAENLEIN; KAPLAN, 2004). Regression analysis only requires normal distribution of the residuals (HAIR et al., 1998).

\section{3) Sample profile}

A descriptive profile was developed for each of the three samples (chapter 4).

\section{4) Data analysis}

- Students - Analysis plan

For student's individual unit the following techniques were applied:

- Structural equation modeling partial least square (SEM-PLS). PLS was chosen as a structural equation model since it owns some advantages, such as smaller sample size requirement; normal distribution is not mandatory; it is more flexible, than other SEM techniques concerning measurement scales (BROWN; MAZZAROL, 2009).

- Confirmatory factor analysis.

- Significance tests.

- Regression analysis.

- Correlation. 


\section{- Instructors - Analysis plan}

For instructor's individual unit the following techniques were applied:

- Exploratory factor analysis.

- Structural equation modeling, Partial least square (PLS)

- Significance tests.

\section{- Coordinators - Analysis plan}

For coordinator's individual unit the following technic was applied:

- Qualitative description.

\section{- General analysis plan}

Besides of individual analysis, comparative analysis among the units was conducted (Figure 39). Student and instructor perspectives were not compared since there is no evidence in the literature the constructs used on student and instructor surveys had a path relationship. In addition, since both instruments were based on validated models, the researcher decided not to modify them in order to test relationships, which is proposed as a future research.

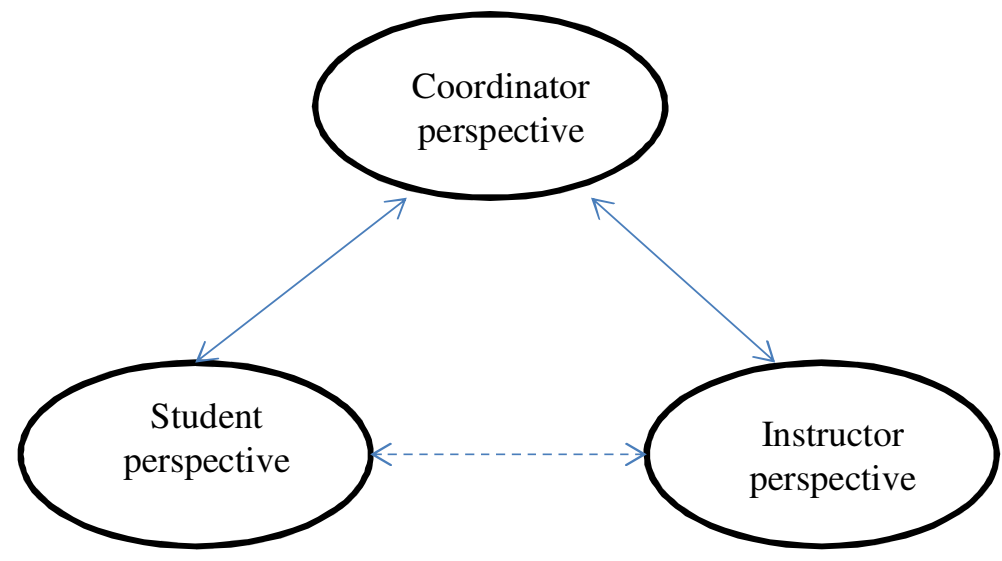

Figure 39. Comparative analysis units 
The following techniques were applied:

- Student x coordinators: GAP analysis (significance tests and qualitative analysis).

- Instructor x coordinators: qualitative analysis.

\section{- Decision rules}

In order to evaluate statistical techniques results, some directions were considered, based on statistical literature, as exposed by Table 15 . This information gave foundation to the analysis described on chapter 4 .

Table 15. Decision rules for statistical techniques

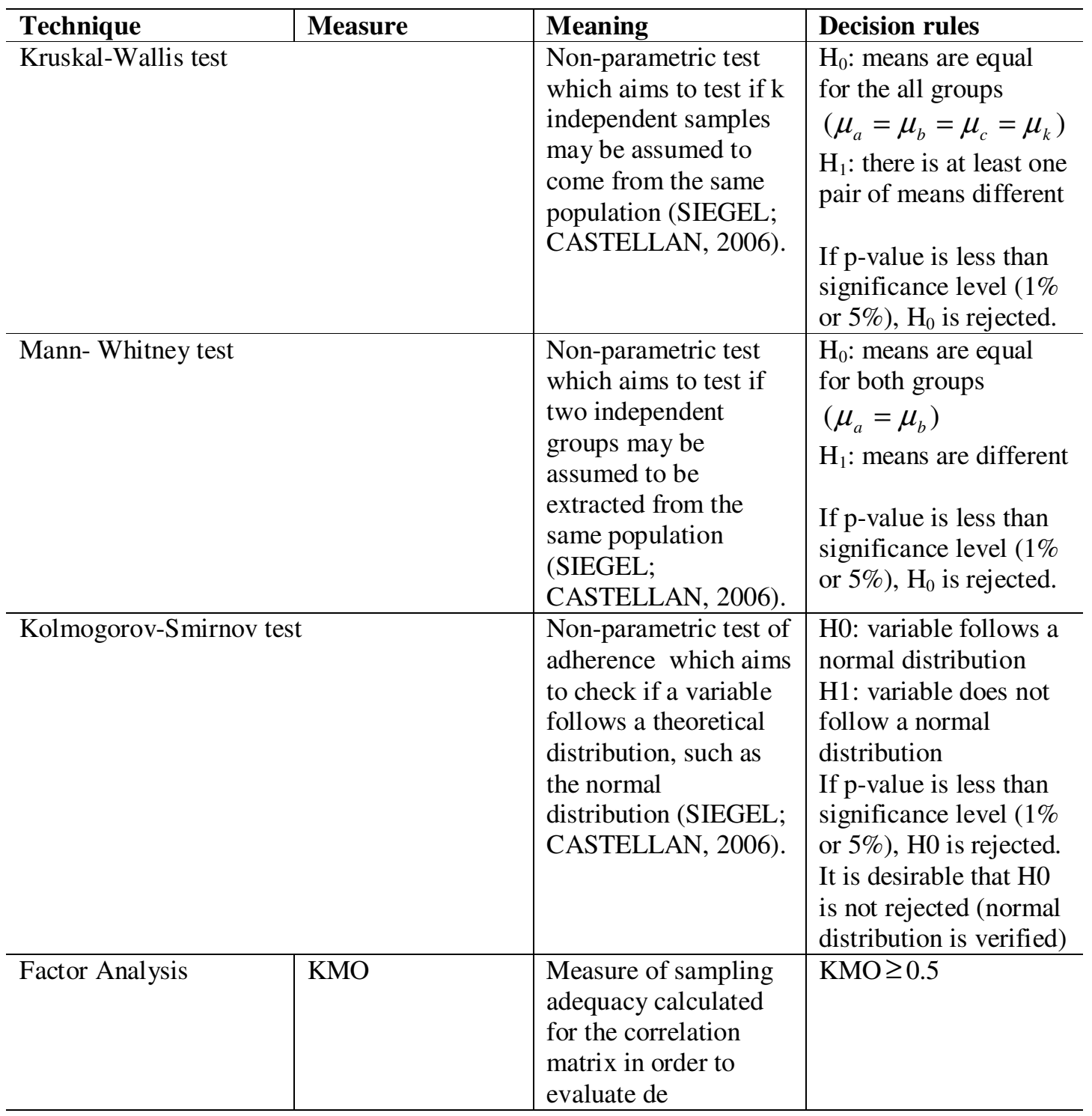




\begin{tabular}{|c|c|c|c|}
\hline Technique & Measure & Meaning & Decision rules \\
\hline & & $\begin{array}{l}\text { appropriateness of } \\
\text { applying factor } \\
\text { analysis (HAIR et al., } \\
1998, \text { p.89) }\end{array}$ & \\
\hline & Bartlett test & $\begin{array}{l}\text { Statistical test for the } \\
\text { overall significance of } \\
\text { all correlations within } \\
\text { a correlation matrix } \\
\text { (HAIR } \text { et al., 1998, } \\
\text { p.88) }\end{array}$ & $\begin{array}{l}\text { Null hypothesis should } \\
\text { be rejected. }\end{array}$ \\
\hline & Communalities & $\begin{array}{l}\text { Total amount of } \\
\text { variance an original } \\
\text { variable shares with } \\
\text { all other variables } \\
\text { included in the } \\
\text { analysis (HAIR et al., } \\
\text { 1998, p.88) }\end{array}$ & Communality $\geq 0.5$ \\
\hline & MSA & $\begin{array}{l}\text { Measure of sampling } \\
\text { adequacy calculated } \\
\text { for each variable in } \\
\text { order to evaluate de } \\
\text { appropriateness of } \\
\text { applying factor } \\
\text { analysis (HAIR et al., } \\
1998, \text { p.89) }\end{array}$ & $\mathrm{MSA} \geq 0.5$ \\
\hline & Varimax rotation & $\begin{array}{l}\text { Orthogonal rotation. } \\
\text { Process in which the } \\
\text { factors extracted are } \\
\text { rotated maintaining } \\
\text { their axes at } 90 \\
\text { degrees, then each } \\
\text { factor is independent } \\
\text { of the others (HAIR et } \\
\text { al., 1998, p.89) }\end{array}$ & $\begin{array}{l}\text { Using an orthogonal } \\
\text { rotation depends on } \\
\text { the study's objectives }\end{array}$ \\
\hline & Factor load & $\begin{array}{l}\text { Correlation between } \\
\text { the variable and each } \\
\text { factor (HAIR et al., } \\
1998, \text { p.89) }\end{array}$ & $\begin{array}{l}\text { Factor load }=0.3 \\
\text { (minimum acceptable) } \\
\text { Factor load } \geq 0.5\end{array}$ \\
\hline & Cronbach's Alpha & $\begin{array}{l}\text { Measure of reliability } \\
\text { ranging from } 0 \text { to } 1 \\
\text { analysis (HAIR et al., } \\
1998, \text { p.88) }\end{array}$ & $\begin{array}{l}\text { Lower limit of } \\
\text { acceptability = } 0.6 \text { or } \\
0.7 ; \\
\text { However, the studies } \\
\text { considered in the } \\
\text { literature review } \\
\text { establish } 0.7 \text { as the } \\
\text { lower limit (UDO et } \\
\text { al., } 2011 ; \text { ROJAS- } \\
\text { MENDÉZ et al., 2009) } \\
\text { or 0.8 (KUO; YE, } \\
\text { 2009) }\end{array}$ \\
\hline Regression Analysis & R-square & $\begin{array}{l}\text { Measure of the } \\
\text { proportion of the } \\
\text { variance of the }\end{array}$ & $\begin{array}{l}\text { The higher R-Square, } \\
\text { the better. } \\
\text { Cohen (1977) defines }\end{array}$ \\
\hline
\end{tabular}




\begin{tabular}{|c|c|c|c|}
\hline \multirow[t]{4}{*}{ Technique } & Measure & Meaning & Decision rules \\
\hline & & $\begin{array}{l}\text { dependent variable } \\
\text { that is explained by } \\
\text { the independent } \\
\text { variables (HAIR et al., } \\
\text { 1998, p.143). }\end{array}$ & $\begin{array}{l}\text { the following } \\
\text { directions for social } \\
\text { sciences studies: } \\
\text { - R-square }=2 \% \text { (weak } \\
\text { effect) } \\
\text { - R-square }=13 \% \\
\text { (moderate effect) } \\
\text { - R-square }=26 \% \\
\text { (strong effect) }\end{array}$ \\
\hline & Beta coefficient & $\begin{array}{l}\text { Standardized } \\
\text { regression coefficient } \\
\text { that allows a } \\
\text { comparison of their } \\
\text { relative explanatory } \\
\text { power of the } \\
\text { dependent variable } \\
\text { (HAIR } \text { et al., 1998, } \\
\text { p.143). }\end{array}$ & $\begin{array}{l}\text { The higher beta } \\
\text { coefficient, stronger is } \\
\text { the variable } \\
\text { explanatory power of } \\
\text { the dependent variable. }\end{array}$ \\
\hline & Residuals & $\begin{array}{l}\text { Error in predicting the } \\
\text { sample data (HAIR et } \\
\text { al., 1998, p.147). }\end{array}$ & $\begin{array}{l}\text { Residuals must follow } \\
\text { a normal distribution }\end{array}$ \\
\hline \multirow[t]{5}{*}{$\begin{array}{l}\text { SEM - PLS (partial } \\
\text { least square) }\end{array}$} & $\begin{array}{l}\text { Average Variance } \\
\text { Extracted (AVE) }\end{array}$ & $\begin{array}{l}\text { Measure of } \\
\text { convergent validity } \\
\text { and model adequacy. } \\
\text { Concerns the amount } \\
\text { of variance in the } \\
\text { indicator, accounted } \\
\text { by the latent construct } \\
\text { (HAIR } \text { et al., 1998, } \\
\text { p.612). }\end{array}$ & $\mathrm{AVE} \geq 0.5$ \\
\hline & $\begin{array}{l}\text { Composite } \\
\text { reliability }\end{array}$ & $\begin{array}{l}\text { Measure of internal } \\
\text { consistency of the } \\
\text { construct indicators } \\
\text { (HAIR et al., 1998, } \\
\text { p.612). }\end{array}$ & $\begin{array}{l}\text { Lower limit of } \\
\text { acceptability }=0.6 \text { or } \\
0.7\end{array}$ \\
\hline & Cronbach's Alpha & $\begin{array}{l}\text { Measure of reliability } \\
\text { ranging from } 0 \text { to } 1 \\
\text { analysis (HAIR et al., } \\
\text { 1998, p.88) }\end{array}$ & $\begin{array}{l}\text { Lower limit of } \\
\text { acceptability }=0.6 \text { or } \\
0.7\end{array}$ \\
\hline & Communalities & $\begin{array}{l}\text { Total amount of } \\
\text { variance an original } \\
\text { variable shares with } \\
\text { all other variables } \\
\text { included in the } \\
\text { analysis (HAIR et al., } \\
1998, \text { p.88) }\end{array}$ & Communality $\geq 0.5$ \\
\hline & R-square & $\begin{array}{l}\text { Measure of the } \\
\text { proportion of the } \\
\text { variance of the } \\
\text { dependent variable } \\
\text { that is explained by } \\
\text { the independent } \\
\text { variables (HAIR et al., }\end{array}$ & $\begin{array}{l}\text { The higher R-Square, } \\
\text { the better. } \\
\text { Cohen (1977) defines } \\
\text { the following } \\
\text { directions for social } \\
\text { sciences studies: } \\
\text { - R-square = 2\% (weak }\end{array}$ \\
\hline
\end{tabular}




\begin{tabular}{l|l|l|l}
\hline Technique & Measure & Meaning & Decision rules \\
\hline & & $1998, \mathrm{p} .143)$. & $\begin{array}{l}\text { effect) } \\
- \text { R-square }=13 \% \\
\text { (moderate effect) } \\
- \text { R-square }=26 \% \\
\text { (strong effect) }\end{array}$ \\
\hline Correlation analysis & Spearman rho & $\begin{array}{l}\text { Non-parametric } \\
\text { correlation coefficient; } \\
\text { used to measure the } \\
\text { relation between two } \\
\text { variables (SIEGEL; } \\
\text { CASTELLAN, 2006) }\end{array}$ & $\begin{array}{l}\text { Cohen (1977) define } \\
\text { the following } \\
\text { directions for } \\
\text { evaluating correlation } \\
\text { coefficient: } \\
-\mathrm{r}=0.1 \text { weak } \\
-\mathrm{r}=0.3 \text { moderate } \\
-\mathrm{r}=0.5 \text { strong }\end{array}$ \\
\hline
\end{tabular}




\section{RESULTS}

\begin{tabular}{|l|}
\hline \multicolumn{1}{|c|}{4 RESULTS } \\
\hline Case description \\
Sample profile \\
Student's results \\
Instructor's results \\
Institutional results \\
General considerations \\
\hline
\end{tabular}

\subsection{Case description}

As mentioned in chapter 1, UAB was created in 2006 by decree no. 5800 (Jun/08/2006) and started offering a few courses including pedagogy and a pilot program on business management. Public institutions signed up to integrate UAB system and started offering courses through public announcements. The system was created through a partnership between Ministry of Education and CAPES (Coordenação de Aperfeiçoamento de Pessoal do Nível Superior/ Coordination for the development of higher education professionals) in order to expand higher education in the country, which was consistent with educational public policies. Since 2009, CAPES has been in charge of UAB system (Ordinance no. 318, Apr./02/2009) (UAB, 2012).

The structure of UAB system includes physical structure of public universities and institutes and support centers. The former are built and maintained by municipal and state government which are responsible for providing appropriate physical, technological and pedagogical structure for the development of learning activities. It is worth highlighting that one particular state may have more than one HEI participating of UAB and, consequently, many courses may be offered simultaneously by diverse institutions. Then, centers accommodate activities from these different courses, offered by different institutions (UAB, 2012).

At the centers face-to-face meetings take place, such as classes, video-conferences, seminars and assessment activities (tests and works development). Each center should have a library, a 
computer lab and count on a center coordinator and a tutor team who are responsible for helping students in many ways (study guidance, time management; sometimes also clarification of content doubts) (UAB, 2012).

Certificates are issued by the HEI, which offers the course through the UAB system and are equivalent to those expedited by traditional courses; that is, online course certificates are valid over the country (UAB, 2012). A set of laws define the UAB functioning (presented on Appendix A); these laws define each HEI is credentialed for five years to offer the UAB system, implementation of centers, conduction of follow-up visits to the institutions and centers, define how resources should be employed and the rights and duties of the institutions (UAB, 2012).

Institutions which are PNAP (Programa National de Formação em Administração Pública/ National Program for Education in Public Management) members had a previous contact with the UAB system offering other courses and the pilot program (Business pilot program). This previous contact offered a rich experience on how to teach management in a distance format, the main challenges of this format and how to deal with them.

PNAP was created due to government recognition of the need to qualify public managers to work on the diverse kinds of public activities. Undergraduate course lasts eight semesters and, besides of offering basic management disciplines, focuses on government management, city management and health system management. Each university member of PNAP follows a basic curriculum that defines a set of disciplines to be offered during the eight semesters, including a final study (TCC - Trabalho de conclusão de curso/ Course conclusion work) and an internship program, in both cases (TCC and internship) students should choose one of the three areas to focus on (government, city or health system management). Curriculum includes disciplines characterized as (CAPES, 2012):

- Basic education: introduction to economics; sociology, philosophy and ethics, psychology, politics sciences, accounting, macro-economy, auditing, law and negotiation.

- Professional education: administration theory, decision making, project design, public budget, strategy, public finance, public planning, human resources in the public sector, 
operations and logistic, information systems, international relations, sustainability management.

- Quantitative studies and technologies: mathematics, statistics, operational research.

- Complementary education: computer training, writing, research method, seminars and LIBRAS (Língua brasileira de sinais/ Brazilian signs language).

A basis material is also provided by $\mathrm{UAB}$, but each member is free to develop additional activities and complementary content. Assessment activities such as study presentations and tests are conducted in person at the centers.

Student selection happens through a process known as "vestibular" (a selection test including contents taught in high school level such as geography, history, mathematics, Portuguese, English, physics; chemistry, biology). Each member is free to define its tests and choose which disciplines to include. In some cases the test includes all disciplines, others are simplified versions and include only Portuguese, mathematics and a computer test.

Course includes four seminar disciplines; the first one aims to train students for the DE method, the other three disciplines aim to present specific content of each area of expertise in public management. Thus, during internship and TCC students may focus on the area they wish to work after graduation.

Structure includes a coordinator, a vice-coordinator and a tutoring coordinator. The first two professionals are responsible for managing the course considering MEC directions and UAB resources and course design. Tutoring coordinator is responsible for guiding tutor team, either online or at the centers. Coordinators interviewed consider the distance course as demanding as face-to-face equivalents.

Course includes an LMS (MOODLE) on which contents (including video classes) and activities are available to students as well as spaces for students deliver their homework, forums and chat rooms. Some institutions also provide video-conference (students have to go to the center to attend it) or web-conferences, depending on resources and the structure available (some states have poor Internet access and precarious center structure). Besides the assessment activities conducted in person at the centers (law requires assessment to be faceto-face) some classes are also offered at these locations, especially those concerning 
mathematics and statistics (management students have difficulties in these subjects) in order to enhance motivation and prevent dropout.

The center structure is based on a partnership relation between the university responsible for the program and local city halls. Both of them are responsible for providing infrastructure at the local centers, for instance, universities should select and hire professionals to work at the center and city halls should provide appropriate physical facility and technology structure. However, in many cases city halls do not provide adequate structure causing problems on the conduction of the course activities. This problem will be further discussed later in this chapter.

\subsection{Sample profile}

This study involved data collection from students, instructors and course coordinators. Each sample and its specific characteristics are described in the following topics.

\subsubsection{Sample of students}

Profile questions were included in the survey instrument and concern gender, age, prior experience with DE, marital status, job status, time dedicated to job and study, family and employer support. All this information is described below. As previously mentioned, research had the participation of ten different institutions member of UAB (students and instructors from one of them did not participate in the survey; then students and instructors from nine institutions composed the sample). Data is presented for the whole sample, and then interesting findings for separated institutions are also exposed.

Sample is composed of $50.1 \%$ male students and $49.9 \%$ female students; mean age is 34.6 years old (standard deviation $=9.5$ years). Discussing age is relevant in DE, as observed in chapter 3, since distance students are usually older, when compared to face-to-face peers; it seems to be the case of PNAP students, since $25 \%$ of them are over 41 years old, three of them are elder students (25\% are under 28 years old; $25 \%$ are $28-33.5$ years old; $25 \%$ are 33.5-41 years old; three of them are older than 60 years) (Figure 40). 


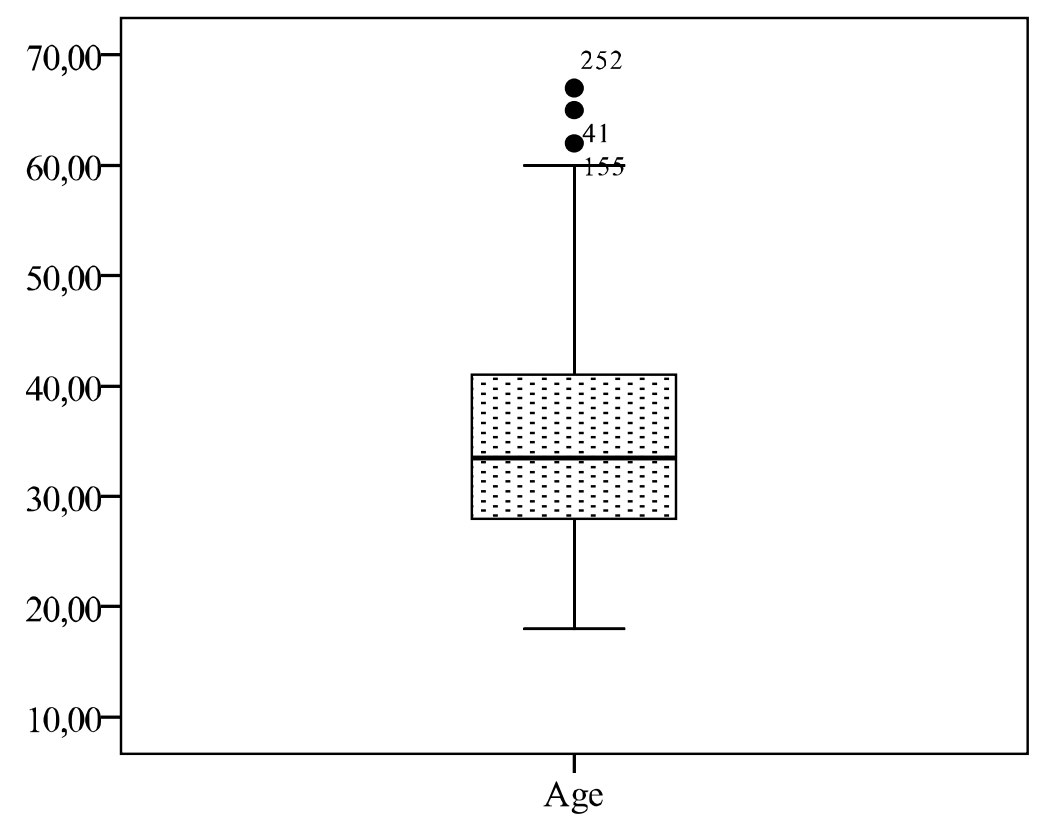

Figure 40. Box plot for age

Marital status indicated $53.1 \%$ are married, $36.9 \%$ are single, $6.6 \%$ are divorced and $3.4 \%$ consider their marital status in another category. In addition, $52.6 \%$ have kids. In a 0 to 10 scale, students attribute a mean score of 8.9 to family support (standard deviation $=2$ ) and a means score of 6.4 to employer support (standard deviation $=3.3$ ). Employer support has high variation, which means for some people employers were very supportive and to others they were very unsupportive.

Most of them work (93.6\%) and have an average workload of 41.7 hours per week (standard deviation $=10.6$ hours). Similarly, most of the students had never studied at a distance before (PNAP undergraduate course is the first distance course for $78.6 \%$ ), and dedicate average 12.8 hours per week to the course (standard deviation= 8.2 hours). As described on item 4.1, PNAP is a distance course that includes both online and face-to-face activities (tests and evaluation activities). Face-to-face meetings happen at the centers distributed through the states where the institution member is located. Some students; however, do not live in the town where the centers and the university campus are located and need to travel to get to faceto-face events. In the studied sample, $45.4 \%$ of students need to dislocate to go to a center. Most of the students in the sample are on their third year of the course (started in $2010=$ $42.8 \%)$. 
Finally, examining data by institution and region, it is found that southeast institutions compose $41 \%$ of the sample, followed by northeast (26.6\%); south (26.1\%) and midwest $(6.2 \%)$. It is worth to remember two universities in the south were surveyed; two universities in the southeast; four universities in the northeast and just one in midwest (no university in the north agreed to be part of the study). Table 16 summarizes general sample data. More details regarding the sample profile will be discussed opportunely during data analysis to help achieve research objectives.

Table 16. Sample profile summary

\begin{tabular}{|c|c|}
\hline Variable & Statistics \\
\hline Institution & $\begin{array}{l}\mathrm{A}=11.8 \% \rightarrow \text { South } \\
\mathrm{B}=18.9 \% \rightarrow \text { Southeast } \\
\mathrm{C}=11 \% \rightarrow \text { Northeast } \\
\mathrm{D}=7.8 \% \rightarrow \text { Northeast } \\
\mathrm{E}=6.2 \% \rightarrow \text { Midwest } \\
\mathrm{F}=22.1 \% \rightarrow \text { Southeast } \\
\mathrm{G}=4 \% \rightarrow \text { Northeast } \\
\mathrm{H}=3.9 \% \rightarrow \text { Northeast } \\
\mathrm{I}=14.3 \% \rightarrow \text { South }\end{array}$ \\
\hline Gender & $50.1 \%$ male; $49.9 \%$ female \\
\hline Age & Mean $=34.6 ;$ standard deviation $=9.5 ;$ c.v. ${ }^{15}=27.5 \%$ \\
\hline $\begin{array}{l}\text { Beginning of the } \\
\text { course }\end{array}$ & $\begin{array}{l}2009=16.9 \% \\
2010=42.8 \% \\
2011=28.5 \% \\
2012=10.3 \%\end{array}$ \\
\hline Dislocation & $\begin{array}{l}\text { Yes }=45.4 \% \\
\mathrm{No}=53.5 \%\end{array}$ \\
\hline $\begin{array}{l}\text { First experience } \\
\text { with distance } \\
\text { education }\end{array}$ & $\begin{array}{l}\mathrm{Yes}=78.6 \% \\
\mathrm{No}=21.4 \%\end{array}$ \\
\hline Work status & $\begin{array}{l}\text { Yes }=93.6 \% \\
\mathrm{No}=6.4 \%\end{array}$ \\
\hline Workload & Mean $=41.7$ hours; standard deviation $=10.6 ;$ c.v. $=25.5 \%$ \\
\hline Marital status & $\begin{array}{l}\text { Single }=36.9 \% \\
\text { Married }=53.1 \% \\
\text { Divorced }=5.6 \% \\
\text { Other }=3.4 \%\end{array}$ \\
\hline Kids & $\begin{array}{l}\text { Yes }=52.6 \% \\
\mathrm{No}=47.4 \%\end{array}$ \\
\hline Weekly study load & Mean $=12.8$ hours; standard deviation $=8.2 ;$ c.v. $=64.1 \%$ \\
\hline Family support & Mean $=8.8 ;$ standard deviation $=2 ;$ c.v. $=22.6 \%$ \\
\hline Employer support & Mean $=6.4 ;$ standard deviation $=3.3 ;$ c.v. $=51.5 \%$ \\
\hline
\end{tabular}

${ }^{15}$ C.V. $=$ Coefficient of variation $=($ standard deviation $/$ mean $) * 100$ 
Considering variable institution as a filter; some interesting differences within the cases may be drawn. Institutions A, D, H and I have more female students than male students. Institution $\mathrm{C}$ has more single students, while institutions $\mathrm{A}, \mathrm{B}, \mathrm{G}, \mathrm{H}$ and I have more married subjects (the other institutions have similar proportions of married and single subjects). In institutions $\mathrm{C}$ and $\mathrm{F}$ most of the students do not have kids. Table 17 summarizes dominant characteristics for each institution.

Table 17. Main characteristics for each institution

\begin{tabular}{|c|c|c|}
\hline \multicolumn{2}{|c|}{ Institution } & \multirow{2}{*}{$\begin{array}{l}\text { Observations } \\
\text { Female dominant } \\
\text { Married dominant } \\
\text { Kids dominant }\end{array}$} \\
\hline A & $\begin{array}{l}\text { Male }=35.7 \% \\
\text { Female }=64.3 \% \\
\text { Work }=94.3 \% \\
\text { Married }=61.3 \% \\
\text { Kids }=58.6 \%\end{array}$ & \\
\hline $\mathrm{B}$ & $\begin{array}{l}\text { Male }=59.8 \% \\
\text { Female }=40.2 \% \\
\text { Work }=100 \% \\
\text { Married }=61.6 \% \\
\text { Kids }=58 \%\end{array}$ & $\begin{array}{l}\text { Male dominant } \\
\text { All students work } \\
\text { Married dominant } \\
\text { Kids dominant }\end{array}$ \\
\hline $\mathrm{C}$ & $\begin{array}{l}\text { Male }=56.9 \% \\
\text { Female }=43.1 \% \\
\text { Work }=96.9 \% \\
\text { Single }=58.5 \% \\
\text { Kids }=35.4 \%\end{array}$ & $\begin{array}{l}\text { Male dominant } \\
\text { Single dominant } \\
\text { No kids dominant }\end{array}$ \\
\hline $\mathrm{D}$ & $\begin{array}{l}\text { Male }=41.3 \% \\
\text { Female }=58.7 \% \\
\text { Work }=97.8 \% \\
\text { Married }=45.7 \% \\
\text { Single }=41.3 \% \\
\text { Kids }=50 \%\end{array}$ & Female dominant \\
\hline $\mathrm{E}$ & $\begin{array}{l}\text { Male }=51.4 \% \\
\text { Female }=48.6 \% \\
\text { Work }=91.9 \% \\
\text { Married }=51.4 \% \\
\text { Kids }=64.9 \%\end{array}$ & $\begin{array}{l}\text { Married dominant } \\
\text { Kids dominant }\end{array}$ \\
\hline $\mathrm{F}$ & $\begin{array}{l}\text { Male }=54.2 \% \\
\text { Female }=45.8 \% \\
\text { Work }=84 \% \\
\text { Married }=45 \% \\
\text { Single }=46.6 \% \\
\text { Kids }=45 \%\end{array}$ & $\begin{array}{l}\text { Male dominant } \\
\text { No kids dominant }\end{array}$ \\
\hline G & $\begin{array}{l}\text { Male }=58.3 \% \\
\text { Female }=41.7 \% \\
\text { Work }=91.7 \% \\
\text { Married }=54.2 \% \\
\text { Kids }=50 \%\end{array}$ & $\begin{array}{l}\text { Male dominant } \\
\text { Married dominant }\end{array}$ \\
\hline
\end{tabular}




\begin{tabular}{l|l|l}
\hline Institution & Observations \\
\hline $\mathrm{H}$ & Male=39.1\% & Female dominant \\
& Female=60.9\% & More subjects who do not \\
& Work $=78.3 \%$ & $\begin{array}{l}\text { } \\
\text { the other institutions } \\
\text { Married }=52.2 \%\end{array}$ \\
& Kids=34.8\% & $\begin{array}{l}\text { Married dominant } \\
\text { No kids dominant }\end{array}$ \\
& Male=42.4\% & Female dominant \\
& Female=57.6\% & All students work \\
& Work=100\% & Married dominant \\
& Karried $=67.1 \%$ & \\
& Kids $=67.1 \%$ & \\
\hline
\end{tabular}

Observing age, load and support, institution $\mathrm{C}$ has the youngest students in average, while institution $\mathrm{B}$ has the oldest students in average. Institutions $\mathrm{A}$ and $\mathrm{H}$ have the highest scores for employer support while institutions B and D have the lowest. Finally institutions B, H and I presented higher study load in hours while institution $G$ had the lowest score. These data show different institutions have different dominant characteristics (Table 18).

Table 18. Demographic characteristics

\begin{tabular}{|c|c|c|c|c|c|c|}
\hline \multicolumn{2}{|c|}{ Institution } & Age & Workload & $\begin{array}{c}\text { Employer } \\
\text { support }\end{array}$ & $\begin{array}{c}\text { Family } \\
\text { support }\end{array}$ & $\begin{array}{c}\text { Study } \\
\text { load }\end{array}$ \\
\hline & Mean & 34.0896 & 43.9242 & 7.8000 & 9.3857 & 10.6522 \\
\hline A & Std. Deviation & 9.69494 & 20.23805 & 2.51992 & 1.43752 & 6.30552 \\
\hline & $\mathrm{CV}$ & $28 \%$ & $46 \%$ & $32 \%$ & $15 \%$ & $59 \%$ \\
\hline & Mean & 37.5091 & 42.1712 & 5.5556 & 8.6518 & 14.5804 \\
\hline $\mathrm{B}$ & Std. Deviation & 8.76581 & 9.10532 & 3.32179 & 2.14648 & 8.83445 \\
\hline & $\mathrm{CV}$ & $23 \%$ & $22 \%$ & $60 \%$ & $25 \%$ & $61 \%$ \\
\hline \multirow{3}{*}{$\mathrm{C}$} & Mean & 30.7619 & 40.7302 & 6.3594 & 9.3231 & 10.2923 \\
\hline & Std. Deviation & 9.46422 & 9.75706 & 3.19904 & 1.07685 & 6.97478 \\
\hline & $\mathrm{CV}$ & $31 \%$ & $24 \%$ & $50 \%$ & $12 \%$ & $68 \%$ \\
\hline \multirow{3}{*}{$\mathrm{D}$} & Mean & 35.1364 & 40.6304 & 5.6000 & 8.7609 & 10.8913 \\
\hline & Std. Deviation & 9.04663 & 8.62131 & 3.81027 & 2.44208 & 5.99343 \\
\hline & $\mathrm{CV}$ & $26 \%$ & $21 \%$ & $68 \%$ & $28 \%$ & $55 \%$ \\
\hline \multirow{3}{*}{$\mathrm{E}$} & Mean & 34.8286 & 42.6176 & 6.8824 & 9.2703 & 10.8378 \\
\hline & Std. Deviation & 10.69218 & 6.98923 & 3.05272 & 1.28341 & 6.61863 \\
\hline & $\mathrm{CV}$ & $31 \%$ & $16 \%$ & $44 \%$ & $14 \%$ & $61 \%$ \\
\hline $\bar{F}$ & Mean & 34.0317 & 41.4091 & 6.1339 & 8.4809 & 12.9070 \\
\hline
\end{tabular}




\begin{tabular}{|c|c|c|c|c|c|c|}
\hline \multicolumn{2}{|c|}{ Institution } & Age & Workload & $\begin{array}{c}\text { Employer } \\
\text { support }\end{array}$ & $\begin{array}{c}\text { Family } \\
\text { support }\end{array}$ & $\begin{array}{c}\text { Study } \\
\text { load }\end{array}$ \\
\hline & Std. Deviation & 10.14766 & 7.32633 & 3.47577 & 2.10987 & 9.06094 \\
\hline & $\mathrm{CV}$ & $30 \%$ & $18 \%$ & $57 \%$ & $25 \%$ & $70 \%$ \\
\hline & Mean & 34.5000 & 40.1905 & 6.0455 & 8.1250 & 9.8261 \\
\hline C & Std. Deviation & 8.53127 & 9.95298 & 3.81073 & 2.70768 & 6.93903 \\
\hline & $\mathrm{CV}$ & $25 \%$ & $25 \%$ & $63 \%$ & $33 \%$ & $71 \%$ \\
\hline \multirow{3}{*}{$\mathrm{H}$} & Mean & 33.2609 & 39.1667 & 7.8421 & 8.9130 & 14.2273 \\
\hline & Std. Deviation & 10.02369 & 9.77542 & 2.24260 & 1.50493 & 7.98768 \\
\hline & $\mathrm{CV}$ & $30 \%$ & $25 \%$ & $29 \%$ & $17 \%$ & $56 \%$ \\
\hline \multirow{3}{*}{$\mathrm{I}$} & Mean & 35.1905 & 41.4353 & 6.9294 & 8.7882 & 16.3690 \\
\hline & Std. Deviation & 8.19561 & 7.64611 & 3.14260 & 2.26828 & 8.32731 \\
\hline & $\mathrm{CV}$ & $23 \%$ & $18 \%$ & $45 \%$ & $26 \%$ & $51 \%$ \\
\hline
\end{tabular}

\subsubsection{Sample of instructors}

Most of the instructors who participated in the study are from South (institution $A=37.5 \%$ and $\mathrm{I}=24.2 \%)($ Table 19).

Table 19. Instructor sample distribution - per region

\begin{tabular}{l|r|r|r}
\hline Institution & Frequency & Percent & Region \\
\hline $\mathrm{A}$ & 45 & 37.5 & South \\
\hline $\mathrm{B}$ & 5 & 4.2 & Southeast \\
\hline $\mathrm{C}$ & 8 & 6.7 & Northeast \\
\hline $\mathrm{D}$ & 7 & 5.8 & Northeast \\
\hline $\mathrm{E}$ & 1 & .8 & Midwest \\
\hline $\mathrm{F}$ & 8 & 6.7 & Southeast \\
\hline $\mathrm{G}$ & 6 & 5.0 & Northeast \\
\hline $\mathrm{H}$ & 9 & 7.5 & Northeast \\
\hline $\mathrm{I}$ & 29 & 24.2 & South \\
\hline Total & 118 & 98.3 & \\
\hline Missing & 2 & 1.7 & \\
\hline & & &
\end{tabular}

There was no gender dominance $($ male $=52.5 \%$ and female $=47.5 \%)$. Level of education indicated $25.8 \%$ are undergraduate level, $28.3 \%$ had a MBA (or similar degree), $22.5 \%$ had a master degree, $18.3 \%$ had a $\mathrm{PhD}$ and $4.2 \%$ had a post-doctoral degree. Mean age was 37.6 
years old (std. deviation=9.6; $\mathrm{cv}=25.5 \%$ ). Career time indicated 6.5 years in average (std. deviation=6.8; minimum $=0$; maximum $=32$ years) and 2.5 years of teaching in $\mathrm{DE}$ (std. deviation=1.9; minimum $=0 ;$ maximum $=10$ years $)$.

\subsubsection{Sample of coordinators}

Nine coordinators were interviewed, one from each institution (except to institution B). Only two of them are female; all of them hold the position of course coordinator since at least 2011. Finally, all of them own a degree in the business area (undergraduate level, or master or doctoral degree in management, accounting or economics) and have at least a master degree. Data is summarized on Table 20.

Table 20. Coordinators' data

\begin{tabular}{|c|c|c|c|c|}
\hline Institution & Gender & $\begin{array}{l}\text { Period as } \\
\text { coordinator }\end{array}$ & Instruction level & Expertise area \\
\hline $\bar{A}$ & Female & 2 years & Master degree & $\begin{array}{l}\text { Business } \\
\text { management }\end{array}$ \\
\hline $\mathrm{B}$ & Male & & & \\
\hline $\mathrm{C}$ & Male & 2.5 years & Master degree & $\begin{array}{l}\text { Bachelor in } \\
\text { engineering. } \\
\text { Master in business } \\
\text { management }\end{array}$ \\
\hline $\bar{D}$ & Male & 2 years & Master degree & $\begin{array}{l}\text { Business } \\
\text { management }\end{array}$ \\
\hline $\mathrm{E}$ & Male & 2 years & Master degree & $\begin{array}{l}\text { Business } \\
\text { management }\end{array}$ \\
\hline $\mathrm{F}$ & Male & 1.5 years & $\mathrm{PhD}$ & $\begin{array}{l}\text { Business } \\
\text { management }\end{array}$ \\
\hline G & Male & 3 years & Master degree & $\begin{array}{l}\text { Bachelor in } \\
\text { economics. } \\
\text { Master in business } \\
\text { management }\end{array}$ \\
\hline $\mathrm{H}$ & Female & $\begin{array}{l}1 \text { year and } 4 \\
\text { months }\end{array}$ & Master degree & $\begin{array}{l}\text { Master in } \\
\text { accounting }\end{array}$ \\
\hline I & Male & 2 years & $\mathrm{PhD}$ & $\begin{array}{l}\text { Business } \\
\text { management }\end{array}$ \\
\hline $\mathrm{J}$ & Male & 2 years & $\mathrm{PhD}$ & $\begin{array}{l}\text { Bachelor in } \\
\text { business } \\
\text { management; } \\
\text { Master and } \mathrm{PhD} \\
\text { in engineering. }\end{array}$ \\
\hline
\end{tabular}




\subsection{Students' results}

In this section data from PNAP students are presented. Firstly data was tested for outlier cases. Mahalanobis distance was used in a conservative t-student test (significance level $=0.1 \%$ ) finding no outliers; then, all the 593 responses were used on data analysis. Normal distribution was also checked through Kolmogorov-Smirnov test and considering $1 \%$ significance level, none of the variables were found to have normal distribution. Nonnormality, as already mentioned in chapter 3 does not impact on the statistical analysis chosen for this dissertation. Considering these previous results, the following techniques were used for data analysis (Table 21).

Table 21. Techniques used for analyzing student's data

\begin{tabular}{l|l}
\hline Analysis & Objective \\
\hline $\begin{array}{l}\text { SEM (Structural Equation Modeling) Partial least } \\
\text { square (PLS) }\end{array}$ & $\begin{array}{l}\text { Applied to SERVQUAL dimensions and overall } \\
\text { quality, satisfaction, loyalty and image in order to } \\
\text { test relationships among the theoretical } \\
\text { constructs. }\end{array}$ \\
\hline Non-parametric significance tests & $\begin{array}{l}\text { ignificance tests were applied in order to find } \\
\text { different perceptions across groups (demographic } \\
\text { variables) }\end{array}$ \\
\hline Correlation analysis & $\begin{array}{l}\text { Correlations were calculated in order to identify } \\
\text { relationships among variables }\end{array}$ \\
\hline Regression analysis & $\begin{array}{l}\text { Regression analysis was conducted considering } \\
\text { image (dependent variable) and myths } \\
\text { (independent variables). This technique aimed to } \\
\text { verify whether myths influence image perception }\end{array}$ \\
\hline
\end{tabular}

\subsubsection{Structural equation modeling - Partial least square}

Partial least square (PLS) was applied in order to check relations between the constructs image, perceived quality, satisfaction and loyalty. As proposed by Parasuraman et al. (1988) services quality has five different dimensions: assurance, empathy, reliability, responsiveness and tangibles. Udo et al. (2011) proposed a modified version of SERVQUAL, adapted to DE, and a theoretical model that relates perceived quality, student satisfaction and behavioral intention. This theoretical model was applied in the present study in order to test the study's hypotheses. Initially, PLS was applied to measure the relationships between SERVQUAL constructs and overall perceived quality. Each rectangle represents a variable of SERVQUAL instrument; the circles represent theoretical constructs; the arrows connecting the circles to the 
rectangles contain factor load value (it shows whether each variable is related to the construct it is trying to measure); the arrows connecting the circles present beta coefficient values; values showed inside the circles present R-square value (how much the independent variables explain the dependent variable). Figure 41 shows factor loadings for all the variables in the model have value higher than 0.3, which suggests good adherence (HAIR et al., 1998). Rsquare for overall perceived quality is $63.2 \%$, which indicates perception of course quality is $63.2 \%$ explained by SERVQUAL dimensions. Beta coefficient shows website content has the strongest influence on perceived quality.

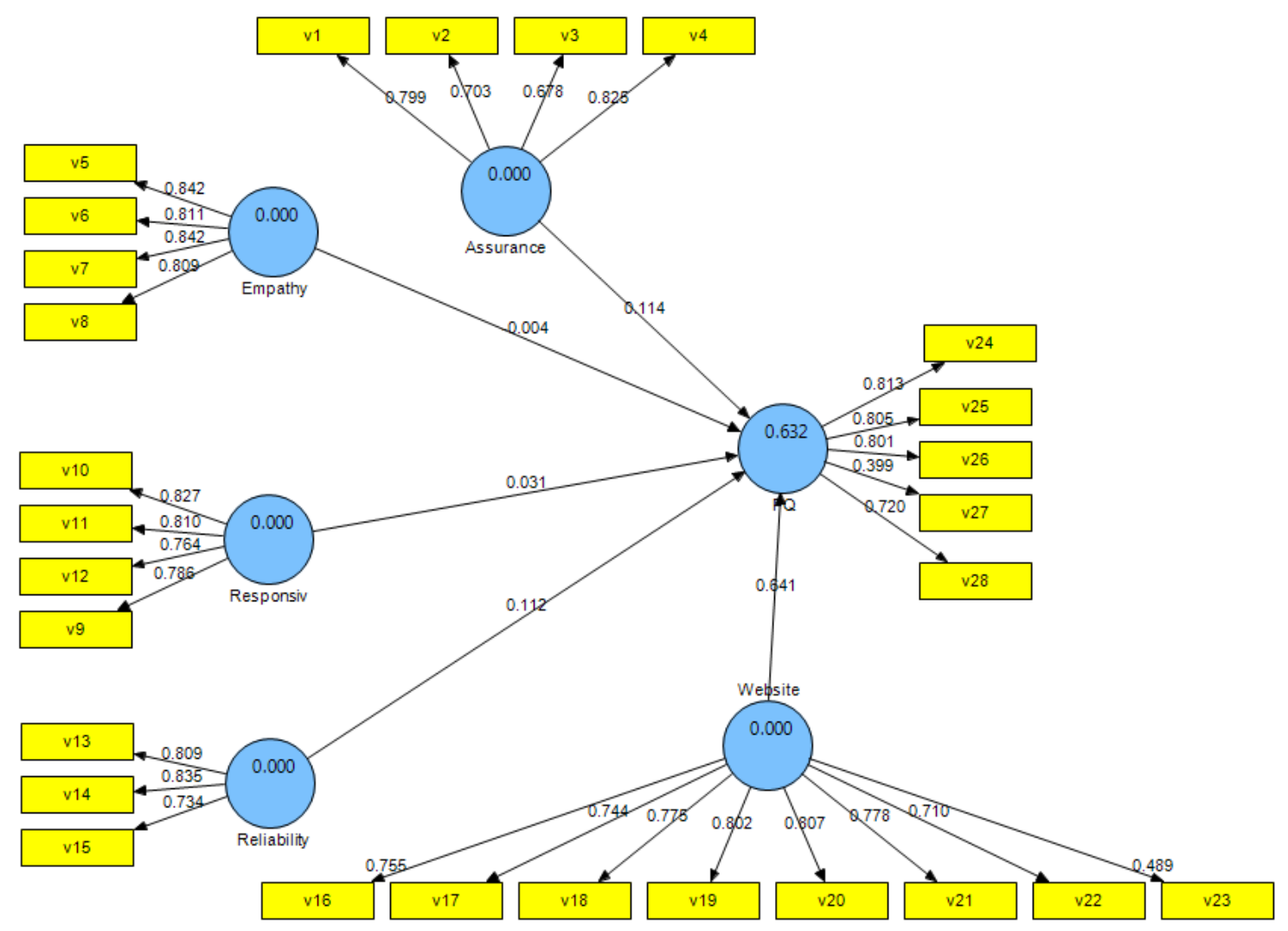

Figure 41. SERVQUAL model

Bootstrapping obtained t-student test results (values on the arrows present observed value of t-student statistic), considering the following hypotheses $\mathrm{H}_{0}$ : beta coefficient $=0 ; \mathrm{H}_{1}$ : beta coefficient is different from zero. Strength of relationships between the constructs was tested and only website content, assurance and reliability have significant influence on perceived quality (Figure 42). Website content has the strongest influence on perceived quality, followed by assurance and reliability (the last two with similar values). Then hypotheses H1, 
H4 and H5 are confirmed, while H2 and H3 are rejected in this study. Udo et al. (2011) also found, in their study, significant relationship between assurance and website content and perceived quality; website content also had the strongest relationship with perceived quality. However, the present study differs from Udo et al. (2011) results since they found a significant relation between empathy and responsiveness with perceived quality and no significant relation between reliability and perceived quality. In addition, Udo et al. (2011) paper reported R-square $=70.6 \%$ for perceived quality, which was slightly higher than that obtained here.

Goodness of fit statistics show the model meets the minimum quality standards (Table 22).

Table 22. Goodness of fit - SERVQUAL model

\begin{tabular}{l|r|r|r|r}
\hline & AVE & $\begin{array}{r}\text { Composite } \\
\text { Reliability }\end{array}$ & \multicolumn{2}{l|}{$\begin{array}{l}\text { Cronbach's } \\
\text { Alpha }\end{array}$} \\
\hline Assurance & 0.57 & 0.84 & 0.75 & 0.57 \\
\hline \multicolumn{1}{c|}{ Empathy } & 0.68 & 0.90 & 0.85 & 0.68 \\
\hline \multicolumn{1}{c|}{ PQ } & 0.53 & 0.84 & 0.76 & 0.53 \\
\hline Reliability & 0.63 & 0.84 & 0.71 & 0.63 \\
\hline Responsiveness & 0.64 & 0.87 & 0.81 & 0.64 \\
\hline $\begin{array}{l}\text { Website } \\
\text { content }\end{array}$ & 0.55 & 0.90 & 0.88 & 0.55 \\
\hline
\end{tabular}

Table 23 shows correlations among the latent variables and on the diagonal AVE square root values. As AVE square root has higher value than the correlations, discriminant validity is accepted.

Table 23. Correlation matrix for latent variables

\begin{tabular}{c|r|r|r|r|r}
\hline & Assurance & Empathy & Reliability & Responsiveness & Website \\
\hline Assurance & 0.75 & & & & \\
\hline Empathy & 0.65 & 0.83 & & & \\
\hline Reliability & 0.68 & 0.71 & 0.79 & & \\
\hline Responsiveness & 0.61 & 0.72 & 0.65 & 0.80 & \\
\hline Website & 0.45 & 0.48 & 0.62 & 0.43 & 0.74 \\
\hline
\end{tabular}




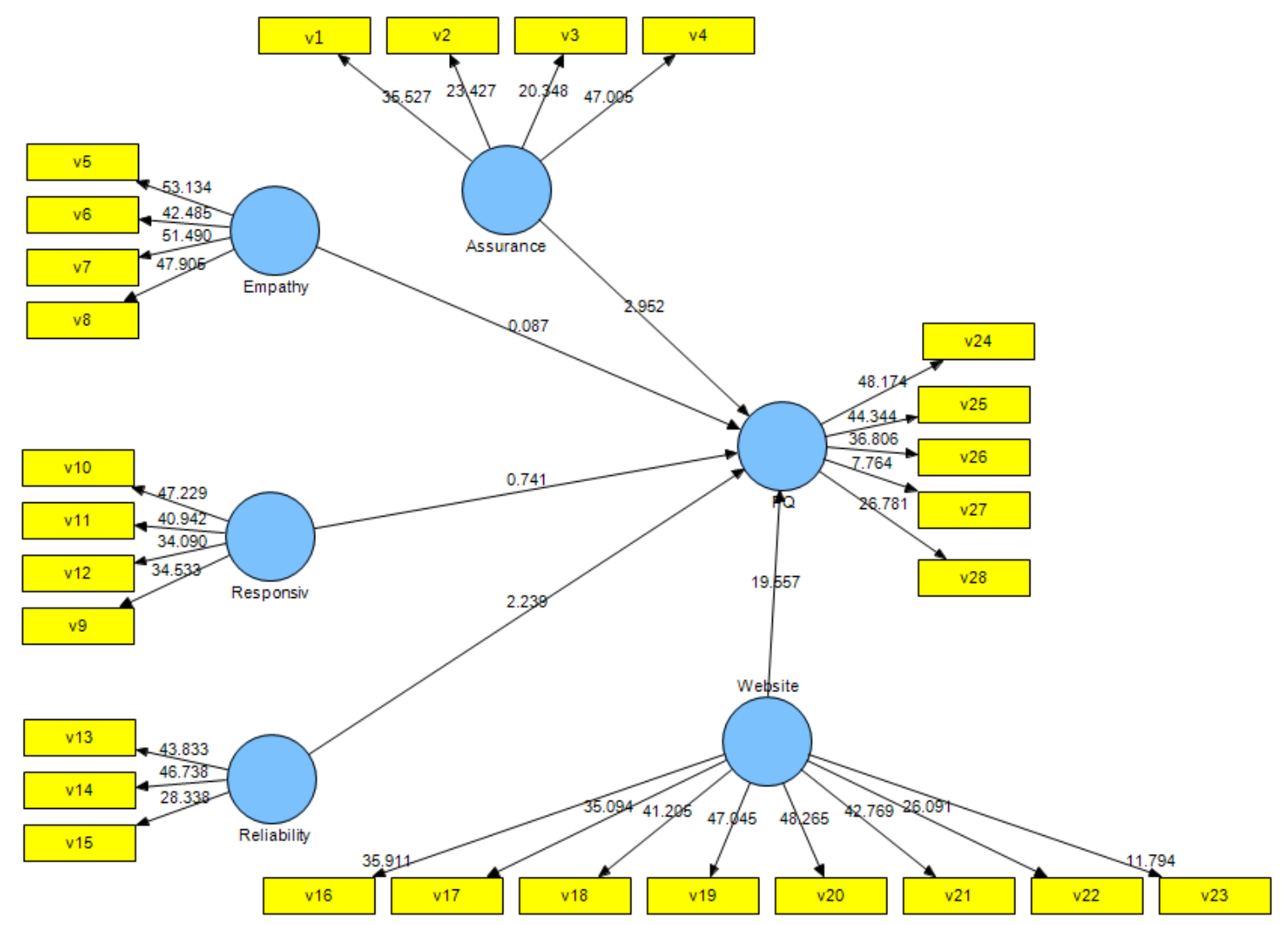

Figure 42. T-student test results for SERVQUAL model

In order to evaluate influence of perceived quality and satisfaction on student loyalty a new model was ran. First solution (model 1) considered five SERVQUAL dimensions, even empathy and responsiveness which do not influence perceived quality (Figure 43). The model shows R-square for perceived quality reduces to $59 \%$ when considering the whole model (including satisfaction and loyalty). R-square was $49.2 \%$ for satisfaction and $75.3 \%$ for loyalty respectively. Bootstrap showed perceived quality has significant direct effect on student loyalty (similar to results found by Bloemer et al. (1998)) as well as significant indirect effect through satisfaction (as found by Udo et al. (2011) and Kuo and Ye (2009)), which confirms hypothesis H7. Perceived quality also has significant effect on student satisfaction (as found by Udo et al. (2011), Kuo and Ye (2009) and Rojas-Méndez et al. (2009)), confirming H6. Satisfaction in turn, has significant relation with student loyalty (similar to findings from Kuo and Ye (2009), Brown and Mazzarol (2009), Bloemer et al. (1998)) (H8 is confirmed). It is worth to observe satisfaction has stronger influence on loyalty than perceived quality (directly). These results are compatible with those found by Udo et al. (2011), except for the fact their perceived quality direct effect on loyalty, which was not 
significant. However, their R-square values for perceived quality, satisfaction and loyalty found by Udo et al. (2011) were higher than those obtained by this dissertation. In attempts to increase R-square value, empathy and responsiveness were excluded from the model, but no differences were found. Table 24 and Table 25 show model adherence is satisfactory.

Table 24. Research model statistics

\begin{tabular}{c|r|r|r|r}
\hline & AVE & $\begin{array}{c}\text { Composite } \\
\text { Reliability }\end{array}$ & \multicolumn{2}{l|}{$\begin{array}{l}\text { Cronbach's } \\
\text { Alpha }\end{array}$} \\
\hline Assurance & 0.57 & 0.84 & 0.75 & 0.57 \\
\hline Empathy & 0.68 & 0.90 & 0.85 & 0.68 \\
\hline Loyalty & 0.69 & 0.87 & 0.77 & 0.69 \\
\hline PQ & 0.52 & 0.84 & 0.76 & 0.52 \\
\hline Reliability & 0.63 & 0.84 & 0.71 & 0.63 \\
\hline Responsiveness & 0.64 & 0.87 & 0.81 & 0.64 \\
\hline Satisfaction & 0.82 & 0.95 & 0.93 & 0.82 \\
\hline Website & 0.55 & 0.90 & 0.88 & 0.55 \\
\hline
\end{tabular}

Table 25. Correlation matrix latent variables

\begin{tabular}{|c|c|c|c|c|c|c|c|c|}
\hline & Assurance & Empathy & Loyalty & $\mathrm{PQ}$ & Reliability & Responsiveness & Satisfaction & Website \\
\hline Assurance & 0.75 & & & & & & & \\
\hline Empathy & 0.65 & 0.83 & & & & & & \\
\hline Loyalty & 0.39 & 0.43 & 0.83 & & & & & \\
\hline $\mathrm{PQ}$ & 0.50 & 0.49 & 0.67 & 0.72 & & & & \\
\hline Reliability & 0.68 & 0.71 & 0.51 & 0.61 & 0.79 & & & \\
\hline Responsiveness & 0.61 & 0.72 & 0.36 & 0.44 & 0.65 & 0.80 & & \\
\hline Satisfaction & 0.42 & 0.45 & 0.86 & 0.70 & 0.52 & 0.35 & 0.91 & \\
\hline Website & 0.45 & 0.48 & 0.44 & 0.74 & 0.62 & 0.43 & 0.44 & 0.74 \\
\hline
\end{tabular}




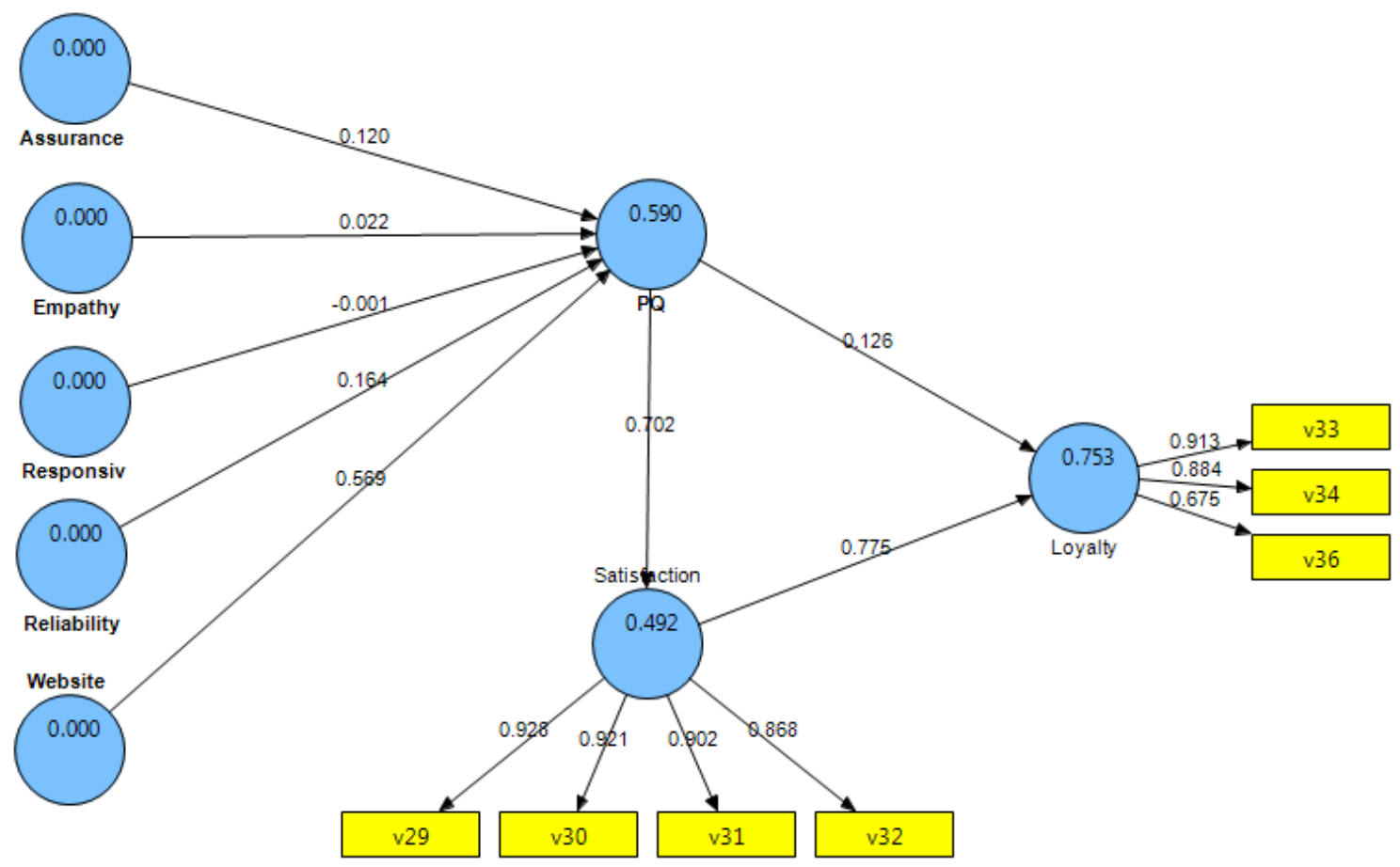

Figure 43. Research model 1

Bloemer et al. (1998) proposed in their study on bank customer loyalty, that image perception has influence on quality perception, which in turn influences satisfaction and loyalty. Although the present study considers distance students instead of bank customers, image construct was included in the model (model 2, exposed on Figure 44). Similarly to Bloemer et al. (1998) results image was found to have significant influence on perceived quality (confirming H12); significant indirect effect on satisfaction through perceived quality and significant indirect effect on loyalty through quality. It is possible to observe on Figure 44, Rsquare for perceived quality increases to $67.3 \%$ and R-square for satisfaction increases to $50.2 \%$. Table 26 and Table 27 show model statistics adequacy. 
Table 26. Model 2 statistics

\begin{tabular}{c|r|r|r|r}
\hline & AVE & $\begin{array}{l}\text { Composite } \\
\text { Reliability }\end{array}$ & $\begin{array}{l}\text { Cronbachs } \\
\text { Alpha }\end{array}$ & Communality \\
\hline Assurance & 0.57 & 0.84 & 0.75 & 0.57 \\
\hline Image & 0.79 & 0.94 & 0.91 & 0.79 \\
\hline Loyalty & 0.69 & 0.87 & 0.77 & 0.69 \\
\hline PQ & 0.52 & 0.84 & 0.76 & 0.52 \\
\hline Reliability & 0.63 & 0.84 & 0.71 & 0.63 \\
\hline Satisfaction & 0.82 & 0.95 & 0.93 & 0.82 \\
\hline Website & 0.55 & 0.90 & 0.88 & 0.55 \\
\hline
\end{tabular}

Table 27. Correlation matrix for latent variables

\begin{tabular}{c|r|r|r|r|r|r|r}
\hline & Assurance & Image & Loyalty & PQ & Reliability & Satisfaction & Website \\
\hline Assurance & 0.75 & & & & & & \\
\hline Image & 0.42 & 0.89 & & & & & \\
\hline Loyalty & 0.39 & 0.65 & 0.83 & & & & \\
\hline PQ & 0.50 & 0.69 & 0.67 & 0.72 & & & \\
\hline Reliability & 0.68 & 0.51 & 0.51 & 0.61 & 0.79 & & \\
\hline Satisfaction & 0.42 & 0.63 & 0.86 & 0.71 & 0.52 & 0.91 & \\
\hline Website & 0.45 & 0.55 & 0.44 & 0.73 & 0.62 & 0.44 & 0.74 \\
\hline
\end{tabular}

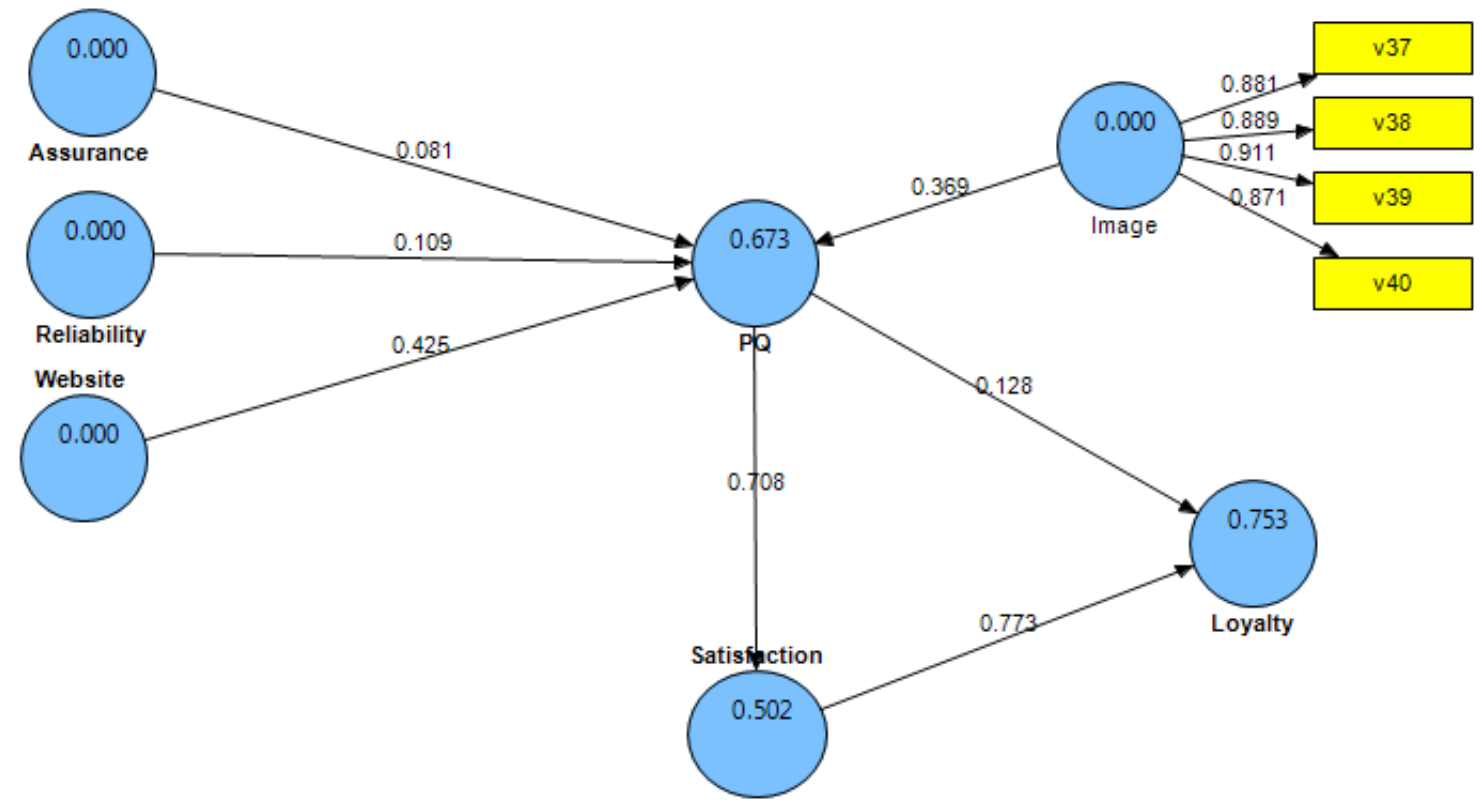

Figure 44. Research model 2 


\subsubsection{Descriptive statistics, correlation analysis, regression analysis and significance tests}

Analysis presented in this item used dimensions SERVQUAL, perceived quality, satisfaction, loyalty and image. These dimensions were calculated as the average of the variables composing each of them. Normality was again tested for the average dimensions and they do not follow a normal distribution. For this reason, non-parametric tests, which do not require normal distribution, were employed.

Table 28 presents descriptive statistics for theoretical dimensions tested on the previous item. As demonstrated, all dimensions have average value higher than 3 which indicates students have indefinite perceptions trending to positive in all of them. Image, satisfaction and loyalty have the highest values, indicating good perception.

Table 28. Descriptive statistics - theoretical dimensions

\begin{tabular}{l|r|r|r}
\hline & Mean & $\begin{array}{c}\text { Std. } \\
\text { Deviation }\end{array}$ & \multicolumn{1}{l}{ cv } \\
\hline Assurance & 3.6 & 0.7 & $20 \%$ \\
\hline Empathy & 3.4 & 0.8 & $23 \%$ \\
\hline Reponsiveness & 3.3 & 0.8 & $23 \%$ \\
\hline Reliability & 3.6 & 0.8 & $22 \%$ \\
\hline $\begin{array}{l}\text { Website } \\
\text { content }\end{array}$ & 3.6 & 0.7 & $21 \%$ \\
\hline Quality & 3.7 & 0.8 & $21 \%$ \\
\hline Satisfaction & 4.0 & 0.9 & $22 \%$ \\
\hline Loyalty & 4.0 & 0.9 & $21 \%$ \\
\hline Image & 4.2 & 0.7 & $17 \%$ \\
\hline
\end{tabular}

\subsubsection{Descriptive statistics}

Considering demographic characteristics, the studied sample presented similar proportions of male and female students (male $=50.1 \%$ and female $=49.9 \%$ ), which is opposite to the affirmation of Kramarae (2001) who states that there are more female students in DE; thus, H11 is rejected. Considering generation, Tricker et al. (2001) pointed distance students are mostly mature (baby boomers and generation X are considered mature in this dissertation). Data showed $51.1 \%$ of students are generation $\mathrm{X}$ and $11.1 \%$ are baby boomers, while only 
$37.8 \%$ are generation Y. This confirms H16, but it is worth to observe that despite of being the minority, generation $\mathrm{Y}$ has an expressive percentage of public management students.

Some variables in the questionnaire (v46 to v56) concerned student's perceptions of institutional support (course organization; technical support; interaction with colleagues and structure availability). These variables were grouped into dimensions through the average of variables that compose each construct. Cronbach's alpha varied from 0.723 to 0.980 (course organization $=0.813$; technical support $=0.860$; interaction $=0.908$; structure $=0.723$ ), indicating good reliability. Descriptive statistics show students have perceptions tending to positive, especially regarding course organization; it means, they recognize they have received sufficient information about the course (Table 29).

Table 29. Descriptive statistics for institutional support

\begin{tabular}{l|r|r|r}
\hline & Mean & $\begin{array}{c}\text { Std. } \\
\text { Deviation }\end{array}$ & $\mathrm{cv}$ \\
\hline $\begin{array}{l}\text { Course } \\
\text { organization }\end{array}$ & 3.8 & 0.8 & $20 \%$ \\
\hline $\begin{array}{l}\text { Technical } \\
\text { support }\end{array}$ & 3.5 & 0.9 & $27 \%$ \\
\hline $\begin{array}{l}\text { Interaction } \\
\text { peers }\end{array}$ & 3.2 & 1.1 & $35 \%$ \\
\hline $\begin{array}{l}\text { Structure } \\
\text { available }\end{array}$ & 3.6 & 0.9 & $24 \%$ \\
\hline
\end{tabular}

\subsubsection{Correlation analysis and regression analysis}

Correlation analysis showed family support and employer support have significant and positive correlation with student loyalty ( $\mathrm{p}$-value $=0.000$ ); that is, the higher support from family members and bosses, the higher is the student's loyalty to the course. However, Spearman coefficient showed correlation values are low (lower than 0.3) since correlation employer $=0.173$ and correlation family $=0.206$. These results confirm H14 and H15.

Satisfaction was correlated to responsiveness (measures perceptions about interaction between student and instructors) and a significant relationship was found ( $\mathrm{p}$-value $=0.000$ ). Nevertheless, Spearman coefficient $(r h o=0.37)$ has only a moderate value. Results confirm H21. 
Performance expectation was correlated to perceived quality (including SERVQUAL dimensions) and loyalty. As supposed by Udo et al. (2011) and Aitken (1989) expectation of performance is related to student perception of course quality and his/her intention to stay in the course. Although all the correlations were found to be significant (significance level=1\%), coefficients values for SERVQUAL dimensions are considered low (lower than 0.3); regarding overall satisfaction, loyalty and intention to finish the course in time (it is the only variable of loyalty dimension that measures intention to stay in the course) correlation coefficient is considered moderate (Table 30). Significance tests for correlation coefficients were conducted and revealed significant results, as exposes Table 30. Then H9 and H18 are confirmed.

Table 30. Correlation coefficients between performance expectation and some other construct

\begin{tabular}{l|l|l}
\hline Correlation pair & Spearman coefficient & p-value \\
\hline Assurance & 0.231 & 0.000 \\
\hline Empathy & 0.222 & 0.000 \\
\hline Responsiveness & 0.196 & 0.000 \\
\hline Reliability & 0.255 & 0.000 \\
\hline Website content & 0.266 & 0.000 \\
\hline Overall quality & 0.407 & 0.000 \\
\hline General loyalty & 0.632 & 0.000 \\
\hline Intention to finish the course on regular time & 0.658 & 0.000 \\
\hline
\end{tabular}

Literature review comments some myths surrounding DE. In the collected sample students have a good perception regarding the interactivity of the LMS used on the course, but they do not have a definite opinion on technology mastery for studying DE (mean=2.9, $\mathrm{cv}=38 \%$, indicates heterogeneity of opinions). They consider studying in DE is more demanding than studying in traditional courses and they have positive perception of motivation in studying in DE but do not have a definite opinion on the special abilities someone should own to study at a distance (mean=2.9, $\mathrm{cv}=43 \%$, indicates high heterogeneity) (Table 31). These results suggest students have a positive feeling regarding DE, but when technology skills and specific abilities are under discussion, they have heterogeneous opinions (high coefficient of variation). In this sample, thus, myths regarding interactivity, course requirements and motivation to study online are not confirmed. 
Table 31. Descriptive statistics for myths

\begin{tabular}{l|r|r|r}
\hline & Mean & $\begin{array}{c}\text { Std. } \\
\text { Deviation }\end{array}$ & $\mathrm{cv}$ \\
\hline Interaction & 3.6 & 1.0 & $28 \%$ \\
\hline $\begin{array}{l}\text { Master } \\
\text { technology }\end{array}$ & 2.9 & 1.1 & $38 \%$ \\
\hline Demand & 4.4 & 0.9 & $21 \%$ \\
\hline Motivating & 3.6 & 1.0 & $29 \%$ \\
\hline Ability & 2.9 & 1.3 & $43 \%$ \\
\hline
\end{tabular}

Stepwise regression analysis was conducted in order to check whether the UAB image is impacted by students' perceptions of myths surrounding DE. The model obtained Rsquare $=42.2 \%$, normal distributed residues $(\mathrm{p}$-value $=0.310)$ and kept the following variables:

- Course website is dynamic and interactive ( $\mathrm{p}$-value=0.000; standardized beta=0,452).

- Distance course is more demanding than face-to-face education ( $p$-value $=0.000$; standardized beta $=0.139$ ).

- Studying at a distance is motivating ( $\mathrm{p}$-value $=0.000$; standardized beta $=0.197$ ).

- Anyone is able to do well in a distance course ( $\mathrm{p}$-value=0.000; standardized beta= $0.125)$.

Interactivity of LMS has the strongest influence on image perception, followed by DE demands, DE motivation and abilities to study at a distance. These results confirm hypothesis H13. Additionally, unstandardized beta coefficient was positive for the four independent variables maintained in the model, which means the better the perception of website dynamic, the better is the institutional image. Similarly, the stronger the belief DE is more demanding than face-to-face education, the better is the institutional image; the higher the perception studying at a distance is motivating and that anyone is able to have satisfactory performance in a distance course, the better will be the institutional image.

\subsubsection{Significance tests}

Significance tests were run in order to identify relationships between the demographic variables and study's constructs. Mann-Whitney test was used to test gender satisfaction; 
results showed significant difference between the levels of satisfaction in men and women (pvalue $=0.004)$; men are slightly more satisfied with the course than women (mean men=4.2; mean women=3.9). These findings confirm H10 and reject H19. Analyzing gender difference for loyalty, Mann-Whitney test showed a significant difference between men and women (pvalue $=0.006$ ); men are slightly more loyal to the course than women (mean men=4.1; mean women=3.9). This finding rejects $\mathrm{H} 22$.

In order to test differences of perception between net and non-net generations, Mann-Whitney test was conducted considering dissertation theoretical constructs; results are presented on Table 32. Generations only have significant different opinions regarding website content; descriptive statistics shows net generation has a more positive perception of the technology employed in the course than non-net generation peers (mean net $=3.69$, std. net $=0.72$; mean non-net $=3.53$, std. non-net $=0.74)$. These results partially confirm $\mathrm{H} 23$, since there is perception difference for only one SERVQUAL dimension.

Table 32. Mann-Whitney test for generations

\begin{tabular}{l|l|l|l}
\hline Dimension & p-value & Mean net & $\begin{array}{l}\text { Mean non- } \\
\text { net }\end{array}$ \\
\hline Assurance & 0.325 & 3.6 & 3.56 \\
\hline Empathy & 0.376 & 3.4 & 3.37 \\
\hline Responsiveness & 0.053 & 3.38 & 3.27 \\
\hline Reliability & 0.184 & 3.62 & 3.54 \\
\hline Website contents & $\mathbf{0 . 0 0 8}$ & $\mathbf{3 . 6 9}$ & $\mathbf{3 . 5 3}$ \\
\hline Overall quality & 0.816 & 3.69 & 3.67 \\
\hline Satisfaction & 0.066 & 3.92 & 4.08 \\
\hline Loyalty & 0.564 & 3.97 & 4.04 \\
\hline Image & 0.731 & 4.18 & 4.17 \\
\hline
\end{tabular}

Kim (2011) pointed students tend to be more satisfied as they stay longer in the course. In this sense, Kruskall-Wallis test was conducted in order to identify satisfaction differences according to the year students entered the course $(2009,2010,2011,2012)$. Results showed there is no significant difference in satisfaction levels for different stages in the course (pvalue $=0.060$ ). These findings reject $\mathrm{H} 20$. 


\subsection{Instructors' results}

In this section data obtained from tutors and the faculty of PNAP are presented, the analyses conducted are summarized on Table 33.

Table 33. Summary of analyses conducted in this item

\begin{tabular}{l|l}
\hline Analysis & Objective \\
\hline variables & $\begin{array}{l}\text { Four factor analyses were applied separately, one } \\
\text { for each set of variables in the original model, in } \\
\text { order to confirm the factor structure proposed by } \\
\text { Tabata and Johnsrud (2008). Firstly one factor per } \\
\text { set was forced; then, since model quality was low, } \\
\text { eigenvalue higher than one was used as criteria } \\
\text { for extraction. Even in this case, results showed } \\
\text { low quality. }\end{array}$ \\
$\begin{array}{l}\text { Exploratory facto analysis for the whole set of } \\
\text { variables }\end{array}$ & $\begin{array}{l}\text { Factor analysis was conducted to the whole set of } \\
\text { variables, not restricting the number of factors } \\
\text { extracted. Eigenvalue higher than one was used as } \\
\text { criteria for extraction. Eight factors were } \\
\text { extracted; from those, six had good quality } \\
\text { standards. These results differentiate from the } \\
\text { original model proposed by Tabata and Johnsrud } \\
\text { (2008), which considered only four dimensions. }\end{array}$ \\
\hline $\begin{array}{l}\text { Structural Equation Modeling (SEM) - Partial } \\
\text { least square (PLS) considering four dimensions }\end{array}$ & $\begin{array}{l}\text { SEM - PLS was applied to the original theoretical } \\
\text { dimensions proposed by Tabata and Johnsrud } \\
\text { (2008). In the present study attitudes and } \\
\text { acceptance of DE do not influence the level of } \\
\text { participation in DE (number of years teaching } \\
\text { DE). This result is opposite to that found on the } \\
\text { original work from Tabata and Johnsrud (2008). }\end{array}$ \\
\hline $\begin{array}{l}\text { Structural Equation Modeling (SEM) - Partial } \\
\text { least square (PLS) considering six factors }\end{array}$ & $\begin{array}{l}\text { An alternate model was tested in order to find the } \\
\text { influence of attitudes and acceptance of DE on } \\
\text { the level of participation in DE. Results also } \\
\text { found no influence of the dimensions on } \\
\text { participation. }\end{array}$ \\
\hline $\begin{array}{l}\text { Significance tests were applied in order to find } \\
\text { different perceptions across groups (demographic } \\
\text { variables) }\end{array}$ \\
\hline
\end{tabular}

\subsubsection{Factor analysis and SEM - PLS}

Initially data was checked for the existence of outlier cases through Mahalanobis distance. Considering significance level $0.1 \%$ no outliers were identified. Normal distribution was checked through Kolmogorov-Smirnov test $(\mathrm{alpha}=1 \%)$ and none of the variables followed a normal distribution. Non-normal distribution does not impact the results of statistical 
techniques applied (factor analysis and SEM - PLS). In order to confirm the factor structure from the theoretical model proposed by Tabata and Johnsrud (2008) four factor analyses were conducted, one for each set of variables (technology use; attitude toward technology; attitude toward DE; innovation adoption). Quality of factors extracted was low (low communalities, low variance explained and low reliability); then principal components analysis was ran to the total set of variables. The following standards were used:

- $\quad \mathrm{KMO} \geq 0.5$

- $\quad$ MSA $\geq 0.5$

- $\quad$ Communalities $\geq 0.5$

- Eigenvalue $>1$

- Varimax rotation

- Cronbach's Alpha>0.6

- $\quad$ AVE $\geq 0.5$

- $\quad$ Composite reliability $>0.6$

First solution extracted eight factors which respected the quality standards fixed for the research. However; some variables presented high factor load in more than one factor; for this reason these variables were excluded (v5 and v15). New solution also presented eight factors within the quality standards $(\mathrm{KMO}=0.710$; Variance explained=70.05\%); Cronbach's Alpha showed some factors (7 and 8 ) had low reliability and were also excluded from the analysis as Table 34 shows. Then, variables v5, v8, v14, v15, v17 and v23 were excluded from the model. It is important to observe the original model proposed by Tabata and Johnsrud (2008) has only four dimensions (technology use; attitudes toward technology; attitudes toward DE; innovation adoption) but this dissertation found eight factors within the same set of variables from which six factors had good quality indices and were kept in the model; in other words, the present research found a different factor structure from that proposed by Tabata and Johnsrud (2008). 
Table 34. Factor analysis results

\begin{tabular}{|c|c|c|c|c|c|c|}
\hline Dimension & Factor & Variables & MSA & Communality & $\begin{array}{l}\text { Factor } \\
\text { load }\end{array}$ & $\begin{array}{l}\text { Cronbach's } \\
\text { Alpha }\end{array}$ \\
\hline \multirow[t]{4}{*}{$\begin{array}{l}\text { Adoption } \\
\text { innovation }\end{array}$} & \multirow[t]{4}{*}{$\begin{array}{l}\text { F1: } \\
\text { Adoption } \\
\text { DE }\end{array}$} & $\begin{array}{l}\text { V18: I am able to share } \\
\text { the results of using DE } \\
\text { with others }\end{array}$ & 0.774 & 0.535 & 0.643 & \multirow[t]{4}{*}{0.806} \\
\hline & & $\begin{array}{l}\text { V19: The advantages of } \\
\text { DE outweigh the } \\
\text { disadvantages }\end{array}$ & 0.809 & 0.748 & 0.812 & \\
\hline & & $\begin{array}{l}\text { V21: I am able to see } \\
\text { results of DE delivery }\end{array}$ & 0.790 & 0.793 & 0.765 & \\
\hline & & $\begin{array}{l}\text { V22: DE is compatible } \\
\text { with my work style }\end{array}$ & 0.723 & 0.703 & 0.735 & \\
\hline \multirow{4}{*}{$\begin{array}{l}\text { Technology } \\
\text { use and } \\
\text { Attitude } \\
\text { toward } \\
\text { technology }\end{array}$} & \multirow[t]{4}{*}{$\begin{array}{l}\text { F2: } \\
\text { Technology } \\
\text { usefulness }\end{array}$} & $\begin{array}{l}\text { V1: It is important to use } \\
\text { hardware equipment in } \\
\text { conducting professional } \\
\text { work }\end{array}$ & 0.654 & 0.738 & 0.787 & \multirow[t]{4}{*}{0.770} \\
\hline & & $\begin{array}{l}\text { V2: It is important to use } \\
\text { software applications in } \\
\text { conducting professional } \\
\text { work }\end{array}$ & 0.587 & 0.705 & 0.623 & \\
\hline & & $\begin{array}{l}\text { V3: It is important to use } \\
\text { online resources in } \\
\text { conducting professional } \\
\text { work }\end{array}$ & 0.782 & 0.737 & 0.791 & \\
\hline & & $\begin{array}{l}\text { V4: Technology is } \\
\text { important for conducting } \\
\text { professional work }\end{array}$ & 0.729 & 0.789 & 0.818 & \\
\hline \multirow[t]{3}{*}{$\begin{array}{l}\text { Attitude } \\
\text { toward DE }\end{array}$} & \multirow{3}{*}{$\begin{array}{l}\text { F3: } \\
\text { Motivation } \\
\text { to DE }\end{array}$} & $\begin{array}{l}\text { V11: DE training and } \\
\text { development is available }\end{array}$ & 0.710 & 0.761 & 0.814 & \multirow[t]{3}{*}{0.719} \\
\hline & & $\begin{array}{l}\text { V12: I am motivated to } \\
\text { teach DE courses }\end{array}$ & 0.746 & 0.642 & 0.655 & \\
\hline & & $\begin{array}{l}\text { V13: Technical support is } \\
\text { available for DE }\end{array}$ & 0.729 & 0.730 & 0.646 & \\
\hline \multirow{3}{*}{$\begin{array}{l}\text { Attitude } \\
\text { toward } \\
\text { technology, } \\
\text { attitude } \\
\text { toward DE, } \\
\text { adoption }\end{array}$} & \multirow{3}{*}{$\begin{array}{l}\text { F4: } \\
\text { Technology } \\
\text { ease of use }\end{array}$} & $\begin{array}{l}\text { V10: Using technology is } \\
\text { stressful }(*)\end{array}$ & 0.688 & 0.624 & 0.588 & \multirow[t]{3}{*}{0.565} \\
\hline & & $\begin{array}{l}\text { V16: Delivering DE } \\
\text { instruction is stressful }(*)\end{array}$ & 0.516 & 0.703 & 0.782 & \\
\hline & & $\begin{array}{l}\text { V20: DE instruction is } \\
\text { difficult }(*)\end{array}$ & 0.510 & 0.742 & 0.702 & \\
\hline \multirow{2}{*}{$\begin{array}{l}\text { Attitude } \\
\text { toward } \\
\text { technology, } \\
\text { adoption }\end{array}$} & \multirow[t]{2}{*}{$\begin{array}{l}\text { F5: } \\
\text { Recognition }\end{array}$} & $\begin{array}{l}\text { V9: Institution recognizes } \\
\text { those who use technology }\end{array}$ & 0.791 & 0.673 & 0.562 & \multirow[t]{2}{*}{0.605} \\
\hline & & $\begin{array}{l}\text { V24: My self-image is } \\
\text { enhanced by using } \\
\text { technological innovations }\end{array}$ & 0.666 & 0.746 & 0.835 & \\
\hline Attitude & F6: & V6: Resources are & 0.747 & 0.745 & 0.808 & 0.566 \\
\hline
\end{tabular}




\begin{tabular}{|c|c|c|c|c|c|c|}
\hline Dimension & Factor & Variables & MSA & Communality & $\begin{array}{l}\text { Factor } \\
\text { load }\end{array}$ & $\begin{array}{l}\text { Cronbach's } \\
\text { Alpha }\end{array}$ \\
\hline \multirow[t]{2}{*}{$\begin{array}{l}\text { toward } \\
\text { technology }\end{array}$} & \multirow[t]{2}{*}{$\begin{array}{l}\text { Conditions } \\
\text { of use }\end{array}$} & $\begin{array}{l}\text { available to support } \\
\text { technology needs }\end{array}$ & & & & \\
\hline & & $\begin{array}{l}\text { V7: I am skillful in using } \\
\text { technology }\end{array}$ & 0.606 & 0.611 & 0.642 & \\
\hline \multirow{2}{*}{$\begin{array}{l}\text { Attitude } \\
\text { toward } \\
\text { technology, } \\
\text { Attitude } \\
\text { toward DE }\end{array}$} & \multirow[t]{2}{*}{$\begin{array}{l}\text { F7: Impact } \\
\text { of } \\
\text { technology }\end{array}$} & $\begin{array}{l}\text { V8: Using technology has } \\
\text { little impact on my career } \\
(*)\end{array}$ & 0.683 & 0.681 & 0.757 & \multirow[t]{2}{*}{0.197} \\
\hline & & $\begin{array}{l}\text { V14: I have DE } \\
\text { instructional skills }\end{array}$ & 0.725 & 0.633 & 0.540 & \\
\hline \multirow[t]{2}{*}{ Adoption } & \multirow{2}{*}{$\begin{array}{l}\text { F8: } \\
\text { Voluntary } \\
\text { use }\end{array}$} & $\begin{array}{l}\text { V17: Participation in DE } \\
\text { is voluntary }\end{array}$ & 0.527 & 0.766 & 0.838 & \multirow[t]{2}{*}{0.465} \\
\hline & & $\begin{array}{l}\text { V23: I am able to try out } \\
\text { DE before deciding to use } \\
\text { it }\end{array}$ & 0.568 & 0.607 & 0.665 & \\
\hline
\end{tabular}

SEM technique was applied in order to test the theoretical model exposed on chapter 3. Two different solutions were tried. Firstly the four dimensions proposed by Tabata and Johnsrud (2008) were used as predictor to participation, although exploratory factor analysis showed the four dimensions solution has poor adherence. Then the six factors obtained by the exploratory factor analysis were used as predictors to participation. Participation in DE was measured in the present dissertation through the period (in years) teaching in DE; Tabata and Johnsrud (2008) used the number of distance courses taught as the measure to participation. It is worth to mention their study collected data from faculty in American universities either teaching or not in DE. The present dissertation considered instructors (both faculty and tutors) who were teaching in PNAP course. As mentioned before, faculty in some universities was signed up to DE as an additional activity in their workload; tutors were hired specifically to work in DE, and for that reason their attitudes and perceptions may be more favorable. In order to test the hypotheses established in chapter $3(\mathrm{H} 25, \mathrm{H} 26, \mathrm{H} 27, \mathrm{H} 28)$, although the original factor structure proposed by Tabata and Johnsrud (2008) (theoretical model) was not maintained in this data basis, SEM was firstly applied to the original model, then to the adapted model. The original model led to the exclusion of some variables: v5, v14, v16, v17 and v20 which did not have significant factor loadings. After this exclusion, model showed Rsquare $=5.5 \%$; which means independent variables (technology use, attitudes toward technology and DE and adoption of innovation) did not have predictive influence on participation in DE in this case. In addition, beta coefficient confirmed there is no relationship among the dimensions and participation in DE. Values on the arrows present factor loadings 
of the variables (rectangles) on the constructs (circles) and beta coefficient connecting the constructs (circles) (Figure 45). Thus, hypotheses H25, H26, H27 and H28 are rejected in this study. These results are different from those found by Tabata and Johnsrud (2008); as they found variables from the four dimensions had significant influence on participation.

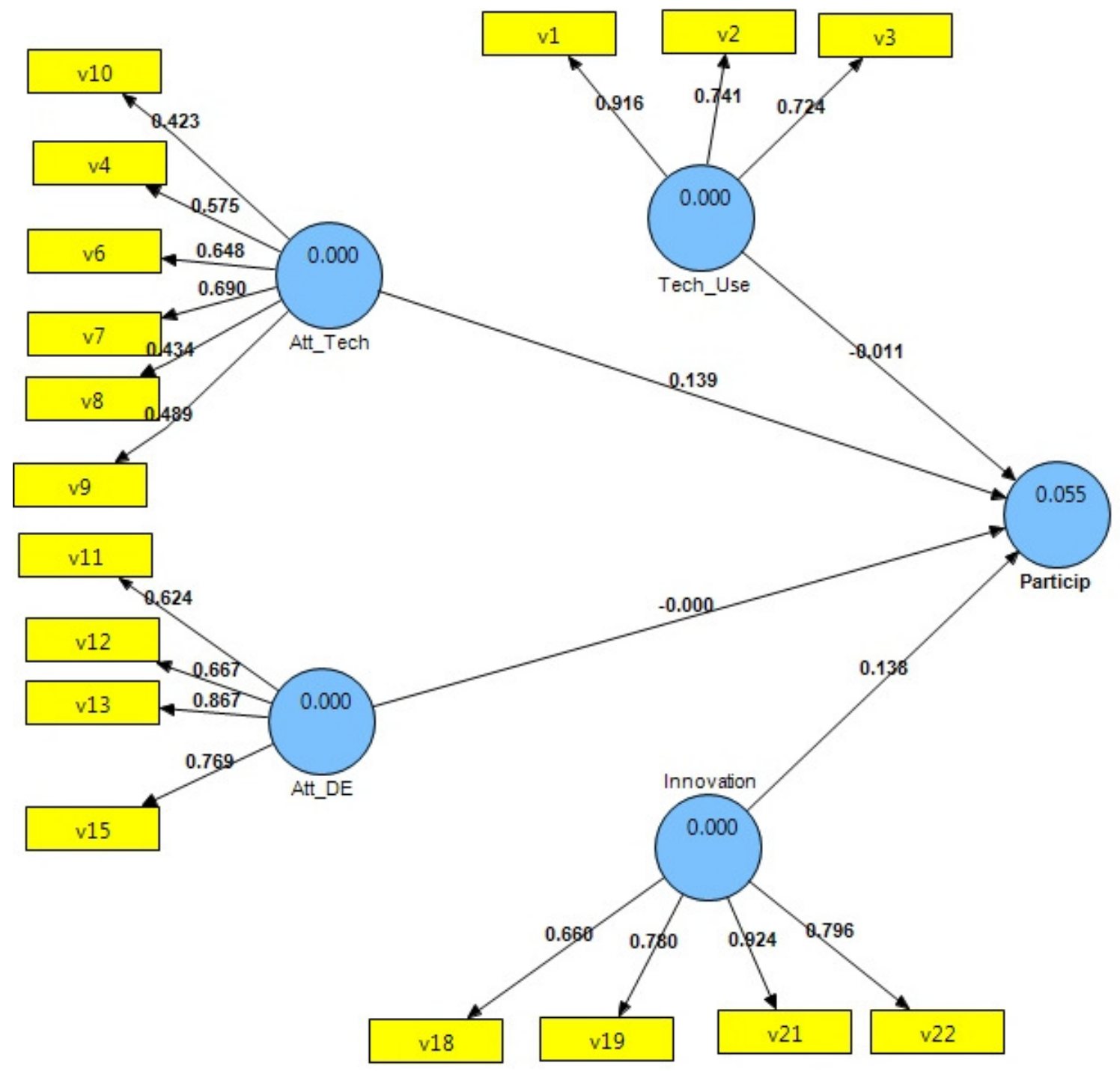

Figure 45. Model 1 - Participation in DE

Model showed adequate statistics, with exception to construct attitude toward technology which had AVE $<0.5$ and alpha<0.6 (Table 35). This result reinforces the indicators do not measure well this construct, as showed before by exploratory factor analysis. 
Table 35. Statistics for model 1

\begin{tabular}{r|r|r|r}
\hline & \multicolumn{1}{|l|}{$\begin{array}{l}\text { Composite } \\
\text { Reliability }\end{array}$} & \multicolumn{2}{l}{$\begin{array}{l}\text { Cronbach's } \\
\text { Alpha }\end{array}$} \\
\hline Att_DE & 0.54 & 0.82 & 0.73 \\
\hline Att_Tech & 0.31 & 0.72 & 0.54 \\
\hline Innovation & 0.63 & 0.87 & 0.81 \\
\hline Tech_Use & 0.64 & 0.84 & 0.72 \\
\hline
\end{tabular}

Table 36 shows correlation between latent variables; since values in diagonal (AVE square root) are higher than the other values of correlation, discriminant validity is accepted.

Table 36. Correlation matrix for latent variables

\begin{tabular}{r|r|r|l|l}
\hline & \multicolumn{1}{|l|}{ Att_DE } & \multicolumn{1}{l|}{ Att_Tech } & Innovation & Tech_Use \\
\hline Att_DE & 0.738 & & & \\
\hline Att_Tech & 0.351 & 0.553 & & \\
\hline Innovation & 0.556 & 0.499 & 0.795 & \\
\hline Tech_Use & 0.097 & 0.470 & 0.354 & 0.799 \\
\hline
\end{tabular}

An alternative model was tested, considering the six factors found by exploratory factor analysis and the same results were found; participation in DE cannot be predicted by the dimensions of the study (Figure 46). Statistics show better adherence of the alternative model (Table 37 and Table 38), although prediction ability is also low (R-square=5\%), which means the constructs considered do not influence significantly the participation in DE.

Table 37. Statistics model 2

\begin{tabular}{c|r|r|r}
\hline & & $\begin{array}{r}\text { Composite } \\
\text { Reliability }\end{array}$ & \multicolumn{2}{l}{ Cronbach's } \\
& Alpha & \\
\hline Adopt_DE & 0.63 & 0.87 & 0.8 \\
\hline Conditions & 0.70 & 0.82 & 0.6 \\
\hline Ease_use & 0.46 & 0.69 & 0.6 \\
\hline Motiv_DE & 0.63 & 0.84 & 0.7 \\
\hline Recognition & 0.56 & 0.67 & 0.6 \\
\hline Usefulness & 0.62 & 0.87 & 0.8 \\
\hline
\end{tabular}


Table 38. Correlation matrix latent variables

\begin{tabular}{c|r|r|r|r|r|r}
\hline & Adopt_DE & Conditions & Ease_use & Motiv_DE & Recognition & Usefulness \\
\hline Adopt_DE & 0.80 & & & & & \\
\hline Conditions & 0.40 & 0.83 & & & & \\
\hline Ease_use & 0.14 & 0.11 & 0.68 & & & \\
\hline Motiv_DE & 0.48 & 0.37 & -0.07 & 0.80 & & \\
\hline Recognition & 0.46 & 0.37 & -0.05 & 0.50 & 0.75 & \\
\hline Usefulness & 0.38 & 0.17 & 0.25 & 0.03 & 0.18 & 0.79 \\
\hline
\end{tabular}

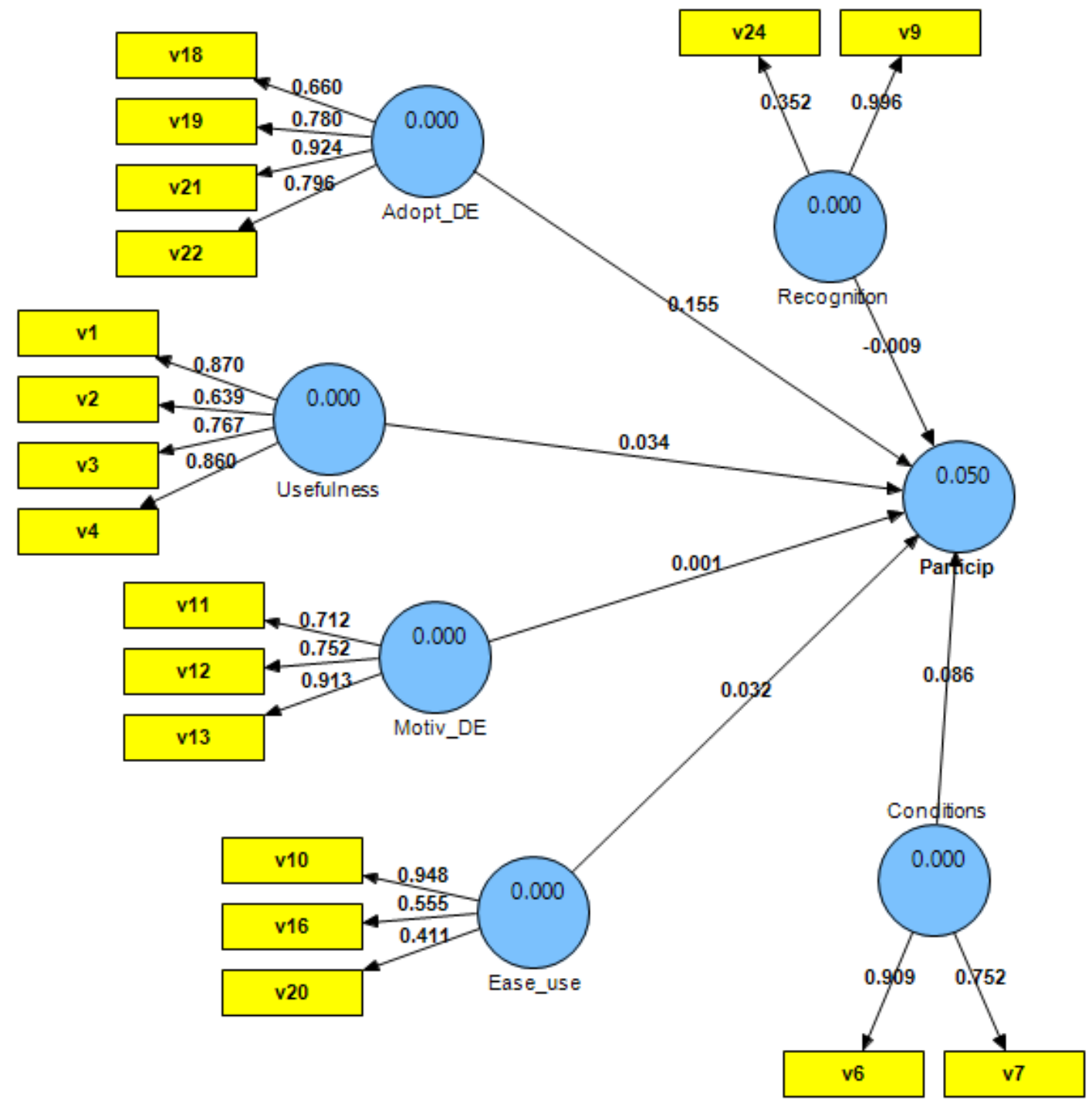

Figure 46. Model 2 - Participation in DE 


\subsubsection{Significance tests}

The results obtained in the exploratory factor analysis (six factors solution) were used as input in this section. Factor scores were computed as the average of the variables composing the factor. Kolmogorov-Smirnov test showed factors 3,4 and 5 have normal distribution ( significance level $=1 \%$ ), which allows the use of parametric tests. However, factors 1, 2 and 6 do not follow a normal distribution; so it would be possible to apply only non-parametric tests for them. In this sense, the researcher decided to use non-parametric tests for all the factors in order to establish a unified analysis. As suggested by Tabata and Johnsrud (2008) demographic variables may influence technology acceptance and attitudes; in their study age, ethnicity and institutional association influenced significantly the participation in DE. In the current study, factors were tested for variables gender and generation. Participation was transformed to ordinal scale (until three years teaching DE and more than three years teaching DE) and also tested.

Mann Whitney test was conducted in order to verify difference between male and female instructors. Considering significance level 5\%, no significant difference was found between genders as Table 39 shows, except for factor 5. This means both male and female instructors have similar perceptions of DE and technology and consider technology important for their work activities, as well as they find DE an effective method. It is worth to observe F5 rejects $\mathrm{H}_{0}$ considering 5\% significance; which means men have a stronger perception that technology use increases their self-image and their image in the institution. Then, H31 is partially rejected (there is significant difference between male and female instructors only regarding factor 5, for the other factors there is no significant difference; thus this hypothesis cannot be completely rejected).

Table 39. Mann-Whitney test for gender

\begin{tabular}{|c|c|c|c|c|}
\hline Factor & \multicolumn{2}{|c|}{ Descriptive } & p-value & Conclusion \\
\hline \multirow{2}{*}{$\begin{array}{l}\text { F1: } \\
\text { Adoption } \\
\text { DE }\end{array}$} & Male & $\begin{array}{l}\text { Mean }=4.30 \\
\mathrm{SD}=0.79\end{array}$ & \multirow[t]{2}{*}{0.635} & \multirow{2}{*}{$\begin{array}{l}\mathrm{H}_{0} \text { cannot be } \\
\text { rejected. There } \\
\text { is no significant } \\
\text { difference } \\
\text { between male } \\
\text { and female }\end{array}$} \\
\hline & Female & $\begin{array}{l}\mathrm{M}=4.36 \\
\mathrm{SD}=0.72\end{array}$ & & \\
\hline \multirow{2}{*}{$\begin{array}{l}\text { F2: } \\
\text { Technology } \\
\text { usefulness }\end{array}$} & Male & $\begin{array}{l}\mathrm{M}=4.63 \\
\mathrm{SD}=0.44\end{array}$ & \multirow[t]{2}{*}{0.58} & \multirow{2}{*}{$\begin{array}{l}\mathrm{H}_{0} \text { cannot be } \\
\text { rejected. There } \\
\text { is no significant } \\
\text { difference }\end{array}$} \\
\hline & Female & $\begin{array}{l}\mathrm{M}=4.56 \\
\mathrm{SD}=0.64\end{array}$ & & \\
\hline
\end{tabular}




\begin{tabular}{|c|c|c|c|c|}
\hline \multirow[t]{2}{*}{ Factor } & \multicolumn{2}{|c|}{ Descriptive } & \multirow[t]{2}{*}{ p-value } & \multirow{2}{*}{$\begin{array}{l}\text { Conclusion } \\
\text { between male } \\
\text { and female }\end{array}$} \\
\hline & & & & \\
\hline \multirow{2}{*}{$\begin{array}{l}\text { F3: } \\
\text { Motivation } \\
\text { to } \mathrm{DE}\end{array}$} & Male & $\begin{array}{l}\mathrm{M}=3.65 \\
\mathrm{SD}=1.01\end{array}$ & \multirow[t]{2}{*}{0.487} & \multirow{2}{*}{$\begin{array}{l}\mathrm{H}_{0} \text { cannot be } \\
\text { rejected. There } \\
\text { is no significant } \\
\text { difference } \\
\text { between male } \\
\text { and female }\end{array}$} \\
\hline & Female & $\begin{array}{l}\mathrm{M}=3.51 \\
\mathrm{SD}=1.05\end{array}$ & & \\
\hline \multirow{2}{*}{$\begin{array}{l}\text { F4: } \\
\text { Technology } \\
\text { ease of use }\end{array}$} & Male & $\begin{array}{l}\mathrm{M}=3.27 \\
\mathrm{SD}=0.91\end{array}$ & \multirow[t]{2}{*}{0.178} & \multirow{2}{*}{$\begin{array}{l}\mathrm{H}_{0} \text { cannot be } \\
\text { rejected. There } \\
\text { is no significant } \\
\text { difference } \\
\text { between male } \\
\text { and female }\end{array}$} \\
\hline & Female & $\begin{array}{l}\mathrm{M}=3.49 \\
\mathrm{SD}=0.88\end{array}$ & & \\
\hline \multirow[t]{2}{*}{$\begin{array}{l}\text { F5: } \\
\text { Recognition }\end{array}$} & Male & $\begin{array}{l}M=3.71 \\
S D=0.97\end{array}$ & \multirow[t]{2}{*}{0.032} & \multirow{2}{*}{$\begin{array}{l}\mathrm{H}_{0} \text { can be } \\
\text { rejected. There } \\
\text { is significant } \\
\text { difference } \\
\text { between male } \\
\text { and female }\end{array}$} \\
\hline & Female & $\begin{array}{l}\mathrm{M}=3.49 \\
\mathrm{SD}=0.91\end{array}$ & & \\
\hline \multirow{2}{*}{$\begin{array}{l}\text { F6: } \\
\text { Conditions } \\
\text { of use }\end{array}$} & Male & $\begin{array}{l}\mathrm{M}=3.86 \\
\mathrm{SD}=0.81\end{array}$ & \multirow[t]{2}{*}{0.669} & \multirow{2}{*}{$\begin{array}{l}\mathrm{H}_{0} \text { cannot be } \\
\text { rejected. There } \\
\text { is no significant } \\
\text { difference } \\
\text { between male } \\
\text { and female }\end{array}$} \\
\hline & Female & $\begin{array}{l}\mathrm{M}=3.87 \\
\mathrm{SD}=0.83\end{array}$ & & \\
\hline
\end{tabular}

Variable age was converted into an ordinal variable named generation; three categories were created (baby boomers=26, Generation $\mathrm{X}=76$ and Generation $\mathrm{Y}=15$ ). Factors were tested through Kruskal-Wallis test for these categories (alpha=5\%). Only for factor 2 and 6 rejects $\mathrm{H}_{0}$; which means generation $\mathrm{Y}$ considers technology more useful than baby boomers and generation $\mathrm{X}$ and this generation evaluates its skills and support as being better than the other generations (Table 40). Thus, H29 is partially rejected (significant differences were found only for factor 2 and 6 regarding generations; which does not allow a complete rejection of the hypothesis).

Table 40. Kruskal- Wallis test for generations

\begin{tabular}{|c|c|c|c|c|}
\hline \multirow{4}{*}{$\begin{array}{l}\text { Factor } \\
\text { F1: } \\
\text { Adoption } \\
\text { DE }\end{array}$} & \multicolumn{2}{|l|}{ Descriptive } & \multirow{4}{*}{$\begin{array}{l}\text { p-value } \\
0.309\end{array}$} & \multirow{4}{*}{$\begin{array}{l}\text { Conclusion } \\
\mathrm{H}_{0} \text { cannot be } \\
\text { rejected. There } \\
\text { is no significant } \\
\text { difference } \\
\text { between } \\
\text { generations }\end{array}$} \\
\hline & Baby boomers & $\begin{array}{l}\text { Mean }=4.39 \\
\mathrm{SD}=0.70\end{array}$ & & \\
\hline & $\mathrm{X}$ & $\begin{array}{l}\mathrm{M}=4.28 \\
\mathrm{SD}=0.75\end{array}$ & & \\
\hline & $\mathrm{Y}$ & $\begin{array}{l}\mathrm{M}=4.34 \\
\mathrm{SD}=0.73\end{array}$ & & \\
\hline $\begin{array}{l}\text { F2: } \\
\text { Technology }\end{array}$ & Baby boomers & $\begin{array}{l}M=4.54 \\
S D=0.48\end{array}$ & 0.014 & $\begin{array}{l}\mathrm{H}_{0} \text { can be } \\
\text { rejected. There }\end{array}$ \\
\hline
\end{tabular}




\begin{tabular}{|c|c|c|c|c|}
\hline Factor & Descriptive & & p-value & Conclusion \\
\hline \multirow[t]{2}{*}{ usefulness } & $\mathrm{X}$ & $\begin{array}{l}M=4.56 \\
S D=0.60\end{array}$ & & \multirow{2}{*}{$\begin{array}{l}\text { is significant } \\
\text { difference } \\
\text { between } \\
\text { generations }\end{array}$} \\
\hline & $\mathrm{Y}$ & $\begin{array}{l}\mathrm{M}=4.88 \\
\mathrm{SD}=0.21\end{array}$ & & \\
\hline \multirow{3}{*}{$\begin{array}{l}\text { F3: } \\
\text { Motivation } \\
\text { to DE }\end{array}$} & Baby boomers & $\begin{array}{l}M=3.63 \\
S D=0.82\end{array}$ & \multirow[t]{3}{*}{0.111} & \multirow{3}{*}{$\begin{array}{l}\mathrm{H}_{0} \text { cannot be } \\
\text { rejected. There } \\
\text { is no significant } \\
\text { difference } \\
\text { between } \\
\text { generations }\end{array}$} \\
\hline & $\mathrm{X}$ & $\begin{array}{l}\mathrm{M}=3.47 \\
\mathrm{SD}=1.1\end{array}$ & & \\
\hline & $\mathrm{Y}$ & $\begin{array}{l}\mathrm{M}=4.09 \\
\mathrm{SD}=0.72\end{array}$ & & \\
\hline \multirow{3}{*}{$\begin{array}{l}\text { F4: } \\
\text { Technology } \\
\text { ease of use }\end{array}$} & Baby boomers & $\begin{array}{l}\mathrm{M}=3.54 \\
\mathrm{SD}=0.79\end{array}$ & \multirow[t]{3}{*}{0.084} & \multirow{3}{*}{$\begin{array}{l}\mathrm{H}_{0} \text { cannot be } \\
\text { rejected. There } \\
\text { is no significant } \\
\text { difference } \\
\text { between } \\
\text { generations }\end{array}$} \\
\hline & $\mathrm{X}$ & $\begin{array}{l}\mathrm{M}=3.27 \\
\mathrm{SD}=0.92\end{array}$ & & \\
\hline & $\mathrm{Y}$ & $\begin{array}{l}\mathrm{M}=3.8 \\
\mathrm{SD}=0.77\end{array}$ & & \\
\hline \multirow[t]{3}{*}{$\begin{array}{l}\text { F5: } \\
\text { Recognition }\end{array}$} & Baby boomers & $\begin{array}{l}\mathrm{M}=3.69 \\
\mathrm{SD}=0.81\end{array}$ & \multirow[t]{3}{*}{0.331} & \multirow{3}{*}{$\begin{array}{l}\mathrm{H}_{0} \text { cannot be } \\
\text { rejected. There } \\
\text { is no significant } \\
\text { difference } \\
\text { between } \\
\text { generations }\end{array}$} \\
\hline & $\mathrm{X}$ & $\begin{array}{l}\mathrm{M}=3.43 \\
\mathrm{SD}=0.99\end{array}$ & & \\
\hline & $\mathrm{Y}$ & $\begin{array}{l}M=3.73 \\
S D=1.03\end{array}$ & & \\
\hline \multirow{3}{*}{$\begin{array}{l}\text { F6: } \\
\text { Conditions } \\
\text { of use }\end{array}$} & Baby boomers & $\begin{array}{l}\mathrm{M}=4.02 \\
\mathrm{SD}=0.85\end{array}$ & \multirow[t]{3}{*}{0.014} & \multirow{3}{*}{$\begin{array}{l}\mathrm{H}_{0} \text { can be } \\
\text { rejected. There } \\
\text { is significant } \\
\text { difference } \\
\text { between } \\
\text { generations }\end{array}$} \\
\hline & $\mathrm{X}$ & $\begin{array}{l}\mathrm{M}=3.74 \\
\mathrm{SD}=0.83\end{array}$ & & \\
\hline & $\mathrm{Y}$ & $\begin{array}{l}\mathrm{M}=4.37 \\
\mathrm{SD}=0.55\end{array}$ & & \\
\hline
\end{tabular}

Finally, Mann-Whitney test was applied to ordinal variable participation in DE. Considering $5 \%$ of significance, no significant difference was found between new and experienced users of DE. This means that perceptions are similar and positive for both groups of instructors no matter how long they have been working in DE courses (Table 41). Thus, H30 is rejected.

Table 41. Mann-Whitney test for level of participation in DE

\begin{tabular}{l|l|l|l|l}
\hline Factor & Descriptive & p-value & Conclusion \\
\hline $\begin{array}{l}\text { F1: } \\
\text { Adoption } \\
\mathrm{DE}\end{array}$ & New user & $\begin{array}{l}\mathrm{Mean}=4.19 \\
\mathrm{SD}=0.86\end{array}$ & 0.076 & $\begin{array}{l}\mathrm{H}_{0} \text { cannot be } \\
\text { rejected. There } \\
\text { is no significant } \\
\text { difference } \\
\text { between users }\end{array}$ \\
\cline { 2 - 3 } & $\begin{array}{l}\text { Experienced } \\
\text { user }\end{array}$ & $\begin{array}{l}\mathrm{M}=4.5 \\
\mathrm{SD}=0.56\end{array}$ & & $\begin{array}{l}\mathrm{H}_{0} \text { cannot be } \\
\text { rejected. There } \\
\text { is no significant } \\
\text { difference } \\
\text { between users }\end{array}$ \\
\hline \begin{tabular}{l} 
F2: $\begin{array}{l}\text { Technology } \\
\text { usefulness }\end{array}$ \\
\cline { 2 - 3 }
\end{tabular} & $\begin{array}{l}\text { Experienced } \\
\text { user }\end{array}$ & $\begin{array}{l}\mathrm{M}=4.62 \\
\mathrm{SD}=0.61\end{array}$ & 0.205 & \\
$\mathrm{SD}=0.464$ & & $\begin{array}{l}\mathrm{H}_{0} \text { cannot be } \\
\text { rejected. There }\end{array}$ \\
\hline $\begin{array}{l}\text { F3: } \\
\text { Motivation }\end{array}$ & New user & $\begin{array}{l}\mathrm{M}=3.55 \\
\mathrm{SD}=1.05\end{array}$ & 0.720 & \\
\hline
\end{tabular}




\begin{tabular}{|c|c|c|c|c|}
\hline \multirow{2}{*}{$\begin{array}{l}\text { Factor } \\
\text { to DE }\end{array}$} & \multicolumn{2}{|l|}{ Descriptive } & \multirow[t]{2}{*}{ p-value } & \multirow{2}{*}{$\begin{array}{l}\text { Conclusion } \\
\text { is no significant } \\
\text { difference } \\
\text { between users }\end{array}$} \\
\hline & $\begin{array}{l}\text { Experienced } \\
\text { user }\end{array}$ & $\begin{array}{l}\mathrm{M}=3.63 \\
\mathrm{SD}=1.01\end{array}$ & & \\
\hline \multirow{2}{*}{$\begin{array}{l}\text { F4: } \\
\text { Technology } \\
\text { ease of use }\end{array}$} & New user & $\begin{array}{l}\mathrm{M}=3.40 \\
\mathrm{SD}=0.84\end{array}$ & \multirow[t]{2}{*}{0.459} & \multirow{2}{*}{$\begin{array}{l}\mathrm{H}_{0} \text { cannot be } \\
\text { rejected. There } \\
\text { is no significant } \\
\text { difference } \\
\text { between users }\end{array}$} \\
\hline & $\begin{array}{l}\text { Experienced } \\
\text { user }\end{array}$ & $\begin{array}{l}\mathrm{M}=3.34 \\
\mathrm{SD}=0.97\end{array}$ & & \\
\hline \multirow[t]{2}{*}{$\begin{array}{l}\text { F5: } \\
\text { Recognition }\end{array}$} & New user & $\begin{array}{l}M=3.48 \\
\mathrm{SD}=0.95\end{array}$ & \multirow[t]{2}{*}{0.466} & \multirow{2}{*}{$\begin{array}{l}\mathrm{H}_{0} \text { cannot be } \\
\text { rejected. There } \\
\text { is no significant } \\
\text { difference } \\
\text { between users }\end{array}$} \\
\hline & $\begin{array}{l}\text { Experienced } \\
\text { user }\end{array}$ & $\begin{array}{l}M=3.61 \\
S D=0.97\end{array}$ & & \\
\hline \multirow{2}{*}{$\begin{array}{l}\text { F6: } \\
\text { Conditions } \\
\text { of use }\end{array}$} & New user & $\begin{array}{l}\mathrm{M}=3.81 \\
\mathrm{SD}=0.84\end{array}$ & \multirow[t]{2}{*}{0.414} & \multirow{2}{*}{$\begin{array}{l}\mathrm{H}_{0} \text { cannot be } \\
\text { rejected. There } \\
\text { is no significant } \\
\text { difference } \\
\text { between users }\end{array}$} \\
\hline & $\begin{array}{l}\text { Experienced } \\
\text { user }\end{array}$ & $\begin{array}{l}\mathrm{M}=3.94 \\
\mathrm{SD}=0.83\end{array}$ & & \\
\hline
\end{tabular}

Descriptive statistics show average scores for the factors are high; all the factors own scores higher than 3. This result suggests perceptions of technology, DE and willingness to adopt DE are positive. Low coefficient of variation $(\mathrm{cv}<30 \%)$ indicates the sample is homogeneous, people have similar opinion regarding the studied variables (Table 42). The present study found higher average values in the variables than Tabata and Johnsrud (2008) had found in their published article. This means instructors from the sample under study have a good perception of technology and DE.

Table 42. Descriptive statistics for the factors

\begin{tabular}{l|r|r|c|r|r}
\hline & Minimum & Maximum & Mean & $\begin{array}{c}\text { Std. } \\
\text { Deviation }\end{array}$ & $\begin{array}{c}\text { Coefficient } \\
\text { of variation }\end{array}$ \\
\hline Adoption DE & 1.50 & 5.00 & 4.3292 & 0.75313 & $17 \%$ \\
\hline Usefulness & 1.00 & 5.00 & 4.6000 & 0.54368 & $12 \%$ \\
\hline Motivation & 1.00 & 5.00 & 3.5861 & 1.03171 & $29 \%$ \\
\hline Ease use & 1.67 & 5.00 & 3.3750 & 0.89668 & $27 \%$ \\
\hline Recognition & 1.00 & 5.00 & 3.5417 & 0.95615 & $27 \%$ \\
\hline $\begin{array}{l}\text { Conditions } \\
\text { use }\end{array}$ & 2.00 & 5.00 & 3.8667 & 0.83448 & $22 \%$ \\
\hline
\end{tabular}




\subsection{Coordinators' results}

Coordinators ${ }^{16}$ provided information about the course considering its planning, activities, problems and statistics. Table 43 shows general data from each university. Attrition rates vary from $25 \%$ to $46 \%$ which is concerning; however, interviewees reported these percentages are expected and happen mostly during the first semester of the course, which corroborating the arguments of Tinto (1988) and confirming H17. It is important to remark UAB was already in function with other courses (i.e. pedagogy, business administration etc.) before initiating PNAP. The studied institutions already had a previous experience with the UAB system through the pilot project of the undergraduate course in business, which gave them the initial background on teaching business at a distance. Then, when PNAP started, institutions already had knowledge regarding the barriers, weaknesses and strengths in offering DE.

Table 43. Statistics about the course

\begin{tabular}{l|l|l|l|l}
\hline Institution & $\begin{array}{l}\text { Students } \\
\text { enrolled }\end{array}$ & Attrition & $\begin{array}{l}\text { Number of } \\
\text { professors }\end{array}$ & $\begin{array}{l}\text { Number of } \\
\text { tutors }\end{array}$ \\
\hline $\mathrm{A}$ & 456 & $30 \%$ & 38 & $\begin{array}{l}23 \text { online } \\
17 \text { at the } \\
\text { center }\end{array}$ \\
\hline $\mathrm{C}$ & 642 & $46 \%$ & 19 & $\begin{array}{l}27 \text { online } \\
31 \text { at the } \\
\text { center }\end{array}$ \\
\hline $\mathrm{D}$ & & & & $\begin{array}{l}\text { online } \\
3 \text { at the center }\end{array}$ \\
\hline $\mathrm{E}$ & 250 & $40 \%$ & 24 & $\begin{array}{l}6 \text { online } \\
3 \text { at the center }\end{array}$ \\
\hline $\mathrm{F}$ & 200 & $35 \%$ & 10 & $\begin{array}{l}28 \text { online } \\
8 \text { at the center }\end{array}$ \\
\hline $\mathrm{G}$ & 700 & $25 \%$ & 30 & 12 online \\
\hline $\mathrm{H}$ & 800 & $30 \%$ & 32 & Not reported \\
\hline $\mathrm{I}$ & 1000 & $30-40 \%$ & Not reported & Not reported \\
\hline $\mathrm{J}$ & 830 & $40 \%$ & 25 & $\begin{array}{l}15 \text { online } \\
6 \text { at the center }\end{array}$ \\
\hline
\end{tabular}

Reasons reported for attrition included: many students are mature and have been out of the educational environment for a long time which makes it difficult to catch up with the course dynamics; many students chose DE hoping it would be an easy way to get a higher education degree; many students do not appreciate the course (Public Management content); exchange to a face-to-face course; difficulty in becoming a distance student; need to travel to the center

\footnotetext{
${ }^{16}$ Coordinator from institution B (Southeast) was not available for interview; so data from that institution was not provided.
} 
town; changes in personal life (moving to another town; being already in a face-to-face course which accumulates an unviable workload etc.); high workload of the course; lack of social contact with colleagues; center structure was not available to initiate the course; absence of professor and colleagues remembering what to be done (student empowerment). Table 44 summarizes pointed reasons for student dropout. Remarkably eight of the nine coordinators reported one strong reason for attrition is related to the myth DE is easier than a traditional course (KEARSLEY, 1998). This is an interesting finding since this myth motivated attrition in this course; but as presented in student's results, this myth is not strong for students who stayed in the course and plan to conclude it; that is, they believe DE is more demanding than a face-to-face course.

This observation brings to light a question that needs to be further investigated in future research regarding which specific myths lead to dropout and how to prevent it. Institutions E, $\mathrm{F}$ and $\mathrm{G}$ reported policies to avoid dropout. Institution $\mathrm{E}$, in order to enhance motivation and reduce attrition, ask faculty to design learning activities which stimulate interaction; that is, team activities which force students to meet virtually or face-to-face (when possible).

Institution F shows a different approach on trying to reduce attrition; at the moment students present documentation for enrollment, they are interviewed in order to acquire their expectations, previous experiences with technology and DE, time available to the course, professional workload etc. This conversation aims to clarify course requirements and to help students to deal with course. When someone is found to be inexperienced with technology a lower initial load is recommended to avoid demotivation and dropout.

Institution G softened course pre-requisites; it means, when student has trouble with one discipline, he/she can move on the course and solve the pending problems during the next semesters. Students do not get stuck when they fail one discipline; which happens to reduce dropout. 
Table 44. Reasons for attrition

\begin{tabular}{l|c|c|c|c|c|c|c|c|c}
\hline Reasons for attrition & A & C & D & $\mathbf{E}$ & $\mathbf{F}$ & $\mathbf{G}$ & $\mathbf{H}$ & $\mathbf{I}$ & $\mathbf{J}$ \\
\hline Long period out of educational environment & $\mathrm{X}$ & & & $\mathrm{X}$ & & $\mathrm{X}$ & & & \\
\hline Belief DE is easy & $\mathrm{X}$ & & $\mathrm{X}$ & $\mathrm{X}$ & $\mathrm{X}$ & $\mathrm{X}$ & $\mathrm{X}$ & $\mathrm{X}$ & $\mathrm{X}$ \\
\hline No appreciation of public management content & $\mathrm{X}$ & & & & & & & & \\
\hline High workload & & & $\mathrm{X}$ & & & & & & $\mathrm{X}$ \\
\hline Change to a face-to-face course & & $\mathrm{X}$ & & & & & & & $\mathrm{X}$ \\
\hline Difficulty to adapt to the method & & $\mathrm{X}$ & & & $\mathrm{X}$ & & $\mathrm{X}$ & & \\
\hline Need to travel to the center & & $\mathrm{X}$ & & & & & & & \\
\hline Personal reasons & & $\mathrm{X}$ & & & $\mathrm{X}$ & & & & \\
\hline Lack of social contact with colleagues & & & $\mathrm{X}$ & $\mathrm{X}$ & & & & & \\
\hline Incomplete structure of the centers to initiate the course & & & & $\mathrm{X}$ & & & & & \\
\hline $\begin{array}{l}\text { Student empowerment (students need someone to recovery } \\
\text { what to be done for the course) }\end{array}$ & & & $\mathrm{X}$ & $\mathrm{X}$ & & & & \\
\hline
\end{tabular}

The main reasons indicated for initiating DE in the universities varied across the studied institutions: additional resources received from federal government; possibility to take education to remote areas in unprivileged states; possibility to offer a public management course which is not broadly disseminated in the country and consistent to the government goal of developing qualified workforce to work in public institutions in the three levels (local, state, federal) and improve public administration (enhances institutional and academic competitiveness); being in touch with other institutions offering the same course and exchange experiences; opportunity to discuss and bring to light a new educational paradigm which is changing the roles of professors and of research and is a trend in education; opportunity to develop a course with some autonomy; including DE on the institution portfolio. Results are summarized on Table 45; main common reasons to offer DE were the possibility to take higher education to remote areas and to offer a public management course as part of the university portfolio. The first reason is consistent with the UAB mission to disseminate education to unprivileged areas in the country; the second motive reported is more related to a market view, since offering a new product enhances institution competitiveness and image in the market. 
Table 45. Reasons for adopting DE

\begin{tabular}{l|l|l|l|l|l|l|l|l|l|l}
\hline Motives for adopting DE (UAB system) in the institution & A & C & D & E & F & G & H & I & J \\
\hline Government resources & $\mathrm{X}$ & $\mathrm{X}$ & $\mathrm{X}$ & & & & & & \\
\hline Take education to remote areas & & $\mathrm{X}$ & & $\mathrm{X}$ & $\mathrm{X}$ & $\mathrm{X}$ & $\mathrm{X}$ & $\mathrm{X}$ & \\
\hline $\begin{array}{l}\text { Offer public management course (qualify workforce for public } \\
\text { service) }\end{array}$ & & $\mathrm{X}$ & & $\mathrm{X}$ & $\mathrm{X}$ & $\mathrm{X}$ & & & $\mathrm{X}$ \\
\hline $\begin{array}{l}\text { Integration with other institutions offering the same course } \\
\text { and exchange of experiences }\end{array}$ & $\mathrm{X}$ & & & & & & & & \\
\hline Discuss a new paradigm & & & $\mathrm{X}$ & & & $\mathrm{X}$ & & & \\
\hline Autonomy to manage the course & & & $\mathrm{X}$ & & & & & & \\
\hline Market exposition and enhanced image & & & & & $\mathrm{X}$ & & & & \\
\hline Include DE on the portfolio & & & & & & & & $\mathrm{X}$ & \\
\hline
\end{tabular}

The main difficulties emerging from the implementation of the distance course, reported by the coordinators, were: the bureaucratic process to receive financial resources (bidding for hiring services and purchasing supplies); infrastructure at the centers (city hall in each town is responsible to provide structure to the center, but it was insufficient in some cases); difficulty to administer activities that might happen simultaneously at diverse centers; getting used to a new way of thinking in order to teach in DE; limited budget. Table 46 summarizes the difficulties reported by coordinators. Faculty resistance and infrastructure are frequent problems presented by the coordinators.

Resistance from faculty members was cited for coordinators A, D, F, H and I as a barrier to implement DE. Reasons for this resistance were the high workload found by professors (DE is one more activity they develop in the department), resistance to the method (some consider $\mathrm{DE}$ as a competitor to traditional course; some do not believe it is an effective method), lack of commitment (many engaged in DE because of the additional remuneration). In all the cases reported, there are certainly many professors committed to DE and who have a good performance (some also implemented distance activities into the traditional courses they teach $^{17}$ ), but some did not engage in the course and others, although engaged did not commit to it. Difficulties were specially found in dealing with professors from other departments, such as accounting, economics and law. As previously mentioned, pilot project offered a rich experience on how to handle resistance and other problems emerging from distance course. Institution $\mathrm{D}$, for instance, suggests the creation of a remuneration system in which scholarship payment would be made if all the activities of the discipline were accomplished. Institution $\mathrm{E}$ did not have resistance problems due to the coordination style, in which faculty

\footnotetext{
${ }^{17}$ Brazilian law for education allows $20 \%$ of face-to-face courses to be offered at a distance.
} 
group was turned into a team; it means, every professor share his/her experiences, good practices and issues he/she found, and solutions are developed by the team. Coordinator G, despite of not recognizing resistance from faculty, stated professors have a high workload, since they work also in face-to-face courses and in graduate program (master degree), which reinforces workload as a sensitive variable when talking about faculty attitude toward DE. Coordinator $\mathrm{J}$, although did not recognize resistance from his institution faculty, also reports the high workload as a demotivating factor for faculty to participate in DE, since administrative, face-to-face activities accumulate to distance activities.

Coordinator $\mathrm{H}$ reported disciplines from face-to-face undergraduate course are planned to be converted to blended format. For this reason; some faculties from face-to-face resisted to DE, as they consider it compromises the quality of the traditional course. One way to minimize resistance was inviting faculty from other universities to work in DE; then those professors who do not support the system were not signed up to integrate it.

Institution I reported initially there was resistance to DE, since there was not a culture of DE. After training on technology use and DE method culture was disseminated and reduced resistance.

Considering tutors, UAB recommends they are graduate students or government employee, which may restrict their recruitment and selection. However, most of the members reported it is not a problem to hire and train tutors to work online or to work at capital centers, it may be difficult to find professionals to work at centers in remote areas. In addition, considering remuneration is paid as scholarship, retention may be an issue. Abandonment is common, and happens for many reasons: better job opportunities, non-adherence to the job demands, personal reasons, high workload etc. Institution D reported that in order to reduce tutor abandonment they designated one tutor per discipline (instead of one tutor per group) and kept the same professional during the whole year. Thus, they could develop expertise in some specific disciplines and offer better student support. Coordinator $\mathbf{J}$ adds tutoring scholarship value complicates tutor retention and commitment to the project.

Coordinator $\mathrm{H}$ interestingly comments tutors try to reduce isolation feeling but, since they cannot offer personalized attention, students evaluate them as insufficient and unqualified. 
This was also reported by coordinator $\mathrm{G}$, who additionally mentioned students do not trust tutor's competence as much as they trust faculty's competence.

It is important to observe the difference between professor's and tutor's roles. Professor is responsible for planning and designing the discipline, including complementary materials and activities and assessment procedures, as well as for evaluating all the materials delivered by students. They are also the reference in the discipline; however, online tutor is the first line of contact to students, they filter the contacts and contents delivered to faculty. In addition, online tutors are responsible for answering content doubts, interacting in forums and in some cases, helping students with technical problems. At the centers there are also tutors who are responsible for supporting students during their period in these locations. They may help students with problems in organizing study activities, managing time, with technical difficulties and with eventually content doubts (it is the online tutor's responsibility). In some institutions, at the center tutors are the main face-to-face contact in the course and are an important source of information regarding the student's perceptions of the course.

Then, it is possible to consider instructors' (professors and tutors) skills and attitudes toward DE are not formally acquired but it is reasonable to recognize institutions' previous experience with DE made them able to recognize committed and non-committed professors. Tutors, in turn, are specifically selected to work with distance education and their hiring process tries to differentiate professionals with some experience with the method and good perceptions about it. Thus, although attitudes and skills are not formally studied institutions have their mechanisms to choose professionals more willing to engage in the course. This confirms $\mathrm{H} 32$, but it is worth to remember that, although coordinators make these efforts to find faculty and tutors whose profile matches DE, they sometimes fail since workforce offer may be scarce (small departments do not have so many faculty to allow a selection focused on attitudes, some geographic areas are scarce and it is not possible to find DE experienced people).

Table 46. Difficulties found on DE implementation

\begin{tabular}{l|c|c|c|c|c|c|c|c|c}
\hline Difficulties for implementation & A & C & D & E & F & G & H & I & J \\
\hline Bureaucracy for receiving resources & X & & X & & & $\mathrm{X}$ & & & \\
\hline Faculty resistance & $\mathrm{X}$ & & $\mathrm{X}$ & & $\mathrm{X}$ & & $\mathrm{X}$ & $\mathrm{X}$ & $\mathrm{X}$ \\
\hline Tutor retention & $\mathrm{X}$ & & $\mathrm{X}$ & & & & & & $\mathrm{X}$ \\
\hline Tutor recruitment & & & & & & $\mathrm{X}$ & & & $\mathrm{X}$ \\
\hline
\end{tabular}




\begin{tabular}{l|c|c|c|c|c|c|c|c|c}
\hline Difficulties for implementation & A & C & D & E & F & G & H & I & J \\
\hline Infrastructure an the centers and relationships with city halls & & $\mathrm{X}$ & $\mathrm{X}$ & $\mathrm{X}$ & & $\mathrm{X}$ & $\mathrm{X}$ & $\mathrm{X}$ & $\mathrm{X}$ \\
\hline $\begin{array}{l}\text { Technology structure including on the campus (internet } \\
\text { access) }\end{array}$ & & & & $\mathrm{X}$ & & $\mathrm{X}$ & $\mathrm{X}$ & & \\
\hline Adapt to the new method & & & & & $\mathrm{X}$ & & & $\mathrm{X}$ & \\
\hline Organize real time activities an all the centers & & & & & $\mathrm{X}$ & & & & \\
\hline UAB policies are not totally clear & & & & & & & & $\mathrm{X}$ & $\mathrm{X}$ \\
\hline Budget restriction & & & & & & & & & $\mathrm{X}$ \\
\hline
\end{tabular}

Support services are offered both to students, faculty and tutors. Faculty are usually trained to use LMS (MOODLE) and to teach a distance education course, since most of them come from traditional courses and had little experience with this new educational method. In addition, they are supported by tutors who have broader knowledge in technologies employed in the course; pedagogical orientation is provided also by the coordinators in order to clarify the specific characteristics of each discipline in the online format. Students are also oriented about the use of technologies and the dynamics of studying online in the beginning of the course. During the semester they can find help at the centers and some guides on the LMS. Table 47 shows the types of support offered by the studied institutions.

Thus, H33, H34 and $\mathrm{H} 35$ are confirmed since all the institutions offer basic training and; somehow, technical and pedagogical support to the students. It is worth to observe that levels of technical support vary among the institutions; this means some offer more help channels than others. Considering study organization and time management, at the center tutor is available to help students; however, this support is passive; which means help is provided only when students ask for it; so there is not a pro-active attitude from the tutor to identify students with difficulties.

Table 47. Support services provided for instructors and students

\begin{tabular}{l|c|c|c|c|c|c|c|c|c}
\hline Support services offered to instructors and students & A & C & D & E & F & G & H & I & J \\
\hline Technology training to faculty & $\mathrm{X}$ & $\mathrm{X}$ & $\mathrm{X}$ & $\mathrm{X}$ & $\mathrm{X}$ & $\mathrm{X}$ & $\mathrm{X}$ & $\mathrm{X}$ & $\mathrm{X}$ \\
\hline Technology training to students (guides in the LMS) & $\mathrm{X}$ & $\mathrm{X}$ & $\mathrm{X}$ & $\mathrm{X}$ & $\mathrm{X}$ & & $\mathrm{X}$ & $\mathrm{X}$ & $\mathrm{X}$ \\
\hline Support for technological problems to teachers & $\mathrm{X}$ & & & $\mathrm{X}$ & $\mathrm{X}$ & & $\mathrm{X}$ & & $\mathrm{X}$ \\
\hline Support for technological problems to students & $\mathrm{X}$ & & & & $\mathrm{X}$ & & $\mathrm{X}$ & & $\mathrm{X}$ \\
\hline Training on DE pedagogy (instructors) & $\mathrm{X}$ & $\mathrm{X}$ & $\mathrm{X}$ & $\mathrm{X}$ & $\mathrm{X}$ & $\mathrm{X}$ & $\mathrm{X}$ & $\mathrm{X}$ & $\mathrm{X}$ \\
\hline Orientation on DE (students) & $\mathrm{X}$ & $\mathrm{X}$ & $\mathrm{X}$ & $\mathrm{X}$ & $\mathrm{X}$ & $\mathrm{X}$ & $\mathrm{X}$ & $\mathrm{X}$ & $\mathrm{X}$ \\
\hline $\begin{array}{l}\text { Support for problems with DE method (students) - time } \\
\text { management, study organization }\end{array}$ & $\mathrm{X}$ & $\mathrm{X}$ & & $\mathrm{X}$ & & & & $\mathrm{X}$ & $\mathrm{X}$ \\
\hline $\begin{array}{l}\text { Access to administrative support and coordination through } \\
\text { LMS }\end{array}$ & $\mathrm{X}$ & & & & & & & & \\
\hline
\end{tabular}


Positive and negative reactions heard from the students regarding studying at a distance include (Table 48):

- Positive aspects: opportunity to learn and develop professionally and personally; opportunity to have a bachelor degree (students from small towns in distant areas); use of technology, empowerment of student (responsibility for personal development, freedom to organize study schedule, possibility to study outside a classroom, avoiding shame of being peers with excessively young students like in face-to-face courses); it is not necessary to travel to the center every day; opportunity to access contents as many times as needed; rigidness of the course; quality of the contents.

- Negative aspects: excessive workload in the disciplines; lack of contact with professors; technical problems with the LMS; need to travel to the center for face-toface activities (it is a constraint for students living in small remote towns); poor structure in some centers; rigid deadlines established for delivering course activities; difficulties in organizing study work and time management; lack of interaction with peers; rigidness of the course.

It is interesting that some positive aspects are also pointed as negative aspects, such as course workload, rigidness and deadlines.

Table 48. Positive and negative reactions from students

\begin{tabular}{|c|c|c|c|c|c|c|c|c|c|}
\hline Reactions from students & $\mathbf{A}$ & $\mathbf{C}$ & D & $\mathbf{E}$ & $\mathbf{F}$ & $\mathbf{G}$ & $\mathbf{H}$ & I & $\mathbf{J}$ \\
\hline \multicolumn{10}{|l|}{ Positive } \\
\hline $\begin{array}{l}\begin{array}{l}\text { Opportunity to learn and develop professionally and } \\
\text { personally }\end{array} \\
\end{array}$ & $\mathrm{X}$ & & & & & & & $\mathrm{X}$ & \\
\hline Access to education & $\mathrm{X}$ & & & & & & & & \\
\hline Empowerment of student & $\mathrm{X}$ & $\mathrm{X}$ & $\mathrm{X}$ & $\mathrm{X}$ & & & & $\mathrm{X}$ & \\
\hline Use of technology for learning & & $\mathrm{X}$ & $\mathrm{X}$ & & & & & & \\
\hline Access to course contents as many times as needed & & & & $\mathrm{X}$ & & & & & \\
\hline No need to go to the center every day & & & $\mathrm{X}$ & & & & & & \\
\hline Rigidness of the course & & & & & $\mathrm{X}$ & & & $\mathrm{X}$ & \\
\hline Rigid deadlines for course's activities & & & & & $\mathrm{X}$ & & & & \\
\hline Workload & & & & & $\mathrm{X}$ & & & & \\
\hline Contents provided on LMS & & & & & & $\mathrm{X}$ & & & \\
\hline Center coordination & & & & & & & & & $\mathrm{X}$ \\
\hline Faculty quality & & & & & & & & & $\mathrm{X}$ \\
\hline \multicolumn{10}{|l|}{ Negative } \\
\hline Workload & $\mathrm{X}$ & & & & $\mathrm{X}$ & & & & $\mathrm{X}$ \\
\hline Distance from professors & $\mathrm{X}$ & & $\mathrm{X}$ & $\mathrm{X}$ & & $\mathrm{X}$ & $\mathrm{X}$ & $\mathrm{X}$ & $\mathrm{X}$ \\
\hline Technology problems & $\mathrm{X}$ & & & & & & $\mathrm{X}$ & & $\mathrm{X}$ \\
\hline
\end{tabular}




\begin{tabular}{l|l|l|l|l|l|l|l|l|l}
\hline Infrastructure in the centers & & $\mathrm{X}$ & $\mathrm{X}$ & & & & $\mathrm{X}$ & & \\
\hline Need to travel to the center & & $\mathrm{X}$ & & & & & & & \\
\hline Rigid deadlines for course activities & & $\mathrm{X}$ & & & $\mathrm{X}$ & & & & \\
\hline Difficulties in time management and study organization & & & $\mathrm{X}$ & & & $\mathrm{X}$ & & & $\mathrm{X}$ \\
\hline Lack of contact with colleagues & & & & $\mathrm{X}$ & & & & & $\mathrm{X}$ \\
\hline Rigidness of the course & & & & & $\mathrm{X}$ & & & & \\
\hline
\end{tabular}




\subsection{General considerations}

\subsubsection{Student's perception versus coordinator's perception}

This item aims to compare students' and coordinators' perceptions regarding the PNAP course. In general, students showed positive opinions on course quality, satisfaction, loyalty, image and institutional support. Coordinators also reported strengths and weaknesses they can identify in the courses. Specifically considering quality assessment, quality gap model was applied in order to identify differences between students' and coordinators' opinions regarding the course. Figure 47 illustrates the gaps considered in this dissertation.

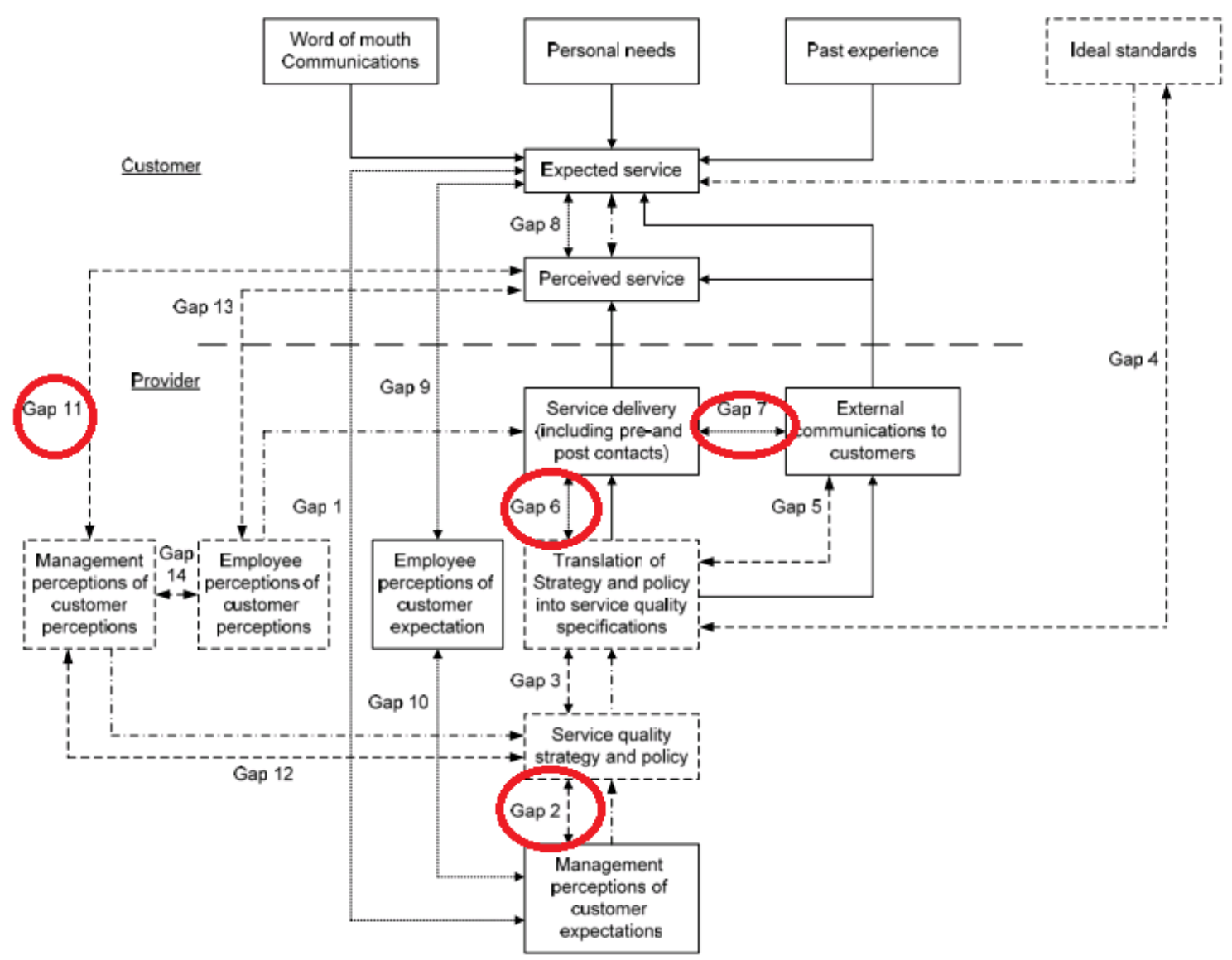

Figure 47. GAPS studied for PNAP case

GAP analysis compared students' and coordinators' perceptions of SERVQUAL dimensions and overall quality, firstly GAP 11, from the model proposed by Shahin and Samea (2010), 
was analyzed. Table 49 shows scores attributed by coordinators for the mentioned dimensions (assurance, empathy, responsiveness, reliability, website content, overall quality).

Table 49. Scores for SERVQUAL dimensions - coordinators' perceptions

\begin{tabular}{l|l|l|l|l|l|l}
\hline Institution & $\begin{array}{l}\text { Instructors } \\
\text { involved in } \\
\text { the course } \\
\text { are } \\
\text { committed } \\
\text { to DE }\end{array}$ & $\begin{array}{l}\text { Instructors } \\
\text { involved in the } \\
\text { course master } \\
\text { the contents of } \\
\text { the disciplines } \\
\text { they teach }\end{array}$ & $\begin{array}{l}\text { Instructors } \\
\text { are willing to } \\
\text { help distance } \\
\text { students }\end{array}$ & $\begin{array}{l}\text { Instructors } \\
\text { are } \\
\text { dependable }\end{array}$ & $\begin{array}{l}\text { LMS is } \\
\text { reliable and } \\
\text { offers } \\
\text { adequate } \\
\text { resources } \\
\text { to the } \\
\text { course }\end{array}$ & $\begin{array}{l}\text { Course } \\
\text { has high } \\
\text { quality }\end{array}$ \\
\hline A & 2 & 4 & 4 & 4 & 4 & 4 \\
\hline C & 4 & 3 & 1 & 4 & 5 & 4 \\
\hline D & 4 & 4 & 3 & 4 & 2 & 3 \\
\hline F & 5 & 4 & 4 & 4 & 4 & 4 \\
\hline G & 3 & 4 & 3 & 3 & 4 & 5 \\
\hline H & 5 & 5 & 5 & 5 & 3 & 5 \\
\hline I & 3 & 5 & 5 & 5 & 5 & 4 \\
\hline J & 3 & 5 & 3 & 4 & 5 & 4 \\
\hline mean & 3.8 & 4.3 & 3 & 3 & 5 & 4 \\
\hline
\end{tabular}

Significance test was applied in order to verify quality gaps. There was difference in students' and coordinator's perceptions on all the tested constructs. Observed gaps are negative; which means coordinators' perceptions are higher than students' perceptions regarding course quality. However, it is worth to observe students' perceptions are favorable though lower than coordinators' perceptions. Table 50 summarizes results (H24 is rejected).

Table 50. GAP 11 analysis

\begin{tabular}{l|l|l|l|l}
\hline Dimension & $\begin{array}{l}\text { Students' } \\
\text { score }\end{array}$ & $\begin{array}{l}\text { Coordinators' } \\
\text { score }\end{array}$ & p-value & GAP \\
\hline Assurance & 3.57 & 3.8 & 0.000 & Negative \\
\hline Empathy & 3.38 & 4.3 & 0.000 & Negative \\
\hline Responsiveness & 3.31 & 3.4 & 0.000 & Negative \\
\hline Reliability & 3.57 & 4 & 0.000 & Negative \\
\hline $\begin{array}{l}\text { Website } \\
\text { content }\end{array}$ & 3.59 & 4.1 & 0.000 & Negative \\
\hline Overall quality & 3.68 & 4.1 & 0.000 & Negative \\
\hline
\end{tabular}

Shahin and Samea (2010) also proposed GAP 2 as the difference between coordinators' perception of students' expectations and actual service quality policies and strategies. In order to measure that gap, coordinators were asked whether and how students' expectations were 
surveyed. In addition, they were asked regarding how that information was used in practice. Students' expectations are surveyed by some of the institutions:

- Institution A offers a channel through LMS where students can send their suggestions and complaints permanently.

- Institutions $\mathrm{C}$ and D survey students in the end of every module to acquire their perception regarding tutors and contents. Every year students and tutors are surveyed about diverse aspects of the course. Institution D also has an evaluation board and professors (not only students and tutors) are also invited to evaluate the course.

- Institution E organizes a coordinator visit to each center (coordination meeting) once per semester and, in this occasion he talks to students and to the center tutors. In these meetings students have the opportunity to express their feeling regarding the experience of studying online. This information is used in the didactic planning for the following semesters.

- Institution G does not survey student opinion; only gets information from informal conversation.

- Institution H does not conduct surveys, but visits the centers once a semester and acquires tutors' and students' experiences.

- Institution I conducts surveys in the beginning of each semester in order to get feedback about the course.

- Institution $\mathbf{J}$ surveys center coordinators to find out problems and perceptions of students.

Thus, it is possible to observe institutions somehow survey their students in order to apprehend their expectations and perceptions of the course; however, how this information is used in practice to design educational and course management strategies is not clear in all cases (except for institution $\mathrm{E}$ which stated the information is taken to the faculty board and changes are designed). So, although institutions apply mechanisms through these surveys in order to refine the course, there are complaints and suggestions from students Therefore, there is a quality gap, leading to $\mathrm{H} 36$ rejection.

GAP 6 from Shahin and Samea (2010) model measures discrepancy between translation of service quality strategies and policies into specifications and the service actually delivered. Considering, as cited in chapter 1, HE in Brazil is regulated by the Ministry of Education, and 
specifically the UAB system, being a CAPES initiative, PNAP follows directions from both general educational law and specific norms from the UAB system. There are four steps between the translation of specifications and the real service provided:

- Step 1: recognition of MEC directions (laws and regulations for DE in Brazil and UAB are presented on Appendix A).

- Step 2: definition of institutional strategies and policies (internal ones, considering MEC directions).

- Step 3: translation of the strategies and policies into service specifications.

- Step 4: service delivered.

In this study GAP 6 is measured through the comparison between steps 2 and 4 (internal strategies and policies and the actual service provided), since evaluating the transitions among steps 2 and 3 and steps 3 and 4 would require a very specialized method, which exceeds this study scope.

Then, in order to measure this gap, coordinators were asked about what their institution offers differently from the regular services legally previewed. The following differentials were pointed:

- Institution A defines as differential great administrative staff and the organization of a Business professional week (event conducted face-to-face to which distance students are invited to participate and where career opportunities and trends are presented).

- Institution C reports course management team as differential, since it is composed by business professionals, pedagogy experts, DE experts. This team is considered synergic and autonomous which adds value to the course.

- Institution D considers its tutoring dynamics as the main differential since every tutor is an expert on the contents he/she teaches.

- Institution E considers its class plan as differential since, it contains deep and detailed information of each discipline, including activities to be done, what is expected from each activity, deadline, where to post it, amount of time necessary to develop each activity, a study guide to tests. Another differential was the offering of standardization disciplines (introduction to DE, introduction to technology; basic mathematics) which aimed to qualify students to have a satisfactory performance on the course and helped 
them to organize time and space for studying (seek for family support; find a calm space for studying).

- Institution F considers its tutoring system as a differential, since there is an expert tutor at the center until half of the course and online tutors are available through telephone, chat room, email and Skype (in previously scheduled moments).

- Institution G considers having public management course a differential, which enhances competitiveness of the institution in the state.

- Institution I considers its faculty team and tutor team (master degree students) the main differentials since they are very qualified.

- Institution J points out extra-curricular activities, which merge theory and practice, as its differential.

Besides institution $\mathrm{G}$, which did not present a specific differential related to the course, and institution $\mathrm{H}$ which reported it follows MEC directions exactly, all the other institutions try to provide a differentiate level of service in many ways, for instance, choosing highly qualified and expert tutors, offering diverse tutoring channels, including extra-curricular activities, developing a high performance course management team etc. This suggests GAP 6 happens; however, it is a positive gap, showing institutions are concerned about the service provided (H37 is rejected).

GAP 7 tries to identify whether the service delivered is according to external communications; that is, whether the service delivers what was announced in the press and in official communications. In order to measure this gap, coordinators were asked whether something previewed on PNAP project was not implemented. All the institutions reported that since implementation follows MEC orientations, only activities planned to happen in the last semesters were not implemented, as classes are still in course, for instance, internship and TCC which aim to guide students to an area of expertise (government management, municipal management, health system management) and will take place in the previewed semesters. However, the UAB website published, as commented on item 4.1, centers should have appropriate infrastructure provided by local city halls or state government. Coordinators mentioned during the interviews that infrastructure is an issue especially in remote areas from every state. Thus it suggests there is a quality gap (GAP7), in a negative direction; in other words, communication offers a higher level of service than that really provided. This leads to the rejection of $\mathrm{H} 38$. 


\subsubsection{Instructors' perception versus coordinators' perception}

Five out of nine coordinators reported faculty resistance do DE as an important issue in their institutions. Professors from the traditional courses are invited to join distance courses and many of them resist. In institutions with a smaller number of professors participation may not be completely voluntary which contributes to resistance. In some cases even resistant professors choose to participate in DE motivated by an extra remuneration, not by the opportunity of becoming a distance instructor.

Tutors, on the other hand, are selected according to a profile that focuses on technology selfefficacy and experience and willingness to work with DE. Selection and retention within this profile is not always an easy endeavor, since many of the tutors are master or doctoral degree students and will keep the job for at most the graduate course period. Other problems concern the scholarship value and the difficulty to find candidates out of the campus towns.

In both described situations instructors' commitment and motivation represent a challenge to course management. Coordinators also reported many professors and tutors are truly committed and engaged with the course and the method. Data collected from instructors showed a positive perception of technology use and adoption of distance education (average values higher than 4.0); as well as opinions tend to be positive on the other factors (average scores higher than 3.0). These findings are conflicting with coordinators' perceptions in some instances, since:

- For five coordinators some instructors are resistant to DE and some are engaged and committed.

- For four coordinators there are no resistance issues in their institutions.

- Professors from the sample have positive perceptions of DE and technology.

These findings must be considered with caution, as instructor's participation in the survey was voluntary and it is not possible to determine proportion of committed or resistant participants. In addition, four coordinators reported resistance does not happen in their institution. Thus, considering only data collected, hypothesis H39 is partially confirmed, since for five coordinators there are committed and non-committed professionals, for four coordinators there is no resistance and instructors' sample showed they have a positive perception of DE. 


\subsubsection{Hypotheses evaluation}

Data analysis showed PNAP has some characteristics that differ from those brought by the literature, which is interesting and contributes to the study of DE in Brazil through a management perspective. Table 51 summarizes these findings. In the sequence the contributions and limitations of the study will be further discussed in chapter 5 . 
Table 51. Hypotheses evaluation

\begin{tabular}{|c|c|c|}
\hline Hypothesis & Conclusions & Section \\
\hline H1: Assurance has a positive relation to student perceived quality & Confirmed & 4.3 .1 \\
\hline $\mathrm{H} 2$ : Empathy is positively related to student perceived quality & Rejected & 4.3 .1 \\
\hline H3: Responsiveness is positively related to student perceived quality & Rejected & 4.3 .1 \\
\hline H4: Reliability is positively related to student perceived quality & Confirmed & 4.3 .1 \\
\hline H5: Website content is positively related to student perceived quality & Confirmed & 4.3 .1 \\
\hline H6: Perceived quality has positive relation to student satisfaction & Confirmed & 4.3 .1 \\
\hline $\begin{array}{l}\text { H7: Perceived quality has a positive relation to student loyalty to the } \\
\text { course }\end{array}$ & $\begin{array}{l}\text { Confirmed. Quality has significant direct and indirect } \\
\text { effects }\end{array}$ & 4.3 .1 \\
\hline H8: Satisfaction has a positive relation to student loyalty to the course & Confirmed & 4.3 .1 \\
\hline $\begin{array}{l}\text { H9: Student performance expectation has a positive relation to } \\
\text { perceived quality }\end{array}$ & $\begin{array}{l}\text { Confirmed. There is significant correlation between } \\
\text { performance expectation and perceived quality and } \\
\text { SERVQUAL dimensions }\end{array}$ & 4.3 .2 .2 \\
\hline H10: Satisfaction is related (moderated by) to gender & $\begin{array}{l}\text { Confirmed. There is significant satisfaction difference } \\
\text { between male and female }\end{array}$ & 4.3 .2 .3 \\
\hline H11: Women are dominant within UAB public management students & $\begin{array}{l}\text { Rejected. There are similar frequencies of men and } \\
\text { women. }\end{array}$ & 4.3 .2 .1 \\
\hline H12: Image influences perceived quality & Confirmed. & 4.3 .1 \\
\hline H13: Myths perception influences image & $\begin{array}{l}\text { Confirmed. Myths (except for v42) influenced image } \\
\text { perception through regression analysis }\end{array}$ & 4.3 .2 .2 \\
\hline H14: Family support influences loyalty & $\begin{array}{l}\text { Confirmed. There is significant correlation between } \\
\text { family support and loyalty }\end{array}$ & 4.3 .2 .2 \\
\hline H15: Employer support influences loyalty & $\begin{array}{l}\text { Confirmed. There is significant correlation between } \\
\text { employer support and loyalty }\end{array}$ & 4.3 .2 .2 \\
\hline H16: Distance students are mature & $\begin{array}{l}\text { Confirmed. Most of the students belong to generation } \\
\text { X. }\end{array}$ & 4.3.2.1 \\
\hline H17: Attrition is higher in the first year of course & $\begin{array}{l}\text { Confirmed. Coordinators stated that students dropout } \\
\text { specially during the first semester, for a set of different } \\
\text { reasons. }\end{array}$ & 4.5 \\
\hline H18: Performance expectation influences loyalty & $\begin{array}{l}\text { Confirmed. There is significant correlation between } \\
\text { performance expectation and loyalty. }\end{array}$ & 4.3.2.2 \\
\hline H19: Female are more satisfied & Rejected. Significance test showed men and women & 4.3 .2 .3 \\
\hline
\end{tabular}




\begin{tabular}{|c|c|c|}
\hline Hypothesis & Conclusions & Section \\
\hline & $\begin{array}{l}\text { have different satisfaction level. Men have a slightly } \\
\text { higher score. }\end{array}$ & \\
\hline $\begin{array}{l}\text { H20: Satisfaction is higher for those students in more advanced stages } \\
\text { of the course }\end{array}$ & $\begin{array}{l}\text { Rejected. Students in different stages of the course } \\
\text { have the same satisfaction level. }\end{array}$ & 4.3.2.3 \\
\hline H21: Satisfaction increases as interaction with instructors is higher & $\begin{array}{l}\text { Confirmed. There is significant correlation between } \\
\text { responsiveness and satisfaction. }\end{array}$ & 4.3 .2 .2 \\
\hline H22: Female are more loyal to DE & $\begin{array}{l}\text { Rejected. Significance test showed men and women } \\
\text { have different loyalty level. Men have a slightly higher } \\
\text { score }\end{array}$ & 4.3.2.3 \\
\hline $\begin{array}{l}\text { H23: Net generation and non-net generation have the same perception } \\
\text { of the course }\end{array}$ & $\begin{array}{l}\text { Confirmed. No significant differences were found, } \\
\text { except for dimension website content, in which net } \\
\text { generation has higher score. }\end{array}$ & 4.3 .2 .3 \\
\hline $\begin{array}{l}\text { H24: There is no gap in quality perception considering students and } \\
\text { coordinators views (GAP 11) }\end{array}$ & $\begin{array}{l}\text { Rejected. Coordinators have a higher perception of the } \\
\text { service than students. }\end{array}$ & 4.6.1 \\
\hline H25: Technology use influences instructor's participation in DE & Rejected, there is no significant influence & 4.4 .1 \\
\hline $\begin{array}{l}\text { H26: Attitude toward technology influences instructor's participation in } \\
\text { DE }\end{array}$ & Rejected, there is no significant influence & 4.4 .1 \\
\hline $\begin{array}{l}\text { H27: Attitude toward distance education influences instructor's } \\
\text { participation in DE }\end{array}$ & Rejected, there is no significant influence & 4.4.1 \\
\hline H28: Adoption of innovation influences instructor's participation in DE & Rejected, there is no significant influence & 4.4 .1 \\
\hline H29: Technology acceptance is influenced by age & $\begin{array}{l}\text { Rejected for factors } 1,3,4 \text { and } 5 \text {. Factors } 2 \text { and } 6 \\
\text { showed generation Y has better perception of } \\
\text { technology usefulness and its ability to use it }\end{array}$ & 4.4 .2 \\
\hline H30: Technology acceptance is influenced by experience with DE & $\begin{array}{l}\text { Rejected, there is no difference of perception for both } \\
\text { groups, new and experienced groups }\end{array}$ & 4.4 .2 \\
\hline H31: Technology acceptance is influenced by gender & $\begin{array}{l}\text { Rejected for factors } 1,2,3,4,6 \text {. Factor } 5 \text { showed men } \\
\text { have better impression of the recognition for using } \\
\text { technology }\end{array}$ & 4.4 .2 \\
\hline H32: Institution evaluates instructor's skills and attitude toward DE & $\begin{array}{l}\text { Partially confirmed. Evaluation is not structured and } \\
\text { formal, but in the recruitment and selection of faculty } \\
\text { and tutors they try to find professionals whose profile } \\
\text { is more consistent with DE style. }\end{array}$ & 4.5 \\
\hline H33: Institution offers support to instructors & Confirmed. Training and support are provided. & 4.5 \\
\hline H34: Institution provides support to the students & Confirmed. Training and support are provided; & 4.5 \\
\hline
\end{tabular}




\begin{tabular}{|c|c|c|}
\hline Hypothesis & Conclusions & Section \\
\hline & $\begin{array}{l}\text { however level of support varies depending on the } \\
\text { institution. }\end{array}$ & \\
\hline H35: Institution provides appropriate technology support & $\begin{array}{l}\text { Confirmed. Support is provided, but level of service } \\
\text { varies depending on the institution. }\end{array}$ & 4.5 \\
\hline $\begin{array}{l}\text { H36: There is no gap between managers perception of customer } \\
\text { expectation and service strategy and policy (GAP 2) }\end{array}$ & $\begin{array}{l}\text { Rejected. Expectations are surveyed by some } \\
\text { institutions; however it is not clear how the collected } \\
\text { information is used for designing or modifying DE } \\
\text { strategies and policies }\end{array}$ & 4.6 .1 \\
\hline $\begin{array}{l}\text { H37: There is no gap between the translation of strategies and policies } \\
\text { into specifications and the service delivered (GAP 6) }\end{array}$ & $\begin{array}{l}\text { Rejected. There is a positive gap, since the institutions } \\
\text { (except for } \mathrm{G} \text { and } \mathrm{H} \text { ) provide some kind of } \\
\text { differentiated services. }\end{array}$ & 4.6 .1 \\
\hline $\begin{array}{l}\text { H38: There is no gap between external communications and the service } \\
\text { delivered (GAP7) }\end{array}$ & $\begin{array}{l}\text { Rejected. The UAB official website publishes centers } \\
\text { infrastructure should be appropriate and provided and } \\
\text { maintained by city halls; in many centers structure is an } \\
\text { issue. }\end{array}$ & 4.6 .1 \\
\hline $\begin{array}{l}\text { H39: Coordinator's perception of instructors' acceptance to DE is } \\
\text { compatible with instructors attitudes toward DE }\end{array}$ & $\begin{array}{l}\text { Partially confirmed. Considering only sample data } \\
\text { instructors have positive perceptions of DE and } \\
\text { technology; some coordinators reported there are two } \\
\text { groups of professionals, resistant and non-resistant and } \\
\text { a second group reported no resistance. }\end{array}$ & 4.6 .2 \\
\hline
\end{tabular}




\section{CONCLUSIONS, LIMITATIONS AND FUTURE RESEARCH}

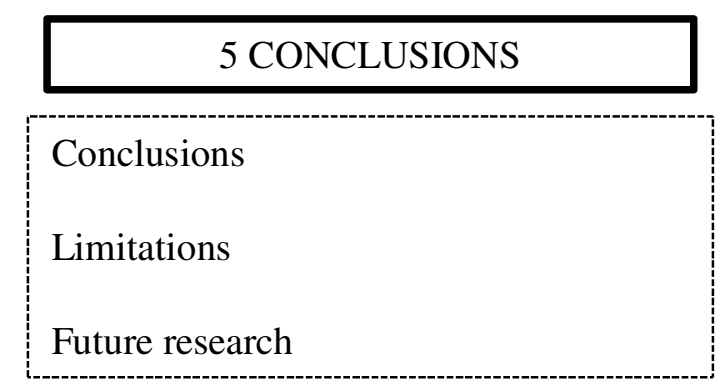

This dissertation aimed to identify three different stakeholder's perceptions (students, instructors and coordinators) regarding DE and the relationships among these results. Public management undergraduate course (PNAP) which is part of the UAB system was chosen for a case study; from the 36 institutions member of PNAP, ten participated in the research. No institution from the north region complied to the survey and in midwest region, just one institution took part of the research, which constitutes a research limitation.

Students' sample showed some consistent results to literature published findings and some different results from those reported in other studies. In general, PNAP students have a favorable perception of their course, especially their satisfaction, loyalty to the course and image perception with positive scores. Considering SERVQUAL dimensions, only assurance, reliability and website content (tangibles) influence significantly overall quality perception, which means, for this sample instructor's expertise and dependability and resources provided on LMS are the only determinants to perceived quality. Specifically website content has the strongest relation with overall quality, which seems reasonable to accept for a distance course study, since on this format students are expected to be more active and independent learners; so contents provided on the course LMS are expected to be relevant. Thus, DE providers should invest on resources offered through the course website in order to make learning experience dynamic, interesting and rich. Instructors attributes are also concerning; thus instructor expertise and instructor-student relationship should be monitored.

Theoretical model tested through SEM - PLS showed satisfaction has the strongest relation to student loyalty; this means the more satisfied with their course, the more willing to finish the course and to recommend it to other people. Perceived quality also influences loyalty but its direct effect is lower than satisfaction effect. Image perception; that is, perception of UAB as 
a system provider of DE, was found to influence perceived quality conjointly with SERVQUAL dimensions (assurance, reliability and website content) and, consequently, to indirectly influence satisfaction and loyalty. These results suggest students' intentions to conclude the course and to recommend it to other people depend on how they assess instructors' performance on the course and resources available on the LMS; how they perceive $\mathrm{UAB}$ and their satisfaction. Then, institutions should create internal strategies and policies for developing instructors' expertise, course resources and UAB image.

Demographic and personal characteristics were tested in order to find differences among categories. Women are not majority within PNAP students, which is opposite to the findings from other studies and to data published by INEP. In addition, differently from other studies in the literature men students are more satisfied and loyal to the course. These findings bring to light the need to study gender variables more deeply; including factors that enhance male and female students' perceptions; so specific policies and strategies may be designed.

Another variable that showed different results from literature was generation. Although, there are more students from generation $\mathrm{X}$, no significant differences were identified between net generation and non-net generation across course dimensions; only on website content net generation presented higher scores. Despite of the results, considering upcoming students belong to generations $\mathrm{Y}$ and $\mathrm{Z}$, factors that influence these students' perceptions are relevant and should be further investigated.

Literature also pointed out some myths surround DE and, as a consequence, may harm attitudes and perceptions of the method. In the present research students did not have the strongest perception of these myths; it means they did not consider DE an easy way to study or a demotivating, non-dynamic method. These findings suggest PNAP students are not influenced by these myths; however, it is important to consider only retained students participated in the survey. Dropout students were not researched and different results could be found for them.

Coordinators reported high attrition rates in the distance course and, in their opinion, these rates are mainly motivated by the belief DE would be easier than studying face-to-face; this is because most of the students are mature and were out of the educational environment for a long time which made it difficult for them to catch up with course dynamics and other issues 
regarding their difficulties in adapting to this new way to study. Even for those students who stayed in the course the main pointed difficulties concern course workload, rigidness, empowerment and isolation feeling. This shows changing educational paradigm is still a problem since students miss personal contact and become bothered with empowerment; this behavior of becoming responsible for their own learning process is an issue for many of them. Coordinators also added students ask for more face-to-face meetings when they can be physically near their teachers, although they are constantly advised face-to-face moments do not aim to "transfer" knowledge, but to enhance motivation. It is important to notice, though students report this need for social contact, presence at the centers is scarce; in other words, as for most of the institutions face-to-face presence is not mandatory (except for assessment activities), most of the students do not attend these sections when they are arranged (usually once or twice a month).

Curiously coordinators expressed more optimistic perception of course quality than students did, which indicated a negative gap. Although this gap was negative, students' opinions can be considered favorable, which indicates course success. In addition, it was previously mentioned HE in Brazil is controlled by the Ministry of Education and is under a set of laws and regulations, which makes it difficult to institutions, especially those member of UAB system, to implement expressive changes in their products. Nevertheless, studied institutions presented differentiated services, such as modified tutoring service, implementation of a set of extra-activities etc., in order to improve educational experience and, consequently, course success. These attempts to improve PNAP lead to a positive quality gap; that is, services specifications offer more benefits than previewed.

Although seven out of nine coordinators reported differentiated services, actions to acquire students' expectations and needs are not completely structured. Institutions collect students' impressions through surveys, by visiting the centers and talking to them or talking to the centers professionals who are constantly in touch with students. There is no clear process for interpreting this information and converting it into policies and strategies (except for institution $\mathrm{E}$ which reported information is used as much as possible as input to changes in course dynamics). This creates a negative gap and enhances the opportunity to implement a formal and periodical process for collecting data from students and even from all staff of professionals involved in the course and evaluating how this information can feed course 
improvement. This synergy creates competitive advantage to institutions and may help avoid and reduce some problems they face, such as attrition and demotivation.

Despite of Brazilian government efforts to take education to all regions of the country technological and physical structure is still an issue. Coordinators reported it is common to have problems at the centers and Internet access restrictions in remote areas. It creates a negative gap, since it is advertised to public that adequate structure would be available to the course, but infrastructure is still a limitation, especially in towns out of the state capital. Considering the relative importance of website content expressed by students, technological structure should be a preferential problem to be addressed.

Students also expressed good perceptions of institutional support, which includes course organization, technical support, interaction with colleagues and structure availability. These findings are consistent to those reported by coordinators who stated students are prepared to join distance education before starting the course; that is, they receive a preparation training to become able to deal with technologies employed (LMS, forums, chat rooms, web-conference software etc.) as wells as to become a distance learner; being clarified regarding courses objectives, technological requirements are exposed and dedication need is expressed. In addition, technical and pedagogical support are provided in some extent, which is consistent to an institution's business positioning, since these are considered in the literature as critical success factors for educational services.

However, it is important to observe that though support is available to students, it has a passive instance, especially in pedagogical issues. Firstly, PNAP is a semester course that restrains time flexibility, since deadlines are rigid; so though students have some freedom to organize their schedules, final deadlines must be respected. This rigidness may make time management and study organization even more difficult. Considering support is passive; that is, students should recognize they have difficulties and ask for help, these questions become even more complicated. For this reason, a more pro-active approach in order to identify students with difficulties should be adopted, since it has the potential to increase motivation, performance and reduce attrition. For that reason new policies and processes need to be developed with a possible impact on courses budget (it may be necessary to hire more tutors for this task). 
Concerning instructors, their perception of technology use and distance education adoption were favorable, which is relatively consistent to coordinators' perceptions. Coordinators reported faculty resistance is an issue but on the other hand part of professors are engaged and committed to the course and the method. Tutors are also considered committed to the course and the method since they are recruited and selected specifically to work in DE. Survey data showed, in general, instructors have good perception of DE, which indicates success of PNAP.

This research found favorable conditions of DE in PNAP case, which makes it possible to consider it as a successful initiative. However; some challenges still need to be addressed: structure conditions, tutoring actions (in order to help students with difficulties), faculty resistance, tutor retention, instructors' development and attrition.

Practical implications may focus on instructors' expertise development, on the development of service to student and on adding resources to the course, as these are relevant variables to quality perception and, as a consequence, satisfaction and loyalty. On instructors' matter, new policies of workload and remuneration should be designed in order to reduce resistance and improve commitment and motivation. Finally, it is also recommended the development of a favorable working environment where decisions are participative and difficulties and challenges may be addressed by a team of professors. 


\subsection{Limitations}

This research shows that service marketing approach may be useful for the educational field study, providing managers with insights regarding their target perceptions of quality, image, satisfaction and loyalty, which will foster decision making. However, the results must be seen carefully since they represent the reality of only one case in Brazil: PNAP bachelor degree. It means results may vary for different courses, for different institutions and for different nations.

Another limitation concerns the sampling approach. Although it was planned to perform a stratified cluster sample, the contingence did not allow a random approach, which forced a convenience method for selecting both first (institutions per geographic area) and second samples (students, instructors and coordinators). In this context, results are biased since probably only interested students and instructors participated on the study. In addition, it is important to say only active students took part of the sample (dropout students were not studied).

Still concerning the sample, it is important to remark that only four out of the five geographic areas were covered in this study. The north region did not participate. This biases results, since north has specific regional characteristics that were ignored. In addition, although four regions were comprehended in the study, the participation of the institutions was neither uniform, nor proportional to the number of institutions in the population. As shown in chapter 3, the midwest region has six institutions in PNAP, but only one joined the research; the northeast region has 14 institutions in PNAP and four joined the study; the north region has three institutions and none of them participated in the study; the southeast region has seven institutions in PNAP and two participated in the dissertation (one of them did not concede the coordinator interview) and the south region has six institutions from which three joined the research (two completely participated and one participated only with the coordinator interview). 


\subsection{Future Research}

Services marketing approach in the study of Distance Education showed interesting results and provided relevant insights for institution and government managers. However, as stated in chapter 2, this approach lies on the lowest levels of program evaluation literature (i.e. it is on level 1 of Kirkpatrick model), which raises an opportunity for exploration of other levels of these models, relating their findings to the results obtained through the services marketing dimensions (quality, loyalty, satisfaction, image).

Additionally, the model applied in this study could be used in other institutions that offer DE in Brazil, not only public ones but private institutions as well; so it would be possible to map DE market and compare different suppliers.

Finally, concerning the UAB system and its relevance in the Brazilian context, the model could be expanded by its application to other undergraduate and graduate courses, in a census perspective; so all the courses and institutions could be studied. Thus, as a result, UAB would have a map of its situation all over the country and insights for improving the existing courses as well as for creating new offers.

A deeper examination of attrition in DE courses and especially at UAB may be useful for strategic decisions. In this sense, inviting resistant instructors and dropout students for an in depth research may bring interesting responses for the attrition issue, which is concerning in the Brazilian DE model.

In this dissertation a general view of the data was provided, analysis for segmented data may offer interesting information, for instance, results could be considered for each region separately or for each gender, or for each generation and so forth.

Finally, this research did not compare students' and instructors' perspectives, since instruments used did not allow such analysis. However, considering instructors importance to DE success and to students' perceptions of DE, a future research should aim to relate both perspectives. 


\section{REFERENCES}

AGHAMOLAEI, T.; ZARE, S. Quality gap of educational services in viewpoints of students in Hormozgan University of medical sciences. BMC medical education, v. 8, p. 34, jan 2008.

AITKEN, N. College Student Performance, Satisfaction and Retention: specification and Estimation of a structural model. The Journal of Higher Education, v. 53, n. 1, p. 32-50, 1982.

ANDREAS, K.; TSIATSOS, T.; TERZIDOU, T.; POMPORTSIS, A. Fostering collaborative learning in Second Life: Metaphors and affordances. Computers \& Education, v. 55, n. 2, p. 603-615, set 2010.

ARTINO, A.; IOANNOU, A. Promoting academic motivation and self-regulation: practical guidelines for online instructors. Tech Trends, v.52,n.3, p.37-45, 2008.

ASHBY, J.; SADERA, W. A.; MCNARY, S. W. Comparing student success between developmental math courses offered online, blended, and face-to-face. Jean Ashby. Journal of Interactive Online Learning, v. 10, n. 3, p. 128-140, 2011.

BACK, K.-J. The Effects of Image Congruence on Customers' Brand Loyalty in the Upper Middle-Class Hotel Industry. Journal of Hospitality \& Tourism Research, v. 29, n. 4, p. 448-467, 1 nov 2005.

BARAN, B. Facebook as a formal instructional environment. British Journal of Educational Technology, v. 41, n. 6, p. E146-E149, 13 nov 2010.

BENSON SOONG, M. .; CHUAN CHAN, H.; CHAI CHUA, B.; FONG LOH, K. Critical success factors for on-line course resources. Computers \& Education, v. 36, n. 2, p. 101120 , fev 2001.

BHUSHAN, P. Connecting or dividing? Examining female learners' information and communication technology access and use in open and distance learning. Open Learning: The Journal of Open and Distance Learning, v. 23, n. 2, p. 131-138, jun 2008.

BLOEMER, J.; RUYTER, K. D. On the relationship between store image, store satisfaction and store loyalty. European Journal of Marketing, v. 32, n. 5, p. 499-513, 1998.

BLOEMER, J.; RUYTER, K. D.; PEETERS, P. Investigating drivers of bank loyalty: the complex relationship between image, service quality and satisfaction. International Journal of Bank Marketing, v. 16, n. 7, p. 276-286, 1998. 
BLOEMER; RUYTER, K. D.; WETZELS, M. Linking perceived service quality and service loyalty : a multi-dimensional perspective. European Journal of Marketing, v. 33, n. 11/12, p. 1082-1104, 1998.

BOLLIGER, D. U.; WASILIK, O. Factors influencing faculty satisfaction with online teaching and learning in higher education. Distance Education, v. 30, n. 1, p. 103-116, maio 2009.

BOURQUE, Linda B; FIELDER, Eve, P. How to conduct self-administered and mail surveys. Thousand Oaks: Sage, v3, 1995, 223 p.

BOWDEN, J. L.-H. Engaging the Student as a Customer: A Relationship Marketing Approach. Marketing Education Review, v. 21, n. 3, p. 211-228, 1 out 2011.

BRADY, M. K.; CRONIN, J. J. Some New Thoughts on Conceptualizing Perceived Service Quality: A Hierarchical Approach. Journal of Marketing, v. 65, n. 3, p. 34-49, jul 2001.

BROWN, R. M.; MAZZAROL, T. W. The importance of institutional image to student satisfaction and loyalty within higher education. Higher Education, v. 58, n. 1, p. 81-95, 21 nov 2009.

BRYMAN, A. Social research methods. 3ed. New York: Oxford University Press, 2008. $748 \mathrm{p}$.

BRYSON, J. M.; PATTON, M. Q.; BOWMAN, R. A. Working with evaluation stakeholders: A rationale, step-wise approach and toolkit. Evaluation and program planning, v. 34, n. 1, p. 1-12, fev 2011.

BURGESS, M. L.; SLATE, J. R.; ROJAS-LEBOUEF, A.; LAPRAIRIE, K. Teaching and learning in Second Life: Using the Community of Inquiry (CoI) model to support online instruction with graduate students in instructional technology. The Internet and Higher Education, v. 13, n. 1-2, p. 84-88, jan 2010.

CAPES. Projeto pedagógico do curso bacharelado em administração pública modalidade a distância. Brasília, 2012. Available in: < http://www.capes.gov.br/educacao-adistancia/pnap $>$. Access in: jul. $10^{\text {th }} .2012$.

CARMINES, E.G.; ZELLER, R.A. Reliability and validity assessment. Thousand Oaks: SAGE, $1979.71 \mathrm{p}$.

CELSI, R. L.; WOLFINBARGER, M. Discontinuous Classroom Innovation: Waves of Change for Marketing Education. Journal of Marketing Education, v. 24, n. 1, p. 64-72, 1 abr 2002. 
CHANEY, BETH HENSLEIGH; EDDY, J. M.; DORMAN, S. M. et al. Development of an Instrument to Assess Student Opinions of the Quality of Distance Education Courses. The American Journal of Distance Education, v. 21, n. 3, p. 145-164, 13 set 2007.

CHANEY, BETH H; EDDY, J. M.; DORMAN, S. M. et al. A primer on quality indicators of distance education. Health promotion practice, v. 10, n. 2, p. 222-31, abr 2009.

CHENG, M. Transforming the learner versus passing the exam: understanding the gap between academic and student definitions of quality. Quality in Higher Education, v.17,n.1, p.3-17, 2011.

CHEN, M.-PUU. An Evaluation of the ELNP e-Learning Quality Assurance Program : Perspectives of Gap Analysis and Innovation Diffusion Quality Measures for E-learning. Educational Technology \& Society, v. 12, n. 1, p. 18-33, 2009.

CHENG, G.; CHAU, J. Study of Using Blogs and Wikis for Collaborative Knowledge Construction. International Journal of Instructional Media, v. 38, n. 1, p. 71-79, 2011.

CHEONG, D. The effects of practice teaching sessions in second life on the change in preservice teachers' teaching efficacy. Computers \& Education, v. 55, n. 2, p. 868-880, set 2010 .

CHURCHILL, D. Educational applications of web 2.0: using blogs to support teaching and learning. British Journal of Educational Technology, v. 40, n. 1, p. 179-183, 2009.

CLARK, D. Psychological myths in e-learning. Medical teacher, v. 24, n. 6, p. 598-604, nov 2002.

CLIFTON, A.; MANN, C. Can YouTube enhance student nurse learning? Nurse education today, v. 31, n. 4, p. 311-3, maio 2011.

COCHRAN, W.G. Sampling techniques. $3^{\text {rd }}$ ed. New York: John Wiley \& Sons, 1977. 428 p.

COHEN, Jacob. Statistical Power Analysis for the Behavioral Sciences. (Revised Edition). New York, Academic Press, 1977.

COX, R. D. Online Education as Institutional Myth : Rituals and Realities at Community Colleges. Teachers College Record, v. 107, n. 8, p. 1754-1787, 2005.

CRESWELL, John, W. Research design: qualitative, quantitative and mixed methods approaches. Thousand Oaks: Sage, 3 ed., 2009, 260 p. 
CRESWELL, J.W.; CLARK, V.L.P. Designing and conduction mixed methods research. Thousand Oaks: SAGE, 2007. 275 p.

CRONIN, J. J.; TAYLOR, S. A. Measuring Service Quality: A Reexamination and Extension. Journal of Marketing, v. 56, n. 3, p. 55, jul 1992.

CRONIN, J. J.; TAYLOR, S. A. SERVPERF versus SERVQUAL: Reconciling PerformanceBased and Perceptions-Minus-Expectations Measurement of Service Quality. Journal of Marketing, v. 58, n. 1, p. 125, jan 1994.

DABBAGH, N. Pedagogical models for e-learning: a theory-based design framework. International Journal of Technology in Teaching \& Learning, v.1, n.1, p.25-44, 2005.

DABBAGH, N. The online learner: characteristics and pedagogical implications.

Contemporary Issues and Teacher Education, v.7, n.3, p.217-226, 2007.

DALE, C.; POVEY, G. An evaluation of learner-generated content and podcasting. The Journal of Hospitality Leisure Sport and Tourism, v. 8, n. 1, p. 117-123, 1 maio 2009.

DAVIS, F. D.; BAGOZZI, R. P.; WARSHAW, P. R. USER ACCEPTANCE OF COMPUTER TECHNOLOGY : A COMPARISON OF TWO THEORETICAL MODELS. Management Science, v. 35, n. 8, p. 982-1003, 1989.

DEVELLIS, R.F. Scale development: theory and applications. $3^{\text {rd }}$. ed. Thousand Oaks: SAGE, 2012. $205 \mathrm{p}$.

DEED, C.; EDWARDS, A. Unrestricted student blogging: Implications for active learning in a virtual text-based environment. Active Learning in Higher Education, v. 12, n. 1, p. 1121, 1 abr 2011.

DROUIN, M.; VARTANIAN, L. R. Students' feelings of and desire for sense of community in face-to-face and online courses. Quarterly Review of Distance Education, v. 11, n. 3, p. 147-159, 2010.

ENOCH, Y.; SOKER, Z. Age, gender, ethnicity and the digital divide: university students' use of web-based instruction. Open Learning, v. 21, n. 2, p. 99-110, 1 jun 2006.

FINK, Arlene a. The survey handbook. Thousand Oaks: Sage, v1, 1995, 129 p.

b. How to ask survey questions. Thousand Oaks: Sage, v.2, 1995, 105 p.

c. How to design surveys. Thousand Oaks: SAGE Publications, 1995, v.5, 73 p. 
FOWLER, Floyd J. Jr, Survey Research Methods. Newbury Park: Sage, v1, 1988, 159 p.

FOWLER, Floyd J. Jr. Improving survey questions. Thousand Oaks: Sage, v.38, 1995, 191 p.

GALL, M.D. et al. Educational research: an introduction. $7^{\text {th }}$. ed. Boston: A\&B, 2003. 656 p.

GARRISON, D.R. E-learning in the $21^{\text {st }}$ century: a framework for research and practice. $2^{\text {nd }}$. Ed. New York: Routledge, 211, 161 p.

GAYTAN, J. Analyzing online education through the lens of institutional theory and practice : the need for research- based and -validated frameworks for planning, designing, delivering , and assessing online instruction. Delta Pi Epsilon Journal, v. 51, n. 2, p. 62-75, 2009.

GIL, A.C. Como elaborar projetos de pesquisa. 4th Ed. São Paulo: Ed. Atlas, 2002. 174 p.

GITHENS, R. P. OLDER ADULTS AND E-LEARNING Opportunities and Barriers. Quarterly Review of Distance Education, v. 8, n. 4, p. 329-338, 2007.

GRUBER, T.; FUS, S.; VOSS, R.; GLÄSER-ZIKUDA, M. Examining student satisfaction with higher education services: Using a new measurement tool. International Journal of Public Sector Management, v. 23, n. 2, p. 105-123, 2010.

GREENE, J.C. Mixed methods in social inquiry. $1^{\text {st }}$. ed. San Francisco: Jossey-Bass, 2007. $216 \mathrm{p}$.

GUTTMAN, I.; OLKIN, I. Retention or Attrition Models. Journal of Educational Statistics, v. 14 , n. 1 , p. $1-20,1989$.

HAENLEIN, M.; KAPLAN, A.M. A beginner's guide to partial least squares analysis. Understanding Statistics, v.3, n.4, p.283-297, 2004.

HAIR, J.F.Jr.; ANDERSON, R.E.; TATHAM, R.L.; BLACK,W.C. Multivariate data analysis. $5^{\text {th }}$ ed. Upper Saddle River: Prentice Hall, 1998. 730 p.

HALVORSON, W.; EWING, M.; WINDISCH, L. Using Second Life to Teach About Marketing in Second Life. Journal of Marketing Education, v. 33, n. 2, p. 217-228, 20 jun 2011. 
HANSON, T. L.; DRUMHELLER, K.; MALLARD, J.; MCKEE, C.; SCHLEGEL, P. Cell Phones, Text Messaging, and Facebook: Competing Time Demands of Today's College Students. College Teaching, v. 59, n. 1, p. 23-30, $27 \mathrm{dez} 2010$.

HEW, K. F. Students' and teachers' use of Facebook. Computers in Human Behavior, v. 27 , n. 2, p. 662-676, mar 2011.

HONG, S.; JUNG, I. The distance learner competencies: a three-phased empirical approach. Educational Technology Research and Development, v. 59, n. 1, p. 21-42, 24 ago 2010.

HOU, H.-T.; CHANG, K. E.; SUNG, Y. T. What kinds of knowledge do teachers share on blogs? A quantitative content analysis of teachers' knowledge sharing on blogs. British Journal of Educational Technology, v. 41, n. 6, p. 963-967, 3 nov 2010.

HUANG, W.-H. D.; NAKAZAWA, K. An empirical analysis on how learners interact in wiki in a graduate level online course. Interactive Learning Environments, v. 18, n. 3, p. 233244 , set 2010.

HUNTER, D. Y. Who Holds the Pen ? Strategies to Student Satisfaction Scores in Online Learning Environments. The Business Review, v. 18, n. 2, p. 75-82, 2011.

INEP. Instituto Nacional de Estudos e Pesquisas Educacionais Anísio Teixeira. Censo da Educação Superior 2009. Brasília, 2010. Available in: < http://portal.inep.gov.br/web/censoda-educacao-superior>. Access in: sep. 19th. 2011.

INEP. Instituto Nacional de Estudos e Pesquisas Educacionais Anísio Teixeira. Censo da Educação Superior 2010. Brasília, 2012. Available in: < http://portal.inep.gov.br/web/censoda-educacao-superior>. Access in: jul. $1^{\text {st }} .2012$.

JAGER, J.; GBADAMOSI, G. Specific remedy for specific problem: measuring service quality in South African higher education. Higher Education, v. 60, n. 3, p. 251-267, 18 dez 2009.

JAMES, Nalita; BUSHER, Hugh. Online interviewing. London: Sage, 2009, 161 p.

JONES, P. Collaboration at a Distance: Using a Wiki to Create a Collaborative Learning Environment for Distance Education and On-Campus Students in a Social Work Course. Journal of Teaching in Social Work, v. 30, n. 2, p. 225-236, 18 maio 2010.

JONES, T.; CUTHRELL, K. YouTube: Educational Potentials and Pitfalls. Computers in the Schools, v. 28, n. 1, p. 75-85, 14 mar 2011. 
KABADAYI, E. T.; OZKIRIS, B. The Effects of Image Congruence on Customer Satisfaction : A Study in Turkish Banking Industry. The Journal of American Academy of Business, v. 16, n. 2, p. 137-147, 2011.

KANG, I.; BONK, C. J.; KIM, M.-C. A case study of blog-based learning in Korea: Technology becomes pedagogy. The Internet and Higher Education, v. 14, p. 227-235, maio 2011.

KAPLAN, M. D.; PISKIN, B.; BOL, B. Educational Blogging: Integrating Technology Into Marketing Experience. Journal of Marketing Education, v. 32, n. 1, p. 50-63, 8 maio 2010.

KASSIM, N. M.; ZAIN, M. Service Quality: Gaps in the College of Business. Business, p. 235-252, 2010.

KEARSLEY, G. A guide to online education. 1998. Available in:

$<$ http://w3.cs.com.uy/u/gux/doc/tech/online.htm>. Access in: aug. 09 $9^{\text {th }} .2011$.

KEEGAN, D. Foundations of distance education. $3^{\text {rd }}$ ed. New York: Routledge, 1996, 224 p.

KENNEY, M. G.; KHANFAR, N. M. Antecedents of Repurchase Intention: Propositions Towards Using Marketing Strategy to Mitigate the Attrition of Online Students. Services Marketing Quarterly, v. 30, n. 3, p. 270-286, 22 jun 2009.

KIM, J.; KWON, Y.; CHO, D. Investigating factors that influence social presence and learning outcomes in distance higher education. Computers \& Education, v. 57, n. 2, p. 1512-1520, set 2011.

KIRKPATRICK, D.L.; KIRKPATRICK, J.D. Evaluating training programs: the four level. 3rd. ed. San Francisco: BK Publishers, 2006. 379p.

KONERU, I. ADDIE : Designing Web-enabled Information Literacy Instructional Modules. Journal of Library \& Information Technology, v. 30, n. 3, p. 23-34, 2010.

KRAMARAE, C. The third shift: women learning online. Washington: AAUW, 2001. 86p.

KUO, Y.-K.; YE, K.-D. The causal relationship between service quality, corporate image and adults' learning satisfaction and loyalty: A study of professional training programmes in a Taiwanese vocational institute. Total Quality Management \& Business Excellence, v. 20, n. 7, p. 749-762, jul 2009.

LENDING, D. Using a Wiki to Collaborate on a Study Guide. Journal of Information Systems, v. 21, n. 1, p. 5-14, 2011. 
LETCHER, D. W.; NEVES, J. S. Determinants of undergraduate business student satisfaction. Research in Higher Education, v. 6, n. 1, p. 1-26, 2010.

LI, Q.; AKINS, M. Sixteen myths about online teaching and learning in higher education: don't believe everything you hear. Tech Trends, v. 49, n. 4, p. 51-60, 2004.

LIM, J.; KIM, M.; CHEN, S. S.; RYDER, C. E. An Empirical Investigation of Student Achievement and Satisfaction in Different Learning Environments. Journal of Instructional Psychology, v. 35, n. 2, p. 113-120, 2003.

LIN, C.P.; TSAI, Y.H. Modeling educational quality and student loyalty: a quantitative approach based on the theory of information cascades. Quality \& Quantity, v.42, p.397-415, 2008.

LOWE, B.; LAFFEY, D. Is Twitter for the Birds?: Using Twitter to Enhance Student Learning in a Marketing Course. Journal of Marketing Education, v. 33, n. 2, p. 183-192, 31 maio 2011.

LUK, S. T. K.; LAYTON, R. Perception Gaps in Customer Expectations : Managers Versus Service Providers and Customers. The Service Industries Journal, v. 22, n. 2, p. 109-128, 2002.

MACELI, K. M.; FOGLIASSO, C. E.; BAACK, D. Differences of students' satisfaction with college professors : the impact of student gender on satisfaction. Academy of Educational Leadership Journal, v. 15, n. 4, p. 35-46, 2011.

MARGARYAN, A.; LITTLEJOHN, A.; VOJT, G. Are digital natives a myth or reality? University students' use of digital technologies. Computers \& Education, v. 56, n. 2, p. 429440, fev 2011.

MARKEL, M. Distance Education and the Myth of the New Pedagogy. Journal of Business and Technical Communication, v. 13, n. 2, p. 208-222, 1 abr 1999.

MARLEY, J. L. Gender Differences and Distance Education : Major Research Findings and Implications for LIS Education. Journal of Education for Library and Information Science, v. 48, n. 1, p. 13-21, 2007.

MARTINS, G. A. de. Estudo de caso: uma estratégia de pesquisa. São Paulo: Atlas, 2006. 96 p.

MITCHELL, B.; GEVA-MAY, I. Attitudes affecting online learning implementation in higher education institutions. Journal of Distance Education, v.23, n.1, p.71-88, 2009. 
MOORE, M.G. Theory of transactional distance. In: MOORE, M.G. Handbook of Distance Education. 2nd. ed. Mahwah: Lawrence Erlbaum, 2007.

MOORE, M.G.; KEARSLEY, G. Educação a distância: uma visão integrada. São Paulo: Cengage Learning, 2008. 398 p.

MORGAN, T.; BULLEN, M. Digital Learners in Higher Education : A Research Project Update. Journal of Distance Education, v. 25, n. I, p. 97-102, 2011.

MORSE, J. M. Principles of mixed methods and multimethod research design. In: TASHAKKORI, A.; TEDDLIE, C. Handbook of Mixed Method in Social \& Behavioral Research. 1st. ed. Thousand Oaks: Sage Publications, 2003.

MOWEN, A. J.; PARKS, S. C. Competitive marketing of distance education : A model for placing quality within a strategic planning context. American Journal of Distance Education, v. 11, n. 3, p. 27-40, 1997.

NESSET, E.; HELGESEN, Ø. Modelling and Managing Student Loyalty: A Study of a Norwegian University College. Scandinavian Journal of Educational Research, v. 53, n. 4, p. 327-345, ago 2009.

NICHOLS, M. Student perceptions of support services and the influence of targeted interventions on retention in distance education. Distance Education, v. 31, n. 1, p. 93-113, maio 2010.

NJENGA, J. K.; FOURIE, L. C. H. The myths about e-learning in higher education. British Journal of Educational Technology, v. 41, n. 1, p. 199-212, 2010.

NORTH, A.; MORELAND, D. Investigating Pedagogical Value of Wiki Technology. Journal of Information Systems, v. 20, n. 2, p. 187-199, 2010.

ORTIZ-RODRÍGUEZ, M.; TELG, R. W.; IRANI, T.; ROBERTS, T. G.; RHOADES, E. COLLEGE STUDENTS ' PERCEPTIONS OF QUALITY IN DISTANCE EDUCATION The Importance of Communication. The Quarterly Review of Distance Education, v. 6, n. 2, p. 97-105, 2005.

PAPASTERGIOU, M.; GERODIMOS, V.; ANTONIOU, P. Multimedia blogging in physical education: Effects on student knowledge and ICT self-efficacy. Computers \& Education, v. 57, n. 3, p. 1998-2010, nov 2011.

PARASURAMAN, A.; BERRY, L.L.; ZEITHALM, V.A. Refinement and Reassessment of the SERVQUAL Scale. Journal of Retailing, v. 67, n. 4, p. 420-450, 1991. 
PARASURAMAN, A.; BERRY, L.L.; ZEITHAML, V.A. Research note : More on improving quality measurement. Journal of Retailing, v. 69, n. 1, p. 140-147, 1993.

PARASURAMAN, A.; GREWAL, D. The impact of technology on the quality-value-loyalty chain: a research agenda. Journal of the Academy of Marketing Science, v. 28, n. 1, p. 168$174,2000$.

PARASURAMAN, A.; ZEITHAML, V. A.; BERRY, L. L. A Conceptual Model of Service Quality and Its Implications for Future Research. Journal of Marketing, v. 49, n. 4, p. 41-50, 1985.

PARASURAMAN, A.; ZEITHAML, V. A.; BERRY, L. L. Servqual : A Multiple-Item Scale For Measuring Consumer Perceptions of Service Quality. Journal of Retailing, v. 64, n. 1, p. 12-40, 1988.

PARASURAMAN, A.; ZEITHAML, V.A.; BERRY, L.L. Alternative Scales for Measuring Service Quality : A Comparative Assessment Based on Psychometric and Diagnostic Criteria. Journal of Retailing, v. 70, n. 3, p. 201-230, 1994a.

PARASURAMAN, A.; ZEITHAML, V. A.; BERRY, L. L. Reassessment of Expectations as a Comparison Standard in Measuring Service Quality: Implications for Further Research. Journal of Marketing, v. 58, n. 1, p. 111-124, jan 1994.

PARASURAMAN, A.; ZEITHAML, V. A.; MALHOTRA, A. E-S-QUAL : A Multiple-Item Scale for Assessing Electronic Service Quality. Journal of Service Research, v. 7, n. 3, p. 213-233, 2005.

PARK, J.-HYE; CHOI, H. J. Factors Influencing Adult Learners' Decision to Dropout or Persist in Online Learning. Educational Technology \& Society, v. 12, p. 207-217, 2009.

PATTON, M. Q. A WORLD LARGER THAN FORMATIVE AND SUMMATIVE.

Evaluation Practice, v. 17, n. 2, p. 131-145, 1991.

PELTIER, J. W.; SCHIBROWSKY, J. A.; DRAGO, W. The Interdependence of the Factors Influencing the Perceived Quality of the Online Learning Experience: A Causal Model.

Journal of Marketing Education, v. 29, n. 2, p. 140-153, 1 ago 2007.

POHL, M.; HERBST, I.; REICHL, F.; WILTNER, S. Students' Attidudes Towards Novel Interfaces in E-Learning. Access, p. 738-747, 2007.

POWELL, R. J.; KEEN, C. The Axiomatic Trap: Stultifying Myths in Distance Education. Higher Education, v. 52, n. 2, p. 283-301, set 2006. 
RINALDO, S. B.; TAPP, S.; LAVERIE, D. A. Learning by Tweeting: Using Twitter as a Pedagogical Tool. Journal of Marketing Education, v. 33, n. 2, p. 193-203, 31 maio 2011.

ROBERTS, T. G.; IRANI, T. A.; TELG, R. W.; LUNDY, L. K. The Development of an Instrument to Evaluate Distance Education Courses Using Student Attitudes. The American Journal of Distance Education, v. 19, n. 1, p. 51-64, 2005.

ROJAS-MÉNDEZ, J. I.; VASQUEZ-PARRAGA, A. Z.; KARA, A.; CERDA-URRUTIA, A. Determinants of Student Loyalty in Higher Education: A Tested Relationship Approach in Latin America. Latin American Business Review, v. 10, n. 1, p. 21-39, 31 mar 2009.

ROSSI, P.H.; FREEMAN, H.E.; LIPSEY, M.W. Evaluation: a systematic approach. $6^{\text {th }}$ ed. Thousand Oaks: Sage, 1999. 499 p.

RUDESTAM, K.E.; SCHOENHOLTZ-READ, J. The flourishing of adult online education. In: RUDESTAM, K.E.; SCHOENHOLTZ-READ, J. Handbook of Online Learning. 2nd ed. Thousand Oaks: Sage, 2010.

SÁNCHEZ, R. A.; HUEROS, A. D. Motivational factors that influence the acceptance of Moodle using TAM. Computers in Human Behavior, v. 26, n. 6, p. 1632-1640, nov 2010.

SCRIVEN, M. Prose and Cons about Goal-Free Evaluation. American Journal of Evaluation, v. 12, n. 1, p. 55-62, 1 fev 1991.

SELIM, H. Critical success factors for e-learning acceptance: Confirmatory factor models. Computers \& Education, v. 49, n. 2, p. 396-413, set 2007.

SELLTIZ, C.; WRIGHTSMAN, L.S.; COOK, S.W. Métodos de pesquisa nas ciências sociais: medidas na pesquisa social. 2 ed. v. 2. São Paulo: EPU, 2005, 133 p.

SEN, R. S.; SAMDUP, P. E. Revisiting gender in open and distance learning - an independent variable or a mediated reality? Open Learning: The Journal of Open and Distance Learning, v. 24, n. 2, p. 165-185, jun 2009.

SHAHIN, A.; SAMEA, M. Developing the Models of Service Quality Gaps : A Critical Discussion. Business Management and Strategy, v. 1, n. 1, p. 1-12, 2010.

SIEGEL, S.; CASTELLAN, N.J.Jr. Estatística não-paramétrica para as ciências do comportamento. 2 ed. Porto Alegre: Artmed, 2006. 448 p.

SIMPSON, O. Student retention in online, open and distance learning. London: Kogan Page, 2003, 168 p. 
SINCLAIRE, J. K. Student satisfaction with online learning : Lessons from organizational behavior. Research in Higher Education Journal, v. 11, n. 2, p. 1-20, 2011.

SPECTOR, J. M. Reconsidering the notion of distance in distance education. Distance Education, v. 30, n. 1, p. 157-161, maio 2009.

STELLA, A.; GNANAM, A. Quality assurance in distance education : The challenges to be addressed. Higher Education, v. 47, p. 143-160, 2004.

STEVENS, R. E.; MCCONKEY, C. W.; COLE, H. S.; CLOW, K. E. College Image: A Strategic Marketing Dilemma. Services Marketing Quarterly, v. 29, n. 3, p. 99-113, 7 jul 2008.

SUDHAHAR, J.C.; ISRAEL, D.; BRITTO, A.P.; SELVAM, M. Service loyalty measurement scale: a reliability assessment. American Journal of Applied Sciences, v.3, n.4, p. 18141818, 2006.

TABACHNICK, B.G.; FIDELL, L. Using multivariate statistics. $4^{\text {th }}$. ed. Boston: Allyn and Bacon, 2001. 966 p.

TABATA, L. N.; JOHNSRUD, L. K. The Impact of Faculty Attitudes Toward Technology, Distance Education, and Innovation. Research in Higher Education, v. 49, n. 7, p. 625-646, 13 abr 2008.

THOMPSON, S.K. Sampling. New York: John Wiley \& Sons, 1992, 343 p.

TINTO, V. Limits of Theory and Practice in Student Attrition. The Journal of Higher Education, v. 53, n. 6, p. 687-700, 1982.

TINTO, V. Stages of Student Departure: reflections on the longitudinal character of student leaving. The Journal of Higher Education, v. 59, n. 4, p. 438-455, 1988.

TRICKER, T.; RANGECROFT, M.; LONG, P. Evaluating Distance Education Courses : the student perception. Assessment \& Evaluation in Higher Education, v. 26, n. 2, p. 166-177, 2001 .

UAB. Encontro da UAB apresenta balanço de 2011 e planejamentos para 2012. Brasília, 2011. Available in: < http://www.capes.gov.br/servicos/sala-de-imprensa/36-noticias/5108encontro-da-uab-apresenta-balanco-de-2011-e-planejamentos-para-2012 >. Access in: jul. $10^{\text {th }}$. 2012. 
UAB. Available in:

$<$ http://uab.capes.gov.br/index.php?option=com_content\&view=frontpage \&Itemid=1 $>$. Access in: jul. 052012.

UDO, G. J.; BAGCHI, K. K.; KIRS, P. J. Using SERVQUAL to assess the quality of elearning experience. Computers in Human Behavior, v. 27, n. 3, p. 1272-1283, maio 2011.

UEDA, Y.; NOJIMA, M. Effect of Student Attitudes on University Loyalty and University Cooperation : An Empirical Study in Japan. International Journal of Management, v. 29, n. 1, p. 133-143, 2012.

VADILLO, G. Five Myths Surrounding K-12 Online Learning. Distance Learning, v. 7, n. 2, p. 61-64, 2010.

VANDER SCHEE, B. Students as Consumers: Programming for Brand Loyalty. Services Marketing Quarterly, v. 32, n. 1, p. 32-43, jan 2011.

VARLAMIS, I.; APOSTOLAKIS, I. The present and future of standards for e-learning technologies. Interdisciplinary Journal of Knowledge and Learning Objects, v.2, n.1, p.59-76, 2006.

VENKATESH, V.; DAVIS, F. D. A Theoretical Extension of the Technology Acceptance Model: Four Longitudinal Field Studies. Management Science, v. 46, n. 2, p. 186-204, fev 2000 .

VENKATESH, V.; MORRIS, M. G.; DAVIS, G. B.; DAVIS, F. D. User acceptance of information technology: Toward a unified view. MIS Quarterly, v. 27, n. 3, p. 425-478, 2003.

VOLERY, T. Online Education: An Exploratory Study into Success Factors. Journal of Educational Computing Research, v. 24, n. 1, p. 77-92, 1 mar 2001.

WANG, C.-YU. Service Quality, Perceived Value, Corporate Image , and Customer Loyalty in the Context of Varying Levels of Switching Costs. Psychology \& Marketing, v. 27, n. 3, p. 252-262, 2010.

WERTH, B. E. P.; WERTH, L. Effective training for millenial students. Adult Learning, v. 22, n. 3, p. 12-19, 2011.

WEVER, B. DE; KEER, H. VAN; SCHELLENS, T.; VALCKE, M. Assessing collaboration in a wiki: The reliability of university students' peer assessment. The Internet and Higher Education, v. 14, p. 201-206, ago 2011. 
WHITE, S. Critical success factors for e-learning and institutional change?some organisational perspectives on campus-wide e-learning. British Journal of Educational Technology, v. 38, n. 5, p. 840-850, set 2007.

WORLEY, B. K. Educating College Students of the Net Generation. Adult Learning, v. 22, n. 3, p. 31-39, 2011.

YIN, R.K. Estudo de caso: planejamento e métodos. 3. ed. Porto Alegre: Bookman, 2005. $212 \mathrm{p}$.

ZEITHAML, V. A.; BERRY, L. L.; PARASURAMAN, A. Communication and Control Processes in the Delivery of Service Quality. Journal of Marketing, v. 52, n. 2, p. 35, abr 1988.

ZEITHAML, V. A.; BERRY, L. L.; PARASURAMAN, A. The Behavioral Consequences of Service Quality. Journal of Marketing, v. 60, n. 2, p. 31-46, abr 1996.

ZEMBYLAS, M. Adult learners' emotions in online learning. Distance Education, v. 29, n. 1, p. 71-87, maio 2008 .

ZHOU, T. Understanding mobile Internet continuance usage from the perspectives of UTAUT and flow. Information Development, v. 27, n. 3, p. 207-218, 11 ago 2011.

ŠIMIĆ, M. L.; ČARAPIĆ, H. Education service quality of a business school: former and current students' evaluation. International Review on Public and Nonprofit Marketing, v. 5, n. 2, p. 181-191, 16 out 2008. 


\section{APPENDIX A}

Distance education programs and actions are under SECADI (Secretaria de Educação Continuada, Alfabetização, Diversidade e Inclusão/ Department of Lifelong Education, Literacy, Diversity and Inclusion) responsibility. SECADI is linked to the Ministry of Education.

Laws which regulate DE in Brazil:

- Decree no. 5622, Dec. $19^{\text {th }}$. 2005. BRASIL. Decreto n. 5622, de 16/12/2005. Diário Oficial - República Federativa do Brasil: Ministério da Educação. Brasília, DF, 2005.

- Decree no. 5773, Mai. 09 ${ }^{\text {th }}$ 2006. BRASIL. Decreto n. 5773, de 09/05/2006. Diário Oficial - República Federativa do Brasil: Ministério da Educação. Brasília, DF, 2006.

- Decree no. 6303, Dec. $12^{\text {th }} .2007$. BRASILb. Decreto n. 6303, de 12/12/2007. Diário Oficial - República Federativa do Brasil: Ministério da Educação. Brasília, DF, 2007.

- Ordinance no. 1, Jan. 10 ${ }^{\text {th }}$. 2007. BRASILa. Portaria n. 1, de 10/01/2007. Diário Oficial - República Federativa do Brasil: Ministério da Educação. Brasília, DF, 2007.

- Ordinance no. 40, Dec. $13^{\text {th }} .2007$. BRASILc. Portaria n. 40, de 13/12/2007. Diário Oficial - República Federativa do Brasil: Ministério da Educação. Brasília, DF, 2007.

- Ordinance no. 10, Jul. 02 ${ }^{\text {nd }}$. 2009. BRASIL. Portaria n. 10, de 02/07/2009. Diário Oficial - República Federativa do Brasil: Ministério da Educação. Brasília, DF, 2009.

- Article 80 Lei de Diretrizes e Bases, Dec. 20th. 1996. BRASIL. Lei de Diretrizes e Bases de 20/12/1996. Diário Oficial - República Federativa do Brasil: Ministério da Educação. Brasília, DF, 1996.

- Quality References (Referenciais de Qualidade para Educação Superior a Distância). MEC. Referenciais de qualidade para educação superior a distância. Brasília, 2007. Available in: <http://portal.mec.gov.br/seed/arquivos/pdf/legislacao/refead1.pdf $>$. Access in: Jul. 10 ${ }^{\text {th }} .2012$. 
Specific laws for UAB system:

- Ordinance no. 1369, Dec. $7^{\text {th }}$. 2010. BRASIL. Portaria no. 1369, de 07/12/2010. Diário Oficial - República Federativa do Brasil: Ministério da Educação. Brasília, DF, 2010.

- Ordinance no. 7, Feb. $9^{\text {th }}$. 2011. BRASIL. Portaria no. 7, de 09/02/2011. Diário Oficial - República Federativa do Brasil: Ministério da Educação. Brasília, DF, 2011.

- Ordinance no. 318, Apr. 02 $2^{\text {nd }}$. 2009. BRASIL. Portaria no. 318, de 02/04/2009. Diário Oficial - República Federativa do Brasil: Ministério da Educação. Brasília, DF, 2009.

- Ordinance no.370, Mar. 29 ${ }^{\text {th }}$. 2010. BRASIL. Portaria no. 370, de 29/03/2010. Diário Oficial - República Federativa do Brasil: Ministério da Educação. Brasília, DF, 2010 .

- Ordinance no.371, Mar. 29 ${ }^{\text {th }}$. 2010. BRASIL. Portaria no. 371, de 09/02/2011. Diário Oficial - República Federativa do Brasil: Ministério da Educação. Brasília, DF, 2010 .

- Ordinance no. 75, Apr. 14 ${ }^{\text {th }}$. 2010. BRASIL. Portaria no. 75, de 14/04/2010. Diário Oficial - República Federativa do Brasil: Ministério da Educação. Brasília, DF, 2010.

- Ordinance no. 78, Apr. 14 ${ }^{\text {th }}$. 2010. BRASIL. Portaria no. 78, de 14/04/2010. Diário Oficial - República Federativa do Brasil: Ministério da Educação. Brasília, DF, 2010.

- Ordinance no. 77, Apr. 14 ${ }^{\text {th }}$. 2010. BRASIL. Portaria no. 77, de 14/04/2010. Diário Oficial - República Federativa do Brasil: Ministério da Educação. Brasília, DF, 2010 .

- Ordinance no. 79, Apr. 14 ${ }^{\text {th }} .2010$. BRASIL. Portaria no. 79, de 14/04/2010. Diário Oficial - República Federativa do Brasil: Ministério da Educação. Brasília, DF, 2010 .

- Ordinance no. 40, Jan. 21st. 2010. BRASIL. Portaria no. 40, de 21/01/2010. Diário Oficial - República Federativa do Brasil: Ministério da Educação. Brasília, DF, 2010.

- Ordinance no. 2, Jan. 10th. 2007. BRASIL. Portaria no.2, de 10/01/2007. Diário Oficial - República Federativa do Brasil: Ministério da Educação. Brasília, DF, 2007. 
- Law no. 11,947, Jun.16th. 2009. BRASIL. Lei no. 11,947, de 16/06/2009. Diário Oficial - República Federativa do Brasil: Presidência da República - Casa Civil. Brasília, DF, 2009.

- Law no. 11,507, Jul.20th. 2007. BRASIL. Lei no. 11,507, de 20/07/2007. Diário Oficial - República Federativa do Brasil: Presidência da República - Casa Civil. Brasília, DF, 2007.

- Law no. 11,502, Jul.11th. 2007. BRASIL. Lei no. 11,502, de 11/07/2007. Diário Oficial - República Federativa do Brasil: Presidência da República - Casa Civil. Brasília, DF, 2007.

- Law no. 11,273, Feb.6th. 2006. BRASIL. Lei no. 11,273, de 06/02/2006. Diário Oficial - República Federativa do Brasil: Presidência da República - Casa Civil. Brasília, DF, 2006.

- Decree no. 5,622, Dec. 19th 2005. BRASIL. Decreto no. 5,622, de 19/12/2005. Diário Oficial - República Federativa do Brasil: Presidência da República - Casa Civil. Brasília, DF, 2005.

- Decree no. 5,800, Jun. 08th 2006. BRASIL. Decreto no. 5,800, de 08/06/2006. Diário Oficial - República Federativa do Brasil: Presidência da República - Casa Civil. Brasília, DF, 2006.

- Resolution no. 49, Sep. 10th. 2009. BRASIL. Resolução no. 49, de 10/09/2009. Diário Oficial - República Federativa do Brasil: Ministério da Educação. Brasília, DF, 2009.

- Resolution no. 26, Jun. 5th. 2009. BRASIL. Resolução no. 26 CD/FNDE, de 05/06/2009. Diário Oficial - República Federativa do Brasil: Ministério da Educação. Brasília, DF, 2009.

- Resolution no. 24, Jun. 4th. 2008. BRASIL. Resolução no. 24 CD/FNDE, de 04/06/2008. Diário Oficial - República Federativa do Brasil: Ministério da Educação. Brasília, DF, 2008.

- Resolution no. 44, Sep. 29th. 2006. BRASIL. Resolução no. 44 CD/FNDE, de 29/09/2006. Diário Oficial - República Federativa do Brasil: Ministério da Educação. Brasília, DF, 2006. 


\section{APPENDIX B}

Institutions credentialed to offer Public Management Undergraduate course through UAB System

\begin{tabular}{|c|c|c|c|c|}
\hline Case & Region & State & $\begin{array}{l}\text { University } \\
\text { abbreviation }\end{array}$ & University name \\
\hline 1 & Midwest & DF & UnB & $\begin{array}{l}\text { UNIVERSIDADE DE } \\
\text { BRASILIA }\end{array}$ \\
\hline 2 & Midwest & GO & UEG & $\begin{array}{l}\text { UNIVERSIDADE } \\
\text { ESTADUAL DE GOIAS }\end{array}$ \\
\hline 3 & Midwest & MS & UEMS & $\begin{array}{l}\text { UNIVERSIDADE } \\
\text { ESTADUAL DE MATO } \\
\text { GROSSO DO SUL }\end{array}$ \\
\hline 4 & Midwest & MS & UFMS & $\begin{array}{l}\text { UNIVERSIDADE } \\
\text { FEDERAL DE MATO } \\
\text { GROSSO DO SUL } \\
\end{array}$ \\
\hline 5 & Midwest & MT & UFMT & $\begin{array}{l}\text { UNIVERSIDADE } \\
\text { FEDERAL DE MATO } \\
\text { GROSSO }\end{array}$ \\
\hline 6 & Midwest & MT & UNEMAT & $\begin{array}{l}\text { UNIVERSIDADE DO } \\
\text { ESTADO DE MATO } \\
\text { GROSSO }\end{array}$ \\
\hline 7 & Northeast & $\mathrm{AL}$ & IFAL & $\begin{array}{l}\text { INSTITUTO FEDERAL DE } \\
\text { EDUCACAO, CIENCIA E } \\
\text { TECNOLOGIA DE } \\
\text { ALAGOAS }\end{array}$ \\
\hline 8 & Northeast & $\mathrm{AL}$ & UFAL & $\begin{array}{l}\text { UNIVERSIDADE } \\
\text { FEDERAL DE ALAGOAS }\end{array}$ \\
\hline 9 & Northeast & $\mathrm{BA}$ & UNEB & $\begin{array}{l}\text { UNIVERSIDADE DO } \\
\text { ESTADO DA BAHIA }\end{array}$ \\
\hline 10 & Northeast & $\mathrm{CE}$ & UECE & $\begin{array}{l}\text { UNIVERSIDADE } \\
\text { ESTADUAL DO CEARA }\end{array}$ \\
\hline 11 & Northeast & $\mathrm{CE}$ & UFC & $\begin{array}{l}\text { UNIVERSIDADE } \\
\text { FEDERAL DO CEARA }\end{array}$ \\
\hline
\end{tabular}




\begin{tabular}{|c|c|c|c|c|}
\hline Case & Region & State & $\begin{array}{l}\text { University } \\
\text { abbreviation }\end{array}$ & University name \\
\hline 12 & Northeast & MA & UEMA & $\begin{array}{l}\text { UNIVERSIDADE } \\
\text { ESTADUAL DO } \\
\text { MARANHAO } \\
\end{array}$ \\
\hline 13 & Northeast & MA & UFMA & $\begin{array}{l}\text { UNIVERSIDADE } \\
\text { FEDERAL DO } \\
\text { MARANHAO } \\
\end{array}$ \\
\hline 14 & Northeast & PB & UEPB & $\begin{array}{l}\text { UNIVERSIDADE } \\
\text { ESTADUAL DA PARAIBA }\end{array}$ \\
\hline 15 & Northeast & $\mathrm{PE}$ & UFRPE & $\begin{array}{l}\text { UNIVERSIDADE } \\
\text { FEDERAL RURAL DE } \\
\text { PERNAMBUCO } \\
\end{array}$ \\
\hline 16 & Northeast & $\mathrm{PE}$ & UPE & $\begin{array}{l}\text { UNIVERSIDADE DE } \\
\text { PERNAMBUCO }\end{array}$ \\
\hline 17 & Northeast & PI & UESPI & $\begin{array}{l}\text { UNIVERSIDADE } \\
\text { ESTADUAL DO PIAUI }\end{array}$ \\
\hline 18 & Northeast & PI & UFPI & $\begin{array}{l}\text { UNIVERSIDADE } \\
\text { FEDERAL DO PIAUI }\end{array}$ \\
\hline 19 & Northeast & $\mathrm{RN}$ & UFRN & $\begin{array}{l}\text { UNIVERSIDADE } \\
\text { FEDERAL DO RIO } \\
\text { GRANDE DO NORTE } \\
\end{array}$ \\
\hline 20 & Northeast & SE & UFS & $\begin{array}{l}\text { UNIVERSIDADE } \\
\text { FEDERAL DE SERGIPE }\end{array}$ \\
\hline 21 & North & $\mathrm{AM}$ & UFAM & $\begin{array}{l}\text { UNIVERSIDADE } \\
\text { FEDERAL DO AMAZONAS }\end{array}$ \\
\hline 22 & North & PA & UFPA & $\begin{array}{l}\text { UNIVERSIDADE } \\
\text { FEDERAL DO PARA }\end{array}$ \\
\hline 23 & North & RO & UNIR & $\begin{array}{l}\text { FUNDACAO } \\
\text { UNIVERSIDADE } \\
\text { FEDERAL DE RONDONIA }\end{array}$ \\
\hline 24 & Southeast & $\mathrm{MG}$ & UFJF & $\begin{array}{l}\text { UNIVERSIDADE } \\
\text { FEDERAL DE JUIZ DE } \\
\text { FORA }\end{array}$ \\
\hline 25 & Southeast & MG & UFLA & UNIVERSIDADE \\
\hline
\end{tabular}




\begin{tabular}{|c|c|c|c|c|}
\hline Case & Region & State & $\begin{array}{l}\text { University } \\
\text { abbreviation }\end{array}$ & University name \\
\hline & & & & FEDERAL DE LAVRAS \\
\hline 26 & Southeast & MG & UFOP & $\begin{array}{l}\text { UNIVERSIDADE } \\
\text { FEDERAL DE OURO } \\
\text { PRETO }\end{array}$ \\
\hline 27 & Southeast & MG & UFSJ & $\begin{array}{l}\text { UNIVERSIDADE } \\
\text { FEDERAL DE SAO JOAO } \\
\text { DEL-REI }\end{array}$ \\
\hline 28 & Southeast & MG & UFU & $\begin{array}{l}\text { UNIVERSIDADE } \\
\text { FEDERAL DE } \\
\text { UBERLANDIA } \\
\end{array}$ \\
\hline 29 & Southeast & MG & UNIMONTES & $\begin{array}{l}\text { UNIVERSIDADE } \\
\text { ESTADUAL DE MONTES } \\
\text { CLAROS }\end{array}$ \\
\hline 30 & Southeast & $\mathrm{RJ}$ & UFF & $\begin{array}{l}\text { UNIVERSIDADE } \\
\text { FEDERAL FLUMINENSE }\end{array}$ \\
\hline 31 & South & PR & UEM & $\begin{array}{l}\text { UNIVERSIDADE } \\
\text { ESTADUAL DE MARINGA }\end{array}$ \\
\hline 32 & South & PR & UEPG & $\begin{array}{l}\text { UNIVERSIDADE } \\
\text { ESTADUAL DE PONTA } \\
\text { GROSSA }\end{array}$ \\
\hline 33 & South & PR & UFPR & $\begin{array}{l}\text { UNIVERSIDADE } \\
\text { FEDERAL DO PARANA }\end{array}$ \\
\hline 34 & South & PR & UNICENTRO & $\begin{array}{l}\text { UNIVERSIDADE } \\
\text { ESTADUAL DO CENTRO- } \\
\text { OESTE }\end{array}$ \\
\hline 35 & South & $\mathrm{RS}$ & UFSM & $\begin{array}{l}\text { UNIVERSIDADE } \\
\text { FEDERAL DE SANTA } \\
\text { MARIA }\end{array}$ \\
\hline 36 & South & $\mathrm{SC}$ & UFSC & $\begin{array}{l}\text { UNIVERSIDADE } \\
\text { FEDERAL DE SANTA } \\
\text { CATARINA }\end{array}$ \\
\hline
\end{tabular}

Source: UAB, 2012. 


\section{APPENDIX C}

Student Perceptions Survey

(https://docs.google.com/spreadsheet/viewform?formkey=dFJVRUVtaHRiTlBFeHpUT3ZzS GJWX2c6MQ)

Prezado (a) aluno (a),

Esta pesquisa tem como objetivo levantar suas percepções acerca do curso a distância "Administração Pública", com vistas a identificar aspectos positivos e oportunidades de melhoria do curso.

Por favor, preencha as questões a seguir, assinalando a resposta que melhor reflita sua opinião. O preenchimento das questões leva em torno de 15 minutos.

Será sorteado um iPod Shuffle entre os alunos que responderem a pesquisa. Para concorrer preencha corretamente seu endereço de e-mail no campo "e-mail" ao final do questionário. $\mathrm{O}$ sorteio ocorrerá no dia 30/05/2012.

Todas as informações obtidas serão mantidas em sigilo.

Sua participação é muito importante!

Muito obrigada.

Daielly Mantovani (daimantovani@gmail.com; daielly@usp.br)

Para cada uma das afirmações a seguir, assinale a alternativa que melhor represente seu grau de concordância

\begin{tabular}{|l|l|l|l|l|l|}
\hline $\begin{array}{l}\text { Avaliação do curso Administração } \\
\text { Pública - PNAP/UAB }\end{array}$ & $\begin{array}{l}\text { Discordo } \\
\text { totalmente }\end{array}$ & $\begin{array}{l}\text { Discordo } \\
\text { em parte }\end{array}$ & $\begin{array}{l}\text { Não } \\
\text { concordo } \\
\text { nem } \\
\text { discordo }\end{array}$ & $\begin{array}{l}\text { Concordo } \\
\text { em parte }\end{array}$ & $\begin{array}{l}\text { Concordo } \\
\text { totalmente }\end{array}$ \\
\hline $\begin{array}{l}\text { V1: Os instrutores (professores e } \\
\text { tutores) possuem bons conhecimentos } \\
\text { em sua área }\end{array}$ & 1 & 2 & 3 & 4 & 5 \\
\hline $\begin{array}{l}\text { V2: Os instrutores são justos e } \\
\text { imparciais ao atribuir notas aos } \\
\text { trabalhos e provas }\end{array}$ & 1 & 2 & 3 & 4 & 5 \\
\hline $\begin{array}{l}\text { V3: Os instrutores respondem todas as } \\
\text { dúvidas a eles enviadas de forma } \\
\text { completa e cuidadosa }\end{array}$ & 1 & 2 & 3 & 4 & 5 \\
\hline $\begin{array}{l}\text { V4: Acredito que os instrutores } \\
\text { possuem conhecimento profundo do } \\
\text { conteúdo contido nos materiais do } \\
\text { curso }\end{array}$ & 1 & 2 & 3 & 4 & 5 \\
\hline $\begin{array}{l}\text { V5: Os instrutores preocupam-se } \\
\text { verdadeiramente com os alunos }\end{array}$ & 1 & 2 & 3 & 4 & 5 \\
\hline $\begin{array}{l}\text { V6: Os instrutores compreendem as } \\
\text { necessidades individuais dos alunos }\end{array}$ & 1 & 2 & 3 & 4 & 5 \\
\hline $\begin{array}{l}\text { V7: Os instrutores sempre pensam nos } \\
\text { interesses de longo prazo dos alunos }\end{array}$ & 1 & 2 & 3 & 4 & 5 \\
\hline $\begin{array}{l}\text { V8: Os instrutores motivam e } \\
\text { estimulam os alunos a darem o seu } \\
\text { melhor no curso }\end{array}$ & 1 & 2 & 3 & 4 & 5 \\
\hline $\begin{array}{l}\text { V9: Os instrutores são acessíveis fora } \\
\text { dos momentos de encontro síncrono } \\
\text { ou presencial }\end{array}$ & 1 & 2 & 3 & 4 & 5 \\
\hline V10: Os instrutores dão retorno às & 1 & 2 & 3 & 4 & 5 \\
\hline
\end{tabular}




\begin{tabular}{|c|c|c|c|c|c|}
\hline $\begin{array}{l}\text { Avaliação do curso Administração } \\
\text { Pública - PNAP/UAB }\end{array}$ & $\begin{array}{l}\text { Discordo } \\
\text { totalmente }\end{array}$ & $\begin{array}{l}\text { Discordo } \\
\text { em parte }\end{array}$ & $\begin{array}{l}\text { Não } \\
\text { concordo } \\
\text { nem } \\
\text { discordo }\end{array}$ & $\begin{array}{l}\text { Concordo } \\
\text { em parte }\end{array}$ & $\begin{array}{l}\text { Concordo } \\
\text { totalmente }\end{array}$ \\
\hline \multicolumn{6}{|l|}{$\begin{array}{l}\text { solicitações dos alunos rapidamente e } \\
\text { eficientemente }\end{array}$} \\
\hline $\begin{array}{l}\text { V11: Os instrutores fazem tudo o que } \\
\text { podem para ajudar os alunos, mesmo } \\
\text { que isso vá além de suas } \\
\text { responsabilidades }\end{array}$ & 1 & 2 & 3 & 4 & 5 \\
\hline $\begin{array}{l}\text { V12: Os instrutores apreciam e } \\
\text { valorizam as perguntas e comentários } \\
\text { dos alunos }\end{array}$ & 1 & 2 & 3 & 4 & 5 \\
\hline V13: Considero as aulas muito boas & 1 & 2 & 3 & 4 & 5 \\
\hline $\begin{array}{l}\text { V14: Os instrutores } \\
\text { confiança }\end{array}$ & 1 & 2 & 3 & 4 & 5 \\
\hline $\begin{array}{l}\text { V15: Os instrutores sempre dão } \\
\text { retorno sobre as atividades de } \\
\text { avaliação do curso (provas, trabalhos } \\
\text { e atividades) }\end{array}$ & 1 & 2 & 3 & 4 & 5 \\
\hline $\begin{array}{l}\text { V16: Considero os recursos de áudio } \\
\text { utilizados no curso apropriados }\end{array}$ & 1 & 2 & 3 & 4 & 5 \\
\hline $\begin{array}{l}\text { V17: Considero os recursos de vídeo } \\
\text { utilizados no curso apropriados }\end{array}$ & 1 & 2 & 3 & 4 & 5 \\
\hline $\begin{array}{l}\text { V18: O curso utiliza ferramentas } \\
\text { multimídia (áudio, vídeo, animações, } \\
\text { gráficos) adequadamente }\end{array}$ & 1 & 2 & 3 & 4 & 5 \\
\hline $\begin{array}{l}\text { V19: O ambiente virtual apresenta } \\
\text { informações úteis }\end{array}$ & 1 & 2 & 3 & 4 & 5 \\
\hline $\begin{array}{l}\text { V20: O ambiente virtual apresenta } \\
\text { informações confiáveis }\end{array}$ & 1 & 2 & 3 & 4 & 5 \\
\hline $\begin{array}{l}\text { V21: O conteúdo disponibilizado é de } \\
\text { alta qualidade }\end{array}$ & 1 & 2 & 3 & 4 & 5 \\
\hline $\begin{array}{l}\text { V22: O conteúdo apresentado no } \\
\text { ambiente virtual é relevante para mim }\end{array}$ & 1 & 2 & 3 & 4 & 5 \\
\hline $\begin{array}{l}\text { V23: Há flexibilidade de horário para } \\
\text { realização das atividades propostas no } \\
\text { curso }\end{array}$ & 1 & 2 & 3 & 4 & 5 \\
\hline V24: O ambiente virtual é atualizado & 1 & 2 & 3 & 4 & 5 \\
\hline $\begin{array}{l}\text { V25: O ambiente virtual e as } \\
\text { ferramentas tecnológicas usadas no } \\
\text { curso funcionam bem }\end{array}$ & 1 & 2 & 3 & 4 & 5 \\
\hline $\begin{array}{l}\text { V26: O ambiente virtual apresenta as } \\
\text { informações de forma clara }\end{array}$ & 1 & 2 & 3 & 4 & 5 \\
\hline 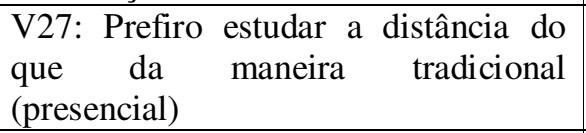 & 1 & 2 & 3 & 4 & 5 \\
\hline $\begin{array}{l}\text { V28: Considero que meu curso possui } \\
\text { alta qualidade }\end{array}$ & 1 & 2 & 3 & 4 & 5 \\
\hline $\begin{array}{l}\text { V29: Estou satisfeito com minha } \\
\text { decisão de estudar a distância }\end{array}$ & 1 & 2 & 3 & 4 & 5 \\
\hline $\begin{array}{l}\text { V30: Acho que acertei ao decidir } \\
\text { fazer o curso a distância }\end{array}$ & 1 & 2 & 3 & 4 & 5 \\
\hline V31: Minha experiência em estudar a & 1 & 2 & 3 & 4 & 5 \\
\hline
\end{tabular}




\begin{tabular}{|c|c|c|c|c|c|}
\hline $\begin{array}{l}\text { Avaliação do curso Administração } \\
\text { Pública - PNAP/UAB }\end{array}$ & $\begin{array}{l}\text { Discordo } \\
\text { totalmente }\end{array}$ & $\begin{array}{l}\text { Discordo } \\
\text { em parte }\end{array}$ & $\begin{array}{l}\text { Não } \\
\text { concordo } \\
\text { nem } \\
\text { discordo }\end{array}$ & $\begin{array}{l}\text { Concordo } \\
\text { em parte }\end{array}$ & $\begin{array}{l}\text { Concordo } \\
\text { totalmente }\end{array}$ \\
\hline \multicolumn{6}{|l|}{ distância tem sido agradável } \\
\hline $\begin{array}{l}\text { V32: O curso atende minhas } \\
\text { expectativas }\end{array}$ & 1 & 2 & 3 & 4 & 5 \\
\hline $\begin{array}{l}\text { V33: Eu recomendaria este curso a } \\
\text { distância aos meus amigos e } \\
\text { familiares }\end{array}$ & 1 & 2 & 3 & 4 & 5 \\
\hline $\begin{array}{l}\text { V34: Eu certamente faria outro curso } \\
\text { a distância }\end{array}$ & 1 & 2 & 3 & 4 & 5 \\
\hline $\begin{array}{l}\text { V35: Tenho obtido bom desempenho } \\
\text { no curso }\end{array}$ & 1 & 2 & 3 & 4 & 5 \\
\hline $\begin{array}{l}\text { V36: Acredito que terminarei o curso } \\
\text { no prazo regular }\end{array}$ & 1 & 2 & 3 & 4 & 5 \\
\hline $\begin{array}{l}\text { V37: A Universidade Aberta do Brasil } \\
\text { é confiável }\end{array}$ & 1 & 2 & 3 & 4 & 5 \\
\hline $\begin{array}{l}\text { V38: A Universidade Aberta do Brasil } \\
\text { é inovadora }\end{array}$ & 1 & 2 & 3 & 4 & 5 \\
\hline $\begin{array}{l}\text { V39: A Universidade Aberta do Brasil } \\
\text { serve de exemplo em educação a } \\
\text { distância no Brasil }\end{array}$ & 1 & 2 & 3 & 4 & 5 \\
\hline $\begin{array}{l}\text { V40: A Universidade Aberta do Brasil } \\
\text { é sinônimo de qualidade de ensino }\end{array}$ & 1 & 2 & 3 & 4 & 5 \\
\hline $\begin{array}{l}\text { V41: O ambiente virtual de } \\
\text { aprendizagem é interativo e dinâmico }\end{array}$ & 1 & 2 & 3 & 4 & 5 \\
\hline $\begin{array}{l}\text { V42: É necessário ter grande domínio } \\
\text { de tecnologia para estudar a distância }\end{array}$ & 1 & 2 & 3 & 4 & 5 \\
\hline $\begin{array}{l}\text { V43: O curso a distância exige mais } \\
\text { do aluno do que um curso presencial }\end{array}$ & 1 & 2 & 3 & 4 & 5 \\
\hline V44: Estudar a distância é motivador & 1 & 2 & 3 & 4 & 5 \\
\hline $\begin{array}{l}\text { V45: Acredito que qualquer pessoa } \\
\text { possa se sair bem em um curso a } \\
\text { distância }\end{array}$ & 1 & 2 & 3 & 4 & 5 \\
\hline $\begin{array}{l}\text { V46: Os objetivos do curso estão } \\
\text { claros para mim }\end{array}$ & 1 & 2 & 3 & 4 & 5 \\
\hline $\begin{array}{l}\text { V47: Antes de iniciar o curso fui } \\
\text { avisado sobre os } \\
\text { tecnológicos exigidos }\end{array}$ & 1 & 2 & 3 & 4 & 5 \\
\hline $\begin{array}{l}\text { V48: Antes de iniciar o curso fui } \\
\text { avisado sobre as habilidades } \\
\text { tecnológicas necessárias para o meu } \\
\text { bom desempenho }\end{array}$ & 1 & 2 & 3 & 4 & 5 \\
\hline $\begin{array}{l}\text { V49: Antes de iniciar o curso fui } \\
\text { avisado sobre o nível de dedicação } \\
\text { necessário para o bom desempenho no } \\
\text { curso }\end{array}$ & 1 & 2 & 3 & 4 & 5 \\
\hline $\begin{array}{l}\text { V50: Há suporte técnico adequado aos } \\
\text { alunos }\end{array}$ & 1 & 2 & 3 & 4 & 5 \\
\hline $\begin{array}{l}\text { V51: O suporte técnico conseguiu } \\
\text { resolver os problemas que surgiram } \\
\text { durante o curso }\end{array}$ & 1 & 2 & 3 & 4 & 5 \\
\hline V52: A carga de trabalho em cada & 1 & 2 & 3 & 4 & 5 \\
\hline
\end{tabular}




\begin{tabular}{|l|l|l|l|l|l|}
\hline $\begin{array}{l}\text { Avaliação do curso Administração } \\
\text { Pública - PNAP/UAB }\end{array}$ & $\begin{array}{l}\text { Discordo } \\
\text { totalmente }\end{array}$ & $\begin{array}{l}\text { Discordo } \\
\text { em parte }\end{array}$ & $\begin{array}{l}\text { Não } \\
\text { concordo } \\
\text { nem } \\
\text { discordo }\end{array}$ & $\begin{array}{l}\text { Concordo } \\
\text { em parte }\end{array}$ & $\begin{array}{l}\text { Concordo } \\
\text { totalmente }\end{array}$ \\
\hline disciplina é adequada & & & & & \\
\hline $\begin{array}{l}\text { V53: Há bastante interação entre os } \\
\text { alunos da turma }\end{array}$ & 1 & 2 & 3 & 4 & 5 \\
\hline $\begin{array}{l}\text { V54: Os alunos se tornaram uma } \\
\text { comunidade de amigos ao longo do } \\
\text { curso }\end{array}$ & 1 & 2 & 3 & 4 & 5 \\
\hline $\begin{array}{l}\text { V55: Os serviços de secretaria são } \\
\text { eficientes }\end{array}$ & 1 & 2 & 3 & 4 & 5 \\
\hline $\begin{array}{l}\text { V56: A instituição apresenta uma boa } \\
\text { estrutura ao aluno }\end{array}$ & 1 & 2 & 3 & 4 & 5 \\
\hline
\end{tabular}

\section{Perfil do aluno}

V57: Instituição em que estuda:

V58: Gênero

- Masculino

Feminino

V59: Data de nascimento (dia, mês e ano)

V60: Ano de início do curso

V61: Cidade onde vive

V62: Cidade onde frequenta o pólo de apoio presencial

V63: É o seu primeiro curso a distância

O Sim

Não

V64: Trabalha?

( $\mathrm{Sim}$

○ Não

V65: Em caso positivo, qual a sua carga de trabalho semanal (em horas)? 
V66: Em uma escala de 1 a 10, como classifica o apoio de seu empregador para a realização do curso?

\begin{tabular}{lllllllllll}
1 & 2 & 3 & 4 & 5 & 6 & 7 & 8 & 9 & 10 \\
\hline pouco apoio & $\bigcirc$ & $\bigcirc$ & $\bigcirc$ & $\bigcirc$ & $\bigcirc$ & $\bigcirc$ & $\bigcirc$ & $\bigcirc$ & $\bigcirc$ & total apoio
\end{tabular}

V67: Estado civil:

(1) Solteiro

(1) Casado

Separado

Outros

V68: Tem filhos?

Sim

ก Não

V69: Em uma escala de 1 a 10, como classifica o apoio de seus familiares para a realização do curso?

\begin{tabular}{lllllllllll} 
& 1 & 2 & 3 & 4 & 5 & 6 & 7 & 8 & 9 & 10 \\
\hline pouco apoio & $\bigcirc$ & $\bigcirc$ & $\bigcirc$ & $\bigcirc$ & $\bigcirc$ & $\bigcirc$ & $\bigcirc$ & $\bigcirc$ & $\bigcirc$ & $\bigcirc$ \\
\hline
\end{tabular}

V70: Quantas horas de estudo dedica semanalmente ao curso?

V71: Comentários gerais

V80: E-mail

\section{Muito obrigada por sua participação!}

Em caso de dúvidas ou sugestões, entre em contato:

Responsável: Daielly Mantovani

daimantovani@gmail.com 


\section{APPENDIX D}

Instructors Survey

(https://docs.google.com/spreadsheet/viewform?formkey=dDVDYXU5Z0FyWmFGV3E0Nk ZhZ0pLYmc6MQ)

Prezado (a) docente,

Esta pesquisa faz parte de um projeto de tese de doutorado e tem como objetivo avaliar a percepção do docente acerca da Educação a Distância.

O preenchimento das questões leva em torno de 10 minutos.

Sua participação é muito importante!

Para cada uma das afirmações, assinale a resposta que melhor reflita seu nível de concordância

\begin{tabular}{|l|l|l|l|l|l|}
\hline Tecnologia e Educação a Distância & $\begin{array}{l}\text { Discordo } \\
\text { totalmente }\end{array}$ & $\begin{array}{l}\text { Discordo } \\
\text { em parte }\end{array}$ & $\begin{array}{l}\text { Não } \\
\text { concordo } \\
\text { nem } \\
\text { discordo }\end{array}$ & $\begin{array}{l}\text { Concordo } \\
\text { em parte }\end{array}$ & $\begin{array}{l}\text { Concordo } \\
\text { totalmente }\end{array}$ \\
\hline $\begin{array}{l}\text { V1: Considero importante utilizar } \\
\text { equipamentos eletrônicos no meu } \\
\text { trabalho }\end{array}$ & 1 & 2 & 3 & 4 & 5 \\
\hline $\begin{array}{l}\text { V2: Uso diversos softwares e } \\
\text { aplicativos no meu trabalho }\end{array}$ & 1 & 2 & 3 & 4 & 5 \\
\hline $\begin{array}{l}\text { V3: Considero importante utilizar } \\
\text { recursos online para realizar meu } \\
\text { trabalho }\end{array}$ & 1 & 2 & 3 & 4 & 5 \\
\hline $\begin{array}{l}\text { V4: A tecnologia é importante para o } \\
\text { meu trabalho }\end{array}$ & 1 & 2 & 3 & 4 & 5 \\
\hline $\begin{array}{l}\text { V5: Espero ser reconhecido por } \\
\text { utilizar a tecnologia }\end{array}$ & 1 & 2 & 3 & 4 & 5 \\
\hline $\begin{array}{l}\text { V6: Tenho todos os recursos } \\
\text { tecnológicos que preciso para } \\
\text { desempenhar meu trabalho }\end{array}$ & 1 & 2 & 3 & 4 & 5 \\
\hline $\begin{array}{l}\text { V7: Tenho habilidade suficiente para } \\
\text { usar a tecnologia }\end{array}$ & 1 & 2 & 3 & 4 & 5 \\
\hline $\begin{array}{l}\text { V8: O uso da tecnologia tem impacto } \\
\text { pequeno na minha carreira }\end{array}$ & 1 & 2 & 3 & 4 & 5 \\
\hline $\begin{array}{l}\text { V9: A minha instituição reconhece } \\
\text { aqueles que utilizam a tecnologia para } \\
\text { desempenhar seu trabalho }\end{array}$ & 1 & 2 & 3 & 4 & 5 \\
\hline $\begin{array}{l}\text { V10: Usar a tecnologia me deixa } \\
\text { tenso }\end{array}$ & 1 & 2 & 3 & 4 & 5 \\
\hline $\begin{array}{l}\text { V11: Minha instituição oferece } \\
\text { treinamento e capacitação em } \\
\text { educação a distância }\end{array}$ & 1 & 2 & 3 & 4 & 5 \\
\hline $\begin{array}{l}\text { V12: Estou motivado a lecionar nos } \\
\text { cursos a distância }\end{array}$ & 1 & 2 & 4 & 5 \\
\hline $\begin{array}{l}\text { V13: Há suporte técnico adequado } \\
\text { para os cursos a distância }\end{array}$ & 1 & 3 & & \\
\hline
\end{tabular}




\begin{tabular}{|l|l|l|l|l|l|}
\hline Tecnologia e Educação a Distância & $\begin{array}{l}\text { Discordo } \\
\text { totalmente }\end{array}$ & $\begin{array}{l}\text { Discordo } \\
\text { em parte }\end{array}$ & $\begin{array}{l}\text { Não } \\
\text { concordo } \\
\text { nem } \\
\text { discordo }\end{array}$ & $\begin{array}{l}\text { Concordo } \\
\text { em parte }\end{array}$ & $\begin{array}{l}\text { Concordo } \\
\text { totalmente }\end{array}$ \\
\hline $\begin{array}{l}\text { V14: Tenho as competências } \\
\text { necessárias para ensinar a distância }\end{array}$ & 1 & 2 & 3 & 4 & 5 \\
\hline $\begin{array}{l}\text { V15: A qualidade do processo de } \\
\text { ensino-aprendizagem na educação a } \\
\text { distância é equivalente ao presencial }\end{array}$ & 1 & 2 & 3 & 4 & 5 \\
\hline V16: Ensinar a distância é estressante & 1 & 2 & 3 & 4 & 5 \\
\hline $\begin{array}{l}\text { V17: A participação no projeto de } \\
\text { educaçáo a distância é de adesão } \\
\text { voluntária }\end{array}$ & 1 & 2 & 3 & 4 & 5 \\
\hline $\begin{array}{l}\text { V18: Eu compartilharia os resultados } \\
\text { de minha experiência com educação a } \\
\text { distância com outros colegas }\end{array}$ & 1 & 2 & 3 & 4 & 5 \\
\hline $\begin{array}{l}\text { V19: As vantagens da educação a } \\
\text { distância superam as desvantagens }\end{array}$ & 1 & 2 & 3 & 4 & 5 \\
\hline $\begin{array}{l}\text { V20: Ensinar em educação a distância } \\
\text { é difícil }\end{array}$ & 1 & 2 & 3 & 4 & 5 \\
\hline $\begin{array}{l}\text { V21: Reconheço os resultados que a } \\
\text { educação a distância pode trazer }\end{array}$ & 1 & 2 & 3 & 4 & 5 \\
\hline $\begin{array}{l}\text { V22: A educação a distância é } \\
\text { compatível com meu estilo de } \\
\text { trabalho }\end{array}$ & 1 & 2 & 3 & 4 & 5 \\
\hline $\begin{array}{l}\text { V23: Posso usar a educação a } \\
\text { distância como teste antes de decidir } \\
\text { por aderir ao método efetivamente }\end{array}$ & 1 & 2 & 3 & 4 & 5 \\
\hline $\begin{array}{l}\text { V24: O uso de inovações tecnológicas } \\
\text { influenciam positivamente minha } \\
\text { auto-imagem }\end{array}$ & 1 & 2 & 3 & 4 & 5 \\
\hline
\end{tabular}

V25: Instituição de ensino em que leciona

\section{V26: Gênero \\ Masculino \\ Feminino}

\section{V27: Data de nascimento}


V28: Escolaridade

() Graduação

Mestrado

D Doutorado

Especialização

Pós-doutorado

Other:

V29: Formação

V30: Tempo de docência em anos

V31: Tempo de docência na EAD

V32: Comentários gerais

\section{Muito obrigada por seu apoio!}

Em caso de dúvidas ou sugestões contatar Daielly Mantovani (Faculdade de Economia, Administração e Contabilidade FEA):

e-mail: daimantovani@gmail.com 


\section{APPENDIX E}

\section{Coordinators Interview Script}

V1: Instituição

V2: Tempo no cargo de coordenação do curso de graduação do PNAP

\section{V3: Gênero}

V4: Escolaridade

V5: Área de formação

V6: Quantidade de alunos matriculados

V7: Quantidade de docentes envolvidos no curso

V8: Quantidade de tutores envolvidos no curso

V9: Principais motivos para a adesão à UAB.

V10: Quais as principais dificuldades encontradas?

V11: Quais os principais benefícios da implantação do PNAP?

V12: Observou-se resistência por parte do corpo docente?

V13: Há dificuldades no processo de recrutamento e seleção de tutores?

V14: Quais serviços de apoio são oferecidos ao professor (suporte técnico, treinamento em tecnologia, desenvolvimento pedagógico etc.)?

V15: Quais serviços de apoio são oferecidos ao aluno (orientação de carreira, gestão do tempo, tecnologia, suporte técnico, etc.)? 
V16: Quais os principais pontos positivos citados pelos alunos para se estudar a distância?

V17: Quais os principais pontos negativos?

V18: Qual a porcentagem média de evasão? Quais os principais motivos para isso em sua visão?

V19: Quais atividades e tecnologias são usadas no curso?

V20: Como as expectativas dos alunos são identificadas (ex: pesquisas, benchmarking de outros casos etc.)?

V21: Quais os diferenciais do curso em sua instituição?

V22: Todos os pontos previstos no projeto inicial já foram implantados? Em caso negativo, o que não foi implantado e por quê?

Atribua seu grau de concordância para cada uma das seguintes afirmações:

\begin{tabular}{|l|l|l|l|l|l|}
\hline PNAP & $\begin{array}{l}\text { Discordo } \\
\text { totalmente }\end{array}$ & $\begin{array}{l}\text { Discordo } \\
\text { em parte }\end{array}$ & $\begin{array}{l}\text { Não } \\
\text { concordo } \\
\text { nem } \\
\text { discordo }\end{array}$ & $\begin{array}{l}\text { Concordo } \\
\text { em parte }\end{array}$ & $\begin{array}{l}\text { Concordo } \\
\text { totalmente }\end{array}$ \\
\hline $\begin{array}{l}\text { V23: Os instrutores envolvidos no } \\
\text { curso são engajados com o curso e } \\
\text { com o método EAD }\end{array}$ & 1 & 2 & 3 & 4 & 5 \\
\hline $\begin{array}{l}\text { V24: Os instrutores envolvidos no } \\
\text { sistema UAB possuem domínio } \\
\text { profundo das disciplinas que } \\
\text { ministram }\end{array}$ & 1 & 2 & 3 & 4 & 5 \\
\hline $\begin{array}{l}\text { V25: Os instrutores são solícitos e } \\
\text { dispostos a ajudar o aluno a distância }\end{array}$ & 1 & 2 & 3 & 4 & 5 \\
\hline $\begin{array}{l}\text { V26: Os instrutores envolvidos no } \\
\text { projeto conseguem inspirar confiança } \\
\text { nos alunos }\end{array}$ & 1 & 2 & 3 & 4 & 5 \\
\hline $\begin{array}{l}\text { V27: O ambiente virtual é confiável e } \\
\text { apresenta recursos adequados ao curso }\end{array}$ & 1 & 2 & 3 & 4 & 5 \\
\hline V28: O curso possui alta qualidade & 1 & 2 & 3 & 4 & 5 \\
\hline
\end{tabular}




\section{APPENDIX F}

\section{Carta de apresentação}

São Paulo, 12 de abril de 2012

Prezado (a) Prof (a) Coordenador (a),

Solicitamos, por meio desta, seu apoio para a realização da coleta de dados para a tese de doutorado de Daielly Melina Nassif Mantovani matriculada no programa de Pós-graduação em Administração da Faculdade de Economia, Administração e Contabilidade da Universidade de São Paulo (FEA/USP).

O projeto de tese intitulado "Educação a Distância na Perspectiva dos Stakeholders: a Percepção de Alunos, Instrutores e Coordenadores de Curso", propõe-se a analisar as percepções dos alunos da Universidade Aberta do Brasil, dos professores e tutores envolvidos com o curso a distância e do coordenador do curso acerca das dimensões qualidade, lealdade, satisfação, imagem e atitude em relação à Educação a Distância.

Neste sentido; solicitamos sua autorização para que seja enviado o questionário eletrônico aos alunos de sua instituição, bem como aos docentes, além de sua colaboração, concedendo uma entrevista à doutoranda. As informações levantadas serão tratadas em caráter confidencial, podendo ser omitido, caso necessário, o nome da instituição. Adicionalmente, os resultados obtidos serão enviados em relatório, em formato eletrônico, aos seus cuidados, de modo que os achados da pesquisa possam também contribuir com o trabalho de sua instituição

Agradecemos antecipadamente seu apoio e colocamo-nos à disposição para quaisquer esclarecimentos.

Atenciosamente,

Profa. Dra. Maria Aparecida Gouvêa

Docente do Depto. de Administração (FEA/USP)

Orientadora da Pesquisa

Daielly Melina Nassif Mantovani

Doutoranda do Programa de Pós-Graduação em Administração (FEA/USP)

Pesquisadora Responsável 